\title{
The (Literary) Special Effect: \\ (Inter)Mediality in the Contemporary US-American Novel and the Digital Age
}

\author{
Dissertation \\ zur Erlangung des philosophischen Doktorgrades an der Philosophischen \\ Fakultät der Georg-August-Universität Göttingen
}

\author{
vorgelegt von \\ Bogna Kazur \\ aus Lodz, Polen
}

Göttingen 2018 


\section{Contents}

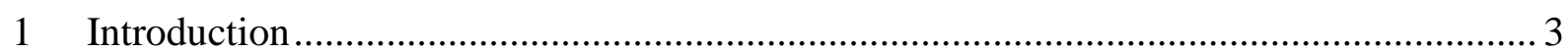

2 The Question of Medium Specificity in the Digital Age ............................................ 29

3 House of Leaves (2000) and the Uncanny Dawn of the Digital...................................... 39

3.1 Digital Paranoia: Arriving on Ash Tree Lane ............................................................. 39

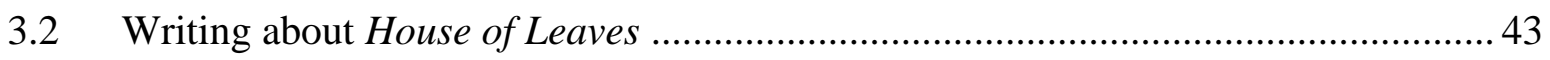

3.3 Intermedial Overabundance: Taming House of Leaves ........................................... 49

3.4 An "Explicit" Approach to the Digital Age.............................................................5

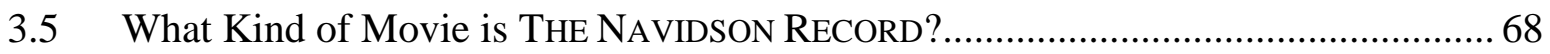

4 In the Midst of the Post-Cinematic Age: Marisha Pessl's Night Film (2013) .................. 88

4.1 Meant for Adaptation: Night Film and the Fallacy of First Impressions.................. 88

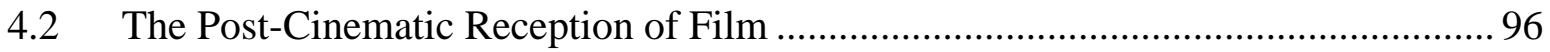

4.3 The Last Enigma: Cordova's Underworld............................................................. 111

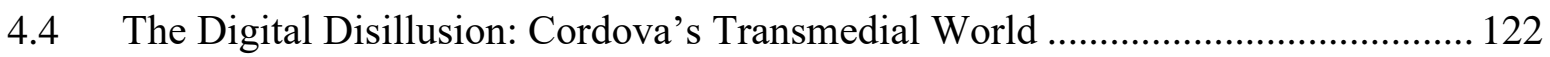

4.5 Reading Marisha Pessl's Night Film: A Reconsideration of the Intermedial Gap.. 132

4.6 (Post-)Photography in Night Film .............................................................. 145

5 “The world's going virtual anyway": Verbalizing Post-Photography in Siri Hustvedt's

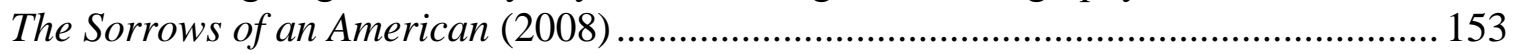

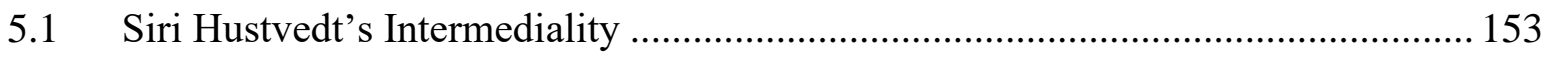

5.2 Two Worlds Collide: Writers Looking at Pictures ................................................. 158

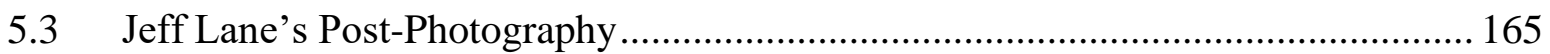

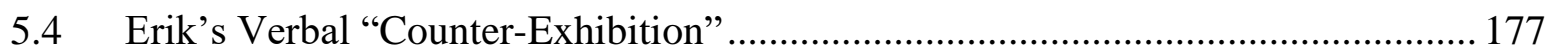

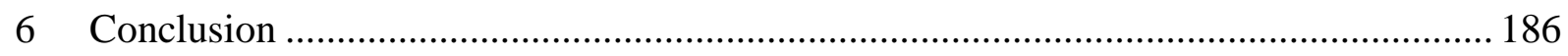

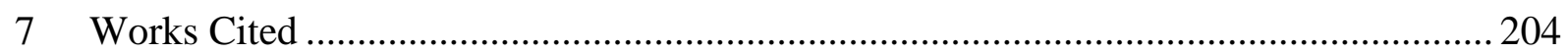




\section{Introduction}

In his 2009 article "Digital Doctoring: Can We Trust Photography?," Hany Farid describes how the advent of computer software has facilitated deception and made it more commonplace. As a digital forensics expert and professor in computer science, Farid introduces "some recent innovations for detecting digital tampering that have the potential to return some trust to photographs" (98). He has developed computer programs that automatically expose inconsistencies in lighting conditions typically occurring in composites of several photographs. Further, the verifying algorithm serves to reveal cases of re-touching and image cloning, which may occur both in tabloid magazines and in less expected contexts, such as the stem cell research "documentation." ${ }^{1}$ Most interestingly, however, Farid has also developed a program that enables him to differentiate between photographic and computer-generated images (CGI). Hence, he does not only recognize the necessity of detecting traces of digital forgery; Farid also calls for reliable strategies to distinguish between images that haven been taken by actual cameras and those that were completely fabricated inside a computer. To illustrate why such a distinction is necessary in the first place, Farid draws on examples that imply the life realities of alleged victims and perpetrators: The talk is of such notorious court cases in which video evidence of child pornography or police violence was questioned on the basis of the blurred lines between virtual, manipulated, and indexical images. An image can be said to have an indexical relation to the so-called pro-filmic event when it rests on a physical and causal connection to what has occurred in front of the camera, a connection that is traditionally triggered by a photochemical process.

In contemporary cinema, this indistinguishability of non-/indexicality is brought about by the increasing occurrence of invisible special effects - digitally fabricated details, which are as realistic and "trivial" as actual recordings. What scholar Lev Manovich terms "elastic reality" and novelist Mark Z. Danielewski describes as a climate of ontological uncertainty can be considered to play a crucial role in the contemporary production and reception of film. ${ }^{2}$ One may in fact question the necessity of detecting CGI in cinematic fiction given that the latter

\footnotetext{
${ }^{1}$ By "image cloning," Farid means the practice of duplicating details of the respective image and arranging them in a way that exaggerates their size, volume, or scope. Adnan Hajj, a freelance photographer based in the Middle East, and his photographs of an Israeli bombing serve Farid as an example here: "In order to create more smoke in his photograph, Hajj cloned (duplicated) parts of the existing smoke using a standard tool in Photoshop, a popular photo-editing software. In this case the duplication was fairly obvious because of the nearly identical repeating patterns in the smoke. When care is taken, however, it can be very difficult to visually detect this type of duplication" (Farid 5).

${ }^{2}$ See Manovich, „What Is Digital Cinema?“ 8, and Danielewski, House of Leaves.
} 
remains fictional regardless of technological details or production circumstances. And yet, specific styles and genres attempt to shatter precisely this kind of certainty. The analog/digital shift has propelled the pseudo-documentary style and even a deliberately misleading mixing of genres and aesthetics. I will further elaborate on this development with respect to the found footage horror genre, which figures prominently in one of my case studies, Danielewski's "filmic" novel House of Leaves. Concerned with the increasing confusion between recorded and computer-generated images, the novel entertains (future) scenarios that stress the necessity of detecting CGI in what looks like amateur recordings and, even more importantly, of detecting indexicality in what looks like digital synthesis.

Hany Farid has discussed technological ways to detect cases of digital manipulation. In this study, I will discuss creative and intermedial ways to raise awareness of the increasingly elastic reality and ontological uncertainty stimulated by film and photography in the digital age. For this purpose, I will look at the films and photographs entertained, referenced, narrated, and partly depicted by contemporary US-American literature. I will thus look at cases in which "the literary medium becomes the background which reflects and exposes the altermedial system and its rules on account of the medial difference" (Rajewsky, Intermedialität 146). ${ }^{3}$ Literary references to film "raise awareness of the rules of the filmic system, be they conventional and thus valid or invalid, necessary or absurd, and most interestingly, different from or analogous to the literary system" (146). ${ }^{4}$ Intermedial literature, in other words, exposes developments of the digital age that might go unnoticed for the average viewer. In the realm of this exposure, it produces what I shall refer to as "literary special effects:" filmic evocations that break the rules of linear narrativity and other literary conventions, using the potential of the text in a rather unconventional and striking way. In the wake of developing taxonomies for "intermedial references," Irina Rajewsky has already described some of these deviations. From her examples, which derive primarily from Italian literature, we learn that some novels act "as if" they were films by verbal evocations of dissolves (98) or simulations of hard cuts introduced by onomatopoetic accentuations such as "jag" (94-95). When literary special effects are to lend visibility even to these most ordinary and general aspects of filmmaking, then they become particularly intriguing with regard to the perfected invisibility of certain digital effects and

\footnotetext{
${ }^{3}$ ("das literarische Medium wird [jedoch nach wie vor] zur Folie, die das fremdmediale System bzw. dessen Regeln reflektiert und ausstellt und aus der Mediendifferenz heraus offenlegt")

${ }^{4}$ ("die Regeln des filmischen Systems in ihrer Konventionalität - und damit in ihrer Gültigkeit oder Ungültigkeit, Notwendigkeit oder Absurdität und insbesondere in ihrer Differenz bzw. Analogie zum literarischen System bewußt gemacht werden")

5 (“zack")
} 
mechanisms. At the same time, this sort of intermedial tension puts emphasis on the mediality of the novel and its continuing printed manifestation in the digital age.

The research focus of my study is thus twofold: First, I will draw on a literary perspective to shed light on photography and film in the digital age. By providing an intermedial reading of three novels - Mark Z. Danielewski's House of Leaves (2000), Marisha Pessl's Night Film (2013), and Siri Hustvedt's The Sorrows of an American (2008) - I shall thus contribute to a discussion that revolves around the gradually surfacing concept of "post-cinema." Concerned with the shift from analog to digital cinema, the thematic scope of post-cinema is wide but heuristically reduced in this study to what I identify as its three, closely interrelated, main parameters: the materiality, the indexicality and the viewing experience of films produced, distributed, and watched under digital conditions. ${ }^{6}$ When I draw on the discourse of postcinema, I automatically include the concept of "post-photography" in my considerations. After all, the question of indexicality and its loss can be considered an originally post-photographic concern, as it were. What is more, the novels' intermedial references to film considerably overlap with those to photography, the latter supporting the former and vice versa, claiming an approach that addresses both media anyway. To sum up, I shall examine how the post-cinematic discourse, which comprises and is closely related to the post-photographic discourse, is being translated into a narrative and literary aesthetic, and thus possibly illuminated and reified.

The second layer of my research focus is directed at the mediality of the novel. The aim of this focus shift is to assess how self-referential or, in other words, "metamedial" the novels become in their attempt to narrate post-cinema. Especially House of Leaves and Night Film warrant this question, as they provide almost experimental reconfigurations of their printed book form in terms of typographic idiosyncrasies, the inclusion of pictures and QR-codes, for instance. Do the literary references to film and photography thus correlate with or result in forms of metamediality? Or are they possibly even motivated by a metamedial purpose, which might be to put emphasis on the unique affordances and media-specific potential of the novel? Located at the threshold between print novel and digital media, my case studies unfold a particularly critical potential regarding the discussion of the analog/digital transition.

Regarding the literary exploration of post-cinema, my first case study, Mark Z. Danielewski's House of Leaves, can be considered the most anticipatory and path-breaking example. Published right at the turn of the millennium, House of Leaves generates ontological

\footnotetext{
${ }^{6}$ Ariel Rogers aptly describes "digital cinema" as "a label that came to be used to refer to movies incorporating digital technology at some point in their making, distribution, or exhibition, although this point varies from film to film" (95).
} 
uncertainty in terms of THE NAVIDSON RECORD, a fictional yet fully re-narrated movie, which oscillates somewhere between amateurish home video and highly professional horror flick. It shows the creepy journey of photo-journalist turned filmmaker Will Navidson through his constantly and inexplicably shifting house. In various pseudo-academic footnotes and excursuses, the main narrator, Zampanò, ponders different interpretations of the notorious house on Ash Tree Lane. One of the questions he raises concerns the movie's indexicality, that is, whether it is a product of live-action recording or (invisible) digital manipulation. However, House of Leaves does not only pose a riddle, it looks and feels like a riddle as well. It experiments with typography and mirror writing, plays with colors and foreign languages, and takes the reader back and forth through its heavy 709-page print by a complex network of excessive footnotes. How do these literary special effects relate to the invisible digital effects possibly accounting for the impossible house? The reader is invited to interact with the book and decode it, and thus to investigate the eventuality of imaginary digital manipulation. Infected with both a sense of nostalgia for more reliable photographic media and weary anticipation of a less trustworthy digital future, House of Leaves can be assumed to take place at the dawn of the post-cinematic era.

Marisha Pessl's Night Film (2013) in turn reflects a different media-historical moment, featuring a more advanced stage of the post-cinematic landscape. Journalist and first-person narrator Scott McGrath investigates the case of Stanislas Cordova, an imaginary film director, who has not been seen in public for many years. Bewildered by the recent death of Cordova's daughter, Ashley, and the shocking realism of Cordova's horror films, Scott becomes obsessed with solving this last enigma of the digital age, which the director seems to embody. In the investigation of the Cordova phenomenon, Scott consults a wide range of different media and seeks a wide range of different places. Watching Cordova's movies or going to the cinema, however, play a minor role, if any at all, in the attempt to understand the director's oeuvre and enigmatic personality. The Internet becomes Scott's main source of research and the different websites, forums, and photo series he finds only deepen his mistrust in the harmlessness of Cordova's fiction. The question of indexicality is treated in Night Film and the oeuvre of fictional director Stanislas Cordova as well, but not as a new or urgent subject. Rather, Pessl has drawn the picture of a post-cinematic environment, in which the film industry has become self-conscious about the question of indexicality. It deliberately tricks the audience into confusion about fact and fiction and extends this illusion across a transmedial, seemingly paratextual world. This extended cinematic experience is not only narrated but also simulated among the pages of Night Film. The novel features numerous facsimiles of websites and fan 
forums that include various photographs documenting the Cordova phenomenon. The simulation of a post-cinematic environment is not only very graphic but truly interactive, as there is an app for the book, the so-called Night Film Decoder, which allows the reader to scan QR-codes scattered throughout the book and thereupon access additional (audio-)visual material about Cordova. The paradox of Scott's and the readers' many encounters with digital media is that there is an undertone of digital pessimism throughout the novel. It remains to be seen if and how Night Film reconciles its critical stance on overstimulation in the digital age with the excessive multimedia simulation and partly actualization in the novel's own pages.

It is hardly insignificant that two of my three case studies can be clearly assigned to the horror and mystery genre and thus set a rather pessimistic, if not dystopian, and certainly harshly critical tone regarding the zeitgeist in and of the digital age. And even The Sorrows of an American, though not a classic horror story, bears traces of the genre by entertaining the (psychological) horror of a stalking photographer. In fact, the fateful encounter between psychiatrist Erik Davidsen and the relentless "post-photographer" Jeffrey Lane further complicates the concept of literary intermediality in the digital age. The Sorrows of an American encourages a more media-ecological approach to the novel's portrayal of the contemporary uses of photography. Erik's encounter with post-photography revolves around the threat and consequences of surveillance, privacy loss, and public disgrace. The novel does not ask how to detect cases of digital trickery but how to deal with the increasingly manipulative power of images in the digital age. In this context, Hustvedt reconsiders the role of language regarding both the underrated power of captions and the linguistic impotence in the face of "lying" (and yet partly truth-telling) photographs of oneself. This leads me to the second idiosyncrasy of Sorrows in comparison to the other novels. Rather than exploiting the intermedial tension between book and photography in experimental or graphic ways, Sorrows simply narrates the tense encounters between writers and painters, between the characters who prefer to talk and those who prefer to take photographs. In the end, the focus of my study does not only shift from film to photography in terms of the altermedial system in question, but to the most basic intermedial relation between word and image. In short, it juxtaposes the verbal and the visual and transports the thesis to a more abstract level of reflection. This reflection takes place in the conventional form of a purely textual novel. Hustvedt's mainly 'ekphrastic' approach to the complexities of photography in the digital age, which does without color, striking page design, or font experiments, thus adds yet another critical angle to my study. 
I shall conduct the analysis of the novels in the form of comprehensive intermedial readings. The most common intermedial reference to photography or film manifests itself in "ekphrastic" descriptions. Basically, ekphrasis can be defined as "verbal representation of visual representation," that is, for instance, the literary description of a picture (Heffernan, The Museum 93). James A.W. Heffernan explicitly includes the verbal retelling of films into the realm of ekphrasis:

To describe or narrate a film is to represent in words a work of visual art, which is what ekphrasis traditionally does. But while pictorial ekphrasis often turns an arrested moment into a story, cinematic ekphrasis typically narrates what is already a story told by a sequence of images. So I consider cinematic ekphrasis a kind of narrative - a subgenre of narrative. ("Notes" 4)

Ekphrastic descriptions alone represent intriguing pieces of literature, as they demonstrate the capacity of language to conjure up different images. And still, it is particularly the literary reference to film that seems most interesting in the ways it exceeds mere ekphrasis. As ClaudeEdmonde Magny's famous study The Age of the American Novel (1948) exemplifies, French critics around the 1950s were intrigued by the comparative cinematic simplicity of American literature. Writers like Hemingway and Dos Passos dispensed with explanations, commentaries, or psychological insights in order to focus on a sequence of actions, as if through a camera eye. From the perspective of the French and especially Proustian abundance of introspection, numerous critics considered this kind of writing "modern and exciting" (Menand 209). Already the minimalistic description of successive scenes, the "and then, and then, and then effect," pushes literary texts beyond ekphrasis (Menand 209; emphasis in the original). It verges on the literary evocation of cinematic techniques, which in this case might be montage and ellipsis. There are various forms and nuances of how literature may represent film and there have been ambitious undertakings to describe and distinguish them.

With her 2001 publication, Intermedialität, Irina Rajewsky has made a decisive contribution to the identification of the complex workings of films in literature. My study largely draws on Rajewsky's typology, which distinguishes between two basic categories of the intermedial reference - "system-mention" and "system contamination"7 - and thus articulates the degree to which the "contacting medium" is infiltrated by the "contacted medium," that is, literature by film. ${ }^{8}$ It does not mean that I intend to impose a fixed theoretical or methodological

\footnotetext{
7 ("Systemerwähnung" and "Systemkontamination")

${ }^{8}$ Rajewsky borrows the terms "contacting medium" ("kontaktnehmendes (= Objektmedium)") and "contacted medium" ("kontaktgebendes Medium (=Referenzmedium)") from Werner Wolf’s publications on intermediality,
} 
framework on the whole of the three novels. Rather, I will proceed from the bottom up and draw on the most relevant concepts and discourses to live up to the complexity of each novel's motivation and manifestation of intermediality.

Furthermore, I will not only use but also critically reflect on Rajewsky's theory of intermediality against the backdrop of my case studies. I will question her concepts in the wake of using them, and thus even increase their productivity. The concept of the "intermedial gap," for example, is theorized by Rajewsky as the fundamental condition of every literary reference to film and describes the necessarily illusory character of the filmic system occurring within literature and its media-specific limitations. While a given text may oscillate between displaying and concealing the intermedial gap, the latter "in any case can only ever be bridged in the figurative mode of the 'as if'" (Rajewsky, Intermediality 55). My case studies show how significant the (in)visibility of this gulf between print novel and filmic system might be and renegotiate its alleged insurmountability under new, digital conditions. The intermedial gap turns out to be extremely useful as an analytical tool, especially in chapter four, where I focus on Marisha Pessl's Night Film and its use of QR-codes that make readers turn from their print copies to actual smartphone screens for further consumption of the Cordova world.

By explicitly taking into account the question of the digital in my intermedial reading, I build on the theoretical reasoning that Johanna Hartmann has initiated in her essay "Ekphrasis in the Age of Digital Reproduction," published in the Handbook of Intermediality (2015). Hartmann declares it a matter of urgency to rethink and reconceptualize ekphrasis in the digital age and reach at least "tentative answers" to begin with (124). Digital ekphrasis "opens up a space for the negotiation of the ethical and ontological dimensions" automatically implied by the diegetic occurrence or mention of digital imaging (122). In fact, Hartmann argues that "ekphrasis in the digital age has to be able to address these dimensions" (120). In this respect, her argumentation corresponds with my introductory assumption that the revelatory character of intermedial literature lends itself in particular to the ontologically problematic question of the special effect. According to Hartmann, this layer of inquiry cannot be ignored if a novel's ekphrasis of a film lays claim to a digital context. Ultimately,

the question of the nature of digital ekphrasis in the age of digital reproduction is one of continuities and discontinuities in literary practices, the aesthetics of

in which he also speaks of the so-called "literature-centered intermediality" ("literaturzentrierte Intermedialität") (see Wolf 1996 and 2002). 
the literary text, and the changed circumstances that describe the reading experience. (Hartmann, “Ekphrasis” 116)

This is why it is worth to take a second, analytical look at such experimenting examples as House of Leaves and Night Film rather than dismissing them as desperately ornamented in the face of competitive digital formats.

In how far has the current discussion of intermedial phenomena already touched upon my specific research interest? Worth mentioning is, for example, Hannasofia Hardwick's recently published dissertation, The Narrative Role of Films in Four Contemporary Novels (2017). Hardwick's study of post-millennial literature, including The Book of Illusions (2002) by Paul Auster and Point Omega (2010) by Don DeLillo, examines the different narrative functions of the literary representation of film. She covers the question how characters use films for the construction of the self and how the filmic embeddings ultimately reflect the narrative whole. While my approach also implies the narrative context of filmic and photographic insertions, my main interest lies in their historicity and digital intervention and is thus rather to be located in the field of media theory and media philosophy. The present study employs intermediality as a critical category in order to explore the role of the digital in literary representations of film and photography. ${ }^{9}$ It thus considerably paves the way for a research focus that until now has scarcely guided intermedial readings. Two of the few exceptions known to me are Simone Arcagni's “Pattern Recognition: The 'Postcinema' Seen by William Gibson," published in the anthology Imaginary Films in Literature (2015), and Julia Breitbach's Analog Fictions for the Digital Age: Literary Realism and Photographic Discourses in Novels After 2000, published in 2012. Arcagni draws on the post-cinematic discourse to discuss the portrayal of the contemporary media environment in Gibson's Pattern Recognition (2003). In a similar vein as I do, Arcagni argues that the literary text may considerably contribute to a more "precise idea of this galaxy that we call "postcinema"' (204). The novel revolves around enigmatic film clips anonymously released over the Internet and their subsequent cult following; it thus features similar elements as my case study of Pessl's Night Film. Resorting to Gibson, Arcagni draws an intriguing picture of how "cinema now crosses media displays and devices, hybridizes and colonizes new spaces, while building new forms, new practices, and new models of

\footnotetext{
${ }^{9}$ By that I do not mean cases of actual convergence between literature and film clips in terms of enhanced e-books, for example. This kind of encounter between the two media constitutes a so-called "media combination" which is characterized by the presence of at least two conventionally distinct medial forms in their own materiality. I, however, am interested in literature-centered intermedial references and their exploitation of the media-specific potential of the contacting medium for the sake of an illusory media combination. (Rajewsky roughly distinguishes between three sub-categories of intermediality: the media combination, the intermedial reference, and the medial transposition, which denotes, for example, the cinematic adaptation of a novel (Intermedialität 15-18).)
} 
experience, such as interaction" (204). He thus examines only one aspect of post-cinema, that which concerns the convergence between cinema and digital media environment in terms of film reception. In comparison to his rather short article, my study provides a more critical introduction of post-cinema and a more in-depth analysis of the intermedial strategies employed by the novel(s).

To my knowledge, the only book-length study that puts post-cinema (or postphotography respectively) into context with literature-centured intermediality is Julia Breitbach's above-mentioned Analog Fictions for the Digital Age. Breitbach yields new perspectives on the relation between literature and photography in the twenty-first century, focusing on novels by Don DeLillo, Michael Ondaatje, and Ali Smith. She provides a critical assessment and thorough discussion of post-photography before examining its influence on contemporary writing. Her study follows the intriguing claim that the literary discussion of photographic practices propels and illuminates the pursuit of literary realism. In accordance with my bottom-up approach, I do not examine the relation between book and photography, text and image, or watching and reading with regard to the overarching question of literary realism. A full discussion of Breitbach's approach lies beyond the scope of this study, and yet my case studies relativize if not complicate the pursuit of literary realism while problematizing, referencing, and discussing the implications of digital imaging.

In his introduction to the anthology Imaginary Films in Literature, Massimo Fussilo considers the question how contemporary literature describes and represents movies "a very promising topic," especially with regard to the "new configurations of old media" in our age (xiii). Promising, as I would add, is also the question how the contemporary novel responds to the media of film and photography given that the latter are undergoing a thorough identity crisis in terms of profound digital changes regarding their ontology, materiality, and reception. Julia Breitbach has argued that some novels respond by a new take on literary realism. In my attempt to identify these responses, I shall additionally problematize the crisis of the novel in the face of the rising e-book and other "digital threats," as it were. James Heffernan reminds "intermedial readers" to consider "the paragonal struggle for power between image and word: the struggle that invariably complicates the verbal representation of visual representation" (93). My study assumes that the digital age propels this struggle and expands it by the discursive dimension of book versus film and reading versus watching. In this respect, my study reflects on several discourses that I shall introduce in more detail on the following pages. But before 
detailing post-cinema, on the one hand, and the digital book culture, or 'post-print' culture, on the other, I shall discuss in greater detail the title-giving term of my project: the special effect.

There is hardly any other term in the filmic vocabulary that appears more self-evident than the so-called special effect. Be it the luscious landscapes of Tim Burton's ALICE IN WONDERLAND (2010), the explosive space battles from the STAR WARS franchise, or Steven Spielberg's magically resurrected dinosaurs, the special effect seems to be easily detectable, and unlikely to pose any definitional challenges. This is, however, not the only fallacy informing the common understanding of special effects. Especially the rapid progression of digital technologies and computer-generated imagery (CGI) since the 1980s continually reinvests the special effect with a fallacious air of novelty. Marketing campaigns for theatrical releases are still in search of wonder, alluring spectators with the sensory appeal of allegedly unprecedented audiovisual spectacles. ${ }^{10}$ In response to this rhetoric of newness, Scott Bukatman humorously calls to mind that "even digital effects have been around long enough to have a history," let alone the special effect per se, as I would add (ix). A quick look in the Oxford English Dictionary suffices to realize that the concept of the special effect not only covers a broad diversity of techniques and practices but features a long history as well. Building on sources which date back to 1907 , the $O E D$ speaks of "an unusual or spectacular illusion or other audio-visual effect, esp. one created by camerawork, computer graphics" as well as "a large variety of items, materials, equipment and processes."11

In a certain sense, the special effect can even be traced back to the founding myth of cinema and thus to such a mundane occurrence as the arrival of a train in Auguste and Louis Lumière's eponymous silent movie. At the premiere back in 1895, speechless viewers found themselves in terror of an oncoming locomotive. According to traditional accounts, the "train effect" triggered such hysterical reactions among early audiences, striking them as utterly palpable and incomprehensible. ${ }^{12}$ The accuracy of this (quite possibly exaggerated) anecdote, however, needs to be reconsidered in terms of its historical context. Indeed, the logic of marvelling was at the core of the "cinema of attractions" prevalent until about $1906 .{ }^{13}$ Tom Gunning's basic aesthetic of early moving images envisioned cinema as series of visual shocks

\footnotetext{
${ }^{10}$ According to what we learn from press campaigns, the number of movies standing out due to a groundbreaking use of special effects is virtually uncountable. See, for example, the wording used in an article about the newest JUNGLE BOOK (2016): "A new live action film version of The Jungle Book has used 800 artists working on powerful computers to create unprecedented realism. Images from the Disney movie, to be released in UK cinemas on April 15, are so convincing that the only sign of special effects is that the animals happen to talk" (Alberge).

${ }^{11}$ Oxford English Dictionary, 2nd ed., s.v. "special effect."

${ }^{12}$ See Stephen Bottomore, "The Panicking Audience?: Early Cinema and the "Train Effect." (1999)

${ }^{13}$ See Tom Gunning, "The Cinema of Attraction[s]: Early Film, Its Spectator and the Avant-Garde." (2006)
} 
and uncanny effects. In this non-narrative cinema of attractions, astonishment was precisely not a question of a passive immersion in a fictional world but of the highly conscious awareness of and exposure to the filmic image. In his demythologising approach to the train tale, Tom Gunning claims that these early spectators were "not primarily gullible country bumpkins, but sophisticated urban pleasure seekers, well aware that they were seeing the most modern techniques in stage craft" ("An Aesthetic" 117). Even though or precisely because this anecdote of running spectators stands for their amazement with the new medium rather than their naivety or "temporary psychotic state," it perfectly underpins the special effect's ultimate relativity (116). What this tale of quick astonishment actually nurtures is, in other words, the notion of all cinematography being a special effect from scratch.

The paradox of the term is that it requires drawing a line on the basis of rather vague criteria. Do stage blood and fog machines belong to the realm of special effects or are they part of standard cinematic repertoire? And what is so special about action sequences, only their digitally enhanced explosions or their cunning arrangement of jump cuts as well? "To define some aspects of film production as "special," Michael S. Duffy et al. explain, "is to assume that the apparatus of the medium of film has some baseline technical properties that are somehow not illusionist, not extrinsic to reality, not special" (4; emphasis in the original). Does our awareness of the cinematic illusion render the concept of the special effect obsolete and tautological? Or do special effects "merely provide a more overt kind of construction," as Stephen Prince puts it in one of his introductory remarks (Digital Visual Effects 29)? In 1977, Francoise Meltzer and Christian Metz devoted an influential essay to the ubiquity of "trucage" or trickery in film, articulating taxonomies for techniques that comprise special lenses, blurred focus, backwards motion, accelerated or slow motion, the use of a freeze frame, dissolves, superimposition, overexposure, split screens and montage itself, even though "it would occur to no one to add to the list of trucages ... such an ordinary and general manipulation" (672). In spite of their mission to raise awareness of the constructed character of film itself, Metz and Meltzer make an effort to distinguish between the conventional trucage characteristic for "all cinema" and what may count as a more special effect:

The concept of trucage as presented here must not be confused with the 'special effects' of which studio technicians speak. Preoccupied with the practical problems of their craft, technicians consider as special all those effects which they must create specially and which demand, in addition to the normal work of filming, a small, particular technique. There are, in fact, 'special effects men' in 
studios - their names occasionally figure in the credits. Thus loosely defined, the rubric of special effects will obviously form, for the semiologist, a heteroclitical group. (659)

On the one hand, we will have to content ourselves with the fact that the special effect has been and always will be a vague term. One can hardly deny that the term invites quite a broad understanding that ranges somewhere between the more or less thrilling arrival of a train and the CGI-enhanced showdown of the latest superhero movie. On the other hand, there are some practices and techniques that historically have qualified as intuitively special, pushing the limits of photographic processes and the pro-filmic world. ${ }^{14}$ In the analog era, special effects men were into miniature art, had specialist knowledge in pyrotechnics, or resorted to their outstanding equipment of animatronic puppetry. Already in 1940, they were involved in postproduction in order to project imaginative sceneries smoothly onto the recorded blue or green screen backgrounds (e.g. THE THIEF OF BAGDAD (1940)). This is how already in the early years of cinema, fantastic worlds and creatures permeated the big screens.

The art of special effects, once surfaced, has rarely been at a standstill. With the advent of digital technology, there has been a downright revolution of the special effect, which became increasingly ubiquitous and limitless. Milestones of visual trickery such as the HARRY POTTER (2001-2011) and STAR WARS (1977-2017) franchises as well as the evolutionary use of motion capture technology in THE LORD OF THE RINGS (2001-20003) trilogy and the RISE OF THE PLANET OF THE APES remake (2011) set whole new standards. ${ }^{15}$ As mentioned at the outset, it seems that every major Hollywood release makes another decisive, or at least rhetoric, step toward technological progress. There is, however, also a certain sense of saturation permeating the contemporary media landscape, where movies happen to be dismissed as "another numbing smash-and-bash orgy of CGI mayhem" (Ahmed). So, is it all a question of time and the next era of special effects is just about to dawn in the form of a virtual reality train? Or does the term

\footnotetext{
14 "The pro-filmic refers to everything placed in front of the camera to be filmed. It includes such things as the actors (and therefore casting decisions and performance style), lighting, set design, selection of locations, and selection of props. Strictly speaking, pro-filmic elements do not appear on the screen except through the next level of discourse, their capture on film as enframed images. However film viewers see the images on the screen as images of things, and the selection of the things that make up the image plays an extremely important role in conveying narrative information" (Gunning, "Theory and History" 19).

15 "Motion capture is a technique which combines live-action performances with computer-generated animation: in The Lord of the Rings: The Two Towers (Peter Jackson, 2002) and The Lord of the Rings: The Return of the King (Jackson, 2003) the character of Gollum was created by recording the performance of actor Andy Serkins while he wore a suit with nodes identifying key parts of the body. The movements of the nodes were scanned into a computer, and used to define the movement and posture of the wholly computer-generated Gollum. This enabled the expressiveness of the individual actor's physical performance to be replicated by the virtual character. The case of Gollum is interesting, in that it suggests that advances in CGI utilise, the craft that actors bring to films" (Speidel 96).
} 
as such no longer make sense in a predominantly computer-generated 4D media landscape? In fact, there were certain terminological adjustments, even prior to the explosion of digital technology. In 1972, the Academy of Motion Picture Arts and Sciences ceased to award Oscars for outstanding Special Effects. The category was renamed Best Visual Effects - the term that is still used today. According to some theorists, the traditional special effect designates mechanical and practical trickery created on set during or before live-action shooting (see Prince, Digital Visual Effects 3). Visual effects, in turn, primarily take place in post-production and perform "numerous other roles and functions beyond this," that is beyond the visual idiosyncrasies formerly called special effects (Prince 3). The question is whether, under these circumstances, the latter maintains any terminological relevance whatsoever. I understand that effects art has matured as a profession and covers areas that, at the bottom line, concern the entire texture of films and thus are more accurately described as visual rather than exclusively special. But is this reason enough to claim that "the era of the special effect is over," just as Stephen Prince does (3)? According to Prince, the terminological distinction between visual and special effects is hardly insignificant. After all, the trickery characteristic of the analog past was special "because the joins were generally visible between the elements comprising the effect, and this made boundaries between live-action cinematography and composited shots clear" (4). "In today's era," however, "visual effects can blend seamlessly with live action so that clear boundaries between the domains often do not exist" (4). Stephen Prince contrasts the analog with the digital era in terms of visible versus invisible effects and thus risks simplifying a highly complex and hardly linear process. In fact, I would rather argue that in the wake of this anything but clear-cut shift from analog to digital, the distinction between invisible and visible special effects has become an all the more intriguing subject. At least with regard to the present study, this digitally encouraged discrepancy appears more crucial than the question whether to prioritize one term over another.

The digital era of cinema, in other words, features both visible and invisible special effects alike. Stephen Prince is certainly right when he observes an increasing seamlessness in the digital age. After all, the progressing sophistication of digital technology and CGI is driven by a desire for greater realism and immediacy. Compare, for example, Ishiro Honda's 1954 clumsy GoDZILLA to Gareth Edwards' 2014 CGI-textured reboot, which "has that reality and sense of scale that we've probably never quite seen before." ${ }^{\prime 6}$ It is unquestionable that the digital age allows for a new degree of attention to the smallest detail in the motion picture

\footnotetext{
${ }^{16}$ See "Godzilla (2014) Behind the Scenes" on YouTube.
} 
industry. Realism and seamless blending with the storyworld or setting, however, does not necessarily mean that the special effect goes unnoticed or tends to be forgotten during the viewing. For one thing, matters are more complicated with regard to the ambiguous dynamics of remediation and the fine line between immediacy and hypermediacy, which I shall elaborate on later. For another thing, this emphasis of incongruities hinges on the denial of any active role spectators might play in the reception of special effects. Especially in the case of watching GODZILLA, the average viewer might be amazed by the creature's credibility but at the same, of course, aware of the digital refinement behind this effect. With reference to many Hollywood cases it is not necessary to get lost in such subtleties anyway. On the contrary, high-budget productions target their use of exceptional technique precisely at widespread viewer awareness. GoDZILLA counts as a typical case of such a movie, "where the plot becomes a pretext for the self-reflexive display of technological prowess" (Duffy et al. 6). Other common examples of this sort of visible special effects comprise futuristic, fantastic, and historical settings as well as the already mentioned action spectacles.

All in all, I would argue that the question of the special effect is not obsolete but almost ubiquitous in the contemporary media world and ranges between the so-called CGI fatigue and the undaunted struggle for the next cutting-edge sensation. Even in some of the less fantastic scenarios, such as Alejandro González Iñárritu's epic drama THE REVENANT (2015), special effects are ultimately meant to be seen and become part of a cunning press strategy. In interviews during the promo tour, Leonardo DiCaprio hesitated to disclose any details about how the meanwhile iconic bear attack has been accomplished. However, the secret of the bear scene did not last particularly long - only a few days after the release, revealing behind-thescenes material lost its exclusivity and permeated the Internet. ${ }^{17}$ Obviously, spectators were invited to contemplate how the trick was achieved and get similarly absorbed by the story of this intriguing special effect as by the story of the revenant's long and toilsome journey.

As already mentioned, this palpable aspect of today's visual effects is only one side of the coin. While some special effects are either exposed or all-too-discernible anyway, others remain hidden or at least leave the spectator wondering. After all, the increasing seamlessness of digital manipulation does not merely serve the smooth and credible integration of otherworldly monsters into a this-worldly setting. This familiar, allegedly pro-filmic setting may also

\footnotetext{
${ }^{17}$ See, for example, Jason Guerrasio writing about "How that infamous bear-attack scene in 'The Revenant' was made, and other secrets of the movie revealed."
} 
turn out to be composed of many conveniently digitized details. Thomas Elsaesser speaks of instances of computer-generated imagery

that enhance the impression of reality but stay within the boundaries of verisimilitude and photographic realism (so-called invisible special effects, such as the waves, the smoke from the ship's funnels, or the iceberg in James Cameron’s Titanic). (“Digital Cinema: Convergence or Contradiction?”36)

In fact, the digital age has in a sense perfected the art of the invisible special effect. According to Lev Manovich, contemporary cinema is characterized by a so-called elastic reality, which allows digital manipulation to increasingly occur within the scope of possible, even trivial events - leaving hardly any indication of digital artifice whatsoever. The analog/digital shift in the world of film production has seen an ambiguous proliferation of special effects - rendering them both more visible and invisible. The sum of visible and invisible trickery may be referred to as visual effects at the annual Academy Awards. After all, its special character seems relativized considering its partial indistinguishability from any pro-filmic trivialities. Alternatively, the described ambiguity may warrant a revival, or simply the continuity of the traditional yet inherently functional term, whose special prefix may either contribute to some effects' desired visibility or acknowledge their impressive invisibility, and yet hint at the ultimate distinction from the pro-filmic or indexical.

Among my case studies, House of Leaves provides the most explicit, pseudo-academic discussion of the digital use of special effects, as well as its ontological and ethical consequences. It is also House of Leaves that warrants my title-giving concept of the literary special effect in particular. The way Danielewski's text adapts to the climactic passages describing the eerily shifting walls on Ash Tree Lane is reminiscent of concrete poetry. ${ }^{18}$ When I refer to this kind of typographic experimentation as a literary special effect, I raise the question of its analogy to the novel's thematic preoccupation with cinematic special effects, and their ambiguous detectability. Night Film does not quite live up to House of Leaves' literal blending of cinematic and literary special effects, or the latter's visualization of the former. Nevertheless, its preoccupation with the increasingly fragmented reception of film in the digital age goes together with a striking insertion of visual and even multimedia elements via App and QRcodes. By providing the narrative with this sort of literary special effects, Night Film might not lend visibility to diegetic special effects but other mechanisms of the digital age that seamlessly

\footnotetext{
${ }^{18}$ In the $O E D, 2$ nd ed., "concrete poetry" is defined as follows: "a form of poetry in which the significance and the effect required depend to a larger degree than usual upon the physical shape or pattern of the printed material."
} 
and unnoticeably have permeated most readers' everyday media consumption. The utter and prompt visibility of the literary special effects in these two books can be said to stand in a revealing contradistinction to the increasing seamlessness of digital cinema. My analysis shows how the two novels both tackle and visualize the issues of digital manipulation and other specific challenges of the digital age. This angle of inquiry allows me to contribute to the discourse of post-cinema.

Post-cinema does not merely relate to the transformation of cinema and designate the medium's obsolescence. According to an increasing number of scholars, the so-called newer media are post-cinematic. As I understand the term and exploit it as most productive, it suggests specifically looking at how cinema has changed in the wake of the digital age in order to understand and process the new media landscape. To speak of post-cinema, in other words, means to look at how cinema has developed from a dominant audio-visual medium in the twentieth century to part of the more fragmented, post-cinematic media landscape of the twentyfirst century. ${ }^{19}$ At the same time, the question arises whether the vastly circulating term cinema is still adequate or maybe more appropriate than possibly expected. The burgeoning critical discourse on post-cinema, while it largely overlaps with the digital cinema scholarship, ultimately aims at a more ambitious level of abstraction. The discourse oscillates between a rather narrow understanding of the concept, which explicitly proceeds from cinema as a point of departure, and a very broad understanding, which strives grasping new forms of affect or sensibility. Media scholar Steven Shaviro, for example, applies the Post Cinematic Affect in his eponymous work to four case studies in order to point out sentiments typical for the postcinematic age. His "larger aim is to develop an account for what it feels like to live in the early twenty-first century" (2). Therefore, he looks at one music video and three films as "symptomatic and productive" works of the computing-and-information technology infrastructure, which in turn comes together with neoliberal economic relations, an overall reification of human activities (2). In the course of Nick Hooker's music video, "Corporate Cannibal," the artist's, that is Grace Jones', visibly digitized and thus mutable and fluid face twists and distorts all over the screen. According to Shaviro, Hooker curiously puts the video's exposure of digital elasticity in relation to the transnational culture of financial circulation:

\footnotetext{
${ }^{19}$ By writing about "a dominant audio-visual medium in the twentieth century", I intentionally use the indefinite article to imply that cinema did not claim this status throughout the entire century as in its second half the role of television can be considered predominant in mass entertainment.
} 
Just as the groundless figures of digital video are no longer tied to any indexical referents, so too the endlessly modulating financial flows of globalized network capitalism are no longer tied to any concrete processes of production. (30)

In contrast to the inflexible Fordist industrial regime, today's control society of corporate cannibals springs from an "algorithmic grid of variations" whose prioritized structure of feeling takes underlying flexibility as top priority (13).

In their publication, The State of Post-Cinema: Tracing the Moving Image in the Age of Digital Dissemination, Malte Hagener et al. state that today,

film is no longer just cinema, no longer a medium that is based on the photochemical recording and replaying of movement, or on the projection of analogue $35 \mathrm{~mm}$ material. Film has become a purveyor of image worlds and virtual worlds of seemingly unlimited scope. It is no longer an art form celebrated only at public screenings, but a medium of cultural expression easily attainable through informal communication. (9)

Just like Shaviro speaks of a certain fluidity in the "heavily digitized" media regime (1), Hagener et al. use a similar metaphor in their introductory chapter "Like Water: On the ReConfigurations of the Cinema in the Age of Digital Networks." Whereas Shaviro strives to conclude a larger episteme of the digital age from the shift of cinema to post-cinema, Hagener et al. focus on the increasing liquidation of certain power hierarchies and transcultural restrictions with regard to concrete, post-cinematic manifestations of cinema, such as the reception of banned films in Iran or the (in)stability of the Multiplex market.

The latest, most comprehensive contribution to the post-cinema discourse is Shane Denson and Julia Leyda's online anthology Post-Cinema: Theorizing 21st-Century Film. The volume has gathered some of the most relevant voices that may count as post-cinematic in one way or another. It is divided into contributions to "experiences," "techniques and technologies," "politics," "archaeologies," and "ecologies of post-cinema" and concludes with "dialogues on post-cinema." As they point out in their introduction, this multifaceted range of approaches is supposed to help Denson and Leyda to "develop a grounded but emphatically speculative film and media theory for our times" (7). Despite the speculative character of the debate and the variety of angles applied, the editors have managed to point out three main "parameters for post-cinema." The eponymous introductory chapter features Lev Manovich's phenomenological inquiry of digital cinema and his discussion of a waning indexicality; Steven Shaviro's elaboration of post-cinematic aesthetics and "post-continuity" as a new action-movie 
style; and Richard Grusin's paper on new forms of film reception, which he theorizes as the "new cinema of interactions." While the idea of post-continuity certainly adds a crucial - yet genre-specific - angle to the gradual identification of a post-cinematic style, this study will focus on the waning of indexicality and the rise of a new kind of film reception as the two fundamental aspects, as well as Lev Manovich and Richard Grusin as two pioneering thinkers of the post-cinematic age. The issue of indexicality connects the filmic with the photographic discourse developed primarily in William J. Mitchell's detailed 1992 analysis, The Reconfigured Eye: Visual Truth in the Post-Photographic Era. I will critically reflect on these fundamental readings in the wake of my three intermedial analyses and thereupon further illuminate the concept of post-cinema. In its entirety, the analytical body of my thesis can be regarded as a story of post-cinema. While I certainly do not wish to suggest any kind of grand narrative about post-cinema, I want to look at creative literary attempts to do so, taking grand in quite a literal sense given the sheer length and complexity of the novels. In this context, House of Leaves lays both the discursive and (pseudo-)theoretical ground for reading Pessl and Hustvedt as a continuation of this grand narrative about the uncertain digital future of cinema.

The uncertain future of the book has become a widespread concern in the digital age, too. In fact, the intermedial tension examined by this study does not unfold merely between film, photography, and novel, but between the sentiments of post-cinema and "post-print" as well (Gunkel 280). House of Leaves and Night Film are interested in the waning materiality of film and at the same time strikingly, if not anxiously, concerned with their own material form, the print book. Besides examining cinema in the digital age, my second research interest thus concerns the question of the medium of the novel itself in the digital age, not as a mere point of departure for discussing film but as a major, self-reflexive actor in the intermedial arrangements at hand. Typographic experiments, QR-codes, and complex footnote systems foster both readers' (haptic) interaction with and awareness of the bundles of paper held together between two covers. According to Jessica Pressman, this sort of "bookishness" constitutes a response to the fear of a dying print and reading culture. On the one hand, this rhetoric of the book's pending mortality is not to be treated as something particularly new, ${ }^{20}$ and neither is the "fetishized

\footnotetext{
${ }^{20}$ Kathleen Fitzpatrick referred to a period in which the American literature was allegedly threatened by television when she pointed out the obsolescence of the novel's anxiety of obsolescence. To get a vague idea of Fitzpatrick's scepticism, it suffices to look at a short excerpt from her reasoning: "The book and its main champion, the writer, are repeatedly represented as latter-day Quixotes, tilting at the windmills of mind-numbing, dehumanizing, overpoweringly visual forms of entertainment and communication. The main locus of blame for this literary decline is, of course, television, but such metaphors of media in conflict have recurred throughout the last dozen decades... Such conventional concerns about the book's imminent demise are more than a bit specious, as a cursory at the urban and suburban landscapes of the late 1990s and early 2000s reveals. A Borders or a Barnes and Noble has arisen (or will arise) on every corner in major metropolitan areas, as well as in most small towns...Given
} 
focus" on the book form (Pressman, "The Aesthetic" 465). On the other hand, Pressman argues that the works of twenty-first-century fiction "exploit the power of the print page" in a largely unprecedented way (465):

This focus on the book and the aesthetics it promotes is not merely another form of postmodern reflexivity in which the author toys with the reader in a layered process of simulacra. There is a decisively different tone and ambition at work in the novels of our moment. (466)

Thereby, she draws on the rise of digital technologies and the unique threat and stimulus it constitutes with regard to the potential of book-bound fiction. ${ }^{21}$ Lindsay Thomas also points to the specific correlation between bookishness and literary fiction in the digital era:

Bookishness has to do not only with aesthetic experimentation, but also with the status of novels themselves in relation to digital technologies. More specifically, bookish texts are concerned with how the print novel functions in ways that differentiate it from digital technologies (184; emphasis in the original).

The House of Leaves scholarship, for example, has already begun to explore the novel's metamediality and its bookish manifestations. My study is particularly interested in the subtleties of the tension between the striking bookishness of the novels and their thematic and visual focus on the new, digital media. In fact, a leading question of my thesis is whether this clash between metamedial and intermedial elements within one literary work constitutes forms of intermedial rivalry. What these intermedial novels put forward is thus not simply a literary

this growth of the market, how can one imagine the book to be an endangered species? And, not incidentally, whose interests does it serve to claim so?" (The Anxiety of Obsolescence 4). Fitzpatrick is interested less in the actual influence of television on literature and more in what purpose this discourse serves. In her readings of white male authors, she questions the mechanisms of white privilege in the art milieu and the martyrish "celebration" of the death of the book, which leads to further marginalization of already marginalized writers. Fitzpatrick provides an intriguing reading of how the discourse might be exploited. I would rather not dismiss the question of the changing print and reading culture due to the doubtful intentions of certain writers. However, the curious aspect about my approach is that I do not simply speak of the arrival of yet another overpowering rival medium. My case studies rather discuss the "digital demise" of the long-established media of film and photography. In a sense, one could thus ask whether my literary examples praise their own mediality at the expense of an intermedial friendship to film and photography, thereby deliberately contrasting the revival of the novel to the alleged death of cinema, for instance.

${ }^{21}$ In the remainder of her essay "The Aesthetic of Bookishness," Pressman uses British novelist Steven Hall's The Raw Shark Texts (2007) as an example. The novel's central villains are sharks that are literally made of text and materialize on the surface of the print page. Rather than discussing digitization via concrete intermedial references, the novel exploits its own mediality in the more abstract context of "digital systems," which hardly figure in the narrative at all (475). The aspects Pressman addresses range from disembodied digital information and the fear of data loss to information overload and the threat of memory loss. In another essay, Pressman has analysed House of Leaves in terms of its bookishness as well. I shall reflect her reading in my pending review of the House of Leaves scholarship that is relevant in comparison and contradistinction to my intermedial analysis of the novel (see chapter 3.2 "Writing about House of Leaves"). 
comment on the status of film in the digital age, but a fruitful juxtaposition of film and book with regard to their respective digital future. Put simply, my case studies' bookish responses to post-cinematic phenomena are worth to be discussed in terms of the "crisis of book culture" in the digital age, as well (Striphas 2). This crisis concerns the (digital) future of the novel, the book, and reading in general. Will Self's article "The Novel is Dead (This Time it's for Real)" grasps the inconclusive character of the discourse while being genuinely concerned about the digital future of literary fiction, in which not only "the physical book [is] in decline, but the very idea of 'difficult' reading is being challenged."22 Given that this paradigm shift, or, in other words, Gutenbergian identity crisis is in part happening before our eyes, I shall spend some time reflecting on it - in the following lines and in the course of the study. For Amazon, the sale of physical books has become a multibillion-dollar business (see Baron 4). Yet at the same time the world's largest online retailer has taken a decisive step towards defying the print book - or in the words of CEO Jeff Bezos "the last bastion of analog" (Levy) - when introducing the Kindle, a portable e-reader, in 2007. The effects were palpable but less overwhelming than expected. In 2010, Amazon announced that Kindle titles have outnumbered hardcover sales, moving ahead of paperbacks by January 2011 (Baron 7). By 2013, digital book sales accounted for a solid $27 \%$ of American publishers' revenues (at least as far as adult trade book are concerned) (see Baron 7).

The new technology comes with a number of striking and hardly disputable benefits. Not only does the digital edition show a more affordable price than its paper counterpart, it gives avid readers the chance to act eco-friendly. Passionate readers were suddenly able to take their personal weightless libraries on vacation, no longer compelled to decide between one of their heavy print copies taking up too much of the backpack's valuable space. Another indisputable convenience is the e-reader's FIND function. In this respect, search engine giant Google leads the field with its famous book-scanning project "Book Search." In the ambitious attempt to compile a cross-referenced universal library, Google turns the library stock of 30 research institutes digital and thus easily searchable. ${ }^{23}$ In an unprecedented way, e-reading platforms grant entrance to a social community of readers. The communal experience is about seeing other readers' reactions and favorite passages and the chance to respond or add one's

\footnotetext{
${ }^{22}$ For further reading, see David A. Bell, “The Bookless Future” (2005), and Sven Birkerts, The Gutenberg Elegies (2006).

${ }^{23}$ The ultimate success of this quest, which began in 2004, has been thoroughly questioned. After all, the world's self-proclaimed largest online library does not only raise copyright issues but hardly appears representative and transparent enough to warrant, for example, distant reading practices (see Stephen Heyman, "Google Books: A Complex and Controversial Experiment." and Tim Wu, "What Ever Happened to Google Books?”).
} 
own thoughts (Baron 40). In general, being connected to resources on the web during reading or writing is no longer to be considered a technological asset but a matter of course, especially so for the digital natives. "If it isn't on the Internet, it doesn't exist"; this is how philosopher Mark Perlman grasps the sentiment of this techno-cultural as well as generational phenomenon in his article. Are books gradually turning into archaic relics, as Perlman suggests? How is the domestic pastime of solitary reading changing? Against all the odds, "the data suggest that people who read on digital devices tend to do more reading overall than those only reading print" (Baron 208). ${ }^{24}$ The lingering question is nevertheless: What do we trade for this significant gain of digital convenience?

In fact, the potential consequences of exclusive screen reading already inspired a considerable number of academic publications, including Paul Socken's anthology The Edge of the Precipice: Why Read Literature in the Digital Age? (2013), Bill Cope and Angus Phillips' The Future of the Book in the Digital Age (2006), Ted Striphas' The Late Age of Print: Everyday Book Culture from Consumerism to Control (2009) and Naomi S. Baron's Words Onscreen: The Fate of Reading in a Digital World (2015), to name but a few. For one thing, the collective anxiety about the uncertain future of print is linked to the history of the haptic book. Naomi Baron highlights how "a book was always physical. You could smell its binding. Admire it on a shelf. Lend it to a friend. Lose it. Burn it" and stumble upon it by a happy coincidence (131). Digital texts, in turn, are less likely to pass Baron's "stumble-upon test." In fact, I came across Night Film while randomly strolling through a bookstore, and its coincidental discovery essentially paved the way for this study. Ironically, my extensive Internet research of contemporary intermedial literature did not produce any results leading to Marisha Pessl. What struck me was how it sat on the shelf, the large book spine setting it off from the others, and of course the big letters reading "Film" in its title. The circumstance that the death of the book would entail the disappearance of book shelves might occur to some as a mundane fact of life. Ted Striphas, however, points out that "books are more than just things people read. They're also props, part of the decor, psychological barriers, and more" (12). In a historical account, he reminds us of the book's "Shelf Life" (26-31): In response to the 1930 economic depression, major New York book publishers and PR specialists decided to build housings for readers' precious volumes, and this is how bookcases became virtually indispensable elements of US

\footnotetext{
${ }^{24}$ Baron draws on a national poll by USA Today and Bookish, a website providing passionate readers with bookrelated news and recommendations. The respective quote on www.usatoday.com reads: "Adults with a reading device say they read an average of 18 books a year; those without devices say they average 11 books" (Minzesheimer).
} 
American homes. The disgrace of empty bookshelves was countered with a trade in book dummies, which quickly became so commonplace that people did not even bother to keep it a secret. Even though these books of illusion are less common today, many readers still take pride in filled bookshelves. Michael Austin's use of his valuable furniture piece, for example, is comparable to that of a vitrine - as he likes exposing his particularly tedious and complex reading achievements or, in other words, "troph[ies]" (Austin 16). The problem with e-books is, in comparison, that they "won't be owned. They'll be accessed" (Kevin Kelly quoted in Baron 131/ cf. Baron 138). They are deprived of scribblings, dog ears, coffee stains and other personal vestiges indicating ownership.

The second question preoccupying the e-book scholarship is that of (the quality of) reading. Does navigating between hyperlinks, skimming snapshots on Google Books, or cyberscanning words count as reading at all? Not according to Mark Perlman who is deeply concerned about the (waning) depth of meaning conveyed under these circumstances. It can be said that the digital revolution is redefining what it means to read, and not necessarily so in the most positive or productive sense. For Mirit Barzillai and Maryanne Wolf, reading, or to be more precise, "deep reading" relies on "the array of sophisticated processes that propel comprehension and that include inferential and deductive reasoning, analogical skills, critical analysis, reflection, and insight" (32). These aspects stand in striking contradiction to what some e-reading contexts feature and require, namely fragmentation, distraction, multitasking, a high level of stimulation, and a low threshold for boredom. In fact, the industry has already reacted to this paradox by releasing the Kindle Paperwhite in 2012, a refined book simulation cutting back on unnecessary frills and trimmings. A huge amount of online reading, however, takes place on laptops, iPads, smartphones, and tablets. Only recently, the so-called Nielsen survey has revealed that mobile phones and tablets had even superseded e-readers as the most common device used to read e-books (see Cain). Embedded in such multifunctional contexts, such "obvious" benefits of e-books as availability, searchability, and connectivity may quickly turn out to be rather overwhelming and distracting, in short, "Janus-faced" (Baron 41). What can be juxtaposed in the digital age is thus the waning phenomenon of deep reading, on the one hand, and what Katherine Hayles calls "hyper reading," on the other.

Hyper reading, which [according to Hayles] includes skimming, scanning, fragmenting, and juxtaposing texts, is a strategic response to an informationintensive environment, aiming to conserve attention by quickly identifying 
relevant information, so that only relatively few portions of a given text are actually read. (How We Think 12)

The Internet-driven priority of efficiency appears likely to interfere with the production of highquality works and in-depth studies on the part of students as well. Regarding the question of paper versus digital reading, Perlman concludes that especially in the "field of philosophy, serious, detailed, rigorous treatments of complex arguments and subtle views remain firmly rooted in those old-fashioned information-storage devices we old-timers call 'books"” (20).

The discourse and the lasting, partly nostalgic perpetuation of these "archaic relics" may appear exhausting but turns out to be far from exhausted (Perlman 25). After all, author Nick Harkaway's 2014 claim that "quite shortly we'll stop having this debate about paper vs ebooks because it will no longer make a lot of sense," has not necessarily proven to be true. On the contrary, such rather unexpected headlines as "Ebook sales continue to fall as younger generations drive appetite for print" recurrently revive the debate (Cain). The $7 \%$ rise in printed book sales and 4\% decline in e-book sales in 2016 can be explained by an increase in publications that simply "tend to translate better in the print form," as Steve Bohme, research director at Nielsen Book Research UK, points out (Cain). 25 "E-Book Sales Slip, and Print Is Far From Dead" is also what The New York Times wrote in 2015 about this international "Plot Twist" on the book market (Alter). Now in 2017, the print renaissance continues, as The Guardian online section headlines that “'Screen fatigue' sees UK ebook sales plunge $17 \%$ as readers return to print" (Sweney). ${ }^{26}$

At a first glance, House of Leaves and Night Film seem to lend themselves to a reading screen. Noteworthy in this context is House of Leaves' hypertextual structure, let alone Night Film's alleged hunger for multimedia as well as both novels' thematic preoccupation with the multifaceted impact of the digital age. Paradoxically, this is why they make more sense in printed form, after all. ${ }^{27}$ The two writers consciously exploit the novel's material anchor for their creative purposes. Marisha Pessl, with her QR codes scattered throughout the print copy, produces an actual bridge between online and print reading and thus a particularly curious case of both liminality and meaningful intermediality. And also House of Leaves provides a very

\footnotetext{
${ }^{25}$ At another point, Bohme dampens the euphoria about this "really promising" sales figure, since one should not forget that "over the past four years, the proportion of book buyers who perceive themselves as reading books daily has fallen by about 3\%" (Albanese).

26 "There is generally a sense that people are now getting screen tiredness, or fatigue, from so many devices being used, watched or looked at in their week. [Printed] books provide an opportunity to step away from that" (Stephen Lotinga, chief executive of the Publishers Association, qtd. in Sweney).

${ }^{27}$ As I shall elaborate more closely throughout the study, they can be considered print remediations of "digitally native books" and as such convey their critical message in the first place (Baron 6).
} 
'bookish' response to the digital age, which is not even available as an e-book. It thus lends authenticity to its metafictional talk of "reams and reams of paper" (323).

It is important to note that House of Leaves, published in 2000, can hardly be regarded as a critical response to the still emerging e-book market. However, the digital future of the book has been an issue already in the 1990s. Ben Bova's 1989 novel Cyberbooks, for example, paints the picture of a future devoid of books and abundant in e-readers. The protagonist's sensational invention of "a gray oblong box about five inches by nine and less than an inch thick" with a "dark display screen" and "a row of fingertip-sized touchpads beneath the screen" dramatically shakes up the publishing industry in the blink of an eye (19). In 2000, Stephen King and publishing house Simon \& Schuster finally took on a dare and decided to pioneer this pending e-book revolution. They uploaded the author's novella Riding the Bullet as the world's first mass-market e-book, attracting hundreds of thousands of fans for $\$ 2.50$ per download. In this climate of millennial anticipation, House of Leaves has proven to be visionary not only in terms of the found footage horror film movement (with the notorious THE BLAIR WITCH PROJECT being released only a few months prior to the novel's publication) but also in terms of the contemporary Gutenbergian crisis. In a way, it put down a marker against a digital threat to print, and tellingly did so at the very turn of the century. In fact, the scenario imagined in Cyberbooks has not occurred yet, the e-book revolution "hasn't quite reached the fevered pitch that book industry insiders had anticipated" (Striphas 19).

As I have already implied, "the enduring pleasures of paper, type, page, and ink" (Gass 45) can partly be explained with the deeply rooted view of books "as a kind of 'sacred product"" (L. Miller 19). The latter is perpetuated by a considerable amount of bibliophilic and possibly even nostalgic voices within the academic and reading community. The moral, aesthetic and intellectual value of the novel appears incompatible with merchandising techniques that aggressively stress the sellable commodity over the emotional value and the digital entertainment (of enhanced e-books, for instance) over the contemplative reading experience. The irony of such experimental examples as House of Leaves and Night Film is that their eyecatching character might either be accused of saleability or acknowledged for exploiting the elasticity and adaptability of the novel's mediality. In the wake of examining such novels, one might thus face a thin line between thriving and surrendering in the light of a new technological regime. Cope and Kalantzis argue that the digital revolution "is a revolution that may well breathe new life into the book, not only as an information architecture, but even its printed 
manifestation" (194). I proceed from the same assumption when approaching my selection of literary examples and their rather confident responses to the digital book culture.

I shall begin my study with "The Question of Medium Specificity in the Digital Age." This chapter is all about the balancing act of articulating a coherent idea of mediality, on the one hand, and laying emphasis on its contemporary status of constant flux, on the other. Jay David Bolter and Richard Grusin's remediation theory will be introduced as a productive take on the dynamic character of today's complex, hardly graspable media landscape. It makes sense to address and discuss most of the pending methodological and theoretical questions in the course of the analyses themselves. I have already mentioned that the novels are meant to serve as my points of departure when it comes to renegotiating what cinema and photography means in the digital age. After all, my corpus, Sorrows and House of Leaves in particular, already springs from declared, highly intellectual narrators whom I merely need to enter into a dialogue with to arrive at a sophisticated discussion of post-photographic, post-cinematic, and post-print phenomena and the recognition of alternating sober and nostalgic, enthusiastic and critical, if not eye-opening, viewpoints.

My analysis starts with Mark Z. Danielewski's House of Leaves, in which a prizewinning photographer turns into a bold filmmaker. After reviewing what has been written about this millennial novel, I shall contribute a systematic if not ultimately "taming" intermedial approach to this complex work of art. Narrator Zampanò's pseudo-academic paper about THE NAVIDSON RECORD provides a footnote-heavy, explicit discussion of film in the digital age, which I draw on and develop further. Against the backdrop of this discussion and in consideration of the novel's metamedial tendencies, I shall develop a response to the pivotal question whether the novel suggests the THE NAVIDSON RECORD to be a product of digital manipulation. Its striking kinship with the found footage genre, which I shall enlarge upon by this occasion, further complicates matters. The concluding section of this chapter also entertains the idea of the book as a code, which comes to mind when the abstraction of the digital code is exposed not despite but because of the novel's bookishness. After all, the meaningful arrangement of words and letters highlights the benefits of careful reading and thereby provides clues to the cryptical manifestation of THE NAVIDSON RECORD as well as the possibility of digital trickery.

In the fourth chapter, my focus on Marisha Pessl's Night Film triggers a theoretical discussion of film reception in the digital age. It draws on Richard Grusin's “digital cinema of interactions," its abundance of demystifying, meta-reflexive dynamics, and the thin line 
between a mere "relocation of cinema" (Casetti) and its thorough remediation. After all, the fictional world Pessl has created around Cordova can be considered symptomatic of this multifaceted media environment, which oscillates between the continuing allegiance to traditional structures and the more mainstream emphasis on the new and unprecedented. What follows are two different readings of this world. Is Cordova's mysterious underworld meant to be a nostalgic response to an "overexposed" digital media landscape (Night Film xi)? Or does it turn out to be a rather profit-oriented case of sensational transmediality, inviting fan interaction and consumerism $?^{28}$ My analysis of the reading experience offered by Night Film entails a reconsideration of Rajewsky's intermedial gap, which is repeatedly challenged throughout the novel and even explicitly crossed upon the readers' migration to a digital device via QR code. The question is whether this repeated emphasis on the gap disturbs the reading process or, against all odds, raises awareness of the necessity of contemplative reading in the first place. At last, I will show how the novel's considerable number of different (post-)photographic depictions ties in with and even reinforces my findings on the Cordova phenomenon's ultimate ambivalence.

My last case study, Siri Hustvedt's The Sorrows of an American, poses the question of post-photography in that it challenges the protagonists' traditional concepts and understandings of photography. In contrast to the existing Hustvedt scholarship, I would like to lay a stronger focus on the role digitization plays in the novel's tale of stalking photographer, Jeff Lane, and his victims, who find themselves struggling for the right words in the face of distorted portraits and particularly bold privacy invasions. Among my examples, Sorrows is the most classical case of intermedial references since it sticks to the means of linear text only. Its analysis thus makes the study conclude with a discussion of the intricate relationship between verbal and visual language, which lies at the heart of the question of (inter)mediality and crucially inspires the conclusion of my thesis.

\footnotetext{
${ }^{28}$ Basically, "transmediality" refers to medially unspecified phenomena or, in other words, the occurrence of certain aesthetics, characters, and subject matters across different media (Rajewsky, Intermedialität 13). Throughout the study, I shall further enlarge upon this concept. Night Film provides the paradoxical yet highly intriguing case of a transmedial world imagined between two book covers.
} 


\section{The Question of Medium Specificity in the Digital Age}

One of the conclusions to be drawn from the multi-layered (and multi-bracketed) title of my project is that the question of "mediality in the digital age" is going to constitute an inseparable part of the subject matter. In our digital world, where boundaries blur and hybridity flourishes, it becomes increasingly difficult to work out a unified, global definition of the medium. However, to claim that the traditional idea of a medium is threatened in the face of recent technological and aesthetic developments appears problematic. Debates about medium specificity (including a variety of broad as well as narrow approaches) had been held long before ones and zeros began to further complicate the subject matter. As Joshua Meyrowitz observes, "it is a glaring problem for media studies" that "we have no common understanding of what the subject matter of the field is" (37). Paradoxically, there seems to be consensus regarding the crisis of the medium, yet still no common definition of the medium. And the terminological challenges gradually brought about since the 1980s by the digital revolution seem to have fostered this paradox.

D.N. Rodowick points out what it is that intuitively defies (at least) the ordinarylanguage understanding of the concept of the medium and primarily concerns the blurry standard-plurality of so-called new media:

Because the digital arts are without substance and therefore not easily identified as objects, no medium-specific ontology can fix them in place. The digital arts render all expressions as identical since they are all ultimately reducible to the same computational notation. The basis of all representation is virtuality: mathematical abstractions that render all signs as equivalent regardless of their output medium. Digital media are neither visual, nor textual, nor musical - they are simulations. (10)

Such word pairs as digital cinema or enhanced e-book circulating among the new media may thus only be temporary terms, simulating a terminological conclusion that has hardly taken place in the midst of a major paradigm shift. "The designation 'new media' is misleading for a number of reasons. First, it encompasses too wide a variety of computationally processed artifacts ... and all the varieties of computer-mediated communication" (94), writes Rodowick. In an academic discussion of digital phenomena, it is thus crucial to address their questionable medium-specificity and vague terminology, in short, their stable instability. How to deal with 
a situation in which one's object of study is in constant flux ${ }^{29}$ Is it advisable to apply a particularly broad or, on the contrary, a particularly narrow understanding of the medium? Is this kind of liminality graspable at all?

In the wake of this conceptual crisis, Noël Carroll's 1996 categorical dismissal of medium specificity appears worth (re)considering. Obviously proceeding from a materialist framework, Carroll argues that a medium's productivity, rather than freely unfolding, is limited by its material essence, and thus might inhibit artistic inventiveness:

Proponents of this purist program argue that if the medium in question is to be truly regarded as an art, then it must have some range of autonomous effects, effects that are its own and that are not merely copied from pre-existing, established artforms. The purist then specifies the range of effects peculiar to a given medium, and goes on to urge that artists within that medium focus their energies upon experimentation within this range of effects. Needless to say, different theorists will identify different potentials of that medium. Thus, at stage two in our scenario, we are greeted by contesting recommendations about the correct line of stylistic development within that medium - recommendations, moreover, which are each putatively based upon having isolated the peculiar potentials or capacities of the medium in question. (3)

The necessity of a radical antiessentialism applies, according to Carroll, to audiovisual art forms in particular, that is film, video, and products of digital synthesis. Instead of "meticulously" distinguishing between the different materialities, or non-materialities respectively, he anticipates “a history of 'moving images,' of which the age of film, strictly speaking, is likely to be only a phase" (xiii). "Moving images" is the general category of artistic expression which Carroll advocates and which comprises, at best, certain styles, norms or practices. There are, however, still multiple aspects that speak against abandoning what Carroll, with a slightly pejorative undertone, calls the "medium-specificity myth" or "thesis" (34). Rodowick, for example, does not agree that the terminological and conceptual incongruences caused by the digital age warrant a relief from the question of mediality, which, on the contrary, may turn out to be more urgent than ever. He points out that "artists care very much about the material they

\footnotetext{
${ }^{29}$ Given that the medial landscape has always been in constant flux, this question may appear hackneyed or even redundant. And still, the digital landscape and especially the Internet can pose a particularly difficult challenge for media scholars. Compare, for example, the study of an epistolary print novel with the analysis of an online blog that might be revised, updated, or even deleted at any time.
} 
work with, and spectators, too, make strong intuitive aesthetic judgements about the differences between film, video, and digital presentations" (40).

Manovich, in turn, makes a valid point about the paradoxical concurrence of "the obvious inadequacy of the concept of medium to describe contemporary cultural and artistic reality" and the persistent (new) media talk:

In fact, regardless of how often we repeat in public that the modernist notion of medium specificity ('every medium should develop its own unique language') is obsolete, we do expect computer narratives to showcase new aesthetic possibilities that did not exist before digital computers. In short, we want them to be new media specific. (The Language 237)

The concept of the medium persists, for one thing, "through sheer inertia" and, for another thing, through a sheer lack of new adequate distinguishing criteria ("Postmedia Aesthetics" 36). What lies behind this strong interest in new-media specificity is thus the (actual) necessity of a new typology or new conceptual system. Instead of simply dismissing medium specificity talk, Manovich at least makes an effort to develop a "program for postmedia aesthetics," which implies suggestions for the conceptual direction to be pursued (37).

Manovich's experimental derivation of new concepts and metaphors from the computer and net culture is certainly an interesting and worthwhile intellectual exercise. I, for my part, focus on the massive (self-)transformation of formerly leading media and thereby speak of postcinema and post-photography, precisely because these terms do not lay claim to any kind of closure. It can be productive to approach the rapid media change with a deliberately narrow definition of mediality, for example, a materialist framework. It is, however, one of this project's aims to dive right into the dizzying complexity of medial phenomena and those of the digital age in particular; even if that implies the risk of complicating matters even further. In other words, I deliberately apply a more flexible notion of mediality, that is not so much about superimposing a set of certain criteria as approaching medial phenomena bottom up. This is how I shall intuitively do justice to the post-cinematic sentiment, which neither relies on a new fixed typology nor entirely abandons the habits and hierarchies prevalent in the 20th century. Therefore, my take on the question of medium specificity combines Marie-Laure Ryan's three dimensions of mediality and Jay David Bolter and Richard Grusin's concept of remediation.

Acknowledging a medium's polyvalence (be it inherent or discursively constructed), Ryan distinguishes between a semiotic substance, and technological as well as cultural dimension. The semiotic substance of media can either be image, sound, language, or 
movement. The groupings yielded by this taxonomy broadly correspond to art types, namely literature, painting, and music. To bring further refinement to media theory, we must ask about the materials and the technologies that support the various semiotic types or, depending on the case and angle, play a media-defining role. In other words, TV, Internet, photography, film, radio, computer games and others are not only manifestations of the visual, verbal, and aural but media in their own right. And still other media, such as the press, the theater, comics or the opera are primarily culturally defined. According to Ryan, they "cannot be distinguished on purely semiotic or technological grounds" (30). In general, Ryan's medial trajectory is rarely a question of either/or. "The degree of prominence of these three dimensions differs from medium to medium, but all of them must be taken into consideration in the description of a medium's narrative affordances and limitations" (Ryan and Thon 5). What Ryan presents here can hardly be referred to as a solid definition. The mere awareness of these three layers and their possibly shifting prominence, however, might be helpful in identifying media in motion and thus illuminating the dynamics of remediation. In sum, I do speak in favor of medium specificity. I do so precisely because of the hybridity characterizing the contemporary media landscape. Rodowick puts it as follows:

But what makes a hybrid cannot be understood if the individual properties being combined cannot be distinguished. If we cannot be precise about the range and nature of these options, we cannot understand, as either artists or philosophers, what media might do, how they may evolve with respect to one another, or how we might work with a medium or even invent a new one, even if that recognition occurs only after the fact. (41)

This paradoxical simultaneity of medial autonomy and hybridity is mirrored in the pattern of thinking proposed by Bolter and Grusin: they define the medium as "that which remediates" (65). Consequently, to define a medium (nowadays) means to speak of the medial changes that it undergoes or triggers. Just as Carroll has replaced theory with theorizing to "lay emphasis on theorizing as an activity - an ongoing process rather than a product" (xiii), I shall prioritize the question of remediation over that of the medium. Throughout my study, I shall thus repeatedly draw on the concept of Bolter and Grusin's often-quoted study, Remediation: Understanding New Media (1999).

In the course of remediation, new media refashion and reform older media with the purpose of providing a more immediate and authentic experience. Bolter and Grusin's claim that there is no mediality without remediation rests on the assumption that "a medium in our 
culture can never operate in isolation, because it must enter into relationships of respect and rivalry with other media" (65). Hereby the double logic of immediacy and hypermediacy applies. Basically, the aim behind immediacy is to erase all traces of mediation and create an illusion of transparency. In other words, "the medium itself should disappear and leave us in the presence of the thing represented" (5-6). The contemporary media landscape is filled with sophisticated transparency efforts: The most popular buzzword that embodies the logic of immediacy is, of course, virtual reality. Then, there is the vision of an "interfaceless interface" that dispenses with the already immediate activities of "touching, dragging, and manipulating visually attractive ideograms" (23).

Whereas immediacy suggests a unified visual space, the logic of hypermediacy offers a heterogenous space and promotes the conscious recognition of mediation. The "windowed style" of interfaces and the interactivity it yields, for instance, results in the user's heightened awareness of the mediation itself (31). According to Bolter and Grusin, hypermediacy also takes place at the intersection of multimedia and physical space, for example, in theme parks and video arcades that grant "random access" to a highly fragmented entertaining area (31). In one line of argument, immediacy and hypermediacy, or in other words, transparency and opacity should be considered interrelated. "Our culture wants both to multiply its media and to erase all traces of mediation: ideally, it wants to erase its media in the very act of multiplying them" (5). There is, for example, the webcam, which operates under the logic of transparency, but is more often than not embedded in a hypermediated website. More subtle manifestations of this double logic are the already mentioned (in)visible special effects. The feather that floats through the opening titles of FORREST GUMP (1994) and fatefully lands on the protagonist's feet may serve as an example here. The accuracy of the feather's landing on Forrest's shoe is smoothly fit into the overarching immediacy of a Hollywood narrative. At the same time, of course, an evergrowing cineliteracy makes spectators aware of the digital refinement behind these effects. ${ }^{30}$ The mere promise of reform inevitably leads to the awareness of the new medium as a medium, or the effect as an effect - not least because this topic is frequently covered by the press that is eager to reveal new levels of CGI achieved. Both dynamics can quickly be reserved into their supposed opposite.

\footnotetext{
${ }^{30}$ Indeed, the behind-the-scenes documentary THROUGH THE EYES OF FORREST GUMP: THE MAKING OF AN EXTRAORDINARY FILM (1994) explains how this sequence was digitally choreographed. A real feather was recorded against a blue screen from different angles; this material was then animated and composited against shots of the respective landscape.
} 
But however well these examples illustrate the usual simultaneity of hypermediacy and immediacy, they do also disclose a certain hierarchy. The primacy of transparency is characteristic explicitly for the early stage of remediation during the new medium's initial striving to live up to and preferably outdo the old medium. Paradoxically, it is the digital media that, on the one hand, serve Bolter and Grusin as their primary example and, on the other hand, render it problematic due to the lack of historical distance. Things become additionally complicated with the unprecedented simulacral and all-encompassing capacity of digital media. In a sense, the contemporary digital media landscape seems to be stuck in the early stage of remediation. Explicitly in the case of digitization, it is thus useful to shift from a rather synchronic to a diachronic perspective, in order to arrive at a proper and productive understanding of hypermediacy and how it gradually subverts its subordinate role. Bolter and Grusin themselves point out the following chronology: "The rhetoric of remediation favors immediacy and transparency, even though as the medium matures it offers new opportunities for hypermediacy" (60). So, however alternating both dynamics in individual works of art operate, on the large scale, immediacy leads to hypermediacy. At an early stage of this process, digital cinema signifies a code of zeros and ones that transmits motion pictures without transcending the boundaries of photorealism. But in the wake of an ongoing cross-fertilization, digital cinema may gradually evolve from a mere instrument of photorealistic perfection to a (new) medium in its own right, and showcase rather than conceal its idiosyncrasies. ${ }^{31}$ Bolter and Grusin write that this "excess of media becomes an authentic experience, not in the sense that it corresponds to an external reality, but rather precisely because it does not feel compelled to refer to anything beyond itself" (53-54).

I believe that the concept of remediation is a lot subtler than it is oftentimes interpreted. There is, for example, the reproach of meliorism allegedly inherent in the term. The claim that every new medium constitutes an improvement over an old one cannot be sustained from a narratological and aesthetic point of view. The claim of improvement, however, is not meant literally in my understanding of the concept, maybe in a technological and pragmatic sense but not in a narratological or aesthetic one. Technological progress is naturally based on the idea of improvement or refinement. It does not necessarily mean that new media are universally "better" than older media. After all, remediation operates in both directions and thus also bottom-up: "older media refashion themselves to answer the challenges of new media" (Bolter and Grusin 15). When I speak throughout this study of how the book or the film reasserts its

\footnotetext{
${ }^{31}$ See pages 59-67 in the chapter on House of Leaves for a more detailed analysis of the question of "the (new) medium in its own right".
} 
mediality against the odds of an overwhelming hybridity, I might seem to lay emphasis on quite a static notion of mediality. Reassertion, however, means self-transformation and movement rather than standstill or stubborn perpetuation of a medium's most traditional manifestation. It is a case of bottom-up remediation.

This subchapter is also devoted to (working) definitions of cinema, film, and video, given that the contemporary use of these terms becomes increasingly blurry and overlapping. The multitude of contexts to speak of cinema (be it as an industry, art form, or social space) further multiplies in the digital age, as well as the ensuing definitional confusion. I will differentiate between a broad and narrow understanding of cinema and discuss the colloquial prevalence of film despite the phenomenological prevalence of video in the contemporary endto-end digital cinema.

In a chapter about medium specificity, it makes sense to provide a definition of the media in question. And still, it makes little sense to precede the analytical body of my work with definitions when these analyses are all about arriving at a decent understanding of these media in the first place. Then again, I need at least working definitions as points of departure. Therefore, I shall provide some introductory thoughts with regard to the media in question and develop working definitions that take into consideration the transitional moments that are about to be addressed throughout the work.

First, I shall take a look at the conceptual pair film/cinema in light of technological change. In line with Marie-Laure Ryan's grasp on media, I proceed from a rather broad understanding of cinema. One can say that the term evokes a number of different associations: industry, art form, technology, place - then there is national cinema, transnational cinema, independent and mainstream cinema, popular cinema, experimental cinema, and the multiplex as well the arthouse cinema. All these different facets contribute to the multifaceted identity of the medium. In common parlance, the roughly twofold understanding of cinema is reflected in the alternate use of cinema with and without a definite article, as either a mass noun or a countable noun. The $O E D$ makes this distinction as well. The cinema relates to "a building in which cinematographic films are exhibited"; it is the darkened place and situation of collective spectatorship. (The) Cinema, in turn, refers to "films collectively, esp. considered as an artform," and as an industry, as I would add. ${ }^{32}$ It also encompasses "the production of such films." Given the broad understanding encouraged particularly by the latter conceptualization, there is a number of schools of thought working on the specification of cinema's most basic gesture.

${ }^{32}$ Oxford Dictionary of English, 2nd ed., s.v. "cinema." 
When Manovich states that "cinema is the art of the index ... an attempt to make art out of a footprint," he refers to the realist approach most prominently represented by André Bazin (The Language 796). When Bazin posed the question "what is Cinema?" in his eponymous and influential publication, the answer was quite unambiguous: an attempt at "a total and complete representation of reality" (20).

I proceed from two manifestations of cinema that are crucial for my study: the cinema as a space of collective spectatorship and cinema as the art of the index. In both senses, (the) cinema has until now been strongly tied to film, or more precisely, the film roll. The hum of the film projector has been a crucial part of the traditional cinematic experience. And the filmstrips were the sources of cinema's photochemical "reality." But once it has disappeared in a phenomenological sense, film has also become the main reason for cinema's identity crisis. Instead of film rolls, so-called DCPs (Digital Cinema Packages) are projected on the screens of multiplex theaters. What most of us still refer to as film is in a strictly phenomenological sense, in most contemporary cases, a digital video. The arrival of the digital code in theaters has considerably complicated what Christian Metz has prominently referred to as the "super-genre" of twentieth-century cinema: the fictional live-action film and its reliance on lens-based recordings of reality, which determines the so-called art of the index ("The Fiction Film" (1980)). The loss of film has also changed the materiality of the cinema, whose former noise and grain was a defining characteristic of the cinematic experience. Apart from the lack of the movie projector noise, the notion of the cinema has been complicated in more profound terms. The digital convergence of screens has led to new forms of film reception which transform the traditional cinema-going culture.

When David Rodowick claims that "film may disappear, [but] cinema nonetheless persists," one may wonder how this persisting cinema looks like (30). I would like to complement Rodowick's claim by arguing that a considerable "amount" of cinema (as we know it) persists in the process of its profound digital reconfiguration. The continuity of the cinematic in the digital landscape manifests itself in such terms such as digital cinema or what Grusin more precisely relates to as digital cinema of interactions. These labels can be considered terminological snapshots of the ongoing digital remediation of cinema. Also, the lack of historical distance complicates any attempt to delineate conceptual boundaries around gradually surfacing digital phenomena. In this sense, it appears more useful to speak of and discuss today's liminal state of post-cinema, as I shall do in the course of this study. 
To articulate a point of departure for the pending discussion of post-photography is no less complex an undertaking given the sheer variety of different understandings and practices of photography that has been circulating since its advent. Martin Lister even argues that "it is more helpful to think of 'photographies' which have different 'histories' than it is to think of a singular medium with a singular, grand and sweeping history" (11). The photograph's ontological relation to reality has never been unproblematic. Both evidential and non-evidential manifestations of photography have been around since the first days of the medium. Now that digital technology considerably facilitates and, what is more, conceals non-evidential forms and uses, the value of photographic indexicality is reconsidered in current debates. Now that indexicality threatens to be at stake, in other words, the monolithic view of photography as a document is resurrected. It is resurrected due to the

transition from the photo-mechanical image, a material analogue, with its compelling sense of a referent in a prior reality, to the immaterial digital constructions and hybrids whose sources may be mathematical and 'virtual' as much as empirical. (Lister 4)

Digital manipulation and image generation techniques have taken the gnawing question of photographic credibility to a new level. W.J. Mitchell announced that

an interlude of innocence has passed. Today, as we enter the post-photographic era, we must face once again the ineradicable fragility of our ontological distinctions between the imaginary and the real, and the tragic elusiveness of the Cartesian dream. We have indeed learned to fix shadows, but not to secure their meanings or to stabilize their truth values; they still flicker on the walls of Plato's cave. (The Reconfigured 225)

W.J. Mitchell most prominently blamed the digital age for the far-reaching loss of indexicality in photography. ${ }^{33}$ The paradox of this alleged loss is that digital technology contributes to the growth of surveillance systems and other forms of documentation practices. Digital snapshots are easily done and uploaded onto the Internet, fusing both our everyday communication culture and the mass media to an unprecedented degree. This changing photographic culture gives rise to new layers of authenticity, or practices of authentication: See, for example, the significant role of participatory culture, user-generated material, Instagram filters and hashtags in today's

\footnotetext{
${ }^{33}$ W.J. Mitchell's radical interpretation of the post-photographic condition raised a lot of controversy and dialogue. One of his most ardent opponent is his namesake W.J.T. Mitchell, whose theories will be examined in the House of Leaves chapter.
} 
cultural framing of photographs. In their anthology about The New Face of Photography, Jonas Larsen and Mette Sandbye point out the importance of understanding photography "simultaneously as a social practice, a networked technology, a material object and an image" (xxiii). The concept of post-photography is thus little productive when associated with the death of photography, or even of its indexical character. My literary case studies of post-photography question this dualism of truth/analog versus construction/digital. They pose the complex and intriguing question of rupture versus continuity.

House of Leaves, Night Film and Sorrows illuminate our understanding of cinema, film, and photography. And still, they are most revealing regarding the mediality of the novel itself. Knut Ove Eliassen argues that "House of Leaves raises the issue of what kind of medium a novel in the codex format is, given the present media ecology. House of Leaves is a book about what books are today" (99). Eliassen's observation of House of Leaves is not only perfectly apt but applies to Night Film as well and even better to the sum of the three novels in question here. Rather than representing a blind spot in this theoretical part of the dissertation, the issue of the contemporary US-American novel and its mediality shall gain center stage throughout the study and in the concluding as well as comparative discussion of these three novels. 


\section{House of Leaves (2000) and the Uncanny Dawn of the Digital}

\subsection{Digital Paranoia: Arriving on Ash Tree Lane}

Once Mark Z. Danielewski's House of Leaves had been published, it started to generate considerable buzz. The "stunning, mind-and-genre expanding work" was widely discussed by critics and scholars, readers and numerous fans, for whom the MZD Forum ${ }^{34}$ quickly became a valuable communication tool (McCaffery 99). A crucial thought to be entertained about the immediate and widespread interest in the novel is that it did not require to be read in order to be talked about. After all, for its most striking features one merely needs to flip it open. Unconventional textual layout, typographic experimentation, use of color and different languages - to a certain degree these aspects certainly speak for themselves. House of Leaves is clearly not a text that has been simply written, but one that has been tediously assembled. Different fonts associated with different narrators permeate the almost 700-page read. A labyrinth of overlapping footnotes deforms the conventional book page, materializing as centered text block or window, crossed out fragment, incomplete sentence, and empty bracket. There are paragraphs written entirely in German and French throughout the book, as well as untranslated excerpts from The Divine Comedy, plus various others. In some instances, one sentence spans multiple pages and turns the novel into a flip book. In other cases, the space of three pages is entirely devoted to the representation of a single word. Sometimes the text is printed upside down, sideways, filling only the top or bottom, the upper left-hand corner or, at times, the bottom right hand corner of the page. Reading House of Leaves, which includes to constantly reposition the book, flip it back and forth, and readopt one's focus, promises to be a dizzying experience. Rather than merely representing another exciting novel, House of Leaves was clearly perceived as a contemporary comment on the mediality of the book. As such, Danielewski's debut can be considered to continue the tradition of such literary milestones as Vladimir Nabokov's Pale Fire (1962), Thomas Pynchon's V (1963) or David Foster Wallace's Infinite Jest (1996). With its metamedial consciousness rooted in postmodern classics, House of Leaves certainly looks back on a literary past.

At its core, however, it develops the idea of a film titled THE NAVIDSON RECORD and in this respect seems informed by a specific notion of future. More precisely, it creates not only an intermedial gap but at the same time a threshold that foreshadows and cunningly anticipates, as I will show, a digital takeover of the media landscape. In this context, a noteworthy aspect

\footnotetext{
${ }^{34}$ The Mark Z. Danielewski Forum (MZD Forum) can be referred to as an online reading community dedicated to his entire oeuvre.
} 
becomes the novel's publication in 2000 - a time when the film industry faced the dawn of endto-end digitization not only in terms of production, distribution, and exhibition. ${ }^{35}$ What further appeared around the turn of the millennium was according to D.N. Rodowick a cinematic communication of "digital paranoia" (3). Films such as THE MATRIX, THE THIRTEENTH FLOOR and EXISTENZ, all released in 1999, were dominated by a narrative tension between the analog and the digital; in concrete terms, they imagined the analog world to be entirely subverted by digital simulation. The digital video camera became a new protagonist of a new wave of horror genre that originated in the release of THE BLAIR WITCH PROJECT towards the end of 1999. The low-budget sensation did not only juxtapose analog and digital recording techniques to literally leave behind a $16 \mathrm{~mm}$ camera but exhausted the potential of Internet marketing to an unprecedented maximum. ${ }^{36}$ A sense of digital horror or rather the horror of the digital seemed to significantly permeate US American fiction. A crucial point to mention from the outset is that, considering its mere plot, THE NAVIDSON RECORD has little to do with digitization per se. The fact that THE NAVIDSON RECORD is embedded in the book turns the alleged film into an instance of digital paranoia. House of Leaves thus marks the anxious beginning of a new millennium, whose circumstances and consequences metaphorically collide with those of the Navidson family's anxious arrival on Ash Tree Lane. At least, this is how one of the novel's storylines begins.

House of Leaves skips back and forth between two main narrative layers that are each assigned a specific font and thus can easily be distinguished. The first narrator to encounter in Courier New is Johnny Truant, a rather unstable and emotionally burdened tattoo shop assistant in his mid-twenties, who leads his life primarily in the party and drug scene of Los Angeles. Johnny tells the reader about the fateful day when he came into possession of a mysterious manuscript titled "The Navidson Record," written by a certain, recently deceased Zampanò. ${ }^{37}$ Johnny finds notes scattered in the dead man's apartment and decides to compile them into a coherent narrative while soon finding himself engaged in a heated reading, increasingly unable

\footnotetext{
${ }^{35}$ The novel's publication in 2000 coincided with a historical moment whose numerous technological changes reshaped cinema. The film industry took its first decisive steps to what we now take for granted as the cycle of digital production, distribution, and exhibition. Another significant development was the digital intermediate process: such films as PLEASANTVILLE (1998) and O BROTHER, WHERE ART THOUGH (2000) were among the first to be scanned into a digital file to faciliate treatment in postproduction. In June 2000, Twentieth Century Fox as a first studio combined digital distribution over the Internet and digital projection, thus producing a first instance of end-to-end digital cinema. Soon, security and copyright issues were solved and the days of the "clumpy" celluloid film stock numbered (see Rodowick 7 and Prince 73).

36 The analogy between The Blair Witch PROJECT and THE NAVIDSON RECORD, which is striking due to the found footage aesthetic, shall be elaborated in greater detail in section 3.5.

${ }^{37}$ Please note that I use double quotation marks to refer to the diegetic manuscript ("The Navidson Record") and small capital letters to refer to the diegetic movie (THE NAVIDSON RECORD), which the manuscript is allegedly based on.
} 
to distinguish fact from fiction. After all, Zampanò's legacy turns out to be a detailed study of a film that features a very, to say the least, curious incident back in the 1990s. One of the most disturbing introductory facts about this subject is its putative documentary basis. In fact, THE NAVIDSON RECORD, as Zampanò describes it, starts as a home video and in the course of time and events "escalates" into a documentary film. At first, everything points to a rather conventional haunted-house horror story. ${ }^{38}$ When Pulitzer-Price-winning photojournalist Will Navidson, his wife, Karen, and their two kids, Chad and Daisy, move into their new home on Ash Tree Lane everything appears perfectly normal. Will even installs video surveillance all over the house to capture how the family settles in and reconciles after a period of his careerrelated absence and estrangement. This initial triviality turns out to be deceptive when the Navidsons come back from a weekend away to find a new closet appeared in their bedroom. Shaken by how they both could have overlooked an entire closet, Will and Karen, and soon friends and family start to measure the house only to repeatedly arrive at one and the same downright impossible conclusion: the house's interior exceeds its exterior by a quarter of an inch. Just as they start to reconcile with that uncanny yet apparently harmless spatial violation, another incidence unsettles the family ultimately. Will discovers a "dark doorless hallway which has appeared out of nowhere in the west wall" of the living room and this time he cannot think of leaving the riddle unsolved and the unknown unexplored (57). This is how the journey starts. Upon entering the hallway on his own for the first few times, he learns that it constantly grows and changes. As additional pathways and doors materialize randomly, Will is quickly threatened to get lost in a seemingly unlimited maze in the very midst of his earthly house in West Virginia. Soon, Will's brother, Tom, his friend Billy Reston, and even the experienced Holloway Roberts team of fully equipped hunters and explorers arrive to face the mystery together. Still, it is neither with ultra-bright glow sticks, nor with human logic, nor with Will's cameras and camcorders, and not even with a simple compass that they manage to make sense of the hallway's pitch-dark irregularity. On the contrary, it is the hallway that subdues its intruders and confuses their sense of time and space to the point of driving Holloway into murderous insanity and literally devouring Navidson's brother in a catastrophic climax.

Zampanò's ekphrastic description intrigues Johnny to the point that it starts to determine and mingle with his dreams and everyday life. Johnny's comments and thoughts are added to the ekphrasis by recurrent footnotes. His voice, however, is just one of many. The opinion

\footnotetext{
${ }^{38}$ In her reading of the novel, N. Katherine Hayles is quick to qualify this conspicuous comparison: "Camouflaged as a haunted-house tale, House of Leaves is a metaphysical inquiry worlds away from the likes of The Amityville Horror" ("Saving the Subject" 779).
} 
leaders that Zampanò includes and cites in his footnote maze range from director Stanley Kubrick to French philosopher Jacques Derrida to a number of fictional public figures. The tape is being discussed from a psychological, mythological, historical, religious, philosophical, architectural, and finally technological point of view. There is reason to believe, however, that Zampanò's major scholarly interest concerns the ontological consequences of the digital age. He contemplates the threats of digital manipulation and thus comes up with a possible explanation for the impossible hallway. Despite (or due to) the fact that the issue of digital effects stands in striking contrast to the record's documentary context, it shall constitute the golden thread of the following reading.

In the course of the analysis, I shall come back to some of the mentioned films accounting for the notion of digital paranoia in the recent cinematic landscape. These examples accentuate the intermedial approach at hand while primarily serving the purpose of illustration. It seems most fruitful to read House of Leaves as a special case of both a literary contribution to and meta comment on the sense of digital uncanniness prevalent at the turn of the century. It unites the themes of film, horror, and digitization in a highly specific, printed form. Thereby, the novel represents both a basic, since explicit, form of intermedial references and one of the most striking examples of contemporary experimental literature. In fact, its oscillation between an explicit scholarly discussion, on the one hand, and a creative (partial) actualization of the digital threat in question, on the other, leads me to the central thesis of this chapter: House of Leaves uses intermedial references to a traditionally indexical medium to communicate the "horror" of how indexicality is unnoticeably replaced by an infinitely malleable digital code. It also uses the flexibility of words and phrases, highlighted against the backdrop of the book's materiality and finiteness, to entertain the uncanny notion of digital contamination. ${ }^{39}$

To draw the full picture of this assertion, I will proceed as follows: First, the challenge of "Writing about House of Leaves" comes into focus in section 3.2. It thematizes how the novel in its complexity both invites and defies critical approaches. Moreover, it provides a brief overview of the existing House of Leaves scholarship and classifies my analysis against its backdrop. In the same vein, I shall point out the productivity of an intermedial approach that has not been exhausted in the Danielewski criticism so far. Departing from the novel's core, Navidson's film, it allows to reconcile certain aspects that have been considered separately so far and thus to offer a new perspective. The following step is accordingly a methodological one.

\footnotetext{
39 While used metaphorically here, contamination actually derives from Irina Rajewsky's terminological differentiation of intermedial phenomena. Interestingly, its rather negative connotation appears warranted against the backdrop of the novel's digital reading. This correlation shall be addressed in greater detail in section 3.5.
} 
Section 3.3 ponders the best strategy to "tame" a novel that seems overabundant with intermedial references. Drawing on Irina Rajewsky's analytical toolkit, I will shed light on the most relevant concepts, such as 'explicit mentioning' and 'system contamination,' and articulate an itinerary for the subsequent analysis. The latter shall thus begin with Zampanò's "explicit" discussion of the digital transformation of the photographic and filmic system. His thoughts on "rumpled" versus "slick" images and his illustrative anecdote of a film titled LA BELLE NICOISE ET LE BEAU CHIEN raise the question of indexicality (144). Zampanò thus draws on an existing discourse which is essentially divided between two camps of scholars and shall be scrutinized in the same vein.

With this context provided and elaborated, I shall finally arrive at the question of what kind of film THE NAVIDSON RECORD actually is. This question guides my fifth section with reference to the novel's evocation of the found footage genre. The dilemma between the documentary style of the alleged found footage film and the in-novel speculation on its digital manipulation shall be resolved in a consideration of "The Navidson Record" as a found manuscript and thus a curious case of what I shall term "self-reflexive intermediality." What follows thereupon is a reading of the novel's unconventional page design and typographic experimentation in analogy to the digital code accounting for such special effects as an utterly impossible hallway. This is how the book addresses the digital identity of THE NAVIDSON RECORD and, in addition, produces special effects on its own behalf. These intermedial references raise awareness of how the digital code powerfully permeates the contemporary media landscape, leaving behind an uncanny sense of non-indexicality.

\subsection{Writing about House of Leaves}

If there is a word to capture Mark Z. Danielewski's House of Leaves in a nutshell, the word is probably escalation. At the core of the novel, there is a hallway that escalates into an enormous underground maze literally beyond measure; a peaceful home video that, in the course of time and events, escalates into a full-length documentary film; and a collection of random notes that escalates into an in-depth film analysis. As first-order narrator, Johnny Truant, decides to compile Zampanò's scattered scribbles into a coherent narrative, the latter turns out to be a scholarly versed (second-order) narrator. Zampanò's theoretical approach to THE NAVIDSON RECORD, however, is but one of many: 
Books devoted entirely to The Navidson Record now appear with some regularity. Numerous professors have made The Navidson Record required viewing for their seminars, while many universities already claim that dozens of students from a variety of departments have completed doctoral dissertations on the film. (6)

As Zampanò's frequent quotations of these theories suggest, an entire, to a great extent academic discourse has developed around the mystery of the labyrinth and THE NAVIDSON RECORD itself. The tape is being discussed from various viewpoints in an overlapping arrangement of footnotes. To write about House of Leaves may thus feel like quite an ambivalent undertaking or even "postmodern trap." Once having exposed oneself to the novel's sheer complexity, one may wonder whether the diegetic discussion of THE NAVIDSON RECORD anticipates the critical discourse on House of Leaves. Am I possibly supposed to share the fate of one of the numerous NAVIDSON RECORD scholars and make every effort to explain something that, ultimately, remains unexplainable? Does not the novel downright deny interpretation by illustrating the futility and the limits of academic discussion? From an optimistic viewpoint, the value of interpretation for its own sake is promoted here. A rather discouraging viewpoint would be that the entire concept of literary analysis is rendered meaningless since every imaginable interpretation is already anticipated in the novel. Ultimately, most House of Leaves scholars will find themselves exposed to the novel's two, almost satirical risks: the failure to live up to the novel's self-reflection and the relatively strong probability of finding their core theses already articulated in one of the numerous footnotes.

Any attempt to avoid these "traps," in turn, presupposes a decent, in-depth knowledge of the book. Tellingly, this aura of high expectations of the reader is perpetuated by the novel's environment. The MZD Forum, which every reader or scholar interested in Danielewski's oeuvre eventually comes across, constitutes a good example. In their welcoming notes, the editors of the website encourage users to find new entrances to the novel, new answers to the numerous riddles it poses: "We ask that you do as we once did, and read threads for a while without posting, so you know the general gist of what has been said (and, more importantly, what has not been said)." And also Danielewski himself has become a critical figure when it comes to the code of conduct, the question of the appropriate handling of his 700-page read. In the often-quoted "Haunted House" interview, Danielewski wonders at the discouragement of critics allegedly implied by the novel. After all, he explains the inclusion of this number of footnotes with his enthusiasm for the idea of applying a variety of lenses to a certain subject 
matter. His intention is to encourage critical engagement with the book rather than to possibly mock the academic field (see McCaffery 107). As the following citation underlines, he even challenges the reader to develop an unprecedented approach:

I don't mind admitting that I was extremely self-conscious about everything that went into House of Leaves. In fact - and I know this will sound like a very bold remark, but I will say it anyway since it remains the truth - I have yet to hear an interpretation of House of Leaves that I had not anticipated. I have yet to be surprised, but I'm hoping. (106)

On the one hand, this way of addressing the reader is certainly calculated by the author and publisher, and to a certain degree serves as a marketing ploy. Buying the book means to enter a competition with fellow readers around the world: Will you be the one who finds a new or the right entrance to the house? On the other hand, the question is how academia around House of Leaves has manifested itself so far. Have scholars managed to defy or rather endure the dilemma brought about by House of Leaves' escalations? Has, in sum, the House of Leaves criticism come to terms with its inherent ambivalence? Or is there a certain inhibition palpable?

The first thing to mention in this context is the strikingly low interest in what House of Leaves most basically represents, namely a novel that is intermedially referring to film as an individual work of art and film as a system. As one of the very few scholars who prioritize the significance of the novel's intermediality, Paul McCormick claims that "House of Leaves uses cinema as its primary interface to interact with its particular media environment through its represented world and with its narrative technique" (52). Considering the novel's nuanced treatment of film, one could assume that the House of Leaves scholarship either misses the forest for the trees or consciously refuses to resort to this most obvious since inherently suggested lens. Whereas the literary evocation of film is to a certain degree implied in various examinations, it has hardly been dealt with as a primary concern. Indeed, there might be yet another explanation why House of Leaves counts as an "intimidating book to encounter on a critical level," especially in terms of its intermediality (McCaffery 107). Naturally, the footnotes referring to the notorious NAVIDSON RECORD as an individual work of art are made up while nonetheless assigned to actual public figures such as Stanley Kubrick or Jacques Derrida. In the case of references to the contemporary media landscape in general, however, writers and scholars, such as Susan Sontag and Roland Barthes happen to be accurately cited. Zampanò's confusion of non-existent with existent sources does not merely aim at a reality effect. His play with fiction and this considerable amount of fact raises awareness of the 
author's theoretical competence in numerous fields. In the case of Danielewski, most solid expertise can be expected from the field of film. He considers himself to have a special aptitude for writing about film and concludes this talent from being the child of a passionate filmmaker. In an engaging sequence of the "Haunted House" interview, Danielewski describes how his father insisted on discussing films over dinner and concludes:

My point is that although there is no doubt that I was immersed in the cinema from an early age, I was also immersed in the language necessary to discuss film. On numerous occasions my sister and I would later see a movie that had been spun into our imaginations out of the enthusiasm of my father's words and thoughts, only to discover that we did not like the actual film nearly as much as the conversation we had had about it. (McCaffery 108-109)

The ekphrasis of THE NAVIDSON RECORD is not only nurtured with theories from various exotic fields. It is, first and foremost, embedded in a solid cineliteracy when it comes to film history, film aesthetics, and film theory. Even the current state of the medium in the wake of digitization is explicitly problematized by Zampanò. But however sophisticated and insightful his observations might turn out to be, they can easily be regarded or rather dismissed as a demonstration of Danielewski's alleged expertise that works for its own end. Could this be the reason why the existing scholarship virtually "downplay[s] the prominence Danielewski grants cinema in his novel and in his many published interviews," anxious neither to detail nor to carry on the theoretical dialogues performed in the novel (McCormick 52)? Has everything about film already been said by versed Zampanò? Has the intermedial lens thus already been exhausted within the novel? Or is it - rather than intimidating - possibly conceived as nothing but pseudo-scientific jabber unworthy of any further discussion?

Either way, other interfaces and lenses than film have gained in prominence when it comes to approaching the novel. In the criticism House of Leaves has provoked so far, the following two scholarly lenses can be distinguished as prevalent. The first is more of a mirror than a lens in that it explores the novel's self-awareness in terms of its material reality and accordingly the reading experience it triggers. In her work "Crossing Thresholds and the Exploring Reader of House of Leaves by Mark Z. Danielewski," Alison Gibbons goes into detail about the typographical trickery of House of Leaves and uses it as a starting point for her study of multimodal fiction. ${ }^{40}$ This study deals with

\footnotetext{
${ }^{40}$ See in this context also Wolfgang Hallet's concise introduction to „The Multimodal Novel“ (2009).
} 
unusual textual layouts and page design, varied typography, use of colour ... concrete realization of text to create images, as in concrete poetry ... footnotes and self-interrogative critical voices, flipbook sections and so on. (2)

Her examination of these visual elements closely intertwines with a consideration of the reader's cognitive experience of the novel. The necessity of his or her physical interaction with the book, of rotating it to facilitate reading, is a product of the novel's multimodal arrangement, which puts its physical idiosyncrasy at the center of attention. Rather than just another book of fiction, as Alexander Starre so aptly puts it, "House of Leaves is a minutely calculated 'book fiction' that interweaves text, design, and paper into an embodied work of art" (6). In his study Metamedia, Starre introduces Danielewski's novel as a "master text of metamedial expression in digital print culture" and examines it according to five autoreferential dimensions (129): "external design; typography and visual elements; paratextual framing; diegetic reflexivity; medial mise en abyme and metalepsis" (134). He speaks of the resurgence of the book in the wake of digitization and points to the strategic unavailability of the novel as an e-book. In response to a tendency to overestimate the novel's extension to the digital world, as for example in the form of its cult following in online forums, Starre insists that "its truly unique quality lies in the finite bibliographic form" (129). This finitude is literally put into practice in the novel's diegesis when Will Navidson produces a copy of House of Leaves to kill time during one of his hallway expeditions. With the relentless darkness around him, Navidson is desperate for a source of light. Since his twenty-four matches quickly run out, he starts to turn the pages he finishes reading into torches. Symbolically, its finite paper-based form becomes a necessary condition of reading or shedding light on the novel. This iconic mise-en-abyme perfectly illustrates and considerably supports the theory of the book's essentially metamedial motivation. One can say that this metamedial approach strongly competes with the intermedial lens in terms of the novel's primary interface. Against the backdrop of this prominent bookishness, is it not all the more imperative to consider the novel's intermedial relationship to the audiovisual medium at its diegetic core? How can this pointed self-accentuation be reconciled with such a consequent evocation of another medium? What conclusions can be drawn as to a possible intermedial rivalry?

Another lens that in scholarly discourses gradually aspires to the status of the novel's primary interface is the "digital." Even though the digital is mentioned in the novel solely in the scope of its intermedial references to photography and film, it manifests itself in scholarly discussions as largely detached from the filmic context implied by Danielewski. Mark B.N. 
Hansen, as one of the leading Danielewski scholars, reads House of Leaves through the concept of a digital topography. In one of his most nuanced comments, Hansen paves the way for considering the book's aspiration to rip off the layer of familiarity from the digital and thus convey its disembodied abstraction:

[T] he house must also and more fundamentally be viewed as a figure for the otherness of the digital, both as it enters thematically into the world of the novel and also as it punctures the surface of its textuality; a flexible, topological form capable of infinite and seamless modification; a postvisual figure immune to the laws governing the phenomenology of photography, cinema, and video. (607608)

N. Katherine Hayles finds a more digestible explanation for the novel's engagement with the digital, namely the metaphor of the computer which

has often been proclaimed the ultimate medium because it can incorporate every other medium within itself. As if learning about omnivorous appetite from the computer, House of Leaves, in a frenzy of remediation, attempts to eat all the other media. (Writing Machines 112)

According to Jessica Pressman, in turn, Danielewski's labyrinthine textual arrangements are specifically reminiscent of the "extensive hypertextual navigation system" of the World Wide Web (108). Still, it is not only the footnote hyperbole that - while making the readers go back and forth and constantly disrupting their reading flow - inscribes the Internet's interface into the novel's print pages. Particularly when read against the backdrop of digitization, Danielewski's systematic play with color becomes a critical aspect, more specifically, the fact that every instance of the word house, from cover page to blurb, is blue. This stylistic device has become something of a trademark, being adopted by various reviews and other forms of communication about the novel. Jessica Pressman belongs to, if not heads the camp of critics, who associate this color code with an active hyperlink on the Internet. For those House of Leaves readers who have a high web affinity, the blue house can also serve as a constant reminder of the official House of Leaves website. After all, the book's "fraternal twin" in the online world provides a link to the already mentioned MZD Forum, which, in a sense, turns the novel into an interactive project (Pressman 108). Naturally, the novel's hypertextual inscriptions and its inherent blue-colored threshold to the World Wide Web play a crucial role in the discussion of House of Leaves as a so-called Internet novel. And yet, there is a tension between this latter term and the book's accentuated physical closure and its solely physical 
availability on the market. Worth mentioning is also that the Internet as such is rarely mentioned in the pages of the novel. Whereas it is justifiable, as the analysis will show, to point out the digital as one of the novel's main foci, lending that much substance to the Internet is rather questionable. According to McCormick,

it should be emphasised that it is the total media environment which is the novel's main interest - of which the internet is but one part. And in any case, the novel's primary interface for engaging that media environment is not the internet, but cinema. (55)

This latter observation does also count for the analysis to come. The book fiction and the digital are important parameters of the novel. Nevertheless, I claim that they can be more fully explored and more fruitfully interrelated when tied to the novel's filmic context, or in other words, encountered through the intermedial lens.

The following analysis will thus be comparatively holistic in that it comprises the thematic triad of the 'digital,' the 'book,' and the 'film,' while considering 'film' as the primary interface. Even though it may appear self-evident in the wake of intermedial analyses, in the case of House of Leaves (and later also Night Film), the question is not only how the novel aesthetically and thematically adapts to the medium in question, but how the character and historicity of this alter-medial system affect the book in metamedial terms. In other words, the degree of the novel's self-reflexivity shall be considered a specific correlation of its intermediality. Therefore, the novel promises to add a significant perspective not only to the discourse of the digital life of film, which it explicitly joins through the scholarly voice of Zampanò, but also the question of bookishness in the digital age. Hence, the way out of the dilemma of approaching House of Leaves might be to regard the novel as what it so pointedly claims to be - a voice that takes part in and adds "creative relief" to a complex discourse.

\subsection{Intermedial Overabundance: Taming House of Leaves}

In her study of intermediality, Rajewsky raises awareness of the significance of so-called "intermedial markers." ${ }^{41}$ Especially in the case of novel-based intermediality, which is restricted to its own media-specific means of representation, they serve to signal the novel's intermedial concern and a potential "as-if"-presence of the contacted medium (Intermedialität

${ }^{41}$ (“Intermedialitätssignal”, Rajewsky, Intermedialität 82) 
39-40). Vocabulary belonging to the compound concept of film, for example, directs the reader's attention to the likely presence of an implicit filmic mode that may not be recognizable as such at first sight. Details of technical recording equipment, certain actors, or historical figures related to film may have this effect as well. No less may popular movie quotes already suffice to make the more or less cineliterate reader assume the author's film-related intentions. By definition, these "explicit system mentions" manifest themselves in the plain thematization of the alter-medial system in question. ${ }^{42}$ They take the form of "talking about" or "reflecting on" the other medium. The system is being both simply and unambiguously named without necessarily laying claim to creating any kind of as-if illusion. (Intermedialität 78-83)

Even though a variety of different media occur in House of Leaves, THE NAVIDSON RECORD can unambiguously be assigned to the medial system of film, which, in turn, can be identified as the novel's major concern. After all, we learn that the film production company Miramax accounts for the theatrical release of "Navidson's film [that] seems destined to achieve at most cult status" (7). And despite "the unlikely prospect of any sort of post-release resolution or revelation," Bob Weinstein himself assures at a Cannes press junket with reference to deleted scenes: "But don't worry, you'll have it in the DVD release." 43 Next to the involvement of such film business personalities as Weinstein, Zampanò's frequent use of film scholars and film journals as sources for his critical review are no less significant. In House of Leaves, the intermedial markers fulfil their function par excellence. Indeed, it is important to acknowledge that a film production company accounts for THE NAVIDSON RECORD's release. Navidson's project could otherwise be understood as beginning and ending as a home video, a collection of seemingly endless surveillance video material that has not been edited or otherwise adapted to what is culturally and conventionally understood as a film. As said, these signals of intermediality are fundamental for the verifiability of a specific alter-medial system and a condition for their reception in the first place (Rajewsky, Intermedialität 83). Without such guidance of reception and the explicit discussion of the digital age, the book's experimental scope and unconventional narrative techniques could stand for themselves and be intertextually dated back to the modern era and the beginnings of concrete poetry, for example (146-147).

All in all, one does not have to search long to prove traces of film in the case of House of Leaves. In fact, the presence of film is undeniable if not overabundant. The challenge is thus to systematize the mass of explicit cineliterate comments. Just as Johnny has to struggle to

\footnotetext{
42 (“explizite Systemerwähnung”, Rajewsky, Intermedialität 79)

${ }^{43}$ The Weinstein brothers, Harvey and Bob, are US-American film producers and founders of Miramax.
} 
assemble Zampanò's muddle of notes into a coherent narrative, the House of Leaves critic struggles to filter out the relevant aspects for a coherent examination of the novel's intermedial references. To approach House of Leaves with the ambition to grasp its intermedial core can thus be imagined as an effort to "tame" it. This task shall be faced with a systematic employment of Rajewsky's conceptual distinctions. This chapter provides a theoretical anticipation of the intermedial reading of House of Leaves, which shall roughly be organized according to three distinctions, that are "system reference" versus "individual reference," "system mention" versus "system contamination," and eventually "contamination qua translation" versus "contamination by (partial) actualization."

This order of focus results from the seemingly simple yet urgent question of what the novel refers to or, to be more precise, what the novel's intermediality is essentially aimed at. In order to determine the "what" of the filmic that takes place in literature, Rajewsky suggests differentiating, as a first step, between textual "references to film as a single product," e.g. a specific movie, and "references to film as a system." 44 Rajewsky's work counts as a standard reference in the field of intermediality studies. Still, her preference for dichotomies can quickly become a matter of argument, as a short consideration of Christine Schwanecke's essay "Filmic Modes in Literature" reveals. As an attempt to systematize intermedial references to film, Schwanecke has developed the interrogative triad of "what," "how," and "where." She regards the question of what a filmic mode refers to as crucial and deserving explicit attention - and thus exceeding the dichotomy between individual and system reference. According to Schwanecke, the latter "arguably clouds the variety of filmic codes and conventions an author can possibly refer to and homogenizes them" (275). Highlighting, instead, the importance of understanding the medium as a compound concept composed of four categories, she determines the notorious "what,"

[f]irstly, by its technologies and materiality (Medientechnologien bzw. technisch-mediale Dispositive); secondly, by the semiotic system(s) it makes use of (semiotische Kommunikationsinstrumente); thirdly, by social factors and institutions; and fourthly, by specific media products (Medienangebote, Schmidt 2000, 93-95). (275; emphasis in the original)

It is worth emphasizing that even in Schwanecke's detailed conceptualization, the specific media product counts as a distinct category. Ultimately, her objective in questioning Rajewsky

\footnotetext{
44 (“Einzelreferenz vs. Systemreferenz”, Rajewsky, Intermedialität 65)
} 
is to point out how nuanced the system can turn out to be. And of course, her elaboration of its different implications is not insignificant. More precisely, it can be considered sharpening Rajewsky's intermedial lens by a subcategory of questions: Is it the technological aspect that is focused here and can thus the novel's intermediality be described as an attempt to unveil or even demystify an alter-medial mode of operation? Does the reader face a literary translation of the conventionalized language of film with its different cuts, shots, fade ins, fade outs, split screens, and voice-overs? Or is the cultural experience of going to the cinema at stake in the novel?

Schwanecke's reasoning constitutes a useful supplement to Rajewsky's distinction and needs to be kept in mind throughout the analysis. In the case of House of Leaves, however, this very distinction may serve as a heuristic abstraction, which does not necessarily deny the heterogeneity and complexity of film taking place in the novel. In fact, Rajewsky's theory might prove more productive than homogenizing for yet another reason. While Schwanecke's concept serves the mere identification of filmic modes, the individual/system distinction does, at a closer look, entail the question of functionality. As Rajewsky herself emphasizes, the distinction is more often than not blurry. Whereas system references can occur independently without necessarily relying on a specific manifestation, individual references are always equivalent to system references, as a certain movie, for instance, is always embedded in the system of film. ${ }^{45}$ To claim that the intermedial subject of House of Leaves carries a specific title, namely THE NAVIDSON RECORD, could thus fall off short of the novel's intermedial scope. The question is therefore what surfaces more strongly in the text at hand: the relationship between the text and the thematized media product or between the text and the semiotic system that is evoked by the thematized product (see Rajewsky, Intermedialität 74-75). An analogous question would be whether the bond between House of Leaves and THE NAVIDSON RECORD is rather story-focused or discourse-focused.

And this is when the concept of system contamination in contradistinction to system mention becomes crucial. In short, contamination exceeds the merely punctual thematization, evocation or simulation of film and can rather be described as continuous and elementary (118119). As in the case of Zampanò's narration of THE NAVIDSON RECORD, the text constitutes itself in relation to an alter-medial system throughout. At first sight, the strongly ekphrastic character of Zampanò's narration and its powerful theme of the labyrinth suggests a story-

\footnotetext{
45 To avoid confusion: This is why Rajewsky uses such umbrella terms as "system mention" or "system contamination" even when what counts is primarily the story of the individual work of art in question.
} 
focused contamination. But there are also three crucial points that speak against such a focus: Firstly, Zampanò repeatedly comes to elaborate on the production context of the record, detailing the recording equipment used and the quality of the shots made. To a great extent, this reflection is implied by the self-reflexive character of the record as such, representing a film about an adventurous documentary project. Hence, Zampanò's meta-aesthetic and metafictional comments flawlessly blend in with a system contamination titled "The Navidson Record." Secondly, it is significant in this context that the contamination is at the same time a strongly visible modification of literary conventions. One can assume that such a subversion of the literary system would occur in relation or in opposition to an alter-medial system rather than an individual work of art. In other words, the novel's experimental design, its utter deconstruction of narrative convention, serves as a first indication of the larger context of an alter-medial system that is not only coincidentally implied but of prioritized interest. Thirdly, there is the issue that Zampanò's manuscript is more of a scholarly analysis than a mere ekphrasis. Explicit system mentions are added to the contamination in terms of explicit footnotes. As I argue, it is one of these digressions that provides the decisive indication of the relevance of the alter-medial system for the text analysis. As said, the explicit mentioning realized in House of Leaves both serves and strikingly exceeds the purpose of marking intermediality. What distinguishes House of Leaves is Danielewski's ultimate exhaustion of the explicit system mention in that it verges on his participation in an ongoing academic discourse. Quite clearly marked as an excursus by various footnotes, Zampanò's extensive thoughts on the technological shift from analog to digital and its cultural implications for the art of film can be read as an introduction to the novel's intermediality. Therefore, to speak with Schwanecke, the category concerning the medium's technology and materiality (as one of the various nuances of the system) can be distinguished as the novel's primary concern. Within the novel's system contamination, the story-focused parts of THE NAVIDSON RECORD are subordinated to the novel's actual focus on the alter-medial system, which is characterized by the technological shift from analog to digital.

Taking Zampanò's excursus about digital manipulation as a point of departure, the next question to ask would be: What conclusions can be drawn from how the system is thematized and actualized in the novel? The certain causality implied in the distinction between "mention" and "actualization" is going to be reflected in the structure of the analysis. "Mention" provides a first accentuation of the intermedial reading and should thus be considered first in the analysis. The section “An 'Explicit' Approach to the Digital Age" identifies the ambiguity of rumpled and slick images as the novel's actual intermedial subject and, what is more, as the backdrop 
against which the system contamination can be read. In the subsequent sections, the last distinction between contamination qua translation and contamination by (partial) actualization eventually becomes crucial. It corresponds with the narrative and aesthetic conflict between indexicality and digitization conjured up by the novel. As already mentioned, "contamination" means that the rules of the foreign medium modify the organizational principles of the receiving medium. For one thing, this can happen through translation when foreign media specifics are translated or transferred into the semiotic system of the literary text. They are being evoked or simulated throughout the whole artefact (see Rajewsky, Intermedialität 124-135). This is the case when Zampanò's sole retelling of THE NAVIDSON RECORD is concerned, which conjures up a found footage film with its illusion of authenticity. This contamination qua translation is both supported and strongly questioned in Zampanò "explicit" side notes. They oscillate between a naive excitement about the film's transparency and, as said, the suspicion of its digital manipulation. "The Navidson Record" manuscript and its contamination qua translation shall be examined in the section "What Kind of Movie is THE NAVIDSON RECORD?" In the same section, the focus shifts from what the novel evokes to what it partially enacts on its discourse level. Here, the film's supposed digital source is considered as contaminating the novel by (partial) actualization. Contamination by partial actualization occurs when less media-specific components are involved. In their actual transmediality or partial congruence with the receiving medium, they can partly overcome the as-if-quality of the intermedial reference (see 135-145). It turns out that in their flexibility and limitless malleability, Danielwski's phrases, words, and letters partially actualize the digital code of ones and zeros that is assumed to create the special effect of the house.

\subsection{An "Explicit" Approach to the Digital Age}

As has been elaborated in the previous chapter, it makes sense to examine "The Navidson Record" against the backdrop of Zampanò's explicit discussion of the digital age. This approach makes even more sense after reading the first sentences of Zampanò's manuscript:

While enthusiasts and detractors will continue to empty entire dictionaries attempting to describe or deride it, 'authenticity' still remains the word most likely to stir a debate. In fact, this leading obsession - to validate or invalidate the reels and tapes - invariably brings up a collateral and more general concern: 
whether or not, with the advent of digital technology, image has forsaken its once unimpeachable hold on the truth. (3)

Does Zampanò himself introduce the advent of digital technology as the leading critical aspect of his writing? After this passage, he provisionally postpones the topic in order to proceed with the story of Will Navidson and his family. In a footnote on the same page, however, he announces this "collateral" subject to be more carefully considered in chapter nine. This is how the novel offers the reader at least the option to delve into the discourse first, and into the actual narration afterwards. Interested in the cultural and historical context assumed by the novel, I take precisely this reading path and thus jump forward to chapter nine. There, Zampanò becomes explicit to state that "currently, the greatest threat comes from the area of digital manipulation" (141). Throughout the chapter, he refers to and accurately quotes numerous actual critics and academics pondering the pitfalls of the digital age. This discussion starts with a quote from curator and art critic Andy Grundberg fuelling Zampanò's worries about the future of photography and photojournalism. In a 1990 issue of The New York Times, Grundberg anticipated in his article "Ask It No Questions: The Camera Can Lie" the following scenario:

In the future, readers of newspapers and magazines will probably view news pictures more as illustrations than as reportage, since they will be well aware that they can no longer distinguish between a genuine image and one that has been manipulated. Even if news photographers and editors resist the temptations of electronic manipulation, as they are likely to do, the credibility of all reproduced images will be diminished by a climate of reduced expectations. In short, photographs will not seem as real as they once did. (141)

Reading Grundberg, academically literate Zampanò feels reminded of Marshall McLuhan, who made a similar remark when writing: "To say 'the camera cannot lie' is merely to underline the multiple deceits that are now practiced in its name." Zampanò also turns out to have already researched the NPPA's (National Press Photographers Association) reaction to the growing public suspicion of its profession. On the one hand, its members recognize the impact of a "virtually undetectable" digital manipulation; but on the other hand, they announce to stick to their ethical benchmark, which is "accurate representation" (143). Such promises leave Zampanò rather unaffected. To provide a "powerful summation," he turns to the leading proponent of the post-photographic era, William J. Mitchell. While Mitchell acknowledges that serious journalists, scientists, 
and representatives of the legal system have a strong interest in "the hegemony of the standard photographic image," he points out that

others will see the emergence of digital imaging as a welcome opportunity to expose the aporias in photography's construction of the visual world, to deconstruct the very ideas of photographic objectivity and closure, and to resist what has become an increasingly scelrotic pictorial tradition. (143)

In his pessimistic undertone, Zampanò concludes that "truth will once again revert to the shady territories of the word and humanity's abilities to judge its peculiar modalities" (145).

\section{$\underline{\text { Rumpled vs. Slick Images }}$}

Even though he departs from the field of photography, Zampanò's notion of a future of profound disorientation applies to moving images as well. After all, Zampanò primarily alludes to moving images when he brings up his central idea of rumpled vs. slick technology in order to further elaborate the complexity and utter opacity of manipulation in the digital age. Unlike most of his other citations related to film and photography, this concept is attributed to one Murphy Gruner, a purely fictional critic. At first, Gruner makes a seemingly plain distinction with regard to reception conventions:

Just as is true with Chandler's Marlowe, the viewer is won over simply because the shirts are rumpled, the soles are worn, and there's that ever present hat. These days nothing deserves our faith less than the slick and expensive. Which is how video and film technology comes to us: rumpled or slick. (144)

The first thing to mention, however, is that the distinction between rumpled and slick is not meant as an analogy to a distinction between analog and digital. The digital age features an increase in the occurrence and scope of both rumpled and slick technology. Traditionally, rumpled images are associated with amateurish filmmaking or coincidental recording and thus with authenticity. The role of the digital in this respect does not necessarily diminish verisimilitude. Quite the contrary, the conditions for authentic images are theoretically even improved, "as the recording time for tapes and digital disks increases, as battery life is extended, as camera size is reduced, the larger the window will grow for capturing events as they occur" (144). What is more, the increasing cheapness and availability of such equipment makes it, as Gruner/Zampanò points out, "very dangerous. One needs only to consider The George Holliday 
Rodney King Video to recognize the power of such low-end technology" (144). ${ }^{46}$ Gruner contrasts the credibility of the rumpled image and its aura of imperfection, its flaws and camera shakes, with the utter pretence of slick images. Slick images are those known from marketing campaigns and Hollywood blockbusters. They are usually synthesized by slick technology, which is compared with rumpled technology "expensive [and] cumbersome" but virtually limitless. What Zampanò probably has in mind is the type of rapidly advancing graphics software used to create complex computer-generated imagery (CGI) permeating full-length motion pictures. They are the high resolution, high definition, and high budget manipulations that look so crystal clear and realistic they are automatically considered fake. Nevertheless, slick technology is "also very powerful [since it] allows for the creation of almost anything the imagination can come up with, all in the safe confines of an editing suite, equipped with 24 hour catering and on site masseuse" (144). If the digital can create anything, it can also create the mere layer of rumpled imperfection or coincidence. Ultimately, rumpled images can be as much a trick as Marlowe's humble wardrobe: nothing more than a charming and modest effect to win the audience over. The ambivalence of the digital age thus lies in the increased capacity of recording reality and in the simultaneous permanent threat of its undetectable subversion.

Once he has concluded Gruner's citation, Zampanò further elaborates on the phenomenon of the slick creation of rumpled images and comes to speak of the construction of "grittiness" (145). Grittiness refers to the grainy appearance of a photograph or negative, "an appearance of mottling or granulation." ${ }^{, 47}$ Zampanò also refers to Roland Barthes, who describes grit as a "seemingly functionless detail 'because it is there' to signal that 'this is indeed an infiltered sample of the real"' (146). To illustrate the impact of this detail, he encourages the reader to make an unconventional comparison: "Consider the savage scene captured on grainy $16 \mathrm{~mm}$ film of a tourist eaten alive by lions in a wildlife preserve in Angolaand compare it to the ridiculous and costly comedy 'Eraser' in which several villains are dismembered by

\footnotetext{
${ }^{46}$ In 1992, George Holliday captured footage of an African American man, Rodney King, falling victim to police violence. What Holliday saw and videotaped from the balcony of his apartment went down in history as evidence of police brutality in the USA, entailing riots after its wide TV broadcast. In the same vein, the question of the ambiguity of photographic evidence has been raised and widely debated. Defense attorneys tried to undermine the evidential power of the video, which was apparently featuring sheer brutality, by drawing the jury's attention to the significance of context, narrative, and caption. They demonstrated how the videotape could be understood as a case of self-defense as well: "In the California case, the defense was able in a sense to shift captions on the videotape, to provide a different framework for the seemingly damning images ... The jury was shown the tape more than 30 times in the course of the trial, projected at various speeds. The tape was even broken down into a series of still frames, each of which was then subjected to lengthy analysis by defense witnesses and attorneys. As a result, the defense was apparently able to deaden the impact of the tape, separate it from its reference to reality. The effect of all this was probably like that of saying your own name over and over until it begins to sound strange, and loses any link to meaning" (Hagen).

${ }^{47}$ Oxford Dictionary of English, third ed., s.v. "grain."
} 
alligators" (145). ${ }^{48}$ What Zampanò juxtaposes here is not an unfiltered sample of the real, on the one hand, and Tinseltown alligators, on the other, but two kinds of fake that imply different degrees of credibility. There does not seem to be a reliable connection between grit and indexicality. Obviously, Zampanò's point is that grit is not at all a functionless detail but rather a rumpled detail that can be employed slickly - and all the more so in the digital age.

In fact, as a cineliterate Danielewski reader may know, grit has not vanished with the (digital) end of celluloid. Rather it has ultimately turned into a visual effect, as the example of Quentin Tarantino and Roberto Rodriguez' Double FeATURE: GRINDHOUSE (2007) shows. It contains two movies both memorializing the so-called exploitation films of the 1970s and 1980s. Besides its depiction of extreme graphic violence and blending of horror, action, and science-fiction in a low-quality B-movie fashion, Tarantino and Rodriguez' perpetuation of an analog past in the digital era finds expression in instances of "retro-technology" or, in other words, "techno-nostalgia." ${ }^{49}$ Rodriguez used digital production techniques precisely to evoke analog image interferences comprising film grains and scratches. Ironically, he thus created an equal, if not even more persuasive impression of celluloid than its actually analog GRINDHOUSE counterpart, Quentin Tarantino's DeATh ProOF. As Jay McRoy sums up, GrindHOUSE can paradoxically be considered "a big-budget exploitation film about low-budget exploitation films that deploy high-end digital technologies to (re)create a low-tech analogue experience" (226) ${ }^{50}$ This is what makes Tarantino and Rodriguez' double feature a perfect example of the ambivalence implied in the rumpled/slick distinction. On the one hand, as in the case of GRINDHOUSE, rumpled grittiness is synthesized for the purpose of a tribute to a cult phenomenon. On the other hand, one can imagine its function as a reality effect - based on the denial of any digital post-production whatsoever. In this case, grain would be synthesized to feign celluloid and in the same vein indexicality.

At this point, it makes sense to briefly summarize what idea of the digital age Zampanò tries to convey. Due to the growing awareness of the threat of digital manipulation, slick technology comes to denote fake. Slick images are too hyper-clarified to be real. The problem, however, is that slick technology can as well synthesize so-called rumpled images and thus

\footnotetext{
${ }^{48}$ Zampanò probably refers to a film titled SAVAGE MAN SAVAGE BEAST, which is incorporated in the TRACES OF DEATH, a series of exploitation 'shockumentaries' that presented footage of deviant sexual activities or death. Many scenes, while represented as real, were false. In his article "Traces of Snuff: Black Markets, Fan Subcultures, and Underground Horror in the 1990s," Johnny Walker points out that the TRACES OF DEATH films catered to a "wave of interest in the visceral, the real and the taboo. Through the reappropriation of real-life atrocity footage, the films were responding a niche sector of the horror fan community which ... were less interested in mainstream products than marginal and independent fare beyond Hollywood's approach to the genre" (142).

${ }^{49}$ See Schrey, Dominik. "Mediennostalgie und Cinephilie im Grindhouse-Doublefeature".

${ }^{50} \mathrm{In}$ fact, both films have some metafictional elements.
} 
once again complicate matters. Yet another paradox is that not only the capacity to produce fake images but also the capacity of audiovisual documentation has been improved by the digital age. This is why, the credibility of rumpled images, unlike slick images, both diminishes and, in a sense, revives. What distinguishes the digital age in a negative sense is thus a "climate of reduced expectations" (HoL 141). On the one hand, it makes sense to distinguish between slick and rumpled images in the digital age. Never before in the history of film and photography has the gulf between slick and rumpled been that wide, as the juxtaposition of the grainy tiger and the high-definition crocodile illustrates. On the other hand, this distinction can at any time be nothing but fake and useless in terms of indicating verisimilitude.

\section{The Question of Indexicality}

THE NAVIDSON RECORD's claim to documentary aesthetics and its simultaneous representation of an impossible phenomenon prompts Zampanò to delve into a discussion of the digital impact on indexicality. To be more precise, he ponders whether indexicality can still be regarded as a benchmark or virtue of photography and filmmaking. He discerns an increasing inability to determine whether the events and details that appear on the screen have their origin in a "profilmic 'here and now' (or 'there and then')" or in digital algorithms (Rosen 306). This omnipresent threat of digital manipulation dissociates photographic practices from their formerly decisive characteristic of indexicality. The waning of indexicality in the wake of the digital age is thus rather a matter of a precautionary mistrust than merely a technical aspect. Either way, Zampanò considers the shift from analog to digital as a crucial paradigm change. This is how House of Leaves seems to perpetuate the idea of the post-photographic era, while also implying it by repeatedly mentioning media scholar William J. Mitchell, who has coined the term.

To process the destabilising potential of digital technology and the significance of the rupture it brings about, Mitchell spells out the deeply rooted understanding of photography as the model for impersonal and objective neutrality. The camera, he points out, has traditionally been considered "an ideal Cartesian instrument - a device for use by observing subjects to record supremely accurate traces of the objects before them" (The Reconfigured 28). The relation between the "ideal" photograph and its subject was not intentional but causal; while a certain degree of intention was, as a rule, undeniable, it was anything but essential to the photographing process. Where classical theory dictated that photographs were "transparent windows onto the world," digital creations and also instances of digital image-capture can be 
imagined as "windows with filters" - an assertion that retrospectively has proved visionary in a literal sense, given that in the age of smartphones, unfiltered Instagram images are uncommon enough to warrant their own hashtag (The Reconfigured 114). ${ }^{51}$ By announcing a postphotographic era, Mitchell envisions not only the progression from mechanical reproduction to digital origination and replication, but in a similar vein as Zampanò, also the shift from a comparatively naive notion of authenticity and originality to a more knowing one. One of the earliest high-profile instances of digital photo alteration "forcing us to adopt a far more wary and vigilant interpretative stance" appeared on the cover of the National Geographic in 1982 (The Reconfigured 225). Readers were not informed that photographer Gordon Gahan's pyramids had been moved closer together in order to fit the vertical format of the cover. In fact, the slightly "adjusted" fundaments of ancient Egyptian culture provoked major controversy. In his work, Mitchell repeatedly alludes to this infamous incident, which is one of the reasons why the pyramids may be regarded as the hallmark of the alleged post-photographic era.

However powerful and paradigmatic the introduction of the post-photographic era may appear, the accompanying discourse around the question of indexicality divides itself in two extremes. Critics of Mitchell do not engage so much in the subtleties of the analog/digital shift as in the question whether an appreciable rupture has occurred in the first place. One of the most noteworthy representatives of this opposing camp of scholars is, as a matter of fact, W.J. Mitchell's namesake W.J.T. Mitchell. In critical response to W.J. Mitchell's The Reconfigured Eye, he brings up a more recent example of photographic controversy, namely the case of Abu Ghraib, a prison used by United-States-led forces during the occupation of Iraq. In May 2005, a considerable number of images showing US soldiers torturing and abusing inmates in Abu Ghraib was published worldwide. The shocking depictions of naked inmates, with their heads wrapped in plastic bags, exposed to aggressive dogs and other deeply humiliating, sadistic practices, caused a major scandal with immediate legal consequences. Using this example of immediate controversy provoked by the unquestioned authenticity of images, W.J.T. Mitchell's aim is not simply to highlight that the universal belief in the evidentiary power of photography continues in the digital age. He takes issue with a categorical distinction between analog and digital:

\footnotetext{
${ }^{51}$ Instagram is a mobile app designed for photo taking, editing, and sharing. It offers a considerable array of effects and filters, which can be applied to images to give them a vintage look, add or subtract color saturation, turn them sepia or black and white, and much more. Since it is so common for Instagram users to add a filter to enhance their photos, the "\#nofilter" hashtag has become popular for posting unaltered and unretouched images. The question is whether the respective image is truly filter-free.
} 
My argument is against the reduction of digital photography to a bare material and technical essence, 'grounding it', as William Mitchell puts it, in 'fundamental physical characteristics', rather than social practices and uses. ("Realism" 48)

According to W.J.T. Mitchell, the example of Abu Ghraib perfectly illustrates the actual quality of digitization, which overshadows the question of its "“adherence to the referent' (which is almost always, in any case, established by documentation and testimonial credentials outside the image itself)." It is rather the enhanced "circulation and dissemination" that assured the worldwide perception and awareness of the dire conditions prevailing in Abu Ghraib and distinguishes digital photography from its chemically based predecessor.

This is naturally a difficult and complex debate. Its complexity is also due to the fact that the studies of photography overlap and blend with those of film, video and, in general, cinema, using the question of indexicality as their tertium comparationis. Similarly, House of Leaves seems to deal with a home video, a documentary film, a piece of cinema released by Miramax and a Pulitzer price-winning photographer turned filmmaker at once. It appears that the crisis of photographic authenticity comes together with an identity crisis of cinema. As film scholar Thomas Elsaesser points out, the resulting discourse reveals quite the same dilemma as already described:

Especially widely discussed is this loss of indexicality in the digital image: did it bring about a rupture in the history of cinema that some critics have experienced as traumatic and terminal, or have we simply misunderstood the meaning of 'index'? For those in the former camp, digitization quite literally means the end of the cinema, so that there cannot possibly be convergence. Instead, in this light, an era of post-cinema has begun, with its own characteristics and certainly based on a different ontology. In the latter camp, are those who argue against such a radical 'rupture' theory of cinema. They hold the view that our current uncertainty of what is cinematic about an image does not depend on either indexicality or digitization, and that the dilemma is a false one. ("Digital Cinema" 22)

There is a considerable temptation to abandon the idea of a sweeping revolution. In the case of cinema, however, such a rhetoric appears even more unwarranted. It is not only that there has always been illusion and fake in the history of photography and film and that special effects are not a recent, digital invention. Has not, since its inception, the aim of film been to "artistically 
rearrange the world rather than just slavishly and mechanically duplicate it?" (Carroll 240). The recording aspect of film has been made central by such influential theorists as André Bazin. In his popular attempt to answer the question What is Cinema? he links the ontology of film to that of photography. His viewpoint on the nature of film dictates an identity relation between the photograph and the cinematic shot. What distinguishes cinema as a medium according to Bazin is its " "achievement in time of photographic objectivity" (16). But however questionable this ontological view of film might be, it does not warrant dismissing the question of indexicality altogether. House of Leaves introduces the rumpled/slick dilemma as a pivotal feature of the postmodern image culture - that is based on a (knowing) ontological uncertainty. To understand how cinema is part of, and, what is more, constitutes this very culture, it is essential to acknowledge the traditional association between photograph and cinematic shot.

In his book The Language of New Media, Lev Manovich illuminates how the waning of indexicality in the wake of the digital age radically changes the medium of film and the art of filmmaking. His terminal notion of digital cinema constitutes a suitable point of departure given that the following discussion shall outline how cinematic realism, originally associated with photographic realism, is gradually being replaced by so-called photorealism and, in a further step, digital realism. In Manovich's theory on the subversion of cinematic realism, Christian Metz' notion of the fictional live-action film as the "super-genre" of twentieth-century cinema plays a crucial role; hence, a genre that "largely consist[s] of unmodified photographic recordings of real events which took place in real physical space" (Manovich, The Language 2).$^{52}$ Of course, live-action footage was never already the end product. But it is now more than ever that it merely provides the raw material for further compositing, animating and morphing. ${ }^{53}$ Today, even film classics, whose makers did not ever think of digitization, with increased regularity become subject to sophisticated projects of digital restauration. With the end of celluloid and introduction of digital video, the blending of image capture and synthesis has achieved best possible pre-conditions. This kind of filmmaking, which blurs the distinction between production and post-production, prompts Manovich to describe the shift from analog to the so-called digital cinema as a "shift from rearranging reality to rearranging its images" (303). Once "an attempt to make art out of a footprint" or, plainly and simply, "the art of the index" (295), cinema can nowadays no longer be clearly distinguished from animation due to its reliance on digital compositing. According to Manovich, digital cinema is, in fact,

\footnotetext{
${ }^{52}$ See Metz, Christian. "The Fiction Film and Its Spectator."

${ }^{53}$ In a similar vein, Rodowick observes that the powers of the digital image do not necessarily derive from the fact of digital manipulation, but rather from its enhanced "mutability and susceptibility to transformation and recombination" (102-3).
} 
"a subgenre of painting" rather than of cinema; the "kino-brush" has triumphantly wiped out the "kino-eye" (295). Eventually, Manovich carries his insistence on the contemporary insignificance of indexicality to extremes by bringing up a historical comparison:

In retrospect, we can see that twentieth century cinema's regime of visual realism, the result of automatically recording visual reality, was only an exception, an isolated accident in the history of visual representation which has always involved, and now again involves the manual construction of images. (295)

Clearly, Manovich is far from questioning the ontological character of the paradigm shift from analog to digital. Instead, he explains the difficulty of recognizing it. Here, the contemporary ambivalence of the special effect is at stake - which, on the one hand, becomes increasingly spectacular and, on the other hand, its special character is relativized in that it becomes increasingly indistinguishable from the pro-filmic. Even the most fundamental features of a mise-en-scène, such putative vestiges of the real as a tree or an accelerating car are digital. To illustrate this "elastic reality," as his pointed metaphor reads, Manovich takes the aforementioned FORREST GUMP feather as a decisive example ("What Is Digital Cinema?" 8). As Manovich's elastic reality stresses, photographic realism continues in the form of digital photorealism. In other words, photorealism continues a photographically established aim for transparency that, more often than not, occurs in an immersion-enhancing combination with the narrative and stylistic continuity of Hollywood Realism. As D.N. Rodowick points out,

research in computer graphics has pursued an idea of realism wherein photography and cinema, as well as other images based on the geometry of linear perspective, function as perceptual and spatial defaults. (100)

Due to the persistence of photographic realism as the gold standard, a great extent of digital technology occurs underneath the photorealist surface, as it were. Depending on the perspective, the fact that images in the digital age lose their "anchor" of indexicality does not only count for computer-generated images. "For 150 years the material basis of photography, and then of film, has been defined by a process of the mechanical recording of images through the registration of reflected light on a photosensitive chemical surface," writes Rodowick (9). Digital cameras still rely on light-sensitive sensors. But the photosensitive surface is replaced by an immediately occurring transformation into digital information, into mathematical abstractions. This is what turns the digital recording technology into an efficient observation instrument, putting its images into immediate circulation and dissemination and thus unveiling 
the appalling character of what happens behind prison walls. At the same time, this is what turns the respective shot into a purely algorithmic basis for profound adjustments. These are the considerations that prompt a camp of contemporary media critics to claim, first, that the digital revolution makes a difference, and second, that this revolution should be described in terms of ontology as well as in relation to perception and (a still mimicking) representation.

This discourse of conquest, led by William Mitchell and Lev Manovich, among others, is strongly questioned by the scholars who prefer to deny indexicality any form of critical scrutiny whatsoever. They accuse their contradictors of "vulgar technical determinism," immoderate nostalgia, and all in all, as said, a false dilemma (W.J.T. Mitchell 50). Philip Rosen, for example, is critical of the notion of a radical novelty and makes some relativizing and convincing remarks. He argues that the questionable opposition between old/indexical and new/digital derives from a euphoric rhetoric informed by a consumer culture that is in "perpetual search of product differentiation" (304). The inflationary use of buzzwords thus creates a fetish of the new or of the digital. Specifically, the metaphor of conquest plays a crucial role in the all too linear chronology, as it is being assigned to an analog past and a digital future. Theorists drawing a comparatively clear line thus become subject to "a kind of conceptual and theoretical utopia of the digital" (303). Rosen also challenges the idea of a waning indexicality. What information would surveillance otherwise retain, he asks. In analogy to the "pro-filmic event" he speaks of the "pro-digital event" and introduces a seeming oxymoron, that is, "digital indexicality" (307). This allegedly soberer idea of contemporary visual culture constitutes the permanent backdrop against which representatives of the discourse of conquest have to defend their views.

Still, it shall be discussed whether the critics who argue beyond the seemingly obsolete question of indexicality are themselves that untainted by any utopian or hyperbolic "traps" of the digital age. In this respect, it makes sense to once again turn to W.J.T. Mitchell as one of the most passionate critics of post-photography cited here. According to Mitchell, the digital impact does not constitute itself in challenging the indexical relationship between image and pro-filmic reality, but, on the contrary, in optimizing it. "If we are looking for a 'tendency' in the coming of digital photography," Mitchell points out,

it is toward 'deep' copies that contain much more information about the original than we will ever need, and super copies that can be improved, enhanced, and (yes) manipulated - but not in order to fake anything, but to produce the most 
well-focused, evenly lit image possible - in other words, to produce something like a professional quality photograph of the old style. (52)

In critical response to Mitchell, Rodowick claims that it is wrong to assume "that the primary powers of photography are spatial semblance" (103). This would entail to parallel photographic realism with a kind of "perceptual realism" and thus displace "the problem entirely to a cognitive domain" (104). Since what distinguishes indexicality is a physical causality, Rodowick cautions against confusing spatial semblance with indexicality. Mitchell's "deep" and "super" copies are, in fact, reminiscent of Zampanò's slick technology. As Zampanò would argue, the latter's capacity to produce spatial semblance is an indication of fake, rather than of indexicality. This argument can be developed even further in relation to cinema. But I shall first take a closer look at the concept of perceptual realism, which has been suggested by Stephen Prince to overcome a differentiation that is merely based on (non-)indexicality. The realism of contemporary images should be assessed according to perceptual plausibility and thus better adapted to the blending of digital synthesis and the pro-filmic (or respectively the pro-digital). In other words, with the idea of perceptual realism, Prince tries to articulate a tertium comparationis for image capture and digital synthesis. As mentioned, according to Rodowick this reconciliation of photographic realism (or mimicking photorealism) with a form of realism that even deepens the impression of spatial semblance does not work. After all,

the concept of realism in use by computer graphics professionals has a rather restrictive and circular definition. It does not correspond to an ordinary spatial sense of the world and actual events taking place within it, but rather to our perceptual and cognitive norms for apprehending a represented space, especially a space that can be represented or constructed according to mathematical notation. (103)

Instead of speaking of an overarching perceptual realism then, I would suggest differentiating between photorealism and "digital realism" and acknowledging that the line may be blurry. ${ }^{54}$ The essence of photorealism is "not to look like reality, but like photographs of reality" (Brown 27). Digital realism, in turn, can be described as an umbrella term for changing aesthetic forms of hybrid moving images. ${ }^{55}$ Digitally realistic visualizations show continuity with the

\footnotetext{
${ }^{54}$ See Sebastian Richter, Digitaler Realismus: Zwischen Computeranimation und Live-Action. Die Neue Bildästhetik in Spielfilmen (Digital Realism: Between Computer Animation and Live-Action. The New Image Aesthetics in Feature Films).

55 "With regard to digital moving images, it still makes sense to speak of digital realism - even if it is clear that this term cannot and does not want to denote a uniform realistic style. The term 'digital realism' rather describes
} 
photographic and at the same time go beyond the scope of photographic media. To understand the digital remediation of cinema (as live-action footage), one can thus imagine a continuum stretching from photographic realism over photorealism to the verge of a palpably new aesthetic, which is digital realism. At an early stage of this process, digital cinema may denote no more than numerical means of transmitting motion pictures without transcending the boundaries of photorealism. But in the wake of an ongoing cross-fertilization, digital cinema gradually develops its own idiosyncrasies and evolves from a mere channel of transmission into an autonomous medium of artistic expression. It is precisely this moment of maturation, this hypermediated turning point that features a spatial semblance that could be described as hyperclarified or hyper-real. In other words, digital realism already starts at the point where images no longer warrant to be referred to as digital mimicry of the photographic touchstone. As Rodowick so aptly puts it:

Recent Hollywood practice reveals a curious fault line in this respect. As innovation in digital synthesis or animation strive for ever-greater depictive credibility and visual transparency or immediacy, digital postproduction practices in live-action films are producing ever more powerful effects of hypermediacy: very fast editing with 'intensified' continuity, eccentric manipulation or rate of motion, enhancing the graphical values of the image through digital manipulation of color, and so on. (106)

This hypermediacy must however not only be a question of post-production. What W.J.T. Mitchell most probably has in mind when speaking of deep copies is the increasingly refined technology of digital cameras ("Realism"). Unlike film, with a digital camera one can increase the image sensor's light sensitivity (ISO) with the touch of a button, and thus adapt to the conditions of illumination at hand to get the wished-for image. The question is, as already indicated, whether the resulting deep copy exceeds what can be referred to as indexical. Is thus the non-indexicality of the digital possibly already inherent in the capture system of the digital camera? Does the latter accordingly produce hyper-indexicality in analogy to the hyper-reality produced by digital synthesis? Do Mitchell's super copies or deep copies consequently subvert

the new logic of hybrid moving images, which enables a new kind of realistic expression by fusing the techniques of the animation film and the live-action film" (Richter 177).

("In Bezug auf digitale Bewegungsbilder macht es trotz allem durchaus Sinn, von einem digitalen Realismus zu sprechen - auch wenn klar ist, dass dieser Begriff keinen einheitlichen realistischen Stil bezeichnen kann und auch nicht bezeichnen will. Der Begriff des 'digitalen Realismus' beschreibt vielmehr die neue Logik hybrider Bewegungsbilder, die durch das Verschmelzen von Techniken des Animationsfilms und des Live-Action-Films eine neue Art realistischer Ausdrucksformen ermöglicht" (Richter 177).) 
themselves by "trying too hard" and ultimately producing images that look hybrid rather than photographic? In this respect, Danielewski's Zampanò tells a particularly intriguing anecdote which adds yet another nuance to my discussion, in which I have decided to complicate the concepts of post-photography and post-cinema rather than dismissing them.

\section{LA BELle NiCOISE ET LE BEAU CHIEN}

The story of LA BELle Nicoise ET LE BEAU CHIEN can be considered a climactic moment of Zampanò's explicit discussion of the digital age in chapter nine. It accentuates Zampanò's awe of the digital conquest, which becomes most evident when examined against the backdrop of the larger academic context. The preceding scrutiny of this context has illuminated Zampanò's highly exemplary and anecdotal attempts to grasp the pitfalls of digital technology. As if in response to an opposing academic camp, Zampanò makes all efforts to emphasize and raise awareness of the necessary distinction between indexicality and non-indexicality. He believes in the prevalence of the kino-brush rather than the kino-eye and also considers the field of audiovisual documentation to be affected. The future he predicts bespeaks an ultimate ontological uncertainty:

... this impressive ability to manipulate images must someday permanently deracinate film and video from its now sacrosanct position as 'eyewitness.' The perversion of image will make The Rodney King Video inadmissible in a court of law. (145)

The connotation between nonfictional, rumpled images and a certain reliance on their authenticity becomes less and less valuable. Slick images, in turn, have a desensitizing effect. These copies are visibly too calculated, too deep to be real in the first place. They might be realistic in terms of spatial semblance but not corresponding to any truthful pro-filmic conditions. This is at least the climate that Zampanò senses in society and carries to extremes in the following anecdote.

In the dystopian visual culture drawn in the novel, a movie titled LA BELLE NICOISE ET LE BEAU CHIEN causes major controversy. Zampanò does not reveal much about the French production besides its major twist of a young girl being murdered in "such comic reality" that it meets the most fulsome praise from critics and public alike (147). After "receiving awards at Sundance and Cannes, earning international distribution deals, and enjoying the company of David Lynch," a literally eye-opening fact about the film's production background is revealed 
(147). It turns out that a real murder has taken place in front of the camera. "It was a slickly produced snuff film sold as an art house flick," Zampanò concludes. He imagines thousands of - what I would call - cine(il)literate viewers being tricked into watching a real murder without ever realizing it. Due to the high production values, a slick and polished image quality, and a probably even exaggerated spatial coherence, the film is widely perceived as an attempt to be “"photographic' only more so" and thus fake (Rodowick 125). On the one hand, LA BELLE NICOISE is a perfect example for how "reality" is still recognized only in its photographic appearance, and we are barely prepared for the new ontological situation emerging within composited images" (Rodowick 177). On the other hand, Zampanò's anecdote hardly serves the purpose of unveiling the digital capacity to produce indexical images. Rather, he tries to illustrate the power of slick technology, which is not only to create anything imaginable but to record anything unimaginable. Paradoxically, by producing a deep and slick copy, the filmmaker has virtually undone what happened in front of the (supposedly digital) camera. In other words, the digital realism of the movie overshadows its actual photographic authenticity and the indexical character of the images. Such a reading of LA BELLE NICOISE supports the radical notion that the genuine connection with the pro-filmic has been lost with the phenomenological loss of analog film. Once the pro-filmic is not immediately eternalized on a film strip but translated into a numerical code, its "reality" is altered, or to put it differently, an alternative reality is created at the moment of recording. This deliberately hyperbolic conclusion of chapter nine fits Zampanò's line of argument. Is Zampanò a cultural pessimist or a nostalgic cinephile who cannot stand the idea of his beloved organic celluloid bidding farewell to contemporary cinema? Is he mourning the death of cinema or already one step ahead, trying to put across the critical idea of a new form of post-cinema or digital cinema? Either way, LA BELLE NICOISE can be read as a clear indication that what Zampanò does with THE NAVIDSON RECORD - and respectively Danielewski with House of Leaves - is to ultimately play out the serious ontological disorientation the digital age may bring about.

\subsection{What Kind of Movie is THE NAVIDSON RECORD?}

After having detailed Zampanò's theoretical knowledge, it is now time to find out how he puts his insights into a more profound and less explicit context of intermedial practice. Still, to answer the question what kind of movie THE NAVIDSON RECORD actually is, this section will follow a thesis that is explicitly anchored in the novel towards the end of chapter nine. Here, Zampanò articulates an intriguing juxtaposition: "The Navidson Record looks like a gritty, 
shoestring documentary. LA BELLE NiCOISE ET LE BEAU CHIEN looks like a lushly executed piece of cinema" (147). What he implies is that while LA BELLE NICOISE is unexpectedly indexical, THE NAVIDSON RECORD might turn out to involve (digital) fabrication. "As Murphy Gruner might have observed: 'Rumpled vs. Slick. Your choice'” (147). Rather than documenting a peculiar hallway, Navidson deliberately chooses to give his film a rumpled appearance.

To develop this idea gradually, I shall first take a look at how Zampanò hints at the record's image quality. The first point to mention is the recording equipment used during the hallway explorations, which Zampanò is strikingly precise about. "Navidson ... keeps on hand two $16 \mathrm{~mm}$ Arriflexes and his usual battery of 35mm cameras" (10). Furthermore, he mounts a number of Hi 8 cameras around the house - popular in the consumer camcorder market with a user base comprising mainly amateur filmmakers at the time, a typical example of what Zampanò would refer to as rumpled technology. Due to the limited recording time, Navidson equips the analog cameras with motion detectors. In comparison to $16 \mathrm{~mm}$ cameras, the analog video cameras represented a breakthrough for amateur filmmaking. In comparison to what was about to come in terms of digital technology, however, they were still relatively poor. All in all, the technological equipment proves ultimately insufficient in the face of the dark hallway, as the following array of quotations illustrates:

Holloway remains the most stoic, keeping any doubts to himself, adding only that the experience is beyond the power of any Hi 8 or 35mm camera: 'It's impossible to photograph what we saw.' (86)

The entire sequence covering the escape from the house is reminiscent of something taken off of a cheap surveillance system in a local bank or 7-Eleven. The clips are impartial renderings of a space. If the action slips past the frame, the camera does not care enough to adjust its perspective. It cannot see what matters. It cannot follow. (344)

Ken Burns has used this particular moment to illustrate why The Navidson Record is so beyond Hollywood: 'Not only is it gritty and dirty and raw, but look how the zoom claws after the fleeting fact. Watch how the frame does not, cannot anticipate the action. Jed's in the lower left hand corner of the frame! Nothing's predetermined or foreseen. It's all painfully present which is why it's so painfully real.' (206) 
After the fatal explorations by the Holloway team and the house's collapse during which Navidson's brother has been lost in its depths, Navidson, against all odds and against the will of his wife, starts off for yet another exploration of the house on his own. As Zampanò outlines, numerous critics take pleasure in debating on the exact reason for Navidson's reckless descent. Many critics delve into a psychologically intriguing portrait of Navidson, who decides for another descent to come to terms with his troubled relationship to Tom and his eventual death. Hardly anyone comes up with the most obvious explanation, namely that in almost everything Navidson does, he is driven by his professional ambition, and in this case, by his "aesthetic dissatisfaction" with the footage so far: "We mustn't forget the most obvious reason Navidson went back to the house: he wanted to get a better picture" (418). It seems somewhat paradoxical that while Zampanò describes allegedly unreadable scenes of Navidson's descent, the typographic rearrangements on the respective pages of the book create a striking visuality. The novel builds up a tension between the invisibility conveyed by the story and the visibility conveyed by the discourse and style. This ambiguity deserves thorough consideration and will be addressed later in this chapter. For the time being, however, the novel's narrative insistence on a rumpled, hardly discernible scenery is at stake.

\section{$\underline{\text { THE BLAIR WITCH PROJECT Executed on Paper }}$}

It might be productive to imagine for a while that THE NAVIDSON RECORD was not published as part of a book at the turn of the century but - on the basis of Navidson's detailed descriptions - released as an actual film. If there is a genre THE NAVIDSON RECORD can be attributed to, a comparison with the horror subgenre of the so-called found footage film seems most fruitful. Briefly, the found footage film can be described as a mockumentary usually shot with a handheld camera and promoted as real footage. It is significant that House of Leaves was published just one year after THE BLAIR WITCH PROJECT release, "a millennial cultural phenomenon [that] brought found footage horror dramatically to the attention of mainstream audiences" (Heller 87). In both cases, a group of people sets off to explore something allegedly paranormal, which both provokes and defies documentation. Many critics readily compared the book to the film and claimed that essentially "The Navidson Record" was like THE BLAIR WiTCH PROJECT executed on paper. ${ }^{56}$ Indeed, in the text there are several indications of the record's affinity to

\footnotetext{
${ }^{56}$ Nicholas Rombes, for example, argues that "in many ways, The Blair Witch Project and House of Leaves are flip sides of the same coin, experimental works in the guise of horror stories ... I wanted to write about Blair Witch, but every time I think about it I also think about House of Leaves. And yet House of Leaves isn't a movie, although Mark Danielewski's father was a noted experimental filmmaker, and Danielewski has said that 'most of
} 
this particular subgenre. It is a pop culture phenomenon and has achieved cult status. It is also amateurish and self-reflexive, featuring diegetic cameras and turning the process of filmmaking itself into its main theme. Most strikingly, there is the element of 'having been found' that is reflected in House of Leaves as well. The origin of the record is discussed as pointedly cryptic. Prior to the release and official distribution, mysterious random VHS copies of shorts were passed around by hand. As Zampanò points out, the "dissemination of 'The Five and a Half Minute Hallway' seemed driven by curiosity alone" (5). A few months later, another short "surfaced" and rumors began to circulate about a "truly bizarre house." This context represents yet another marker of factuality, which made a considerable number of critics believe the film to be based on a true occurrence. A certain Sonny Beauregard, for instance, takes for granted that the actual producer of THE NAVIDSON RECORD must be Will Navidson himself. Her explanation for the impossibility of digital manipulation is accordingly simple: "They just never had enough money" (148). After researching the photojournalist and his family's tax statement as well as the virtual unaffordability of special effects in the digital age, she comes to the conclusion: "Considering the cost of special effects these days, it is inconceivable how Navidson could have created his house" (148). Also first-order narrator Johnny is intrigued by the possibility of the house's actual existence, as his life oscillates between drug-related dream and reality anyway. During his assembly of Zampanò's scattered notes, he takes every occasion to project details of the plot onto his own life. Eventually, he cannot resist embarking on a road trip to Virginia to verify the existence of the house. This venture unsurprisingly fails.

In response to THE NAVIDSON RECORD's rumpled found footage style, another prevailing sentiment can be identified in the novel. It can be best described by the pleasure of believing almost but not quite. As Alexandra Heller-Nicholas points out in relation to the "maturation" of the found footage genre:

Rather, the formal encouragement that these films may be 'real' is often consciously understood by media-savvy audiences as an invitation to indulge in an active horror fantasy, one where we can knowingly accept and embrace the real-seeming film frame while never fully suspending disbelief. (8)

This observation of movie reception can be further elaborated with reference to the phenomenon of the cult film. It applies to critics and audiences who perpetuate the cult status of a respective movie and hence turn it into a form of (hyper-)reality. The cult factor is mirrored

the typographical setting is influenced by film.' And Blair Witch isn't a novel, although its dual cameras suggest alternating first-person narration" (10/40/70 12). 
in the sheer mass of ink that has been spilled over the infamous explorations on Ash Tree Lane, and their very details. A good example is the already mentioned question "Why Did Navidson Go Back To The House?" (385). As one can conclude from chapter XVII, the aim to determine the reason why Navidson chooses to reenter the house has taken on an excessive scale, entailing "several years of intense debate." As a result, "three schools of thought" have become prevalent in the academic field: "The Kellog-Antwerk Claim," "The Bister-Frieden-Joephson Criteria" and the so-called "Haven-Slocum Theory." Solely devoted to the respective question, they thoroughly discuss issues of possessiveness and other psychological motifs. Zampanò gives these theories some consideration "though it would be impossible here to address all their respective nuances" (385). This considerable body of theory appears disproportionate to the almost ridiculous simplicity of the question. What is more, it simply relies on the record's authenticity and thus considerably adds to the being-in-the-world of the idea of the infamous hallway.

Zampanò's imagination of audience reaction is, in fact, not as far-fetched as it seems when taking the success of THE BLAIR WITCH PROJECT into consideration. In the moment of its release in 1999, the film constructed a sensation of recorded reality even though in the meantime found footage has become established as a fictional film subgenre, or as Heller puts it, "any threat that these films were 'really real' became significantly reduced" (8). THE BLAIR WITCH PROJECT was a perfect model for how the element of "having been found" can be part of a cunning marketing campaign that deliberately remained under the radar of a too public or too mainstream awareness. In an unprecedented way, it demonstrated the usefulness of the Internet in terms of low-budget film promotion. A website was set up to drop pieces of information about an alleged documentary project of young film students, about the history and the mythology behind the notorious Blair Witch. Circulating missing person posters and doctored $I M D b$ entries suggested that Heather, Josh, and Mike had never come back from their journey to Burkittsville and the Black Hills Forest. ${ }^{57}$ In addition, rumors were spread. The power of word of mouth made people actually express condolences to the cast's families. Whether this was a fan activity of perpetuating the film's cult or sincere expressions of sympathy is unclear, especially since the line between these two options can be vague, after all.

\footnotetext{
${ }^{57} I M D b$ refers to the Internet Movie Database, an online database of information related to film, which refers to itself as "the world's most popular and authoritative source for movie, TV and celebrity content."
} 


\section{$\underline{\text { Reconsidering a Digital Intervention }}$}

By turning a low-budget independent film production into a box-office hit, THE BLAIR WITCH PROJECT introduced the digital age in terms of viral marketing. The film's revolutionary character is primarily attributed to its intelligent exploitation of the Internet as a fruitful marketing platform. It is worth mentioning, however, that the shift from the analog to the digital era is already anchored in the movie itself which is shot on both $16 \mathrm{~mm}$ black-and-white film and digital video. Nicholas Rombes points out that the narrative conflict between these two diegetic cameras is resolved towards the end of the film:

As Heather (using the $16 \mathrm{~mm}$ camera) and Mike (using the video camera) search an abandoned house for Josh ... The sequence ends as Heather follows Mike into the basement, only to find him standing in the corner, facing the wall. She screams his name. Something violent happens to her, and her camera falls on the ground giving us a fixed, sideways view of the basement as the film jitters. The film ends, as does she. The last images we see are from the analogue camera; then the screen goes black. (Cinema 17)

In The Blair Witch PROJECT, released at the turn of the century, film does literally not cross the threshold to the fantastic world of the Blair Witch or, in other words, to a rather uncanny future. According to Rombes, it can thus be described as a "pre-digital digital film" (16). Even though the way House of Leaves acts as a splice between the analog and digital era is differently accentuated, the term pre-digital digital applies here as well. Rather than juxtaposing the analog and digital in terms of two diegetic cameras, it conjures up the omnipresent suspicion of digital intervention in a time still reliant on analog inscription technologies. Whereas THE BLAIR WiTCH PROJECT anticipates the coming of a digital future, or allows the digital to "take over," House of Leaves deals with the threat of a digital basis that is already there but undetectable. Besides the cult following, on the one, and the willing trust in the tape's reality, on the other hand, there is thus a third sentiment in the novel. It is represented by a cinematically versed mindset, which raises awareness of the movie's artificiality, and what is more, the necessarily digital origin of the house on Ash Tree Lane. In other words, it does not only underline the film's fictionality, but, in addition, deny its indexicality. Can one assume that what lurks on the other side of the mysterious doorway is nothing, but a refined special effect elusively framed by a rumpled and gritty documentary style? Among the various hints in the novel indicating that digital technology accounts for the end product of THE NAVIDSON RECORD, there is, for instance, the "curious enigma concerning Part 12" (340). It relates to a scene whose framing 
and lighting "though only slightly different from earlier and later parts, indicate the presence of a recording device other than Holloway's." Tellingly, the enigma has not been adequately resolved yet, "even though the spectre of digital manipulation has been raised."

Such details considerably support the school of thought Zampanò has created in chapter nine. Moreover, his explicit discussion of digital manipulation, starting with the ethics of photojournalism, retrospectively lends substance to other details, prompting the record's plot to be reconsidered from scratch. Read through the lens provided by chapter nine, in other words, it is certainly no coincidence that the protagonist of THE NAVIDSON RECORD, namely Will Navidson himself, is based on the famous photojournalist Kevin Carter. In fact, the use of digital technology in THE NAVIDSON RECORD can be read as curious yet consequent twist in Will Navidson's character development. Throughout the book, Will repeatedly wakes up from nightmares and cries out the name "Delial" in despair. After his wife Karen has been kept in the dark about the mystery of Delial for years, she eventually finds the name on the backside of a photograph showing a vulture preying on a tiny Sudanese girl. As it is affirmed in a footnote, this description perfectly mirrors Kevin Carter's Pulitzer Prize-winning documentation of the 1993 famine in Sudan, which earned him both praise and controversy. Kevin Carter's photographic work was certainly a matter of the right angle, the perfect light, and, ultimately, a cunning composition. But it was precisely the photograph's painful indexicality that conveyed a sense of voyeurism and turned his journalistic work to such a notorious, widely discussed case. As it is quoted in House of Leaves, the St. Petersburg Times in Florida wrote: "The man adjusting his lens to take just the right frame of her suffering, might just as well be a predator, another vulture on the scene" (368). Accordingly, Will Navidson, with his guilty conscience, keeps wondering why he was not "just doing something about this instead of just photographing it" (394). With the ethical issue of "just photographing it" the novel calls to mind the indexical power of photography. To be more precise, it turns out that Navidson's professional past corresponds with a notion of photography that has been coined by Roland Barthes and problematized by Susan Sontag. In Camera Lucida, Roland Barthes describes a photograph as containing "a message without a code" (17). Here, Barthes compares photography to language whose signs establish only arbitrary connections to the objects in question. He contrasts the direct, physical character of photographic representations to the way a linguistic message hinges on an intermediary code in order to be made sense of. Pointing to the potential controversy of the indexical footprint character, Susan Sontag speaks of photography as a medium that has fostered an attitude of non-intervention. Tellingly, Zampanò at one point pretends to quote Sontag in order to process the deeper political meaning of Navidson's work: “As Susan Sontag 
sadly mused many years later: 'Her proximity suggested to us that Delial was still within our reach"" (421). One can assume that Danielewski is familiar with Sontag's thinking and her claim that part of the horror of contemporary photojournalism

comes from the awareness of how plausible it has become, in situations where the photographer has the choice between a photograph and a life, to choose the photograph. The person who intervenes cannot record; the person who is recording cannot intervene. (Sontag 12).

This kind of photography, as said, is explicitly marked as Navidson's past; a past that he is haunted by and that he tries to replace with a future in this disturbingly non-indexical house of absolute physical impossibility. Therefore, the house allegedly created by Navidson must be digital, a result of his creative intervention rather than passive recording. After his traumatic experience of non-intervention, he must turn to the digital in order to regain control over his life. The Navidsons' move to the new house is all about leaving behind Will's professional past, and thus, the art of the index. Has THE NAVIDSON RECORD in fact crossed the threshold to a digital future while keeping up the appearances of an analog past? Has Navidson as a filmmaker used analog recording equipment in order to create fake rumples while in fact exploiting the limitlessness of digital intervention? Does THE NAVIDSON RECORD - in analogy to THE BLAIR WiTCH PROJECT - mark a liminal, pre-digital digital moment in recent cinematic/literary history? Returning to the introductory question of what kind of movie THE NAVIDSON RECORD is, the necessity of a second glance surfaces.

\section{$\underline{\text { THE NAVIDSON RECORD as a Found Manuscript }}$}

As has been shown, House of Leaves engages the reader in a carefully structured enigma of the hallway on Ash Tree Lane and its indexicality. At the heart of the novel, however, there is yet another unresolved question of an even more fundamental character, namely whether such a film as THE NAVIDSON RECORD has ever existed in the first place. So far, the discussion was about concluding from Zampanò's ekphrasis what view of the house the film discloses, how rumpled it looks, and how it strives to cover up its possibly slick origin. As the reading proceeds, one quickly forgets that already at the outset of the novel there is a major twist to the question of watching THE NAVIDSON RECORD. Johnny Truant reveals 
Zampanò's greatest ironic gesture; love of love written by the broken hearted; love of life written by the dead: all this language of light, film and photography, and he hadn't seen a thing since the mid-fifties. He was blind as a bat. (21)

Has Zampanò seen the film before his illness or is this a first indication that THE NAVIDSON RECORD is actually not watchable? Zampanò's blindness, in fact, is not the most striking result of Johnny's research. While pointing out his efforts to gather reliable knowledge about THE NAVIDSON RECORD, Johnny finally reveals the most valuable piece of information concerning its ontology:

After all, as I fast discovered, Zampanò's entire project is about a film which doesn't even exist. You can look, I have, but no matter how long you search you will never find The Navidson Record in theaters or video stores. Furthermore, most of what's said by famous people has been made up. I tried contacting all of them. Those that took the time to respond told me they had never heard of Will Navidson let alone Zampanò. (xix-xx)

In spite of these facts, Johnny himself remains ambivalent about the film's existence. After all, the utter negation of the film, even though based on research, stands in stark contrast to the details Zampanò provides about its release and production context and to its life-changing impact on Johnny. But even when Johnny starts his journey to ultimately disprove the film's existence, the riddle does not simultaneously end for the reader. On the contrary, in the novel's appendix the reader arrives at a section ostensibly supplied by "The Editors," which provides "Contrary evidence" to Johnny’s conclusion. It shows, for instance: a comic strip of a dramatic shooting scene in the hallway, a conceptual model of the house made by a design graduate, and most strikingly, an alleged still image from the film, "Exploration \#4." To end the book with such a visually powerful section is, in fact, very much coherent with its overall theme. It appears as if The Editors were taking the last resort to convince the reader of the film's existence namely by means of visual evidence. Given the mentioned climate of reduced expectations, this can be considered an almost ironic gesture. After all, the reader may prefer to stick to "the shady territories of the word" as suggested by Zampanò earlier in the book (145).

Johnny's cited declaration of the film's non-existence is a metafictional comment, which serves to emphasize his ambivalent character oscillating between reliability and unreliability. It further pushes the line between authentic and fake by depriving the reader of the last vestiges of any certainties whatsoever. However, the denial of any actual film does not only contribute to the House of Leaves identity as a postmodern riddle, but also, and even more 
so, to its identity as nothing more or less than a novel. In its very metafictionality, Johnny's remark may also serve a specifically metamedial purpose, which is to highlight Zampanò's manuscript (with all its footnotes and appendixes) as the primary narrative of "The Navidson Record" rather than a secondary narrative that the author has accomplished upon watching an eponymous film. It does not mean that the novel should no longer be referred to as intermedial; rather, it means that as an intermedial reference, it is self-reflexive. This self-reflexive intermediality manifests itself when Johnny directly addresses the reader promising that "no matter how long you search you will never find The Navidson Record in theaters or video stores" (xix-xx). Is he possibly predicting that "The Navidson Record" shall never actually bridge its intermedial gap to be manifested in a medium other than the novel? The metamedial dimension becomes even more illuminating when regarded in relation to the fact that Danielewski strictly rejects any cinematic adaption of his first best-selling novel. "My reverence for books - for the power and flexibility of phrases unfolding on the page - is the reason why I'm not selling film rights to 'House of Leaves, "' he reasons in the "Haunted House" interview (117). It is not only that Zampanò's “The Navidson Record” has no actually filmic counterpart in the diegetic world of the novel, it is denied any cinematic manifestation whatsoever. The fact that this intradiegetic twist is mirrored in the book's extradiegetic fate lends greater depth to Johnny's revelation and thus deserves further consideration.

With his refusal of entering film business with House of Leaves, Danielewski defies the fallacy that "filmic" literature is particularly well suited for cinematic adaptation. Of course, any filmic technique or convention evoked in a novel can effortlessly be realized by the medium film. This filmic adaptation, however, would not express the motivation behind its textual transposition, which is to thematize, evoke, or unveil the filmic convention as such. This effect, in turn, can only result from the contrast provided by the intermedial gap. Interestingly, Danielewski regards literature's as-if relation to film, its limitation to its media-specific means as a privilege rather than a limitation. The message conveyed is that a filmic counterpart to "The Navidson Record," either inside or outside the diegesis, would not make any sense. From this viewpoint, the diegetic insistence on the non-existence of the film in question turns House of Leaves into an instance of self-reflexive intermediality, as I have termed it. Ultimately, House of Leaves is very consequent about being a found manuscript rather than pretending to be found footage. In other words, as a found manuscript it stands in its own right. This distinction is further accentuated towards the end of the novel when Johnny departs for a trip to verify the setting of THE NAVIDSON RECORD. Once he has realized that there is not even a street called Ash Tree Lane, it is at a local bar that Johnny unexpectedly gets on the right track. Not believing 
his ears, he encounters a band playing "I live at the end of a Five and a Half Minute Hallway." As he inquiries about the song's source of inspiration, expecting to eventually arrive at the evidence for the film's existence, he ends up stunned by what he is about to hear:

'Wasn't it a movie?' I stammered back, more than a little surprised by how fast the mood had just shifted ... the drummer shook his head and explained that the lyrics were inspired by a book he'd found on the Internet quite some time ago. 'Take a look for yourself,' he said, handing me a big brick of tattered paper. 'But be careful,' he added in a conspiratorial whisper. 'It'll change your life.' Here's what the title page said: House of Leaves, by Zampanò, with introduction and notes by Johnny Truant ... I couldn't believe my eyes. (513)

Rather than making him eventually find the footage, Johnny's discovery, in another metamedial twist, underlines the being-in-the-world of House of Leaves and thus "The Navidson Record" in its printed form.

So, the answer to the question what kind of movie THE NAVIDSON RECORD represents is that it represents no film, neither fictional nor factual, at all, but most self-consciously an intermedial reference to film executed in the form of no more and no less than printed text. It does not mean, however, that the question of digital manipulation becomes obsolete. On the contrary, it becomes relevant in the first place. If THE NAVIDSON RECORD was "primarily" a movie, its rumpled surface would not necessarily be questioned as an illusion. Just as the audience of LA BELLE NICOISE ET LE BEAU CHIEN is tricked into taking the film as a lushly executed piece of cinema, the alleged audience - not the readership - of THE NAVIDSON RECORD is likely to be tricked into taking it as a gritty amateurish documentary based on real events. ${ }^{58}$ In this case, the digital would not expose itself. It is only in the intermedial gap that the ambiguity between indexicality and digital synthesis comes to the surface. On the one hand, Zampanò exposes its split rather conventionally by both citing and propelling speculation on the digital fabrication of an apparently rumpled film. As I have shown in the previous subchapters, Zampanò plays with this type of speculation on the story level of his manuscript. In the following, however, the focus shall shift to the discourse level and its unconventional if not experimental exposure of digital trickery. Therefore, it remains to be examined how Danielewski exploits "the power and flexibility of phrases unfolding on the page" to create a

\footnotetext{
${ }^{58}$ This is naturally a heuristic example serving to illustrate how the novel self-reflexively warrants the benefits of its intermedial gap.
} 
textual basis for THE NAVIDSON RECORD, which is, as I shall argue below, reminiscent of the digital code (McCaffery 117).

Zampanò's manuscript, its leaves, phrases, words, and individual letters are specifically arranged to turn the reading experience partly into an act of decoding. This is a particularly creative case of contamination by (partial) actualization. It does not apply to any convention or aesthetic of the art of film, but its underlying technology. It unveils the techniques of contemporary filmmaking by laying bare the infinitely malleable (special) effects of digital coding.

Thus, the novel's self-reflexive intermediality constitutes itself in that it raises the question of indexicality on its story level and simultaneously provides an answer on its level of discourse: the non-indexical but digitally encoded origin of the house can be identified literally between the lines or in their "shady territories."

\section{$\underline{\text { The Book as a Code }}$}

The labyrinthine hallway in the house on Ash Tree Lane is an uncanny place. It is not only that the house inexplicably measures bigger on the inside than on the outside. In addition, the inside of the hallway is, to say the least, lacking any cosiness and thus fits yet another nuance of the term uncanny. In fact, the novel cannot overstress how "unheimlich" or "un-home-like," as the literal translation from German reads, it is (37). It provides an excursus about how German philosopher Martin Heidegger pondered the term. Zampanò cites a passage from his book Sein und Zeit (Being and Time), wherein Heidegger departs from the philosophical notion that tranquillity and self-assurance can be described as a matter of an abstract "Being -in" or, in more concrete terms, of "Being-at-home" as a basic state of "average everydayness" (HoL 25). ${ }^{59}$ In anxiety, however, this "everyday familiarity collapses" so that one feels uncanny or “"not-at-home." The Navidsons certainly do not feel at home on Ash Tree Lane in their "house of darkness, cold, and emptiness" (368). Not only are they constantly threatened to get lost in an incalculable and ever-shifting maze but also exposed to a persistent growl coming from the unlocatable depths of the hallway. When exploring the hallway, Holloway, as a former hunter, is determined to track down with his rifle the origin of the growl. Zampanò finds a plausible explanation for the futility of his manic hunt: "The problem, of course, was that the certain 'something' Holloway so adamantly sought to locate never existed per se in that place to begin

\footnotetext{
${ }^{59} \mathrm{Cf}$. Heidegger $180-185$
} 
with" (95). What constitutes the horror of, not only the growl, but the entire house is that as a certain "something" it does not exist but at the same time cannot be denied a being-in-the-world.

One would expect that the underlying premise that the house is nothing but computergenerated imagery actually serves to demystify and moderate the notion of the unsettling spatial violation the Navidsons have to face. After all, among the three sentiments prevalent in the novel - outlined in the previous subchapter as the enthusiastic embracing of THE NAVIDSON RECORD's factuality, the uncritical cult following, and the questioning of the hallway's indexicality - the latter implies a striking sobriety, particularly in comparison to the other approaches. This is however not the key to the novel's complex construction of "Unheimlichkeit" (uncanniness). In other words, the technological explanation does not make the house less uncanny. Rather, it serves to point out the fundamental uncanniness of digital technology, or to be more precise, of the way in which it enters our contemporary visual culture. To get a better idea of House of Leaves' treatment of the uncanny dawn of the digital, Thomas Elsaesser's reading of Lev Manovich's inside-out model might prove useful. Manovich visualizes the emergence of a new medium, for instance digital cinema, as a gradual process that starts on the inside of the old medium (in this case analog cinema) and only after a while visibly affects its surface. ${ }^{60}$ A good example of this phenomenon would be the earlier mentioned distinction between photorealism and digital realism that is more productive in terms of distinguishing the new from the old medium than the notion of an overarching perceptual realism. What interests Elsaesser is another metaphor Manovich uses, namely that of the socalled Velvet Revolutions:

In the 1989 former Soviet satellites of Central and Eastern Europe have peacefully liberated themselves from the Soviet Union. In the case of Czechoslovakia, this event came to be referred as Velvet Revolution - to contrast it to typical revolutions in modern history that were always accompanied by bloodshed. To emphasize the gradual, almost invisible pace of the

\footnotetext{
${ }^{60}$ See Manovich's elaboration of his inside-out model that, in its essence, mirrors Richard Grusin and Jay David Bolter's concept of remediation: "One way in which change happens in nature, society, and culture is inside out. The internal structure changes first, and this change affects the visible skin only later. For instance, according to Marxist theory of historical development, infrastructure (i.e., mode of production in a given society - also called "base") changes well before superstructure (ideology and culture in this society). In a different example, think of technology design in the twentieth century: typically a new type of machine was at first fitted within old, familiar skin: for instance, early twentieth century cars emulated the form of horse carriage. The familiar McLuhan's idea that the new media first emulates old media is another example of this type of change. In this case, a new mode of media production, so to speak, is first used to support old structure of media organization, before the new structure emerges. For instance, first typesets book were designed to emulate hand-written books; cinema first emulated theatre; and so on" ("Image Future" 5).
} 
transformations which occurred in moving image aesthetics between approximately 1993 and 1998, I am going to appropriate the term Velvet Revolution to refer to this transformation. (“After Effects, or Velvet Revolution" 5)

While initially remarkably unbloody and hardly noticeable, the long-term consequences turn out to be all the more palpable, turning the revolution in retrospect into an actually very painful rupture. ${ }^{61}$ When the new eventually bursts forth, it forces dramatic changes, after all. And this is what, according to Thomas Elsaesser, provides the inside-out model with a sense of the uncanny, "of some malevolent act of disguise, indeed, of conjuring up the host-parasite image, as we know (and fear) it, for instance, from the Aliens films" ("Digital Cinema" 36). Sticking to a similar rhetoric, Elsaesser develops further this image speaking of a new logic "invading" a system, "retrovirus like," in order to "hollow out" the foundations of the respective host medium (37). When THE NAVIDSON RECORD is being imagined as a piece of digital cinema, it comes across as a Velvet Revolution. Its images remain intact in terms of a gritty photorealism while an invisible and intelligible code of zeros and ones invades the system. Rather than the hallway itself, the actual source of uncanniness is the enigma of its true nature and ontology, which prompts Will to again and again cross the threshold to get a better picture.

Given that the hallway is a digital fabrication, its appearance can be read as selfreflexive, as an allegorization of its ontology. The incapacity to measure, grasp, process or even see it also applies to the digital code that has supposedly created it. In a similar vein, Mark Hansen speaks of the novel's "concern with the digital as a subterranean deformational force" (609). One can imagine that Navidson, in his role as a protagonist of THE NAVIDSON RECORD, breaks the fourth wall virtually stepping into the computer-generated imagery of the film when crossing the threshold into the hallway. Every time he enters the hallway, he does not know how it ultimately responds and is unable to determine "how the internal demon of the apparatus operates" (Derrida 23).

D.N. Rodowick ponders how to defy the illusory and camouflaging nature of the digital age: "To comprehend what becomes of visual culture today, including the cinematic image, one must look past or beneath the present image, which is in fact no image at all, but information" (125). Navidson's efforts to gain access to this information remain futile. The question,

\footnotetext{
${ }^{61}$ Cf. Stephen Engelberg's 1992 New York Times article, “The Velvet Revolution gets rough," wherein he describes how peaceful crowds in Prague provoked the fall of Communism and how, in the aftermath, power relations between Czechs and Slovaks, pro-market right-wingers and social democrats, older dissidents who got high positions in the new governments and younger reformers who did not, violently emerged.
} 
however, is whether the rules the house obeys remain equally invisible to the House of Leaves reader, especially when he or she decides to stick to the "shady territories of the words" (instead of the visual evidence in the appendix) while seeking answers (HoL 145). In this respect, House of Leaves sets up an interesting analogy to another instance of digital paranoia around the turn of the century, namely THE MATRIX. In one scene, a character tellingly named Cipher is watching a computer screen that is awash with a stream of alphanumeric characters. It turns out that what he actually watches is the Miss Universe contest. Due to his expert familiarity with the code, it has become transparent to him. He sees right through the numbers and letters to the analog images they represent. This iconic scene is based on a literal manifestation of Rodowick's advice, namely the logic of stripping off the texture of the interface and disclosing the abstract geometry of digital images. As I shall argue, House of Leaves makes the reader encounter a similar phenomenon. On the pages of the novel, literally between the lines, the digital bursts forth and violently disrupts the previous order of letters, words and phrases being arranged on book pages. It renders the ongoing inside-out process, or parasite-host logic, visible. Given that THE NAVIDSON RECORD is based on computer-generated imagery, the challenge of Zampanò's primary narrative is accordingly to write in codes. It is noteworthy in this context that quite at the outset of the novel the reader is redirected by a footnote to a 60page long section of letters that Johnny received from his institutionalized mother, Pelafina. To keep the new director of the psychiatric ward from reading the letters and thus find out her secrets, Johnny's schizophrenic mother starts to write in codes. In one letter she even clearly states that the next letter will be encoded and gives him brief instructions how to decode it. The subsequent letters feature increasingly distorted text arrangements with different font sizes and illegible, mutually layered text passages (see 627). Some interpretations of the novel suggest that the actual narrator of "The Navidson Record" or House of Leaves is neither Zampanò nor Johnny but Pelafina. Instead of going into great detail about Pelafina's narrative significance, it suffices at this point to state that the encoded style of writing introduced in Pelafina's letters continues with the manuscript of "The Navidson Record" and possibly turns into a style that resembles digital code.

In terms of form and aesthetics, I would like to discuss the notion of the book as a code. Rather than imitating certain filmic techniques as zoom shots, fades, dissolves or jump cuts, House of Leaves, as I assume, "digs deeper" and uses its textual flexibility to feign and thus unveil the numerical code behind THE NAVIDSON RECORD. As already mentioned, this experimental layer of the novel can be described in terms of intermedial theory, as operating in the mode of contamination by (partial) actualization. It is particularly intriguing how House of 
Leaves partially actualizes one of the most important special-effects techniques of digital cinema, which is the blue screen. ${ }^{62}$ In footnote 144 , as one of the most striking examples of the novel's encoded design, a blue-outlined frame is set near the top of the page. It contains a list of everything that is not in the house; a list that expands over fourteen right-hand pages of Zampanò's manuscript and yet is self-evidently incomplete. A telling feature of this blue box is that it is mirrored on the back side of the respective page. It means that in its appearance on the left-hand pages, it presents the text in reverse, as if the page was suddenly rendered transparent. The resulting illusion is one of transparency:

Here the back of the page seems to open transparently onto the front, a notion that overruns the boundary between them and constructs the page as a leaky container rather than an unambiguous unit of print. (Hayles, Writing 123)

Paradoxically, it is the materiality of the page that allows the reader to see what is behind the image of the house. In abstract terms, the code in this blue frame does not reference anything beyond itself. There is no indexical reality. You turn the page, you look anew, you reset your perspective, and everything comes down to one and the same code. In a literal and figurative sense, explicit nothingness is projected onto the blue screen. The long enumeration of things that are not in the hallway can be understood as a tautological emphasis of this indexical void. In this context, the blue print of each instance of the word house is worth being reconsidered. As already mentioned, Jessica Pressman and other scholars have associated the blue house with a hyperlink on the Internet. In this intermedial reading, however, the coloration serves as a constant reminder that the house is nothing but a projection surface for digital imagery. Accordingly, after the words cease, the box in which they were inscribed returns to its original condition. It appears bereft of words but filled with a surface of light blue color. With its sharpened focus on the word no, which determines the presence or absence of a subsequent, fourteen-page long list of items, this passage conjures up a binary code. It highlights the arbitrary, if not incidental, character of the hallway's interior. After all, it would suffice to change one tiny detail of the text, for example cross out the word no, in order to turn the house into its complete (possibly even inhabitable) opposite. The presence/absence dichotomy prevalent in the book also manifests itself in the numerous crossed out sections. Zampanò's thorough discussion of the hallway's maze-like architecture provides an enlightening example

\footnotetext{
62 "Actors perform in front of a green or blue screen that is carefully lit with even illumination. In digital postproduction the green or blue screen is isolated from the other elements of the image and in its place another filmed, or CGI-produced, image is inserted, producing a composite shot" (Kuhn and Westwell 260).
} 
in this respect. As he looks to history to find out about the varying reasons for building labyrinths, one of his research results looks as follows:

Most famous of all, however, was the labyrinth Daedalus constructed for King Minos. It served as a prison. Purportedly located on the istand of Crete in the eity of Knossos, the maze was built to incarcerate the Minotaur, a creature born from an illicit encounter between the queen and a bull. As most school children learn, this monster devoured more than a dozen Athenian youths every few years before Theseus eventually slew it. (109-110)

Zampanò dedicates a considerable number of lines to develop his theory that King Minos did not build the labyrinth to imprison a monster but to conceal his deformed child. He even mentions his published book on the reading of Minos' maze as a trope for repression, which, in turn, inspired a playwright to write a play titled "The Minotaur." Nevertheless, everything on that topic is crossed out. For the story, this typographic experimentation may have different implications. Natalie Hamilton, for instance, reasons that

no labyrinth is complete without a Minotaur, and in keeping with its labyrinthine theme, House of Leaves features one. However, this beast is not corporeal. Within the hallway, it appears as darkness, nothingness. Within the text, all reference to the Minotaur appears under erasure ... It is almost as if there is no need for a physical beast, because each character has his or her own psychological demons with which to contend. (12)

Even though the idea of "crossing out" the Minotaur's corporeality is intriguing, the presence/absence dichotomy it conveys manifests itself primarily on the surface of the page. Having thoroughly elaborated the myth of the Minotaur, Zampanò then cancels his entire theory. In other words, he consciously represses the information that paradoxically remains highlighted in red color.

What further hints at a connection between the contamination of the novel's textual layout and the principle of the digital binary code of ones and zeros is the so-called Yggdrasil theme. On the very last page of the book, it says in vertical print: "Yggdrasil. What miracle is this? This giant tree. It stands ten thousand feet high But doesn't reach the ground. Still it stands. Its roots must hold the sky" (709). At first sight, the Yggdrasil as the so-called World Tree provides just another mythological viewpoint on the Navidson house. In general, the house on Ash Tree Lane lends itself to mythological readings, as Zampanò's numerous related excursuses 
suggest. Besides the Minotaur, there are, for example, lengthy passages on the significance and history of the Echo. The Yggdrasil, however, seems to be of particular significance for the understanding of the house and, according to Sebastian Huber, may even count as its “"mastermyth"” (129). Tellingly, the Yggdrasil is an ash tree whose roots reach across the world and whose dragon could be linked to the haunting growl that echoes through the house. The fundamental connection between the house and the tree is evident to a certain degree. As the maze in the hallway expands subterraneously, it may allegorize the rhizome of the Yggdrasil which would then signify the actual house of leaves. As Sebastian Huber's analysis proves, its mythological implications can of course be addressed in considerably greater depth. Most interestingly, however, Jessica Pressman points out that Yggdrasil was the name of an early version of the Linux Operating System. It smoothly fits into Pressman's thesis of the networked novel: "This subtle reference thus links a cultural myth explaining the universe as network to a computer operating system structuring our Internet culture" ("Reading" 122). The most relevant detail regarding the novel's encoded concept, in turn, is the fact that the short poem on the novel's last page is framed by two opposing "O" shapes at the top and bottom of the page. One is bold while the other is black. Pressman eloquently concludes: "The open O corresponds to the dark dot at the top of the page and represents opposing states - absence/presence, zeros/ones - the bits of patterned information that construct the digital world" (122).

Tellingly, the most striking deconstruction of text occurs during Zampanò's most ekphrastic passages. When Zampanò's narration focuses on the "live action" during Navidson and the Holloway team's various explorations, it downright orchestrates the materiality of the page. Danielewski utilizes the space of the page and typographic flexibility to mimic how the house transforms and how Navidson handles these spatial changes. For instance, to illustrate the ceiling's life-threatening motion, Danielewski isolates the statement "Sometimes the ceiling drops in on him" at the bottom of the page (427). Content and location interrelate to convey a sense of compression. Just as the ceiling would force Navidson to the ground, the bulk of the page's blankness has a similarly overwhelming effect on those seven words. Accordingly, the words "rising higher and higher" unfold diagonally up the page when the ceiling eventually lifts again (429). The destabilising power of the contaminating system even disregards the unity of the word and makes use of individual letters to arrive at some sort of concrete visualization. In some instances, fractured words span multiple, subsequent pages that are partly filled with only one letter. For example, as the mysterious staircase inside the hallway unexpectedly begins to stretch and thus exceed the length of Holloway's security rope, Danielewski decides that the rope "sn-a-ps" over the space of three pages (294-296). Just as the baffled Holloway team has 
to face a broken rope, the reader needs to handle a torn and scattered word. Another creative exploitation of the book's materiality is the ladder of words which is mirroring a ladder climbed by Navidson (440-441). Surrounded by white space, it horizontally bridges a double page as each rung materializes as a cluster of two short lines of text. In her study on the cognitive experience of reading House of Leaves, Alison Gibbons elaborates how the reader needs to adapt:

The ladder, its sequence of words and their spatial location, dictates the reading path that must be taken. Even when the book has been rotated, the apparent starting point is in its original top left corner. However, the physical revolution of the book forces a less familiar eye motion. The first three lines, each moving horizontally from left to right toward the next, create vectors that signal reading direction. (73)

Besides the recurrent use of foreign language and other idiosyncrasies, such spatial arrangements as the ladder considerably complicate the reading process, turning it into the challenge of decoding the individual pages. Reminiscent of concrete poetry, this concrete realization of text to provide "a better picture" of the hallway stands in striking opposition to the actual depictions in the appendix. The question is which visualization communicates the right ontology of the house, the one apparently referring to a real referent or the one created by smallest single components of language. Here, Roland Barthes' specific definition of photography mentioned in a previous chapter becomes crucial again. Unlike language, he states, photographs contain "a message without a code" (17). Given that House of Leaves evokes cinematic shots by (partial) actualization in which the arbitrary linguistic system plays a strikingly active, performative role, it must be concluded that the novel conveys a notion of photography that is no longer independent of codes. In a similar vein, Brianne Bilsky concludes from her analysis of Danielewski's typographic experimentation that "symbolic space-the space of interpretation — and physical space — the space of the page-become inseparable" (151). In other words, House of Leaves stages the convergence of code and image in the digital age - rendering Barthes' insistence on indexicality obsolete.

As mentioned earlier, the highly visual pages represent a certain contrast to the poor visual quality of the tape, as Zampanò describes it. In fact, the limited resolution, "ridiculous lighting" (418) and all in all "chaotic bits of tape" (346) even culminate in nearly six minutes of black screen time. For some of the quoted critics these "six minutes of nothing spelled the end of cinema" (468). The resulting question is evident: Why would anyone make the effort 
and take the cost of digital manipulation when the resulting film discloses hardly any images whatsoever? The fallacy in this context is to read the THE NAVIDSON RECORD and its alleged images as mimicked by the novel's typography. It is in the scope of its self-reflexive intermediality that the house's visualization is necessarily restricted to the pages of the book. Furthermore, this primary manifestation of THE NAVIDSON RECORD produces what can be referred to as literary special effects on their own behalf, turning the book page into comparatively "spectacular" scenery. In figurative terms, THE NAVIDSON RECORD (as an imagined film) cannot stand alone - it requires the book to provide the necessary code for the impossible space to emerge and become visible in the first place. In other words, if you want to see the movie, you have to read the book. In short, it aims beyond the visual surface towards the imperceptible and unreadable code - which in this case of being represented in literature becomes readable after all.

The irony of House of Leaves is that its entire enigma of the indexicality of THE NAVIDSON RECORD and the house on Ash Tree Lane is being resolved simply upon opening the book. Flipping it open does not only provide an insight into an elaborate piece of experimental literature but at the same time an insight into contemporary visual culture, that is based on a digitally encoded system rather than actual indexical references. House of Leaves renders the uncanny contamination of digital technology - and thus actual rupture entailed by the analog/digital shift - visible at first sight. In his theoretical reflections on intermediality, Werner Wolf comments on the unfortunate term contamination since it involves the possibility of a negative reading. ${ }^{63}$ Expressing his reservations, he obviously did not have in mind horror novels about the dawn of the digital age, such as House of Leaves, where this connotation is in fact not unwarranted.

\footnotetext{
${ }^{63}$ qtd. in Marcsek-Fuchs 139
} 


\section{In the Midst of the Post-Cinematic Age: Marisha Pessl's Night Film (2013)}

\subsection{Meant for Adaptation: Night Film and the Fallacy of First Impressions}

“Could Marisha Pessl's Night Film really be The New House of Leaves?" was one of the first questions Pessl's second novel, published in 2013, unsurprisingly prompted. ${ }^{64} 65$ The mere literary evocation of horror, mystery, and film might have already sufficed to induce House of Leaves' discursive presence. Pessl's almost 600-page read, however, warrants a comparison not only of kind but also degree. Just like House of Leaves, Night Film renders its author's cineliteracy palpable. Marisha Pessl's film education took place, for instance, at the New York Film Academy and manifested itself in the authorship of two feature-length screenplays, among others. Even though Pessl did not continue any career in film industry, her second book project can hardly be denied representing in some sense also a film project. With THE NAVIDSON RECORD, Mark Z. Danielewski already set an example of how literature can make film history. With (fictional character) Stanislas Cordova, Marisha Pessl puts a lot of effort into creating the image of a historical director of the calibre of Stanley Kubrik. She manufactures a considerable oeuvre of fifteen film titles along with fifteen movie posters and a trailer (available via app), a good deal of press coverage about Cordova (including the facsimile of a fictional Rolling Stone interview as one of the very rare occasions Cordova spoke for himself), and even an entire cult following of so-called Cordovites as well as its digital age manifestation in terms of an online fan forum. Pessl elevates Cordova to a cinematic legend and role model for actual filmmakers like Quentin Tarantino, for instance. Noteworthy in this context is Cordova's film THUMBSCREW, which revolves around married couple Brad and Emily Jackson and a fateful briefcase:

Brad's briefcase dominates the film so entirely - Emily becomes obsessed with it, desperate to steal it, break the locks, see what her husband was stowing inside - it was actually a main character, featured in more shots than Brad himself. Neither Emily nor the audience is ever allowed to see the inside, a narrative device Tarantino used in PULP FICTION fifteen years later. (443)

The image of THUMBSCREW's outstanding impact goes even further and includes receiving the Academy Award for Best Picture in 1980, in the alternate reality of Night Film, naturally.

\footnotetext{
${ }^{64}$ Marisha Pessl's debut novel Special Topics in Calamity Physics (2006) already brought her fame and credit as an author. Unlike Night Film, the story revolving around a father-daughter relationship does not feature any striking intermediality.

${ }^{65}$ See Scott Wampler's review.
} 
Interestingly, the actual Best Picture winner KRAMER VS. KRAMER by Robert Benton is also mentioned by the novel, yet merely as contender and prime candidate. To create, visualize, and substantiate Cordova's biographic and filmographic details, Pessl does not shrink from blending fictional and factual film history, and thus engaging with the readers' knowledge of the latter.

And still, the mentioned discursive presence of House of Leaves sets the bar high in many respects. It begs, for instance, the question, whether Pessl's carefully constructed, cinematically informed yet altered storyworld provides the right framework not only to make film history (in a figurative sense) but also to reflect on film history (in a literal and contemporary sense). Danielewski's narrator Zampanò is a former scholar who enriches his narration with a pseudo-academic, multi-layered discourse via footnotes and thus provides a highly critical approach to the medial phenomenon in question. Among her characters, Pessl does in fact introduce a film scholar named Wolfgang Beckman, but the level of abstraction he brings in is barely worth mentioning in comparison to Zampanò's. He comes in rather as a sort of sidekick for the novel's protagonist and first-person narrator, the investigative journalist Scott McGrath. Scott's investigation of Cordova is driven less by film-historical, let alone media-theoretical curiosity, and more by personal animosity, suspicion, and a journalist's quest for sensation. The striking discrepancy between Scott and Zampanò does not make the former a less valuable voice in the post-cinematic discourse. On the contrary, I would argue that it is precisely McGrath's naivety and unknowingness that makes his encounter with the contemporary, post-cinematic landscape a curious counterpart to House of Leaves.

For Scott, the case of Cordova has become a life obsession since his first attempt to make a startling revelation has failed miserably. It led to an awkward talk show incident which, in turn, ended in public disgrace, lawsuits, and probably Scott's divorce. Nevertheless, Cordova keeps preying on Scott's curious and now revengeful mind. The cult horror film director still intrigues the worn-out journalist in many respects: For one thing, there is the controversial character of his art. Cordova started his career in the 1960s with Hollywood productions but as his work became increasingly unsettling, studios cancelled the collaboration, and Cordova continued on his own as an independent filmmaker. He barricaded himself in his gigantic property, the so-called Peak, where he shot horror films considered to be among the most terrifying ever made. Cordova's viewers, including Scott, are overwhelmed with the films' authenticity and at the same time cannot resist their inscrutable appeal. "Cordova's films were addictive opiates," McGrath explains, "it was impossible to watch just one minute. One craved 
more and more" (188). The Cordovian cinema constitutes a mystery in terms of its reception as well. Rather than going to the theatre, the Cordovites gather underground, in catacombs, where they find the appropriate environment for Cordova's world of horror. In order to discuss his work afterwards they accordingly meet in the deep web, in a blacked-out forum called the Blackboards. What further adds to Scott's curiosity is that Cordova himself has not been seen in public for many years, and neither has he given any interviews. When on top of that Cordova's daughter, Ashley, is found dead at the outset of the novel, Scott is ultimately convinced that there are real bad things happening at the Peak. He decides to investigate Ashley's alleged suicide and accordingly the entire mystery of Cordova and his notorious cinema. He begins to search for clues virtually everywhere - in all kinds of documents, for example police files, press clips, notes, interview transcripts and a variety of online sources, ranging from tabloid websites to the Cordovites' deep-net secrets.

Besides Scott, the reader also comes across a variety of media in terms of facsimiles, illustrations and, what is more, the so-called Night Film Decoder App, which gives the reader access to bonus material and thus some more details about the Cordova world via sound, image, and more text. The book's multimedia character can be considered as both its signature feature and major source of controversy. It appears problematic especially in comparison to Pessl's alleged literary role models. Entertaining Night Film as a 2013 adaptation of House of Leaves, one could argue that Pessl has replaced Zampanò's lengthy academic interventions by the more colourful and promotional choice of visual and interactive elements. An even more radical comparison can be made between Cordova and James O. Incandenza, the fictional filmmaker from David Foster Wallace's novel Infinite Jest (1996), whose works also have paralyzing effects. His viewers, however, literally die from pleasure while watching INFINITE JEST, Incandenza's latest short film. They become actual victims and thus raise critical awareness of visual media's addictive and destructive power. Wallace's media criticism perfectly makes sense with regard to his pioneering role in the meta-discourse on visual culture - television and commercial-art culture in particular. His theories find expression in essays such as the influential "E Unibus Pluram: Television and U.S. Fiction" (1997). Ultimately, Infinite Jest, his longest piece of fiction, is said not only to express Wallace's concern but to realize it as well; the over 1000, multi-layered, and deeply complex pages of pure text are highly demanding, especially for the televisually conditioned eye of the reader. It is hardly a surprise that such a discursive context quickly disqualifies Night Film's comparatively image-heavy design. As Maggie Doherty in her review so aptly puts it: "A writer of winding sentences that demand the 
reader's careful attention, Wallace designed his novel in opposition to visual culture; Pessl designed her novel in imitation of it."

Apparently, it comes down to the question of both novels' intermedial motivation (and ambition). This is why, at first sight, Night Film "suffers" from a comparison to House of Leaves even though the latter features a certain degree of imagery as well. To be more precise, House of Leaves makes a more explicit case for intermedial rivalry or hierarchy. Danielewski places the detailed ekphrasis of a full-length feature film at the centre of his plot. Asking, however, what the main interest of House of Leaves is, film is not the only answer. The novel contains numerous explicitly metamedial moments, in which it raises awareness of its own bookishness, to speak with Jessica Pressman and Alexander Starre. One could thus argue that what is actually at stake in this film-focused novel, is the book and its promising future. This paradox is certainly part of the novel's praised complexity. Night Film, in turn, does not feature this kind of intermediality versus (explicit) metamediality, instead giving way to a full, intermedial evolvement of film. This impression is supported by the fact that Pessl has sold the film rights right after publication, unlike Danielewski who still refuses to give permission for a cinematic adaptation. This is what reaffirms some critics in their claim that Night Film has been written for the sole purpose of a rewarding filmic adaptation. ${ }^{66}$ The novel's apparent embracement of visual culture may fit into this line of argument as well. As if in anticipation of its theatrical adaptation, one could argue, the implied media plurality introduces the book already as only one of numerous possible manifestations of the Cordova world, but not necessarily the primary. The novel's partial visualization might be considered a means to loosen the book's media boundaries and thus invite a media transition. Once again, it is particularly the discursive presence of both House of Leaves and Infinite Jest that casts a shadow on Pessl's intermedial undertaking, its alleged abandonment of book culture, which is driven by a desire to play a part in visual culture.

However, I would propose to approach Night Film and its comparison to House of Leaves from a different angle. This angle complicates the intermedial reference to film as the major tertium comparationis and proceeds, instead, from two digital-age novels. In this context, it is crucial that McGrath's "Cordova story” has been published 13 years after Zampanò's THE NAVIDSON RECORD (Night Film xi). Both fictions engage with the digital age, but at different

\footnotetext{
${ }^{66}$ Tobias Döring, for example, writes: "Sehr viel häufiger hingegen gibt es Romane, die sich nach Verfilmung so offensichtlich sehnen wie ein Fisch nach Wasser. Solch ein Fall ist Die amerikanische Nacht von Marisha Pessl." ("There are, much more often, novels that crave for cinematic adaptation as evidently as fish for water. Such a case is Marisha Pessl's Night Film.")
} 
points of its progression. Published in 2000 and taking place in the 1990s, House of Leaves digs right into the ongoing analog/digital shift whereas Night Film is located at a more advanced point of the digital takeover of the cinematic landscape. As concluded in the preceding chapter, THE NAVIDSON RECORD with its pseudo-academic framework questions the new possibilities of digital manipulation and contemplates the threat of an ontological crisis. While House of Leaves is thus about processing a hardly visible and precarious transformation, Night Film proceeds from the omnipresent and scattered visibility of (digital) cinema today. When, as suggested in my first analysis, the gradual digitization of film follows Thomas Elsaesser's inside-out logic, House of Leaves and Night Film might be considered two sides of a continuum. This is what, in a sense, turns Night Film into the "new" House of Leaves, after all. In 2013, the digital age has come to the surface not only in terms of blockbusters promoting rather than concealing their CGI, but also in terms of an Internet culture that has become integral to everyday life and almost every form of media consumption.

Furthermore, it is important to point out that Night Film is in fact preoccupied with the visual power of the digital age, yet not necessarily in an enthusiastic sense. It introduces characters such as Scott McGrath and film scholar Wolfgang Beckman who have not yet acclimated to the prevalence of digital communication; let alone Cordova himself, who has chosen to disappear from the public sphere altogether. Their voices, or their telling silence respectively, draw the picture of a commercialized and, above all, overexposed world whose new media affect people's everyday life in an unprecedented way. From this viewpoint, a new light is shed also on the comparison between Night Film and Infinite Jest. Pessl's approach to digital culture is certainly less existential and complex than Wallace's approach to televisual culture. However, it should not be dismissed as nothing but an unfiltered and approving imitation of it. I would argue that Night Film represents an attempt at enacting rather than merely implying a critical investigation of the Cordova phenomenon, thus rendering it part of the reading experience. Throughout this investigation, Scott's rather naive and increasingly delusional, if not unreliable, viewpoint is repeatedly put into question.

At the outset of the novel, the Cordova phenomenon is introduced as a nostalgic, antagonistic response to the increasing prevalence of what Richard Grusin relates to as a thoroughly demystified "cinema of interaction" ("DVDs" 66). This response to an environment of blurred media boundaries manifests itself in the establishment of new boundaries. When Scott starts off his investigation, he has to face a number of obstacles: the secrecy of the underground screenings, his frustrating initial lack of access to the Blackboards, the well 
barricaded Peak, and so on. The mystery around Cordova is a question of surface versus underground, of boundaries, barriers and even fences - conveying, all in all, a sense of unavailability that runs counter to the logic of the digital age. It is intriguing as "the last hidden corner" (Night Film 50) in "our overexposed world" (xi), which defies the new media culture of DVD bonus material, making-ofs, behind-the-scenes, constant navigation and interactivity, small screens, and home theater availability, in short, total exposure and demystification. In other words, it tries to create a sense of back-to-the-cinema without actually going back to the theater (but to even darker places), responding to the overexposed world in terms of mysterious invisibility. Is the Cordova phenomenon thus a case of the reclusive relocation of the cinematic in response to its demystifying remediation?

Pessl's critique of the digital culture and the way it embeds cinema turns out to be more complicated than that. As the story proceeds, a number of story twists renders the boundaries around the Cordova cult permeable and thus its subversive character questionable. Scott's climactic journey through the Peak itself concludes in a twist that sheds new light on the actual authorship of the Cordova world and the dubious role its fans play. Proceeding from the assumption that digital also bespeaks a structure of feeling, one can say that the novel ends with a digital disillusion regarding the last hidden corner of cinema in the digital age, after all. In other words, Scott's encounter with the Cordova world ultimately leads to the re-blurring of media boundaries. Especially in retrospect, it thus comes down to the question whether we have been faced with Cordova's mysterious underworld or Cordova's diegetic transmedial world, which draws on the widespread nostalgia of cinephiles in a calculated way. In this case, Night Film's intermedial reference to film would be extended to the more paradoxical notion of an intermedial reference to a fictional transmedial world, which manifests itself inside the boundaries of the book. It is in this respect important to point out that the novel itself is not engaged in building an actual transmedial world. The mere inclusion of multiple media facsimiles and an app does not warrant speaking of an actual transmedial context. And still, it establishes a certain link between today's cinematic experience, which takes place across a variety of media, and the reading experience of Night Film. As mentioned, this analogy is largely interpreted and dismissed as a nonreflective imitation. Such a conclusion, however, falls short in regard to the identity crisis of cinema, that Night Film ultimately indicates by its digital disillusion. Therefore, my reading is about to show how the novel's imitation deliberately fails and thus encourages rather than discourages a critical awareness of the crucial line between reading and using different media for the sake of a fragmented cinematic experience. After all, it is precisely the print copy in question here that leads not necessarily to a smooth integration 
of the numerous visual and (one) interactive element(s), but on the contrary a downright clash. My line of argument complicates, if not reverses, some critics' first impression of the novel's craving for cinematic adaptation. What appears like an invitation of media fusion may turn out to be a particularly striking emphasis of the intermedial gap. It leads to the assumption that the intermedial relationship in Night Film must be all about a distinction between film and literature and their respective role in the digital age. Despite the lack of explicit metamediality, Night Film's intermediality would thus ultimately result in a curious case of media rivalry.

In sum, my introductory observations on Marisha Pessl's Night Film add up to the following thesis: Pessl introduces Cordova as an ambivalent phenomenon of the digital age, which oscillates between remediation and relocation of cinema, nostalgia for the traditional cinematic experience and the realization of a new (fan-driven) digital cinema of interactions. Whereas the protagonist's nostalgic encounters with film end up in a digital disillusion bespeaking the end of cinema (as we know it), the visualized yet imagined transmedial context triggers a reading experience that raises awareness of the book's media boundaries and even reinforces them. The new media and Internet culture monopolizes the Cordovian cinema while it remains an alien element in Night Film.

My intermedial analysis of Night Film shall begin with a discussion of the historical context in which the scope of cinema in the digital age goes beyond the question of digital manipulation and special effects. Therefore, the theoretical section on "The Post-Cinematic Reception of Film" deals with the multiple ways in which cinema is embedded in the new media environment and thus thoroughly remediated or relocated. As a consequence, different manifestations of nostalgia permeate the cinematic landscape, bespeak the alleged death of cinema and, what is more, warrant the reconsideration of a (retrospective) cinematic aura from today's digital viewpoint. I shall discuss how scholars and cinephiles bemoan a situation in which the feature film seems to gradually lose its status as primary narrative and the theater as primary site of reception. The increasing significance of home theaters, mobile screens, Videoon-Demand platforms, DVD special editions and entire transmedial worlds critically challenge the traditional cinematic experience and possibly its (retrospective) aura. Especially with regard to the challenge of finding words for Scott's encounter with the Cordova phenomenon, it makes sense to elaborate how these dynamics change and broaden the understanding of what a cinematic experience may comprise in the digital age. Besides Nicholas Rombes and Richard Grusin, I shall also draw on Italian film scholar Francesco Casetti, who suggests distinguishing between a transforming remediation and the mere relocation of cinema. 
This distinction turns out to be ambiguous in Pessl's storyworld revolving around Cordova, which shall be examined in the two subsequent sections. I shall begin with the attempt to spell out and detail the status quo of the world of Cordova, as it is introduced at the outset of the novel. As mentioned, the Cordovian cinema seems to satisfy nostalgia for what is not "glossy and commercialized" in the digital age (Night Film 169). Its denial of remediation seems to verge on a radical and preserving relocation of an idea of cinema that is determined by an aura of restricted availability, isolation and blacked-out spaces. To describe Cordova's Underworld, as it were, means to describe Scott's initial encounter with boundaries, fences, and barriers of all sorts.

Scott burrows deeper and deeper into this world whereby his motivation oscillates between curiosity, desire for revenge, and cinephilic nostalgia for genuine cinematic immersion. His overall unreliability as a narrator plays a decisive role in that it encourages a more critical approach to the motivation behind the world of Cordova. If not Scott himself, then the readers may recognize the irony of a world that is located underground rather than at the surface of the new media environment, and yet is conveyed to them mainly via facsimiles of quite informative websites. This is what warrants a second glance at the Cordova phenomenon and thus the section on "The Digital Disillusion: Cordova's Transmedial World." It sheds light on the story twists and the eye-opening denouement that in retrospect turns Scott into both consumer and participant of a particularly ambiguous instance of transmedial world-building. In the course of my explicit reconsideration of the world of Cordova (and its ultimately revealed transmediality), I shall draw on Dan Hassler-Forest's discussion of the frequently deceptive character of fan-driven transmedial worlds. The objective of this first part of my intermedial analysis is to get to the bottom of the novel's intermedial conclusion regarding the fate of cinema in the digital age.

The second part, "Reading Marisha Pessl's Night Film: A Reconsideration of the Intermedial Gap," concerns the novel's intermedial implications with regard to the fate of literature in the digital age. It proceeds from the comparison between a fictional version of a cinematic experience and the actual instance of a reading experience under the auspices of the digital age. It entails a close examination of the way the various visual and interactive elements are embedded in the novel. Once again, I shall draw on Irina Rajewsky's theoretical observations on intermediality in literature, and in particular her emphasis on the restrictive intermedial gap inherent to this sort of illusion. In this context, Night Film can be considered an intermedial experiment because it constantly renegotiates its gap to the contacted medium 
and thus the as-if quality of its intermedial references. The intermedial gap emerges not as a corollary of intermedial references but is endowed with decisive agency. Against the backdrop of a highly scattered and blurred cinematic experience, Night Film allows to discuss the intermedial gap as a virtue rather than a deficiency of reading (literature) in the digital age. Given the fallacy of first impressions, the novel thus turns out to be more thought-provoking than some critics might initially expect. In fact, it opens rather than denies the discussion on the endurance and authority of literature in the new media environment.

\subsection{The Post-Cinematic Reception of Film}

The digital remediation of cinema has profoundly affected how, when and also where we watch the art of cinema. Complex media developments do not challenge only the theater as the primary venue in which films are consumed but also the feature film as the main focus of attention regarding the rich possibilities of viewer and user activity. Is cinema dying due to the blurred media boundaries or is it thriving across media boundaries? Is it thoroughly remediated or merely relocated? Assuming that Night Film can be read as a response to this contemporary, multi-faceted, and ambiguous situation of film reception I shall begin the analysis by thoroughly describing and discussing the latter.

While in earlier periods of cinematic production new films were advertised as "coming soon to a theatre near you," nowadays they are rather "coming soon to everyone, everywhere" (Davis, R. 73). The much-anticipated, almost magical moments of theatrical releases are dulled by shortly following DVD releases and the continuously improving quality of home viewing. Robert E. Davis even speaks of the possibility of "the instantaneous worldwide release" making movies simultaneously available in theaters and homes, at video stores and retail outlets (76). In 2006, Davis claimed that "it may not be long before anyone who wants to see a movie on opening day can do so in a variety of ways," and in the meantime he has been proven right. In October 2015, the subscription video on demand (SVOD) service Netflix took a decisive yet controversial step toward a new distribution model for motion pictures. The fictional feature BEASTS OF NO NATION premiered online simultaneously with its theatrical release - which, as a consequence, was considerably limited. Being denied the traditional 90-day release window of exclusivity, four of the largest theater chains in the United States, including AMC Cinemas, Carmike Cinemas, Cinemark, and Regal Entertainment Group, decided to boycott the film and grant distribution only to smaller and independent houses. Outside the US and UK, BEASTS OF 
No NATION was accepted by no other distribution company. In general, establishing such a release strategy in Germany, for example, would be far more unlikely since a six-month release window is still anchored in the German Film Law ("Filmförderungsgesetz FFG"). ${ }^{67}$ Nevertheless, The New York Times considered the Netflix release "something of a milestone in the continued collapse of the already rickety distinction between movies made to be shown in theaters and those destined for online streaming" (Scott).

A typical destination for this erosion is the so-called home theater, which conjures up a convergence of spaces. While, on the one hand, screens considerably shrink in order to adjust to the viewer's permanent mobility, there is also the opposite tendency, namely home entertainment hubs and digital living rooms transforming walls into screens (cf. Chambers). As the trendy term home theater implies, home entertainment business tries to simulate the theatrical experience. Given, however, that digital projection is nothing more than highdefinition video, it appears more accurate to reverse the seemingly obvious hierarchy and speak of cinema as "big-screen television" (Rodowick 109). Cinema is no longer cinema as we knew it in the twentieth century, as it gradually disappears in the programmatic indistinction of convergence culture. In a critical approach to the contemporary media landscape, Thomas Elsaesser raises the question of the thin line between convergence and divergence. In some sense, he argues, the distinction between film and cinema has become "metaphoric" as both media histories may have reached the point at which their division along the lines of product and service has become obsolete ("Digital Cinema" 26). Moving away from a preoccupation with "rupture" and "epistemic breaks", the logic of convergence culture raises awareness of the contact zone, different manifestations of contagion and liminality (24). But Elsaesser also suggests being careful about jumping to conclusions with regard to rather complex layers and dynamics at work. He warns us not to forget about the marketing ploy behind the convergence thesis, which nurtures "the hype that has surrounded digitally based devices as they tried to transform themselves into mass consumption commodities" (20). To speak all too enthusiastically of an all-pervasive convergence culture happens at the risk of missing out on both still existing and newly evolving power relations between media and of overlooking the autonomy of technical advances due to their simultaneity. Elsaesser also raises awareness of cinema as an institution that is as usual business and thus "business as usual" (29). At least on the surface, he indicates, the cinema experience has not considerably diverged from its origin, as it still involves queuing at the box office, sitting in the dark among strangers, and watching

${ }^{67}$ see Drewes 69 
a 90-to-150-minute feature film. This would, however, hardly be the opinion of a cinephile, as Elsaesser admits and underlines. Looking behind the scenes and realizing that the apparent fictional live-action on the screen may as well have been fabricated inside a computer, "it is possible to claim that such a performance is no longer "cinema"' (26). In turn, streaming a new release on high definition at home and marvelling at "the convenience, richness, and sensuousness of the experience" may warrant speaking of the digital living room as already cinema. Ultimately a matter of "whom one asks," contemporary cinema means both that "nothing has changed and that everything has changed" (26).

As the terminological dilemma seems unlikely, if not impossible, to be solved, Elsaesser looks for a compromise to grasp what I would describe as the partly divergent character of the general convergence in the digital age. What he thus terms "bi-vergence" features, in terms of screens for example, parallel developments but in opposite directions, such as larger/smaller or fixed/mobile (21). When it comes to the big screen in the theater and the ever-growing screens at home, in turn, the domestic/public variable is worth considering regarding the respective “"experience economies." In comparison to the multitude of small and mobile occasions of movie watching, the large, fixed and comparatively isolated cinema offers considerably less sources of distraction. But the question of immersion and contemplation becomes more intriguing when the theater is compared to its domestic counterpart, the home theater. On the one hand, one can easily entertain the notion of a virtually empty cinema auditorium, while at the same time a group of potential moviegoers gathers at somebody's living room to watch a recently released movie. Unlike the cinema, on the other hand, the home theater can guarantee ultimate privacy and isolation and lends itself to be visited alone on purpose. It can serve to avoid the social situation of sitting among strangers and being possibly distracted or otherwise influenced. It is hardly surprising that home entertainment has overtaken cinema in terms of popularity and economic relevance (see Sickels 144). Is the image of a spectator sitting in front of her big, possibly curved screen not the very epitome of immersion? The question that arises in the digital living room, however, is whether the viewer is immersed in the movie or in the interaction offered by the respective DVD or Blu-ray. Staying on the couch, contemporary audiences have not just sacrificed quality for convenience, but for interactivity as well. The focus no longer lies on watching a movie in a darkened space, but on managing, controlling, and adapting the viewing experience in a domestic or other social space.

Rombes aptly describes how fundamentally this newly mobilized spectator transforms film consumption. In his broad definition of interactivity, a new, three-layered logic of editing 
is to be applied (see Cinema 45-54): The first level of editing has already occurred during the production and post-production of the film and basically denotes its professional montage (shots, dissolvees, cuts, and so forth). The second phase of editing is done by the viewer through the interface and involves fast-forwarding, reversing, skipping, freezing the frame or selecting alternate versions among the rich DVD bonus material. Lastly, editing may also concern the mobility of the small tablet or smartphone screen, its framing by different environments and contexts. What Rombes juxtaposes in his theory are ultimately two extremes of a continuum. While the third form of editing may produce something of an occasional onlooker, the second phase of editing may cultivate an obsessive examiner. While the onlooker's viewing experience is fragmented and elliptical, the examiner's experience is fragmented too, though not due to distraction but in favor of his or her attention to detail. While the former tends to scan, the latter tends to dissect in pursuit of additional information.

The film industry has already begun to respond to and foster this viewer's desire for exclusive knowledge. Next to the classic add-ons ranging from outtakes over featurettes to deleted scenes, there are also particularly sophisticated and cleverly interactive design schemes. The black humor hallmarking James Wong's fantasy horror FinAL DESTINATION (2000), for instance, cunningly recurs in the DVD release as a special feature. It engages the viewer in a so-called Death Clock Game which calculates how long s/he will live and thus conjures up a sense of being haunted by death, which is anchored in the film plot. In a similar vein, the producers have made an interesting choice to include alternate endings into the bonus material of the second sequel, FinAL DESTINATION 3 (2006), DVD. In a movie franchise that is all about the inevitability and fatefulness of deadly endings such a feature appears particularly meaningful and deconstructive. Examples such as FinAL DESTINATION show that the boundary between film and supplementary material blurs and thus adds to the status of the DVD. In a similar vein, the so-called Easter Eggs, while already integral to the cinematic release, seem to be destined for the flexible viewing experience provided by DVDs and Blu-rays. Easter Eggs are hidden messages, clues, or intertextual elements, which the spectator (or rather cult fan) must "find" via close examination - probably upon comfortably reversing or freezing the film. In some cases, they can be "earned" by playing games specifically designed into the DVD. Rather a standard feature of DVD and Blu-ray designs is the option to divide the film into chapters and thus to watch it in a non-linear fashion.

In case of Christpher Nolan's backwards narrated MEMENTO, however, the very restoration of linearity becomes the DVD's pivotal “hidden feature." In a sense, MEMENTO's 
DVD release complements the preceding cinematic release in that it provides a possibly muchanticipated solution to a riddle behind a highly sophisticated narrative device. As it is optional, it does not necessarily spoil initial viewing but allows the ambitious examiner to reconstruct the diegetic chronology. This reversal of the film's most characteristic gimmick, the subversion of its complex storytelling, is quite a literal example for what Rombes relates to as the increasing demystification of film. He speaks of "the interface level, where the film's aura is not enhanced, but reduced, by the bonus and supplementary features that reveal the secrets of its making" (Cinema 62). Making-of documentaries uncover the employment of special effects and the necessity of stunt men; behind-the-scenes sections allow the viewer to rewatch crucial scenes from a fly-on-the-wall perspective; in interviews, the film crew tells anecdotes about the working climate on set and explains how much time, effort and passion went into making the movie; the director commentary reveals unexpected narrative metaphors; and there might even be footage of the real-life hero who inspired the screenplay (given that the film is based on true events, of course). Do these supplementary narratives possibly subvert, if not overshadow, the actual feature film in question ${ }^{68}$ Is the latter's status as the primary narrative thus threatened? Rombes further elaborates: "The reason there are so many supplementary features on DVDs is because in peeling away the narrative layers of the 'feature' film, what is revealed is a more compelling story than the one told by the film itself" (69). He further points out that the story may not only be superseded but substantially transformed as a consequence. After all, the trend of meta-reflection already manifests itself in an increasing self-awareness of filmic works, when for example the later SCREAM sequels anticipate their own demystification by discussing the rules of the teen horror genre. "There are no secrets left for movies to confess, so they confess to having no secrets," Rombes concludes (76).

At the same time, interfacial demystification exceeds far beyond the boundaries of DVD or Blu-ray menus, as contemporary cinema "ends up piecemeal ... on the internet" (24) primarily on YouTube in a variety of compilations, commentaries, parodies, and animated web series. One of the most striking examples is the weekly "Honest Trailers" show - one of the three shows of the high-ranked and widely subscribed YouTube channel Screen Junkies. The parodically honest trailer intends to unmask the true quality of the respective movie and

\footnotetext{
${ }^{68}$ The so-called feature film is generally understood to mean "a full-length film intended for theatrical exhibition, usually as the main item of a cinema programme ... The use of the term feature film remains as a way of differentiating between a longer film that constitutes the main attraction and other elements of a programme, such as newsreels, serials, cartoons, trailers, advertisements, and so on" (Kuhn and Westwell 155). One can assume that the hierarchy indicated here does not only apply to the feature film and the rest of the theatrical experience, but also to the feature film and the rest of the DVD or Blu-ray material. In the following lines, however, I shall discuss the question whether in the latter case this hierarchy is being reversed.
} 
accordingly the false promises made by its original trailer. By devoting one special episode to "The Making of Honest Trailers," the producers employed the self-ironic gimmick of demystifying their very own demystifying practices. ${ }^{69}$ Another example of what Rombes means when he claims that "films today come with a ready-made demystification apparatus" is the potpourri of online fan forums unfolding around such movie franchises as the one originating from AliEN (10/40/70 2). This is the place where fans devote their energy to closing any narrative or aesthetic gap possibly produced by the most recent film release. The monster antagonist's complex biology can be named as a typical subject of passionate, years-long discussions, which, as one might conclude, have become the franchise's actual appeal.

Another related context in which the feature film's status as the primary text is questioned would be the rising popularity of transmedial worlds, which basically define the manifestation of fictional worlds across different media forms. World building in this case does not occur in exclusively diegetic terms. Instead, these "abstract content systems" also comprise nonnarrative elements such as fan activities, merchandising articles, or theme parks (Klastrup and Tosca). Transmediality is naturally not an entirely new phenomenon, but the digital revolution and its new reproducibility have significantly accelerated and interlinked processes of production, consumption and reception and thus improved the conditions for such media phenomena to grow. Crucial to both the inception and growth of such worlds are increasingly sophisticated strategies of transmedia(l) storytelling. The stories that develop throughout different media can either be unplanned, spontaneous, and viewer-driven (transmedial) or preconceived, rather professional, and producer-driven (transmedia). ${ }^{70}$ Especially the latter form of transmedia storytelling "from scratch" has thrived in the recent decades of digitization. ThE MATRIX and the earlier mentioned BLAIR WITCH PROJECT count as strikingly successful instances of this sort of overarching narration, which included comics, books, posters, YouTube videos, and websites. In his seminal work Convergence Culture, Henry Jenkins pointed out the terminological adequacy when speaking of projects. After all, "to think of The Blair Witch Project as a film was to miss the bigger picture" (103).

Paradoxically, it is precisely against the backdrop of highly dynamic transmedial worlds that feature films may also surface as the dominant “"mother ship,' the primary work which anchors the franchise," even when they were originally not (Jenkins, "Revenge"). ${ }^{71}$ What is

\footnotetext{
${ }^{69}$ Huy Mai. "The Making of Honest Trailers." Online video clip. YouTube.

${ }^{70}$ See Gabriel/Kazur/Matuszkiewicz, "Reconsidering Transmedia(l) Worlds" for further details on this distinction.

${ }^{71}$ In other cases, transmedial worlds grow in aesthetic and design correspondence to films even if the actual source medium is a novel. Take George R.R. Martin's A Song of Ice and Fire novel series that is more commonly known and referred to as Game of Thrones due to the successful TV series adaptation, or the Harry Potter world, whose
} 
more, there are numerous, widespread transmedial worlds that recurrently climax in major cinematic events, for example, much anticipated sequels or prequels. At the same time, it is particularly in light of such major transmedia projects that going to the movies can hardly be considered as the complete experience of a film. Here, again the ALIEN saga serves as a good example. In 2012, when Ridley Scott's Prometheus was about to come to theaters as the climactic prequel of a 22-year old franchise, fans did not have to wait for the magical release date to enter the storyworld. They could learn about the upcoming space mission on pseudoauthentic company websites and even listen to one of the fictional characters giving a TED talk. Concerning "Project Prometheus," the feature film might indeed have been the primary text, but within a larger context of reception. And one can even imagine that the movie itself quickly loses its charm once it ends and the spectators cannot wait to share their opinion on message boards or, even better, fashion and improve the story on one of the numerous fan fiction boards available.

Shortened release windows, instantaneous worldwide releases, home theaters, DVDs as primary texts, transmedial projects - all these aspects constitute transitional moments in the history of cinema. One the one hand, the theater is possibly the last place where film as work of art can be truly experienced, rather than being ripped off its narrative layers for the sake of greater clarity. On the other hand, its seamless embedment in this oversaturated media environment does not only challenge the status of going to the movies. It raises questions of media specificity and media boundaries. The question is how to grasp this multitude of contemporary cinematic experiences in theoretical or terminological terms. What definitions of mediality apply? Referring to Bolter and Grusin, one can say that the digital media gradually remediate the distinct social context and architectural space of the cinema. The resulting postcinematic liminality can be approached either with a focus on the continuities or disjunctures between the analog and digital age of film reception. ${ }^{72}$

What gradually manifests itself with the ongoing remediation of cinema, is according to Grusin the digital cinema of interactions. Grusin reflects on the constitutive relevance of the Internet for the contemporary cinematic experience, assuming that

merchandise is entirely based on the cinematic adaptations of the novels and the omnipresence of actor Daniel Radcliffe.

${ }^{72}$ In the preceding pages, I have pointed out how today's film reception oscillates between the continuity of the traditional theatrical experience (because it is as usual business and thus business as usual) and its profound digital update. 
the Internet or film should be understood as networks or systems of technologies, practices, and social formations that are generally stable for the most part, but that in the process of circulation and exchange tend to fluctuate or perhaps overlap at various nodes or crossings. ("DVDs" 72-73).

He aptly speaks of an "analogous perceptual continuum" between the theatrical screening of a motion picture and its multiple digital remediations, including websites, video games, and DVDs (70). This continuum marks a fundamental change in the aesthetic status of the cinematic artifact and is best illustrated by the crucial empowerment of the home entertainment industry. Grusin further points out the obsolescence of thinking of DVD releases as second-order distribution phenomena with the sole purpose of circulating the original film:

Today the production, design, and distribution of DVD versions of feature films are part of the original contractual (and thus artistic) intention of these films. Consequently, it is now customarily the case that the conceptualization of the DVD precedes the commencement of production of the film itself; indeed, in some cases production of the DVD begins even before the production of the film (as was reported to be true of Spielberg's Minority Report). (71)

No longer a mere afterthought to theatrical releases, the DVD production becomes increasingly interchangeable with film production and thus affects the creative process from scratch. Rather than a distinctively new medium, as Grusin underlines, the cinema of interactions is a scattered form of cinema that does not end with the closing credits, and thus questions medial boundaries per se.

Despite its proceeding remediation, cinema, as D.N. Rodowick points out, still persists as a narrative form and psychological experience. "Film is dead. Long live cinema!" reads his diagnosis, suggesting that while film has disappeared in a phenomenological sense (of the film strip), cinema is alive and possibly even more than ever before - "alive" being quite an adequate description given the dynamic and interactive character of contemporary cinema conceptualized by Grusin.

Francesco Casetti has also discussed whether and how the cinematic continues. Concluding from Casetti's description of domestic and urban spaces being cinematically permeated, his reasoning seems to depart from the 'analogous perceptual continuum' described above. Rather than speaking of remediation or a new cinema of interactions, he introduces the notion of the "relocation" of cinema to refer to "the process thanks to which a media experience 
is reactivated and repurposed elsewhere than the place in which it was formed" (581-2). According to Casetti, his focus on the experience of cinema and its extensions significantly exceeds the concept of remediation, since it concerns the new/old media relationship in terms of reabsorption or remodelling only. "In remediation, what matters is the presence of a device and the possibility of refiguring it," he argues, whereas relocation underscores the role of experience, the specific type of watching, listening, attention, and sensibility associated with cinema (582). This juxtaposition seems not entirely accurate to me, as remediation does in fact raise the question of the cinematic experience and its increasing immediacy or hypermediacy.

I would argue that both concepts overlap considerably. Nevertheless, relocation is a productive term in that it highlights not necessarily just the transformation (which may result in the unrecognizability) of the medium but its migration as well as the relative continuity of the cinematic experience. Casetti might be bothered by the top-down approach that the concept of remediation seems to encourage. With relocation he insists on the importance of a bottomup perspective. In attempt to understand the transformation of the new media landscape, Casetti thus departs from cinema as he knows it and its relocation as "almost the same" (581). Almost, however, can have two opposed meanings. Not at all does the new spectator's lack of isolation and "multitasking form of attention" seem to resemble the traditional experience in question (585). In this case, the new conditions of movie watching rather lead to a "cinema-beyondcinema" experience. A "back-to-the-cinema" experience is what evolves when almost is understood to mean nearly completely instead of not at all. After all,

these same spectators succeed in isolating themselves in an environment, in recuperating the magnificence of images, in concentrating on a story, and in enjoying the reality that reappears on these new screens. (585)

Drawing the line in such a multi-layered media landscape and deciding what is still or no longer cinema can be quite a challenging undertaking, as Niel Niessen accentuates in "Lives of Cinema: Against its 'Death." In response to the question where cinema begins and ends, he gives an answer that is provocatively open-ended:

Does this mean that so-called 'high production value' television series are somehow part of cinema? Does this mean that YouTube clips can potentially be cinematic? Indeed, why not? If television films are not considered cinematic then why are festival films that have never received a theatrical release? Do television series not create a communal moving image experience that is similar to the experience particular to a film screening? And does not the fact that a cinematic 
institute such as Cahiers du cinéma has deemed the US television series The Sopranos and Mad Men worthy of discussion make them at least somewhat cinematic? (176)

Niessen's demonstration of how far notions of the cinematic may be and actually are being stretched against all odds is intriguing. However random and provocative this set of questions may appear, it is not simply aimed at deeming cinema an umbrella term, meaning all and nothing at once. Let us, for example, take a look at Niessen's mention of Mad Men and The Sopranos, or in other words, the new US-American quality television. When it comes specifically to Mad Men, cinematographer Phil Abraham worked with Matthew Weiner to create a "somewhat mannered classical visual style that is influenced by cinema more than TV" (Sprengler 238). Its "visual vocabulary" is marked by the 1960s cinema to the point of shooting on $35 \mathrm{~mm}$ Kodak film. But when it comes to the new US-American quality television in general, Niessen possibly had in mind a more literal relocation of cinema. After all, more and more critically acclaimed filmmakers, who already look back on cinematic careers, are being lured to TV with the promise of more creative freedom. Names like David Fincher (House of Cards), Guillermo del Toro (The Strain), Steven Soderbergh (The Knick) and Martin Scorsese (Boardwalk Empire) all stand for this development. One of the first pioneering examples of this contemporary bond between cinema and TV has been Cary Fukunaga directing True Detective. Its producer Richard Brown points out that "TV is made fast, but often lacks the tools of cinema. With True Detective we wanted to bring more cinema into TV - to find the sweet spot between film and TV" (Helmore).

What is more, cinema does not only reappear in terms of visual style, but in terms of content as well. A considerable number of contemporary series adapts stories widely known from the big screen: Bates Motel (2013), which can be considered a prequel to Alfred Hitchcock's PsYCHO (1960), Fargo (2014), which is based on Joel and Ethan Coen's Oscarwinning film FARGO (1996), and Scream (2015) as an adaptation of Wes Craven's cult franchise, which lured so many spectators into the fittingly darkened movie theatres. From a top-down perspective, one could also argue that these series become part of and extend the respective, film-centred transmedial world. Regarding all these aspects, Niessen's mention of cinema in relation to contemporary TV series does not appear that far-fetched anymore.

And yet, is not the very practice of searching for remaining traces of the cinematic symptomatic for its crisis rather than its smooth continuity? From this viewpoint, Niessen's virtual hyper-awareness of back-to-the-cinema-experiences carries a somewhat desperate 
overtone, even though in many cases it is not necessarily unwarranted. Are we facing media phenomena that merely relocate cinema or that take place beyond cinema, being already too thoroughly remediated? Casetti acknowledges that the response to this question must be "wholly ambiguous, a bit like the images that depict a duck and a rabbit at the same time" (587). Ambiguous, however, is not only the remediation/relocation distinction. The scope of relocation alone may already comprise very contradictory manifestations. In this context, I would like to point to less progressive instances of relocation, which proceed not from the continuity but the disjuncture between the analog and digital age. As a consequence, they produce literal and thus nostalgic back-to-the-cinema-experiences. This kind of relocation is not an alternative to remediation and Grusin's new digital cinema but a radical response to it, a way to lament the alleged death of cinema. Only recently, the contemporary recreation of past cinematic periods has reached another climax with Quentin Tarantino's THE HATEFUL EIGHT, released in December 2015. A limited number of theaters around the globe was capable of releasing the western in its original, particularly rare, and nostalgic Ultra Panavision $70 \mathrm{~mm}$ format. What is more, these theaters, including the ArcLight Hollywood and the Zoo Palast in Berlin, were authorised with the accompanying special event of the so-called Roadshow dating back to the 1950s and 60s. Roadshow releases preceded general releases and typically provided a longer film version, an introductory overture, an intermission, and a souvenir program. Tarantino would rather restore a long-obsolete practice and thus the event character of moviegoing than leave it on the threshold to other forms of media consumption. ${ }^{73}$ In fact, one could say that THE HATEFUL EIGHT with its inviting Roadshow relocates the reception of film back to the cinema.

Tarantino does not try to circumvent the alleged death of cinema, the postulation of which would be premature anyway. The nostalgia such projects as THE HATEFUL EIGHT propel is not for cinema per se, but its allegedly lost aura. To mention aura in the context of contemporary cinephilia in light of the digitization of film appears ironic. After all, it was in the cinematic auditorium where according to Walter Benjamin the ultimate loss of the aura has taken place (in explicit contradistinction to the stage theatre that was bound to a specific time

\footnotetext{
${ }^{73}$ As a popular advocate of the traditional cinematic experience, Quentin Tarantino has declared the death of cinema at the press conference of the 2014 Cannes Festival: "The fact that most films now are not presented in 35 $\mathrm{mm}$ means that the war is lost. Digital projections, that's just television in public. And apparently the whole world is OK with television in public, but what I knew as cinema is dead" (see Festival de Cannes (Officiel). "Cannes 2014 - Quentin Tarantino: The Press Conference.” YouTube.). Tarantino's clear preference for 35mm film has little to do with an aversion to digital manipulation. His nostalgia is not for the indexical capture of the profilmic on the material film reel. It is for the classical cinematic experience that shall be sacred and not confused or combined with other media or forms of reception.
} 
and space). In his seminal The Work of Art in the Age of Its Technological Reproducibility, Benjamin describes aura as "the here and now of the work of art - its unique existence in a particular place" $(21) .{ }^{74}$ Further important characteristics are the traces of time, tradition, and ownership: "It is this unique existence - and nothing else - that bears the mark of the history to which the work has been subject." When Benjamin claims that the advent of film and other revolutionary means of reproduction led to a decay of the aura, he articulates one of the foundations of media theory.

In the cinema, this decay is also a question of the changing idiosyncrasies of reception. The "shock effect" of cinema prevents the audience from auratic contemplation (41). The image changes or "moves" before the viewer had the chance to develop a thought. Discussing the rapid succession of images inherent to cinema, Benjamin writes that "the train of associations in the person contemplating it is immediately interrupted by new images" (53). Unlike a painting, which allows the viewers' eye to settle, giving them the time to process the external stimulation, a film is all violent change and movement.

In light of today's digitization, however, media theorists feel the urge to reconsider this ultimate loss in retrospect. Has the advent of mechanical reproduction already concluded the destruction of the aura or can it be considered the mere starting point of a century-long process of decay? After all, reproducibility has only recently reached an unprecedented dimension. While in the analog age, it was still possible to speak of "master" and "copy," the digital age seems to conclude the collapse of this distinction. "In one sense, Walter Benjamin's proclamation of doom for the aura of originality, authored early in this century, is finally confirmed by these events," Douglas Davis concludes in his essay "The Work of Art in the Age of Digital Reproduction." "In another sense," he adds, "the aura, supple and elastic, has stretched far beyond the boundaries of Benjamin's prophecy into the rich realm of reproduction itself" (381). What Davis suggests here is that aura may be grasped as a gradual concept. What if Benjamin's distracted examiner had to face the two additional layers of montage introduced by the digital age (and described by Rombes above)? Is the return to the enclosed and darkened space of the theater in this case not a return to the (relative) aura of cinema?

\footnotetext{
${ }^{74}$ While The Work of Art offers Benjamin's most influential discussion of aura, the term also plays a significant role in his essays "On Some Motifs in Baudelaire" and "The Short History of Photography," both written in the 1930s as well.
} 
In their essay, "New Media and the Permanent Crisis of Aura," Bolter et al. extend on this kind of reasoning, as they try to show how traditional media theory can be made fruitful for the analysis of contemporary media practices (see 21). They argue:

Benjamin was wrong if he thought audiences and producers would accept a final and irrevocable loss of aura in their popular media forms. What Benjamin identified was not the end of aura, but rather an ongoing crisis, in which the experience of aura is alternately called into question and reaffirmed. (22)

One of the golden threads of Bolter et al.'s discussion is that our culture's pursuit of aura is comparable, if not identical with our culture's pursuit of immediacy, which Benjamin simply did not connect to cinema. In fact, Benjamin anticipated the development of cinema as an art form with an unprecedented political potential. Bolter et al. argue that this reflective and thus hypermediated film genre has not dominated cinema to the extent expected by Benjamin. Instead, the Hollywood style with its aim for immediacy turned film editing into a question of continuity rather than shock:

First, the representational practice of the Hollywood style aims to evoke in the viewer a sense of immediacy, not the reflective attitude that Benjamin ascribes to film. Once a viewer becomes accustomed to continuity editing, the edits disappear from her conscious perception of a film. As the name ('continuity editing') suggests, the visual presentation that is in fact discrete comes to be felt as continuous, and the viewer experiences the shifting point of view as 'natural.'

Bolter et al. certainly make a valid point when claiming that our viewing habits have changed dramatically since the 1930s. In terms of a critical reflection of Benjamin's aura, it is, however, not entirely convincing. One could argue, for example, that it is precisely our internalization of continuity editing that warrants Benjamin's larger claim that film has not only affected our reception, but profoundly transformed our perception. What is more, Benjamin identifies cinema's political potential not necessarily in terms of the shock effect. According to Benjamin, cinema manifests itself as an instrument of political mobilization in that it liberates the work of art from ritual and addresses a mass audience rather than an individual. Bolter et al.'s approach is certainly a worthwhile read as it glosses the range of meanings that aura acquires in Benjamin's theory, including its ambiguities and complexities. But to search for Benjamin's aura in cinema, even retrospectively, must turn out to be futile, as well as the effort to interpret it as a gradual concept. And this is also the case in the matter of analog versus digital 
reproducibility. The loss of Benjamin's aura is not a question of the excess or quality of the art work's reproduction but applies to the "work designed for reproducibility" (Benjamin, The Work of Art 24; emphasis added).

Nicholas Rombes has also discussed the cinephile's alleged reluctance to accept the enclosed and darkened space of the theater as the site of the aura's ultimate loss rather than the site of its last haven in the digital age. "The migration of movies from theatre screens to television in the 1960s (and then to mobile screens in the decades since) has eroded their mythic aura" (10/40/70 2). His approach, however, is based on the effort to define a notion of aura that can be applied to "the rich realm of reproduction itself" (Davis 381). At the moment of its supposed decay, "the 'imprisonment' of the passive spectator ... in the dark confines of the theatre" turns into a subject of nostalgia (65). What is charged with a retrospective aura is thus, according to Rombes, the once ambiguously connoted immobility of the spectator and the experience of being "in the work" end-to-end. ${ }^{75} \mathrm{He}$ further outlines:

If part of the aura of film was its fleetingness, the impossible-to-stop movement of images across the screen, the ways in which the audience remembered and mis-remembered certain moments, and the general availability of film which meant that, if you missed seeing it on the big screen then you might never have the opportunity to see it, then this aura has vanished. (10/40/70 2)

As mentioned, Rombes' aura has vanished due to the demystification of film: be it the pause button of the VHS, the advent of digital platforms or film analyses on YouTube - today, viewers have unprecedented access not only to movies, but their still frames and background details as well.

So, we cannot simply deconstruct Benjamin's theory in order to relate to today's pursuit of aura. But can we simply surpass his leading definition, pretending to never have heard of it? Before concluding this section and proceeding to the analysis of the novel, I would like to include yet another perspective in the discussion of this dilemma. In the volume Actualities of Aura, Graeme Gilloch elaborates on the simulation of aura - which may be one of the most pointed attempts to come to terms with the continuous post-Benjaminian circulation of the term. In response to how Rombes describes the traditional cinematic experience in comparison to the contemporary multitude of cinematic experiences, Gilloch would make the following claim:

\footnotetext{
75 "But now that film's aura has been thoroughly debunked, we are faced with nostalgia for the old movie houses, the prisons where our dreams were given shape and sound" (65).
} 
One is concerned here not with aura per se, but rather with what one might term 'simulated' or 'artificial' aura. Of course, one must admit straight away that the notion of 'artificial aura' is a contradiction in terms - aura is, after all, that which attests to the authenticity, the genuineness, the uniqueness of the traditional artwork. Aura, genuine aura that is, cannot be fabricated - this is what makes it genuine. Nor can aura be re-stored - it is irredeemably liquidated by the logic of reproducibility inherent in new media. Artificial aura, though, refers to the spurious attempt to authenticate the inauthentic, to attach a sense of uniqueness to the commonplace, to maintain or manufacture a semblance of distance despite proximity. Artificial aura imbues objects and images with an 'air' of aura. It is not embedded in tradition but rather fabricated by various modern techniques, ones which, I suggest, run directly counter to what Benjamin and Siegfried Kracauer see as the essential critical imperatives of film and photography. (3)

Benjamin explains the impossibility of simulating aura by taking the example of stages actors versus film actors:

There is no facsimile of the aura. The aura surrounding Macbeth on the stage cannot be divorced from the aura which, for the living spectators, surrounds the actor who plays him. What distinguishes the shot in the film studio, however, is that the camera is substituted for the audience. As a result, the aura surrounding the actor is dispelled and, with it, the aura of the figure he portrays. (The Work of Art 31)

At the same time, Benjamin both was aware and disapproved of the industry's countermovements to the aura's decay - for example, the inevitably futile replacement of aura by "the cult of the movie star" (33). These mechanisms behind stardom are based on the "magic of the personality which has long been no more than the putrid magic of its own commodity character." One can say that Benjamin foreshadowed the continuing talk of aura in the context of cinema but dismissed it from the outset as a ploy of the western capitalist film industry. The discussion of artificiality does not only foster a critical reflection of the contemporary use of the term of aura but also of the motivation behind nostalgic relocations of cinema, which seek to revive its lost aura. This approach to Benjamin is particularly intriguing with regard to the Cordova phenomenon described by Marisha Pessl. As I will show in the following section, it is introduced as a radical and uncompromising effort to relocate cinema in order to rescue its aura - an effort that is emphasized to derive from the independent rather than the mainstream sector. 
But as the reading proceeds, there are more and more reasons to question the motivation behind the Cordova world. Is it a genuine countermovement to the new digital cinema of interaction or a particularly calculated case of aura fabrication? Are Cordova's Black Tapes worshipped in a mysterious underworld or merely a small part of a larger transmedial world? Does the novel's final twist point to a relocation or remediation of cinema, implying its thriving or its death in the digital age? With Scott McGrath as the focalizer, the additional question arises whether the direction in which the reader is pushed is reliable or not. Either way, spectators and, in this case, readers are "pushed towards a solution," as Francesco Casetti points out, no matter how "large and persistent ... a certain 'grey zone' might be" (588). And this is, as I would argue, what makes Night Film a compelling reading experience, worth approaching in terms of the dilemmas described in this section.

\subsection{The Last Enigma: Cordova's Underworld}

In the previous section, I have discussed the aspects of the contemporary media landscape that I think Night Film responds to in its creation of a storyworld. Throughout most of the novel, this response manifests itself in the image of the last enigma, conveyed by the notorious world of Cordova. The overall aim of this section is to present the initial status quo of the Cordova world as an antithesis to the cinema of interactions described above. A crucial aspect to be considered is that the Cordova world unfolds from the specific viewpoint of narrator Scott McGrath. "Everyone has a Cordova story, whether they like it or not," reads the very first line of the novel thus underlining the heterogeneity of possible viewpoints from the outset (xi). Reading the Cordova phenomenon requires discussing its intersection with Scott's perspective, which is marked by unreliability and ambiguity. This is what warrants a heuristic juxtaposition of two worlds, namely that of Cordova and that of narrator Scott - followed later by a discussion of its ultimate collapse.

First-person narrator Scott leads the reader through the world of Cordova while repeatedly raising doubts whether he is the best choice of a guide for this expedition in the first place. The scope of his unreliability, however, cannot be reduced to the drinking problems of a revengeful and worn-out investigative journalist. Another aim of this section is accordingly to detail the actual ambivalence of Scott's unreliable narration, which shall equally be discussed with regard to his cinephilia. In fact, my reading will finally spell out the narrative purpose of Scott's ambivalence by reconciling it with his hidden cinephilia, if not fan identity. 
A first indication of a certain discrepancy between both worlds manifests itself in the novel's formally peculiar, twofold beginning confronting the reader with two distinct ways to access the narrative world. In the prologue, Scott describes how his Cordova tale began, or to be more precise, how it "began for the second time" (xii). He is jogging through Central Park on a rainy October night when a ghostly woman in a red coat appears out of nowhere. Concerned about her welfare, he tries to catch up with her, but the thin, dark silhouette turns out to be hardly graspable in the eerie scenery of the night. There are first signs of Scott's unreliability as a narrator when he admits that the stranger's face was "so entirely in shadow it seemed possible it wasn't even there" and thus concludes: "Clearly I should've held off on that fourth scotch" (13). But however cryptic this encounter might have been, it marks a turning point in Scott's Cordova tale and leaves the reader wondering how the mysterious woman makes the notorious filmmaker reappear in Scott's life.

What follows is comparable to a hard cut in film. After the title page, the actual narrative opens with a reproduced slideshow of online material about Cordova. Tellingly, this section starts with two news articles informing about the death and supposed suicide of "Ashley Cordova, the 24-year-old daughter of cult shadowmaster Stanislas Cordova" (4). The implication seems quite obvious. Was Ashley the mysterious woman in the red coat? Was Scott possibly even the last person to see Ashley alive? Before Scott himself gets the chance to strongly argue for this eventuality, the book guides the reader through further information about Cordova bundled in a TIME online archive titled "The Last Engima" (5-22). Within this archive of photos and comments about the enigmatic life and work of Cordova, one post is particularly interesting in the context of Scott's unreliable narration. It is about how Cordova sued "awardwinning investigative journalist Scott McGrath" for defamation after he appeared on a latenight talk show and compared the filmmaker to such barbaric mass murderers as Charles Manson (19). "Though the suit was settled out of court, it was later revealed the journalist's 'inside source' - a former chauffeur to Cordova - was pure fiction, leading to McGrath's dismissal from Insider magazine," the article says, giving the reader a vague idea of Scott's history with Cordova. This overall twenty-page long website evocation is neither introduced nor concluded by the verbal text - it stands alone. Rather than being smoothly embedded in Scott's narration, it is juxtaposed to it, functioning as a depiction of events that is not necessarily neutral, but independent. What follows throughout the entire novel is thus clearly emphasized as Scott's personal interpretation of the information provided by the online archive. 
The first piece of evidence that Scott provides is a transcript of his phone call with Cordova's alleged chauffeur. The anonymous caller describes eerie nights, in which he drove Cordova to playgrounds, so he could dig sand boxes for children's belongings. If there was really "something he does to the children," as the chauffeur claimed, this would explain Scott's "insistent ... sense that something was wrong with Cordova" (29; emphasis in the original). In fact, the phone call ultimately convinced Scott that in the (imaginary) world of Cordova, fictional horror is being confused with real horror. ${ }^{76}$ As we learn from Scott, his unfortunate choice of words, or "inspired tidbit," at the talk show virtually ruined his life - costing him his career, his reputation, a quarter of a million dollars, and finally his marriage (25). After his disgrace on television, Scott never hears from John, the chauffeur, again, and thus assumes that he has fallen into a "booby trap" designed by Cordova himself. His mistrust in the news of Ashley's suicide becomes the perfect pretext for Scott to re-enter the Cordova world, where he still senses "a chance for absolution" (39).

Scott interprets his alleged encounter with Ashley in the night before her death as the affirmation of his suspicion. She must have sought him out for a particular reason. Solving the mystery behind her death and ultimately Cordova becomes Scott's life challenge and the novel's subject. Departing from this two-fold entrance to the narrative, the reader is torn between trusting the news media, which dismiss Scott's theories as "pure fiction," and a discredited journalist with a taste for excess and alcohol, whose current investigation is likely to be driven by revenge (35). Nevertheless, McGrath's obsession with Cordova is not only a matter of his deeply rooted grudge and the desire to finally clear his name. It is also a matter of "enjoying (and getting creeped out by) some of his early films" (29). After all, one should not overlook that the investigative journalist is also very much a hopeless cinephile. Throughout the novel he repeatedly describes his environment in filmic terms. His language also hints at a solid cineliteracy. "Can you hear me Scarface?," is how he addresses Ashley's friend Hopper when he meets him for the first time and assumes that he must be a drug dealer (67). It is as if

\footnotetext{
${ }^{76}$ Basically, I proceed from Mark J.P. Wolf's notion of the "“imaginary world' [which] is perhaps the broadest and least technical term" and take his example by using it "as a kind of default, unless a more specific term is required" (14). At this point of the analysis, there is no clear response to the question what the world of Cordova ultimately constitutes - to find out is the very purpose of this reading. At the outset of my analysis, I heuristically proceed from two diverging imaginary worlds, one is built around Cordova, his oeuvre, and his cult (by the facsimiles) and one springs from Scott's viewpoint. To put it differently, one could also make the following claim in terms of metafictionality: The reader faces the imaginary world of Night Film unfolding around narrator Scott. The reader also follows Scott, as he faces the imaginary world unfolding around Cordova in a transnarrative fashion, which makes him face its imaginary harmlessness. In fact, the ambiguous notion of what I call "imaginary harmlessness" particularly applies to Scott's alternating perception of Cordova's deceptive world of horror. Is it harmless because it is imaginary and thus does not pose any serious threat? Or is its harmlessness imaginary and thus implies that the fictionality serves to obfuscate a real, lurking danger? As my reading will show, Cordova's case even exemplifies the thin line between both understandings of the term.
} 
he applied a cinematic filter to his encounter with the young man, who had "the raw, beautiful features of some brooding actor from the fifties, the ones who cry when drunk and die young" (69). In the prologue, when Scott repeatedly loses sight of the mysterious woman, the interrupted encounter reminds him of a nearly obsolete cinematic practice, namely of "a film projector sputtering to a halt seconds before a pivotal chase scene, the screen going white" (xiv). Scott clearly thinks of a $35 \mathrm{~mm}$-film projector and is obviously the (wistful) child of a cinematic era that is romanticized by sputtering film reels and genius actors rather than thoroughly demystified. He is downright frustrated with the comparative cine(il)literacy of the younger generation: "You've at least seen the movie. All the President's Men. Robert Redford, Dustin Hoffman? You know who they are, don't you? Or aren't you aware of any movie stars older than Justin Timberlake?" (95) This is why there is a considerably thin line between Scott's hatred of Cordova as the reason for his life crisis and his fascination with him as a filmmaker. As we learn on the first page of the novel, Scott is intrigued by Cordova as a director and artist because he represents "a relentless outbreak of the unknown in our overexposed world" (xi).

Night Film conjures up a media-saturated environment with its variety of online facsimiles and integrated QR-codes. At the same time, the novel's characters are exposed to a merciless digital world, in which investigative journalists have to watch themselves in humiliating mash-up videos on YouTube (see 35) and cult movie directors retreat from the public for many years, recognizing the urgency of protecting their privacy by all means. It is also a world in which according to such worried fathers as Scott, "postings by kids as young as nine and ten" appear on "the hundreds of Cordova blogs and fansites and anonymous message boards" (29). The fact that Cordova is "underground, looming unseen in the corners of the dark" does not mean that he is banned from the Internet (xi). In other words, his absence does not seem to be mirrored in the online spheres. On the contrary, "trying to rid the internet of Cordova was like trying to rid the Amazon of insects" (28). The crucial point is that the online communication about the Cordova phenomenon is vivid but primarily focused on its enigmatic character, and thus the way it resists to be probed and subverted. As we already learn from the introductory online archive, not only the director himself but the entire Cordovian cinema can be discussed under the headline of "The Last Enigma."

How does the director warrant such a momentous nickname? There is, for example, the entire context of his filmmaking. Once Cordova had become an independent filmmaker, he barricaded himself in the Peak. This meant for Ashley that "her family home was a veritable movie set, after all" (380). Cordova's "personal netherworld" is described as an incomparable 
source of creativity and inspiration (376). When Scott interviews one of Cordova's former wives to research life at the Peak, he finds out that actors were expected to arrive on the first day of production, uninformed about the screenplay or the characters they would play, and to stay for several months without maintaining any contact to the outside world. For the sake of "the glory that came with appearing in a Cordova picture," they agreed to embark on "a new journey down a wormhole into something unknown" (375). These were the perfect conditions for his "night films." Unconditional if not spiritual commitment is what makes up the Cordova experience, at least on the production side. While one conclusion of Scott's research is that living in the permanent company of creative and brilliant people must have been some kind of "childhood fantasy dream," the investigative journalist does not lose sight of the "petrifying" dimension implied by this kind of total isolation (331). His "official one-man studio" adds to "the mystique of the director as an agoraphobic recluse and madman" (151). The Last Enigma slideshow contains a photograph of the Peak, an aerial shot of the heart of his oeuvre, as it were. As the caption suggests, "the isolated nature of the compound - and the well-documented fact that it is protected by a 20 -foot military fence have been the subject of much rumor and speculation as to the nature of Cordova's life there" (11). Unsurprisingly, it is Scott who eventually exploits the far-reaching potential of such rumors. Among his notes on the Cordova case, there is a facsimile of the interview he led with Nelson Garcia, one of Cordova's closest neighbors. He explains how a series of medical deliveries intended for the Peak accidentally ended up at his house. According to the old man, the actual addressee was a certain Javlin Cross, whom Scott immediately identifies as the main character of Cordova's IsOLATE 3, a man being held in captivity against his will. Throughout the novel, Scott, and probably the reader, develop wild fantasies as to what is truly happening at the Peak. Still, when it comes to Cordova as a rebellious representative of contemporary cinema, the solid barrier embodied by the Peak's fence primarily protects the secrecy of his filmmaking recipe. The Cordova phenomenon creates nostalgia for a time in which the methods of filmmaking were not exposed by the now prevalent making-of culture. Cordova's "night films" offer what Rombes claims is absent in the contemporary cinematic culture:

Unavailable or mysterious technologies were always one of the elements that conferred an aura of mystery upon movies. Not only were they experienced in the dark, but audiences were largely in the dark about just how they were made. (Cinema 22) 
Accordingly, Pessl assigns to Cordova the aura of the lonesome genius, who would vanish somewhere occasionally during shooting and not show up for weeks (see 376).

In analogy to the honor that befalls only the small number of actors that work with this brooding loner, watching his films counts as a privilege as well. The limited availability of Cordova's so-called Black Tapes considerably frustrates Scott and his investigation. In fact, the Black Tapes are almost impossible to find anywhere. The reason, however, is not that the films are stored on inflexible, old-school film reels. This is at least what Scott reveals, after he asks acquainted film scholar Wolfgang Beckmann for footage:

He had one bootleg copy, which he'd refused to loan me because there was an impenetrable lock on the DVD prohibiting any type of copying or downloading - and Beckman suspected, probably rightly, that I'd never give it back. (165)

Relating to Cordova DVDs as Black Tapes is, on the one hand, certainly a question of perpetuating their cult status, which obviously dates back to sacred VHS collections. On the other hand, the extreme rarity of the tapes despite their digitization creates almost a sense of denying the digital age and its new dimension of reproducibility.

Another crucial aspect of a film copy's cult value is the setting in which it is screened. There are only secret showings of the Black Tapes organized by passionate Cordova fans who call themselves Cordovites. The Last Enigma archive details the idea behind the so-called redband screenings which

began in the Parisian catacombs, a maze of subterranean passageways built during the twelfth century where, fittingly, the walls are constructed out of human bones. The underground screenings soon spread throughout Europe, America, and Japan. This marked the beginning of Cordova's emergence as a subversive sorcerer of a dark, terrifying world liberated from the commercial trappings of mainstream society. (14)

An attached photograph of the mentioned catacombs makes the pitch darkness of these "Urban Underbellies" even more imaginable. In such settings, spectators tend to either pass out or turn into "orgiastic raves" - provided that they have found the way to one of such events in the first place. To join this exclusive community of viewers, one has to decode cryptic directions on the so-called "killer's eye" posters, as a young woman in one of the book's illustrations tries to (16). This symbolic, close-up emphasis of the eye, and its recurrent depiction throughout the book, is telling with regard to the deeper meaning of the red-band screenings. As if in response 
to the multitasking atmosphere of home theaters, the Cordovian cinema redirects the focus to, or virtually runs a poster-campaign for, the sharpness of the eye, while creating the perfect, pitch dark conditions for this revival of what it means to actually be in the cinema. The horror genre, characteristically preoccupied with the question of vision, constitutes a perfect pretext for this sort of discussion. In "The Eye of Horror," Carol J. Clover explains why eyes are so predominant in horror cinema, be it mentioned in titles or wide-open and staring up in terror on movie posters:

Horror privileges eyes because, more crucially than any other kind of cinema, it is about eyes. More particularly, it is about eyes watching horror. Certainly the act of watching horror films or horror television also looms large in horror films. Horror film characters are forever watching horror movies, either in theaters (e.g., Demons) or on television at home (e.g., Halloween), and not a few horror plots turn on the horrifying consequences of looking at horror (e.g., Demons, Terrorvision, Videodrome). (185)

Besides the resulting mirroring effect which instructs the audience to shudder or scream, there is also the psychoanalytical question of the variety of gazes initiated by horror movies, ranging from the (killer's) assaultive, (the victim's) reactive, and the peephole gaze to the pornographic and, of course, the voyeuristic in general (see Frank and Picart 220). And there is always the rather psychoanalytical question whether and to what extent the film implicates the viewer in a specific gaze (see Frank and Picart 213). Without going into too much detail, one can conclude that the horror genre entails a particularly self-conscious act of watching. This is a conclusion that can also be drawn from one's own experiences of going to horror movies and being caught in a circuit of attraction and repulsion, occasionally only too prepared to actually stop watching. According to what Cordova claims in a notorious Rolling Stone interview, "cited" on the last pages of the novel, it is particularly in today's world that the eye-opening effect of horror becomes increasingly valuable and important.

He embeds the theme of "looking" in a critique of consumer society and confronts his viewers with the following questions:

Will you step back and cover your eyes? Or will you have the strength to walk to the precipice and look out? Do you want to know what is there or live in the dark delusion that this commercial world insists we remain sealed inside like 
blind caterpillars in an eternal cocoon? Will you curl up with your eyes closed and die? Or can you fight your way out of it and fly? (591)

Cordova expects a lot from his viewers. And the Cordovites have decided that there is no better place to meet these expectations than the subterranean darkness. When Francesco Casetti ponders the exaltation of vision, he shows awareness of such aspects as curiosity, obsession and the "desire to watch," yet also emphasizes the significance of the darkened room (575). He cites Giovanni Papini who referred to the earlier tradition of silent films when claiming that "“[cinema] occupies a single sense, the sight . . and this unique focus is ensured even further, in an artificial manner by the dramatic Wagnerian darkening of the theatre, which prevents any distraction"" (574-5). With the secret red-band screenings, the Cordovites bring this aspect of the traditional cinematic experience to a climax, providing a more profound manifestation of darkness and isolation. And when according to Robert E. Davis the true slogan of digital cinema reads "Coming Soon to Everyone, Everywhere," the Cordovian cinema explicitly withdraws from this kind of remediation. Cordova's night films (in the form of Black Tapes and unique screening events) stand in stark contrast to the universal availability and limitless reproducibility characterizing the digital age, and thus to the digital conclusion of the aura, whose vestiges are worshipped underground or as Black Tapes in disguise.

This is how the Cordova phenomenon bespeaks divergence. It is preoccupied with boundaries and barriers of all sorts. Cordova himself has erected a literal "twenty-foot electric fence" around the Peak, the heart of his oeuvre (371). One might assume that this sort of consequent isolation somehow contradicts Cordova having a dynamic cult following. But as the red-band screenings already show, the Cordovites manage to "follow" Cordova without disregarding his overriding principle of looming underground. In fact, they can be said to additionally nurture this aura of the director against the odds of a pervasive digitization. Interestingly, though, their mission does not prevent the Cordovites from running a fan website but makes them use the digital underworld for this purpose. ${ }^{77}$ This is at least what warrants the numerous black pages inside the novel or, in other words, the numerous interface mock-ups of the so-called Blackboards. The online community is part of the dark net and has a secret URL so that users would never spot it on Google, or other standard browsers (see 50). Obviously, Cordova fans need a space to somehow interact with each other and their beloved world of horror, after all; a space where they can "not only hash over all things Cordova, but express their every dark urge and dream without judgement" (50). At the same time, they cannot risk

\footnotetext{
77 cf. Bartlett, Jamie. The Dark Net: Inside the Digital Underworld. London: Random House, 2014.
} 
destroying the well-protected and guarded aura of Cordova or the exclusiveness of the Cordova experience. Therefore, the Cordovites do not withdraw from the Internet altogether, but at least from its visible surface. The invisible dark net, in turn, provides them with a "raw and wild space", a "blacked-out space ... a world away from what is glossy and commercialized" (169). Scott learns about the website from Wolfgang Beckman and considers this "last hidden corner" a promising source for his research. But as he tries to open it, the entry turns out to be "fiercely guarded, for authorized Cordovites only" (50). Scott is immediately detected as an illicit intruder, denied access and, what is more, literally kicked out. "Whoever you are, you shouldn't be here. GET OUT" demands the pitch-dark landing page, or, to be precise, book page (84). The picture of a closed door at the end of a corridor makes sure that for any potential intruders the Blackboards emerge as yet another impenetrable barrier. The Cordovites seem to have found a grey area that allows them to interact with Cordova's work without turning it into a new cinema of interactions. They perpetuate their longing for a true cinematic mystery in spite of and at the same time due to the digital age. The Cordovian attempt to hold on to media boundaries is thus not about drawing the line between analog and digital. It is about drawing a line between surface and underground, and in analogy to House of Leaves, slick and rumpled. The point is that the cult's apparent nostalgia for a pre-digital cinematic era overlaps with the renewed tension of Hollywood versus Independent Cinema. As a director who has consciously turned away from the studios in order to follow his interest in a more authentic form of horror, one can assume that Cordova's aversion was primarily directed toward Hollywood's particularly conspicuous employment of digital technologies. Rather than remediated in a commercialized, glossy fashion, Cordova prefers his cinema to be relocated to underground passageways, the dark net, and a fenced-in residence, where it is safely locked up.

This leads me to another of Cordova's protests against digital cinema, namely the subversion of a cinematic style that is predominated by the elastic reality of special effects. One can conclude from what Scott finds out about shooting at the Peak that Cordova's filmmaking works with psychological rather than digital effects. As already mentioned, what the "creative eccentric" demands from his actors is complete devotion and commitment (243). Interviewed by Scott, former actress Marlowe Hughes confirms that at the Peak you were "learning how far you could go - in love and fear, in resilience and sex, in euphoria” (376). For Scott this question of 'how far' is not merely an indication of Cordova's preference for method acting. Scott understands Cordova's independent cinema in terms of an accurate indexicality. After all, Marlowe gives Scott reason to believe that night films imply a dangerous form of authenticity that blurs the line between fact and fiction and has been consciously overlooked yet: 
You see, whatever he was doing to unleash this creativity, get his actors to hack into their own souls and bleed out for the camera so the world would drink it as long as everyone kept their mouths shut, it was business as usual. They looked the other way. We all did. (378)

Scott assumes that the way Cordova's private life intersects with his professional life at the Peak is mirrored in the way his fictional world of horror intermingles with genuine horror a horror Ashely possibly flew from until she ended up dead at the bottom of an elevator shaft.

On the one hand, the way Scott's perspective rounds off the Cordova phenomenon makes perfectly sense: Just as the red-band screenings aim at a more substantial form of darkness and isolation, the filmmaking aims at a more profound form of live-action footage, namely horror that does without special effects. This would of course add the final, radical touch to the new digital cinema's enigmatic antithesis. On the other hand, the question persists how trustworthy an investigative journalist Scott is. At no point in the novel does he reach anything remotely like a sober explanation of Ashley's puzzling and sudden death. To the contrary, Scott's sense that Cordova has something unsavoury to hide only adds to the mystique that surrounds the director and his oeuvre. As already mentioned, cinephilia can be named as a crucial feature of Scott's identity as narrator. And I would argue that Scott's exploration of the world of Cordova is rather comparable to how a passionate fan would approach it than an investigative journalist. Accordingly, the reader would not expect professional journalism from Scott in the first place. Instead, he could be regarded as the disgraced and finished journalist whose search of Cordova parallels or warrants his search of "a last hidden corner" where he can hide from further blind storms of indignation (50).

Repeatedly throughout the narrative, the contemporary digitized culture is described as hardly a desirable life situation. Film scholar Wolfgang Beckman, for instance, vigorously defends Cordova's or any artist's decision to lead a reclusive life:

I don't blame him for going underground. Have you seen the world lately, McGrath? The cruelty, the lack of connection? If you're an artist, I'm sure you can't help but wonder what it's all for. We're living no longer, we social network alone with our screens, and our depth of feeling gets shallower. (56)

In fact, the topic runs like a golden thread through the entire narrative, repeatedly framed by intertextual references to T.S. Eliot's poem “The Love Song of J. Alfred Prufrock.” In a sense, the 1915 tale of a modern man whose endless social gatherings distract him from emotional 
interaction turns into the novel's philosophical framework. At one point, Scott realizes the analogy between the man's unfortunate fate and today's overstimulation with all the "tweeting and friending and status updating" (353). Here, Marisha Pessl develops a critique of a consumer culture characterized by the necessity to be on the move "with all the gravity of a mouse-click" (509). This cultural-critical backdrop, however, appears too superficial to warrant the label of a thorough dystopia and lacks the depth required by a discussion of the digital age. In other words, Pessl resorts to unambiguous means to make the mystique around Cordova as solid as possible. She creates a dichotomy between consumer culture, on the one hand, and the Cordova family, on the other - the latter breaking with a routine that is determined by "the ceaseless chatter of Internet culture" (353). Scott's assistant Hopper claims that the whole Cordova family lives in answer to the Prufrock poem and Scott agrees, "it was doubtlessly a ferocious, intoxicating way to live." Against the backdrop of the repeatedly described cruelty, shallowness and flippancy, the Peak, which offers time and space to get to the bottom of one's soulsearching, appears like an intriguing destination. No less alluring are the Blackboards that allow for the expression of one's darkest thoughts; a space where Scott would be praised rather than disgraced for his bad suspicions.

A considerably more compelling aspect Night Film discusses in the context of the digital age is the question of Scott's cinephilia and media awareness. Scott is generally very much aware of the threat the digital poses to traditional analog media. On the trail of Ashley's last whereabouts, he enters a piano shop which strikes him with its emptiness:

It appeared in the Internet age, pianos, like physical books, were fast becoming culturally extinct. They'd probably stay that way unless Apple invented the iPiano, which fit inside your pocket and could be mastered via text message. With the iPiano, anyone can be an iMozart. Then, you could compose your own iRequiem for your own iFuneral attended by millions of your iFriends who iLoved you. (194)

As one can assume, Scott has very similar concerns with regard to the fate of his beloved cinema. Against the backdrop of such negatively connoted future talk, the Cordova fandom, in turn, can be considered a manifestation of nostalgia. It constitutes a microcosm which preserves the cinematic experience from remediation by virtually relocating it to the flipside of the glossy, slick, and digital world, namely to the "raw" and "wild" spaces of the Parisian Catacombs and the dark net. There, the traditional values of cinema are not remediated and thus rendered more abstract but radicalized and thus rendered more concrete and literal in terms of darkness, 
isolation and a consequent indexicality, that might, in turn, warrant this terrifying dimension ascribed to the night films.

Once again, seen from this perspective, Night Film articulates a powerful antithesis to the previously mentioned new digital cinema of interactions and thus can be said to imagine a world in which the aura of cinema is not dead yet and can still be rescued. Approaching it through the eyes of Scott, however, carries a somewhat desperate if not obsessive accentuation. Scott's attempt to enter the Blackboards, for example, does not necessarily indicate how investigative and revengeful a journalist he struggles to be. In awareness of his cinephilia, his endeavour (that includes snooping around Wolfgang Beckman's office) might as well indicate how desperately he struggles to become a member of the intimate circle of Cordovites. In the same vein, Scott's determination to break into the Peak turns his investigation into a convenient pretext for simply giving in to the place's mystical lure.

Whether the world of Cordova is narrated by an investigative journalist or a fan makes of course a crucial difference. Besides being a revengeful investigative journalist, the gradual revelation of Scott as a potential Cordovite adds another insightful layer to his limited reliability. This ambiguity of narrator characterization shall be emphasized as one of Pessl's most subtle and at the same time cunning narrative strategies - one that is revealed as such primarily in hindsight, after the novel's final twist (that shall be discussed in the following section). However unsophisticated Pessl's dichotomy between a glossy and commercialized world and that of Cordova may at times appear, it is a perfect reflection of Scott's own dilemma, his frustration with the digital age, on the one hand, and his ultimately fan-like naivety, on the other. The consequence is a distorted image of the Cordova world that will be addressed in the next section.

\subsection{The Digital Disillusion: Cordova's Transmedial World}

In the first part of my reading, I have shown the status of the Cordova world that the narrative departs from. The idea that the Cordova phenomenon constitutes the last great enigma in our contemporary overexposed world is already anchored in the novel's "web archive" and supported by Scott's narration, which is burdened by futile attempts to lift the secret around the director. One might say that the outset of the novel is marked by the aura of Cordova's art - an aura that is supported by a twenty-foot military fence, locked doors, urban underground bellies, and pitch darkness. From the contemporary digital viewpoint, it is the retrospective aura of a 
more traditional cinematic experience that becomes subject to alleged relocation. Still, it is not relocated in the more progressive sense that Francesco Casetti obviously had in mind when introducing the term with regard to a digitized cinematic landscape. It is not about recognizing the prevalence of the cinematic in new media and adapting its definition to contemporary dynamics. It is relocated in a more literal, almost regressive, sense so that the traditional can be barricaded and preserved if not radicalized. With this portrayal of a cinematic experience that precedes digitization, Night Film offers a kind of "utopia for the before" (Hassler-Forest 32).

The Cordova world's appeal is characterized by its nostalgic longing for a more traditional and auratic cinematic experience embedded in a mystery world which additionally defies today's vibrant capitalism. After all, the Cordovian advocacy of stronger (media) boundaries seems to be an independent and low-budget enterprise. In this section, I would like to point out how this initial sentiment turns into its opposite in the course of reading and elaborate the overall contradictory character of the Cordova world. The Cordovian cinema, introduced as a powerful antithesis to the demystification of film in the digital age and discussed as such in the previous section, begins to crumble as the narrative proceeds. This is how the novel eventually climaxes in a digital disillusion, which shall be the subject of the following analysis.

What is gradually exposed in a succession of turning points is the actual fragility of the great mystery around Cordova and the various boundaries that might have been introduced for the sole purpose of being transcended. The first major twist occurs when Scott gains access to the Blackboards after all. After Scott's futile attempts, it is his assistant Nora who shows him how to reset an IP address and thus to find a way to enter the "raw and wild space ... a world away from what is glossy and commercialized" (169). It is noticeable or at least unexpected how easily Scott has crossed this previously hypermediated barrier and how quickly the readers find themselves delving into a 17-page-long potpourri of background stories, anecdotes, and photography. As we can see, Cordova's controversial films, strange production methods, and secretive life have inspired rabid fandom and led to wild speculation. The forum reveals various details about Cordova's alleged filmmaking preferences and private life. In a sense, this is a positive if not necessary development of the story as it drives forward Scott's investigation and also satisfies the reader's curiosity. As a matter of fact, with the Blackboards Scott finds proof of some of his theories, especially those concerning Cordova's radical realism in response to Hollywood and the algorithmic slickness of the digital age. One of the posts that illustrate this confusion between real and fictional horror includes a screenshot of a bloody scene from one 
of the Black Tapes, showing a young man pressing his heavily injured hand against a car window. It has been shared by a school teacher who happens to live near the Peak and claims that the man in the picture is Cordova's teenage son Theodore, who had accidentally cut three of his fingers before appearing on the set. When he ran to his father for help, Cordova made his authentically wounded son play a part in the film instead of calling an ambulance. "The devastating pain on Theo's face is real and if you stop the film exactly at the 5:48" mark you can see the raw bone of the severed fingers on his left hand dangling there" (185). Once again Cordova's ambition to capture live footage exceeds moral standards. The apparent abuse of Cordova's children for the sake of a good movie sheds new light on Scott's investigation of Ashley's death. Either way, the Blackboards are full of nasty details, undoubtedly valuable for Scott and his desire for vengeance. One might be tempted to share the narrator's enthusiasm about having access to the privileged knowledge of a Cordovite. Far more interesting is how Scott, upon entering the Blackboards and even writing posts, has formally joined the Cordova fandom. As mentioned in the previous section, the journalistic investigation may also be regarded as a pretext for his actual desire to join this inclusive group of cinephiles. And as it turns out, the fulfillment of this desire does not require as much effort as expected in conclusion to the storyworld's introduction. In fact, one might claim that it virtually happens in the blink of an eye, within one or two clicks.

The paradox of Scott's character is that he, while praising the enigmatic character of Cordova, by all means tries to overcome it - both in his role as investigative journalist and as a secret fan. He is excited about using the Blackboards to proceed in his effort to lift the great secret of Cordova when, in fact, his easy access indicates that the secret might not be that great after all. But still, it is important to note that the revelation of the Blackboards alone does not deprive Cordova of his aura. This turning point, while being a crucial first step towards the novel's climax, does not yet demystify his cinema. It discloses the activities of a fan group that constitutes an important part of the Cordova phenomenon, but does not critically determine it.

What appears all the more resilient in comparison to the digital and thus abstract, ultimately fragile barrier provided by the web, is the physical fence erected around the Peak, the actual heart of Cordova's oeuvre, the actual site of the last enigma, if there is one. But Scott does not shrink from this obstacle either. On the contrary, he is so intrigued by what is going on behind the walls of the Peak that he develops an elaborate plan to break in. With his assistants Nora and Hopper, he embarks on a journey to enter Cordova's notorious mansion, which is admittedly more adventurous than resetting an IP address, but eventually successful. Scott, once 
inside the mansion, faces a darkness that reminds him of "a thick black curtain" (464). Accordingly, the passage describing Scott's trip through the Peak is framed by two entirely black pages. Not only is the Peak isolated from the rest of Pessl's storyworld; the text passage eventually describing its interior is also set off from the rest of the book. Ironically, trespassing this almost sacred barrier eventually requires no more than flipping a page. Either way, another barrier is being crossed, and the reader is made to witness the gradual demystification of the world of Cordova. When Scott finally leaves the thick darkness of the Peak's subterranean corridors behind, he suddenly finds himself in the very midst of Cordova's art. In an almost trance-like state, the narrator stumbles from one of the legendary film settings onto another, overwhelmed with their literal liveliness. When he, for instance, enters the Reinhart family's greenhouse from a movie called WAIT FOR ME HERE, everything appears uncannily intact. Not only do the various plants still bloom. 20 years after the film was shot, Scott finds the Reinharts' pond to be still populated so that "someone must come here regularly to feed the fish" (453). Is it the Reinhart family gardener and suspected serial killer who still lives here and lovingly tends his garden? Or has Cordova possibly locked up illegal immigrants in his world in order to keep it alive? Of all the possible explanations taken into consideration, one remains the most convincing for Scott. "Then his night films were documentaries, live horrors, not fiction," he readily concludes and is alarmed, to say the least (446).

Another soundstage Scott discovers is Brad and Emily Jackson's living room from the movie THUMBSCREW. The "ominous tale of ... paranoia, marriage, and the inscrutability of the human psyche" unfolds around Emily's sneaking suspicion that her husband might be involved with a string of local unsolved murders (443). Brad's briefcase, which he meticulously locks away in a safe, plays a major part in the movie as it is supposed to contain the truth about his guilt. The film has an open ending as the eventual fight between the married couple results in Brad's death, Emily's institutionalisation, and the briefcase being slipped onto the floor between bed and wall. Its content remains unknown, revealed neither to Emily nor the viewer. Tellingly, "the final shot of Thumbscrew is the briefcase, a slow tracking shot pulling out from under the bed, winding down the hall, out the front past the police, into the woods, fading to black" (443). Once inside this fateful diegetic world, Scott's curiosity takes over, making him "literally rummaging through Thumbscrew" (444). First, he searches the couple's closet and puts on some of Brad's clothes (after all, his own clothes got wet when he was forced to hide in a pool to enter the property unnoticed). And besides, what Cordovite would not take the chance of slipping into the role of one of Cordova's most beloved characters? Eventually more intrigued than frightened by the place's "frozen-in-time feel," Scott decides to produce the 
briefcase from under the bed and check its inside (444). His discovery of a child's blood-soaked shirt makes Scott shiver: "It looked harrowingly real, a real souvenir from a real murder" (444445). Once again, he figures that "maybe Cordova's films were real. The terrors on-screen, real terrors, the murders, real murders" and leaves the soundstage with an alleged piece of evidence in his pocket, or just a prop after all (445).

With his intrusion, Scott utterly demystifies the Cordovian cinema. The way he ultimately interacts with Cordova's oeuvre both conjures up and considerably exceeds anything that might be provided by DVD bonus material in terms of alternate endings or room-search games. Interactivity is taken to its extremes as Scott is virtually revealing the outcome of an open-ended movie. Night Film draws the dystopian picture of today's very last enigma being exposed, the sacredness of the last hidden corner irrevocably harmed. Reading Night Film is about witnessing the last vestiges of a cinematic aura being destroyed, when any imaginable boundary of the medium is finally overcome. Scott has not only hacked into the Blackboards and trespassed the Peak's fence, but apparently broken the fourth wall of Cordova's movies. In fact, the dissolution of media boundaries in this case goes so far that it makes Scott fail to distinguish between fiction and reality. Even after Scott leaves the Peak, and the reader turns another black page, he has only one explanation for this remarkable experience: 'I'm inside a Cordova film. One of his narratives. And it's not over" (527). The somewhat hyperreal trip makes Scott obsessed with the Truman-Show-like idea that he has been caught in Cordova's world. But is this the ultimate solution to the riddle? Does the Peak passage serve the purpose of a metafictional twist exposing Scott as one of Cordova's protagonists and Night Film as one of his screenplays? There is reason to mistrust Scott's self-centered fantasy, which at this point of reading results from the wishful (and thus unreliable) thinking of a passionate fan rather than a journalist's thirst for revenge. What is more, Scott's experience of the Peak needs to be identified as what it most probably is - a state of uncontrolled immersion. In a moment of genuine uncertainty, his words indicate nothing more or less:

How long had I been inside that soundstage? Years? Was it some sort of wormhole, a dimension away from time? ... Those sets were narcotics, dominating my head so entirely there'd been no space for any other thought. (460)

But just as Scott has arrived at the peak of immersion (inspired, in turn, by the climactic immediacy of Cordova's world) the narrative adapts to the routine of remediation and necessarily concludes with a moment of hypermediacy that brings Scott back down to earth. In 
the final, most decisive twist to the story, it turns out that Cordova himself has abandoned the Peak many years ago. Instead:

The Peak's been left to the fans ... The Cordovites. It belongs to them now. They've overtaken it ... It's a dangerous theme park, left, free of charge, to his most dedicated. It's become a secret rite of passage, a cult expedition to be there, wander the work or get swallowed inside it ... He hasn't set foot there in years. It's finished for him. His work is done. (554)

This is a moment of great disillusion for Scott and the reader, who both have been set on the wrong track all along. The sober resolution makes Scott realize: There was no big secret to be protected by barriers. There have possibly been no considerable barriers in the first place.

The last hidden corner, if there ever was one, has been subverted by a rabid fandom a long time ago. In light of this all-pervasive if not aggressive fandom, one has to ask whether the director, whose genius has been romanticized throughout the novel, maintains any authority over the Cordova phenomenon whatsoever. In retrospect, the reader may realize: Throughout the novel Cordova himself and his films have played barely any role. It is the communication and fandom revolving around Cordova that primarily preoccupied Scott's investigation. Night Film draws the picture of a cinematic landscape in which the feature film has been fundamentally superseded as the primary narrative. In other words, the enigma at the heart of Night Film has turned out to be the product of a fan-driven transmedial world. Rather than investigating a mysterious case, Scott has been facing a sophisticated illusory world. And rather than being soaked up in a Cordova film, he has been the guest of a theme park.

To fully understand Night Film's representation of transmediality, it makes sense to draw on Dan Hassler-Forest's recent study Science Fiction, Fantasy and Politics: Transmedia World-building Beyond Capitalism. Hassler-Forest resorts to critical theory and the Marxist tradition's radical perspective to discuss the political, anticapitalist potential of storyworlds and its contradictory embedment in a transmediality that is propagated by huge fan cultures. His aim is to point to the contradictory nature of fantastic world-building and complicate the celebratory and utopian tone often found within contemporary fan and transmedia studies. He attempts to look at his case studies of Star Trek, The Lord of The Rings and The Hunger Games in their transmedial entirety, which does not mean to prove knowledge of each medial manifestation. It means to grasp the being-in-the-world of these transmedia franchises in relation to politics and global capitalism - with their political fantasies on the one and realities on the other hand. In his study, Hassler-Forest explicitly avoids "entering into a semantic 
discussion of the exact limitations of the term and to what degree any given transmedia narrative is fully consistent across any given number of textual formations" (4). He thus makes a fresh contribution to a discourse that seems to dwell on questions of terminological accuracy.

His comprehensive approach eventually adds a valuable perspective to the discourse in that it emphasizes audience participation as a key element of transmedia world-building. Without idealizing fan culture, his implicit, and partly explicit, critique of the discussion of transmediality is that it tends to underestimate if not belittle the relevance of the fan. This failure in handling and understanding contemporary media culture is also what Night Film implicitly addresses. The first thing to mention is Scott's questionable understanding of fandom per se. The way he brings up the Cordovites indicates a highly intimate circle of "social outcasts excluded from hegemonic mainstream culture" (Hassler-Forest 40). This understanding of fan culture is obsolete but not fundamentally wrong. It is important to remember that not only Cordova's career but also his fandom might have changed over the course of 40 years. In the wake of the countercultural movements of the 1960s, one can imagine the Cordovites emerging as a radically inclusive, anticapitalist enclave of cinephiles, horror nerds and geeks. But does this description still apply to the Cordovites of the digital present in which the novel is set? In his study, Hassler-Forest highlights how the fan's status in the media industry has been transformed during the last decades. Once an alternative to a corporate-driven mass culture, fans are now addressed not only as ideal consumers, but also invaluable contributors, participants, influencers, and legitimizers (see Hassler-Forest 42-43). Therefore, "the many grassroots forms of organized fandom that emerged in the 1970s as a provocative alternative to mass culture can now no longer be approached with the same naïveté" (41). I would argue that it is precisely this kind of naivety described by Hassler-Forest that most considerably informs Scott McGrath's unreliability as a narrator. Scott is unreliable in that he is stuck in the 1970s and has probably missed the "transformation of the fan from marginalized outsider to collaborative hyperconsumer" (42).

The most crucial and decisive disillusion comes with the revelation of the true character of Cordova fandom, whose ambivalence is noticeable. On the one hand, the Cordovites have shown autonomy and power by virtually conquering the Peak, adapting a director's former mansion to their fannish needs. On the other hand, they are the ones who come to feed the fish and tend the plants and thus voluntarily keep an entire theme park running. In their submissive dedication to the place and cult, the Cordovites can almost be described as Cordova's staff 
(taking care of his cinematographic heritage back at home) or "prosumers."78 This reading of the Cordovites' role, or in fact purpose, provides a vividly concrete illustration for HasslerForest's more abstract concept of fandom as "a form of immaterial and affective labor that operates both in opposition to and in collaboration with the new forms of corporate power" (11).

Scott has failed to identify the Cordovites as brand ambassadors and the mystery of Cordova as the product of a fandom's immaterial labor. ${ }^{79}$ This conclusion brings Scott's unreliability full circle. It puts into question any piece of evidence Scott collected in the wake of his investigation. A new light is shed, for example, on the purpose of the mysterious caller who claimed that "there is something he [Cordova] does to the children" and provoked the notorious talkshow incident (29). Once publicly disgraced, Scott suspects an act of hostility behind the call. The most plausible explanation for this incident, however, has to take into consideration the Cordovites' omnipresent influence. In this context, the caller took this step not necessarily to seek revenge on a snoopy journalist in defence of his or her idol. Rather, he took advantage of Scott's naivety to spread the image of Cordova as a sorcerer of the dark and thus use the investigative journalist as another channel for transmedia world-building. In fact, the story of an ambitious journalist seeking the truth about a legendary filmmaker and the fate of his daughter could hardly be more demystified. Rather than inside a Cordova film, Scott can be assumed to be inside a PR campaign for a theme park. The greatest irony of his failure to understand the logic of the contemporary media industry is thus that he himself has unknowingly become instrumental in creating buzz around the last enigma.

It is remarkable how, until the final twist, the novel's representation of Cordova cannily avoids any direct or recognizable indication of a capitalistic motivation. On the contrary, the wording that permeates the Cordova phenomenon throughout, establishes an explicitly anticapitalist sentiment. After all, the entire concept of the last enigma is based on rejecting anything that is rudimentarily commercialized, glossy, or mainstream. But how can the Cordova world's thoroughly anticapitalist spirit combined with the antidigital nostalgia for a sincere cinematic experience be reconciled with such a downright capitalist conclusion? According to Hassler-Forest's work, it is not unusual for commercial transmedia franchises to be informed

\footnotetext{
${ }^{78}$ For a closer analysis of prosumption, see Olivier Frayssé and Mathieu O'Neil, "Hacked in the USA": "A prosumer is a consumer who takes part in the production or distribution process, without being paid for it in wages. To what extent this amounts to exploitation, and in what sense, has been a recurring question in the literature ... The fact of prosumption is not as new as the word that describes it, but it has undoubtedly gained currency in a hitherto unimaginable way since the advent of the Internet, which has dramatically expanded the range of self-service products and services" (3).

${ }^{79}$ Regarding the maintenance of the Peak, the Cordovites' labor can, in fact, be considered material.
} 
by such competing energies. Concluding from the sum of his case studies, this ambiguity might be even regarded as a significant characteristic of transmedia world-building. In his book, Hassler-Forest starts out with an intriguing reading of THE LEGO MOVIE (2014) as "the perfect cultural product for our times, blithely incorporating a vibrant anticapitalist sentiment into a framework that greases the wheels of global capitalism" (1). The narrative around construction worker Emmet, who spends his monotonous life in unquestioned conformity to the "everything is awesome" doctrine, strikes Hassler-Forest as a painfully obvious satire of consumer society. It indeed went as far as to cause public controversy which included reviews of the film's "“practically communist" message and its questionable child indoctrination with anticapitalist values. Hassler-Forest points out the blatant paradox of discussing anticapitalism in terms of an animated movie that might as well pass off as a feature-length advertisement for a popular toy brand. Another aspect of the movie's "overwhelming irony" is that its storyworld condemns exploitation of participatory culture by drawing a dystopia of monotony (2). At the same time, its actual, economic reliance on audience participation could hardly come across more naturally than with a toy at its focus that represents the epitome of "a highly participatory sensibility" (3). This is what makes THE LEGO MovIE a particularly illuminating, and as I would add, interestingly literal example of the "tension between internally coherent storyworlds and the fandom's radically heterogeneous creative work" (3). Also, in his analysis of Tolkien's Middleearth and the STAR TREK franchise, Hassler shows how "each in its own way embeds a radical anticapitalism within forms and structures that support and even strengthen capitalism's most basic coordinates" (24).

A similar ambiguity can in fact easily be applied to the Cordova world. Cordova's alleged under-the-radar mystery of rumpled filmmaking creates a particular appeal for masses of Hollywood-weary audiences and potential theme park guests. From this viewpoint, the Cordova world manifests itself in ways that perfectly make sense from the context of twentiethcentury capitalism and commercial transmedia franchise. However, what distinguishes this literary evocation of a transmedial world and makes it a valuable case study is that it implies a critique of the lacking awareness of this other side of the coin. A crucial part of the reader's experience of the Cordova world is, after all, the moment of disillusion in the end of the novel. Rather than ambiguity, the novel thus creates a stark contrast between what one is easily (and transmedially) made to believe and the capitalist reality behind it. In other words, Pessl consciously uses the form of the novel to achieve an eye-opening effect and possibly face the reader with his or her gullibility. 
Not only has the novel's revelation clearly reduced and relativized the subversive and radical ideology of the Cordova world. As implied throughout, the transmediality of the Cordova phenomenon contradicts the Cordovites' nostalgia for a more traditional cinematic experience. Hence, the novel's final twist also dramatically readdresses the question of the death of cinema. As I have argued in the previous section, the outset of the novel, its initial worldview, is strongly tied to the specific aura of the cinematic experience provided by the Cordova cult. However, with every boundary Scott crosses, be it the digital barrier of the Blackboards or the fence enclosing the Peak, even this highly enigmatic, last experience of a kind gradually becomes subject to the total exposure and demystification typical of our metareflexive digital age. The novel's sober resolution eventually provides an explanation, not for Scott's investigative talent, but for the many boundaries' actual fragility. It is not only that the Cordovites perpetuate the mystery around Cordova, in the end of the book they can be assumed to have produced it in the first place. In other words, this aura of mystery, so meticulously articulated, has not been destroyed but merely unveiled as artificial. One may wonder whether the evocation of such artificial aura has become a necessity in the contemporary competitive media landscape, where it is no longer enough to "just go to the cinema.' In this case, it has to be a particularly dark isolated and explicitly-not-omnipresent kind of cinema, bringing back the traditional experience of going to the movies. Hence, the notion of cinema Night Film conveys is ultimately determined by two extremes: First, by the artificial, nostalgic surface of isolation, pitch darkness and unavailability and second, the actual heart of Cordova's oeuvre that turns out to be a theme park made of film sets, the epitome of the cinema of interactions. Both aspects can and are being discussed as indication of the end of cinema (as we know it).

It is nevertheless hardly deniable that particularly the situation at the Peak is highly ambivalent. There is a certain paradox of speaking of the alleged death of cinema while all the plant-watering and fish-feeding can be understood as an effort to keep the cinema of Cordova literally alive. Are the Cordovites the ones who "harm" the medium, or are they the ones who fear and try to postpone its death - by keeping it artificially alive? One might be tempted to come to terms with the Peak as a "cinematic sanatorium" rather than a "mortuary" (Niessen 182).

These doubts demonstrate how thin the line between both sentiments actually is. Still, such a reading would ultimately fall into the category of romanticizing transmedia worldbuilding and the role of fans. It would deny the novel its eye-opening effect. After all, it is not 
the Cordova world per se that carries a subversive potential but its cineliterate, media-conscious and critical literary representation. This is what brings me to the unambiguous conclusion that the Night Film reader has to cope not only with the identity crisis of a strung-out, delusional journalist-narrator, but also with the identity crisis of an entire medium - affecting the multiple layers of (the) cinema, which is addressed here as a (growing) industry, an (increasingly complex) practice, a social space and a technology.

\subsection{Reading Marisha Pessl's Night Film: A Reconsideration of the Intermedial Gap}

In his naivety, vengefulness, and ultimate cinephilia, Scott has been the perfect protagonist to show how today's cinematic experience oscillates between reality and illusion, nostalgia and progression, remediation and "mere" relocation. This is how Night Film has managed to articulate, on the level of content and story, a thought-provoking approach to transmedial worldbuilding. Still, holding Night Film in one's hands does not only mean to read about a transmedial cult, it means to partly face it. This leads me to the aesthetic multi-media character of the book, which is going to be the subject of the following analysis.

The first question to ask is certainly whether the reading experience of Night Film is supposed to mirror Scott's cinematic experience, that is fundamentally scattered and climaxes in the heart of transmediality rather than cinema. There are numerous aspects that bespeak such an analogy. Not only does Marisha Pessl relate to her novel as Night Film. The Night Film Decoder App provides extra content comprising a trailer, a slideshow of movie posters bespeaking horror at its finest, the audio of an Academy Award winning speech and the experience report of an actress who used to shoot at the Peak, among others. In a sense, the app turns the novel into a special edition, providing additional features widely known from DVD culture. Pessl introduces the DVD bonus material for the book, as it were - a paradox that can be easily understood as a strategy to confuse media boundaries between film and novel. The implication appears obvious: film pairs with literature in the common endeavour to embrace the interactive digital age - an intermedial love story so to speak. What is more, the book seems to invite the reader to explore the world of Cordova across various illustrations, sounds and texts rather than only reading about it. There are, for instance, police reports, patient files and interview transcripts, and other official documentes - all fictional - which encourage the reader to search for hints and do detective work on his or her own. The exploration of Cordova's world is certainly tied to a (first) engaging impression of immediacy. One does not simply learn about 
the buzz and controversy around Cordova, but one can actually read and see it. Especially noteworthy is in this context the novel's reconstruction of the Internet. Rather than offering an absorbing reading experience, various online articles about Cordova make the reader collect valuable information that might turn out to be useful and enhance understanding at another point in the novel. At any time, the reader can come back to the online archive and flick through it for secret details. In general, Pessl's literary take on the Internet is undoubtedly ambitious in many respects. Rather than remaining on its surface, the novel proceeds to further depths of the online world. In an intriguing way, it imagines the dark net as an instrument of transmedial world-building. The Blackboards, a fake website offering access to a selected group of users, serve the purpose of letting the reader in on the dark secrets of the Cordova cult, and also on the dark secrets of the Internet per se. They virtually reward the reader with the illusion of highly exclusive information or content. To sum up, Pessl appears to invite the reader to engage in a fannish consumption of the novel.

However, the exposed media literacy and accentuated (simulation of) media variety can be easily confused with an unconditional approval of the digital age and its convergence culture. Joe Hill, for example, derives his reading pleasure from the fact that Night Film asserts itself as "a multimedia presentation more than an old-fashioned book." Eugenia Williamson from The Boston Globe makes her point in a similar, even more euphoric way:

Remarkably, Pessl's inclusion of the Internet feels not at all gimmicky or forced; the reader forgets that these pages are static and have been laboriously designed. They deepen the mystery Pessl sets out in traditional text. The cumulative effect is entrancing and delightful, infusing the narrative of this whip-smart humdinger of a thriller with urgency and spookiness. It feels, above all things, new.

There is, however, no way to overlook the downside of such new or digital-age bookishness. The digital revolution critically affects our perception and appreciation of literature. To speak with Sven Birkerts, "we always hear arguments about how the original time-passing function of the triple-decker novel has been rendered obsolete by competing media" (40). It feels as if Night Film was doing a compromise, anticipating the competition by including it and thus adjusting to the reader's digital habits. As Maggie Doherty so aptly puts it:

One wonders whether Pessl's efforts to inundate her readers with materials from this multimedia, extra-textual world doesn't so much capture a reader's attention 
as appeal to his appetite for distraction, an appetite that has only grown stronger in an increasingly digitized world.

Does the novel, in consequent analogy to the narrative fate of cinema, virtually drown in its transmedial context, or, better, in the common transmedial microcosm deriving from the intermedial agenda between novel and film? To put it more plainly, does Marisha Pessl's Night Film warrant a discussion of the death of the novel? The Guardian reviewer Steven Poole points out that Night Film's eager evocation of media plurality is a matter of desperation rather than celebration: "All this bespeaks, perhaps, a literary anxiety about authenticity in the digital age, as though publisher and author were worried that mere words on a page were no longer enough." A preliminary conclusion would thus be that the novel submits to the prevalence of visual media by stretching, if not sacrificing, its media boundaries.

However, this conclusion is not only preliminary but premature as well. It disregards, as I would argue, the novel's critical potential with regard to the digital age. In fact, a certain discomfort with digitization and its impact on almost every sphere of human activity permeates the novel like a golden thread. Through the voice of Scott, the novel laments the dissolution of traditional media into iPianos and similar digital hybrids. What is more, the alleged shallowness of digital communication worries Pessl's characters and inspires the recurrent intertextual reference to T.S. Eliot's "Prufrock" poem. Most importantly, however, the Cordova phenomenon is introduced as a utopia of a nostalgic cinematic experience - one that is unaffected by demystifying digital age influences. And when eventually everything speaks for a case of transmedial world-building after all, it comes across as a retrospective disillusion rather than a desirable circumstance. Cordova himself, in turn, is introduced as a director who is tired of publicity and hides in the underground from the digital culture of constant exposure. Given my line of argument so far, in other words, dismissing Night Film as an unconditional cry for convergence and thus legitimacy overlooks the novel's critical potential.

Instead, I would propose the perspective that the incorporation of different media in the novel does not come with a denial or waning of media boundaries but their emphasis in the first place. I would argue that the backdrop of the cinematic identity crisis serves to highlight and praise the novel as a comparatively autonomous medium that lives on - against the odds of the changing and devouring media landscape. Hence, the novel's intermedial reference to cinemain-the-broadest-sense conjures up tension rather than analogy between both media and their respective embeddedness in the digital world. 
Almost inevitably, this line of argument bears on the critical issue of distraction raised earlier. It seems worthwhile to consider whether the novel confronts the readers with their appetite for distraction rather than merely responding to it in approval. It does not mean that I intend to write off Night Film's costly incorporation of media. I point out that it does not need to carry a positive connotation to play a crucial part in the re-appreciation of our older media. For this latter purpose, literature has to enter a dialogue in the first place. One could argue that the novel must include a transmedial context in order to show that it can equally go without it and to highlight the verbal text as primary narrative against its backdrop. As I will show, Night Film at least encourages this kind of meta-reflexive reading experience, which goes together with a constant renegotiation of media boundaries and hierarchies. In order to make my point, I shall devote the following pages to a closer examination of the novel's multimedia elements and discuss the way in which they are incorporated into the novel and make sense in the larger context of the narrative.

In terms of intermedia theory, the outlined approach entails a reconsideration of the intermedial gap. As a reminder: Irina Rajewsky has introduced the term to point to the limited character of intermedial references in literature:

In this inability to pass beyond a single medium, a medial difference - an 'intermedial gap' - is revealed, one which a given text intentionally displays or conceals, but which in any case can only ever be bridged in the figurative mode of the 'as if.' ("Intermediality" 55)

At first, Night Film seems to make a special effort in concealing its numerous intermedial gaps as it applies a very illustrative sort of intermediality. In this context, the smartphone app becomes the climax of this illusion-forming process, as it makes bonus material actually available and thus eventually bridges the gap. Pessl certainly challenges the intermedial gap the result, however, is ambiguous and manifests itself in a very thin line between concealing and displaying. As I will show, her efforts to conceal or bridge the intermedial gap quickly change to the opposite and raise awareness of medial differences in the first place. Either way, Night Film is a book which particularly lends itself to exploit the intermedial gap as a subject of inquiry. This focus on the intermedial gap is of course also a question of the printed copy. This is important to mention especially since Night Film appears to have been written in order to be read on a digital device, where the evocation of digital media very likely feels more natural and self-evident. It is, however, precisely the clash between the materiality of the permanent 
book page and the vivid media landscape it tries to evoke that foregrounds the intermedial gap (rather than ultimately concealing it).

The first part of my analysis focuses on the novel's visual take on Internet culture. Many critics consider the Internet as the novel's actual concern while they dismiss the role of film as superficial, hardly bearing on the medium itself. Maggie Doherty, for example, claims that "Night Film is not very interested in film. It is, however, very interested in digital media." I would claim that this is a false juxtaposition and invalid contradiction that disregards the prevalent dynamics of remediation. In other words, its focus on digital media does not necessarily prevent film from being the golden, intermedial thread.

To the contrary, the browser windows represent a very familiar framework for today's consumption of film. Especially digital natives will hardly deny that their cinematic experience usually begins and concludes on the Internet - in search for trailers, summaries, reviews, recommendations, film guides, showtimes and online tickets and, why not, some Hollywood gossip. In fact, the book even strikes the nerve of a time in which communication about film and the vast possibilities of meta-reflection become (at least) as important as contemplating the work of art itself. Therefore, I disagree with Doherty and stress that Night Film shows interest in film yet does so by applying a digital-age lens - and thus submits to the kind of historical authenticity Steven Pool mentions in his review. In other words, even when the novel's visual and thematic priority comes down to digital media, this very choice carries substantial implications for film as a medium. In Night Film, the representation of digital media, and the Internet in particular, operates mainly in a dual context; it is telling in relation to film, on the one hand, and in relation to the reading process, on the other. While the former aspect has been discussed in the previous section, I shall now turn to the latter.

For one thing, the illusion of surfing the Internet is sophisticated and rich in detail. The replications of browser windows include address and scroll bar and closely resemble the Safari design. ${ }^{80}$ The fake online articles about Cordova and his daughter draw on a variety of wellknown newspapers ranging from The New York Times to Vanity Fair and other real publications. They include authentic web addresses, logos, online journalism's obligatory combination of text and image as well as all the familiar social media buttons (including Facebook and Twitter). However, this direct confrontation between book page and desktop, reading a book and surfing the Internet, also results in a particularly striking intermedial gap.

\footnotetext{
${ }^{80}$ Safari is a web browser developed by Apple.
} 
A good example is provided just at the outset of the novel, when the screenshot of a short news article reports "Cordova's Daughter Found Dead" and sets the story going (4). Apart from its content, the most curious aspect about this sad news is that it is equipped with a comment section. A title bar offers the option to sort comments either chronologically, randomly by "picks" or by "most replies" - that is to say, those comments which have inspired the most replies from other users (4). There is also the replication of a button, inviting the user to add another comment to a total of 809 . The primary purpose of this number, which intuitively engages in exaggeration, is to illustrate and highlight the controversy inspired by the Cordova phenomenon. Another purpose, as I assume, is to confront the readers with the considerable amount of virtual information denied to them. This is a certain paradox after all: introducing such a busy comment section in order to reveal no more than merely the six newest contributions (and two replies). I do not claim that the novel sabotages the wide-spread online habit of meticulously studying each and every entry of a comment section. But now that there is explicitly no access to the rest of the 809 comments, the notion of actually scrolling down the book page might, in fact, appear tempting. Likewise, the reader might have preferred to get a glimpse of the oldest rather than the newest comments or those with the most replies. On the book page, however, none of the buttons works, the graphical user interface is broken, so to speak. As one can imagine, this kind of staged ellipsis frustrates not only the digital native, for whom the scrollbar means interaction. Diametrically opposed to what is understood as interactive, this case of a frozen scrollbar accentuates the intermedial gap at play. Interestingly, the media boundaries in this example emerge in a strikingly literal sense. After all, it is the margin of the book page that virtually cuts off a promising, possibly illuminating user dialogue about the mysterious red-band screenings. What comes to the surface here is less the specific limitation of the literary medium than its authority. The novel acts as a gatekeeper, which controls the amount of available information and, what is more, protects the reader from getting lost in the comments and thus wandering from the main reading path.

The question of distraction comes into focus here and might be another reason for Pessl's detailed replication of the Internet, besides authenticity. With all the Like buttons, hyperlinks and comment sections, Night Film exposes a considerable potential of distraction, yet without actualizing it. At the moment of explicit non-interaction, a distinction is drawn between unnecessary buzz, which can easily be abandoned, and the actual, superior narrative. In a sense, it relieves the reader from giving in to the omnipresent lure of taking part in digital communication. In other words, Night Film generates awareness of and intervenes with the Internet as a culture of distraction, which " "seizes our attention only to scatter it" (Austin 23). 
This is how Night Film articulates a bookish response to a discourse that focuses on the connection between the Internet and the increasing (in)significance of reading.

In The Edge of the Precipice: Why Read Literature in the Digital Age?, a worthwhile anthology dedicated to the question how reading changes in the digital age, Michael Austin talks about the new, Internet-based, and highly fragmented way to process information, or in short, our digital-age span of attention, and its "real consequences" (22). He argues that constantly changing impulses pose a threat to "the ability, both literally and metaphorically, to read War and Peace" (23). At the same time, these new habits nurture the "“juggler's brain,' whose cravings for complexity are satisfied by paying attention to multiple messages, and multiple media, at the same time - a valuable skill to be sure, but not the same skill as focusing on a single narrative, or a single plot, for hundreds of pages at a time" (23). In a similar line of argument, essayist and literary critic Sven Birkerts writes that "the novel and the Internet are opposites, and ... the latter both undermines the former and makes it more necessary” (27).

Night Film embraces this alleged dichotomy and thus creates a particularly contrastive instance of intermediality. What is more, it addresses and "corrects" the power relation suggested by Birkerts. Unless the reader goes online to check if the websites for some reasons of authenticity actually exist, the novel controls and limits the reader's degree of distraction from the main text. In a sense, the novel scatters the reader's attention only to make him/her focus again. It renders the crossing of the intermedial gap particularly luring yet denies it at the same time.

Since the story of Scott and his investigation is already preoccupied with boundaries, barriers and fences, the agency of the intermedial gap perfectly makes sense in the larger context of the novel. Nonetheless, it is essential to point out that Scott's experience of borders does not mirror that of the reader - or only partly so. When Scott finally bridges the gap that separates him from the Blackboards, the intermedial gap remains intact. The reader can see excerpts from the forum but, unlike Scott, is not given any access - which makes a somewhat self-evident yet noteworthy difference. After all, the Blackboards represent a powerful attempt at concealing the intermedial gap, as I will explain further in the following lines.

Night Film tries to establish the best possible printed counterpart to an actual horror fan forum. Isolated from the rest of the book by color, the black pages indeed make the reader cross a certain barrier, at least from the light to the dark side of the book. Not only does the black/white, illegal/legal dichotomy within the book provide a good framework for a sophisticated illusion of transcendence. It is also a matter of storyline context. Unlike the online 
archive, which comes across abruptly, the Blackboards are introduced with eager anxiety, as a longed-for destination. Upon the first attempt, both Scott and the reader face the same image of a closed door, a frustrating dead end, which makes the entrance even more desirable. In other words, the reader has been drawn into the urge of eventually entering the Blackboards along with Scott. What follows is a landing page, an eerie welcome text (a compliment that "YOU MADE IT") and again a detailed replication of web pages, which even manages to put the scrollbar into motion (169). One can say that Pessl has certainly made the best out of the unavoidable, yet possibly annoying, "as-if."

However, to exhaust the media-specific aspects of literature means in this case to exploit and ultimately foreground its materiality. A closer examination of the Blackboards reveals that Night Film turns its readers into users, only to make them aware of reading a book in the very next moment. A good example might be the already mentioned, allegedly dynamic scrollbar. On the Blackboards, a certain “Specimen 919" has posted a picture of Cordova's assistant Inez Gallo accepting an Academy Award on his behalf (181). In the picture's bottom left corner, there is a close-up of a tattoo on Inez' hand. In the caption, Specimen 919 begins to develop the conspiracy theory that Inez and Cordova are the same person. The page, however, reveals only part of the screen and thus only part of the conspiracy post. Obviously, the fan has uploaded further photographic evidence which is cut off by the book's margin. But as the reader turns the page, the rest of the screen is disclosed, that is, a photo of Cordova himself and a close-up of a similar, possibly the same, tattoo. Accordingly has the scrollbar changed its position from top to bottom of the page.

It is easily conceivable that for one camp of literary critics this causality between book page and scrollbar perfectly illustrates literature's desperate striving for significance in the digital age. Its correlation with the scrollbar, one could claim, makes the old-fashioned flipping of pages relevant again. But one could also apply a different (bottom-up rather than top-down) perspective and suggest that turning the page makes the scrollbar relevant in the first place. After all, this is the inverse logic of interfaces, websites, digital devices, or e-readers that imitate the flipping of pages or produce sounds of paper. To put it differently, Night Film reverses the omnipresent digital remediation of traditional media. It is not remediated by digital media and neither does it profoundly refashion itself in response to digital media; unlike House of Leaves which transforms itself from scratch, on all levels of the surface structure of the text. Instead, I would claim that Night Film provides the example of an old medium that thoroughly remediates new media. Just as the digital remediation may add prominence to the formerly unnoticed sound 
of paper - and tries to even improve it - now literature turns the tables, so to speak. Its remediation of the Internet puts the ever-dynamic scrollbar into a new context, turning it into a question of the book page's limited space that needs to be used wisely.

Reading Night Film as a bookish remediation of digital media entails a palpable shift of power relation. Moving the scrollbar and disclosing the rest of the page is in this sense not a question of adapting to the dynamics of the Internet, but a conscious decision (which, tellingly, in the former example of the comment section had a different outcome). After all, the novel does also largely decide about the Blackboards' irrelevance. Even though a collection of seemingly additional and in this case even exclusive information, the Blackboard section preeminently creates a sense of indeterminacy. As notes at the top of the black pages inform, Scott has made use of the Blackboards' search function and generated a result of 243 'Real Cordova Photos" (171-185). The novel, however, provides only a small and arbitrary selection of these results. While, at first, the barriers of the dark net prevent Scott and the reader from the desired entrance to the forum, it is now the novel which explicitly denies the reader full access and thus, once again, asserts its authority. By turning the pages of the Blackboards, the readers become aware that they read rather than explore (or merely scan) how search result 172 of 243 is followed by search result 218 of 243 and so on. Night Film turns the intermedial gap into a crucial instrument of its critical remediation of the Internet.

At this point, it is already apparent that Marisha Pessl's Night Film must not be dismissed as a desperate, hardly noteworthy instance of contemporary literature, but can also be read as a thought-provoking if not daring piece of literary intermediality. And still, an intermedial analysis of Night Film will not arrive at any final conclusion without having discussed its most notable feature, namely the smartphone app. It is a fallacy to dismiss the Night Film Decoder from scratch as nothing but a PR and marketing ploy. In what follows, I would prefer to approach it from scratch as an intermedial experiment that represents a logical step in the novel's renegotiation of media boundaries, and yet brings it to another, more precarious, level. As such, it requires some explanatory notes regarding its functionality. Some of the numerous illustrations in the book feature small, round icons of black birds. What at first might be interpreted as an allusion to Cordova's oeuvre that features titles like AT NIGHT ALL BIRDS ARE BLACK, turns out to have a surprisingly pragmatic context. The randomly scattered bird symbols serve as QR-codes and will unlock bonus content on smartphone, iPhone, or tablet. Once the reader has downloaded the free app, s/he can use it to scan the respective images and learn more about Cordova on an actual screen. Unsurprisingly, the app further complicates 
the novel's intermedial logic. At first sight, it seems to be perfect evidence for the print novel's urgent or even desperate desire for some kind of identification with the digital age. After all, the question is no longer whether the intermedial gap is being concealed or displayed. With the QR-codes, Night Film manages to actually bridge the gap and overcome the as-if quality of its intermedial reference to digital media.

Nevertheless, I would argue that not even the Night Film Decoder App stands for convergence. It is important to note that the novel itself does not simply cross the intermedial gap; it merely offers the reader the opportunity to consciously cross it. The mere choice between doing and leaving it is what makes the reader aware of the intermedial gap. What is more, the bridge navigates the reader out of the novel. It introduces a distinction between inside and outside the novel, inside and outside the reading experience. Hence, using the app is not just about switching from print novel to digital device; it is also very much about repeatedly reentering the novel for the main plotline and coherent reading experience. Ultimately, the Night Film Decoder App, which renders the reader outside and more importantly back inside the narration, serves the awareness of the traditional print novel as primary text and textual authority.

What reinforces this line of argument is that the app does not necessarily enhance our understanding of the novel, but possibly quite the contrary. First of all, the app has been designed for those who have already finished reading. The instructions about how to download and use the application are placed at the very end of the book. In the final "Note about the Interactive Elements of Night Film" author and publisher suggest to the reader "to continue the Night Film experience" and search for the "hidden Easter eggs" buried throughout the text. Despite the explicit reference to a gimmick from the film industry, the Night Film experience so far is clearly stressed as primarily a reading experience. By making sure that reading the novel remains a sacred, uninterrupted experience, author and publisher already introduce the app as a possibly unwelcome distraction. What further warrants this rather hesitant introduction of the Decoder is the potential flaw of the bond between print copy and digital device. Tellingly, the reading community does not conceal the circumstance that applying the app can be a quite unnerving and laborious undertaking. In his review, Phil McCausland reports how the app made him aware of his priority, which is reading the book, and nothing else:

I discovered the app halfway through the novel ... I downloaded and attempted to use it ... but ultimately couldn't get it to work. Frustrated, I deleted it. I found it just another interruption, a good reason for me to stop reading and pick up my 
phone. I didn't want the phone. This book mesmerized me - I never wanted to stop reading it.

Let me point out some aspects that may lead to this sort of reluctance: First, the readers have to find out that they need to scan a large portion of the entire page, not just the bird image. The device needs to be moved closer or further away from the bird, and the camera constantly readjusted, until the app finally manages to recognize and scan the well-hidden QR-code. On top of that, there is a hint in the instruction saying that not every bird icon hides a secret. It means that while readers struggle to apply the decoder, they cannot even be sure whether it is worth the while or just a waste of time. And once the phone eventually refuses to scan the bird, they cannot be sure whether there is simply nothing to be unveiled or they have failed to apply the scanner and thus have possibly missed something. Either way, one does not miss anything essential since the app does not contribute considerably to any fuller understanding of the plot. Of course, all this may be part of engaging the reader in a detective game in which s/he has to actively decode (bird-shaped) traces scattered throughout the book. As in Pessl's storyworld, some of the traces are useful and others are not. Some of them are easy to find, others are impossible to find in a literal sense. It seems nevertheless likely that in a few cases the reader either fails to cross the intermedial gap or simply gives up trying. He or she might prefer or even be relieved to stay within the novel rather than taking another intermediate step, namely that of acquiring technical support, which is, indeed, readily and repeatedly offered by the publishers. As if in anticipation of all these issues with the app, the publishers provide tips for troubleshooting at seemingly every occasion: on the RandomHouse website, the Marisha Pessl website, in the Google PlayStore, and even the final note of the novel concludes with the hardly thrilling advice that "if you experience any issues with the Night Film Decoder app, please email support@ randomhousedigital.com.” To content onself with just being a reader at last might become apparent as the best of all solutions. After all, what could be more counterintuitive than a mystery print novel that requires technical support? The irony of the juxtaposition is palpable, not only displaying but, in a final gesture, considerably widening the intermedial gap in question. In other words, what requires technical support must not be integral to the novel, let alone supersede it in any sense.

Even though Night Film is also available as an ebook, its paper copy, as I would conclude, contradicts the "digital age idea that a book is its content and not its physical form" (Austin 16). Even though my analysis has not included a comparison to the ebook edition, one can vividly image that Night Film is a perfect example of how the material existence of a novel 
can affect and change its reading experience; not because the entire concept of the novel works much better on a digital reading device and makes the app fit in much more smoothly, but because implied in the print copy is a meta-medial comment on the sacred distinction between book and any digital context of reading. In his article "Solitary Reading in an Age of Compulsory Sharing," Drew Nelles enlarges upon this distinction:

Neither the iPad nor the Kindle Fire, two leading devices, can properly be called e-readers; they're keyboardless computers that also happen to work for reading electronic books. They connect to the Internet and play video, which ... isn't exactly conductive to immersive reading. E-readers started out by mimicking books and wound up mimicking smartphones - and that makes them dangerous.

The appeal of a printed copy (in comparison to iPad or ebook) thus lies in its lack of a connection to the Internet and the prospect to read without processing streams of information and distraction from several media at once. Night Film seems to subvert this possibly healthy distinction between the "good old" print copy and digital device. It invites the source of distraction in. Once the readers have picked up their phone to scan the bird symbols, they might at this occasion check their emails, or catch up on social media conversations. Depending on the viewpoint, as I have argued, this does not necessarily mean that the novel gives in to a culture of distraction. Proceeding from the assumption that iPhone, tablet, or smartphone pose a digital threat to immersive reading either way, Night Film can be said to at least control and thus to complicate these deviations and link them to a heightened awareness of the intermedial gap. In the best case, it holds up a mirror to the readers and makes them aware of their digital habits that might disturb an otherwise absorbing reading experience. In the best case, in other words, it leads to a certain defiance of the digital distraction and raises the desire to actually read, now more than ever. Most importantly, however, it introduces a hierarchy between reading and interactive experience by introducing the latter among the book's very last pages. This is what leads me back to the print copy's metamediality. It is especially in the discrepancy produced by the book's materiality that this succession might come across as an instruction to pick up the digital device (or any digital device) after and not during reading.

What are thus the final implications for Night Film's apparent analogy between cinematic and reading experience in the digital age? What comes to mind in this context is the question of the so-called Easter eggs. As I mentioned in the first section of this chapter, Easter eggs have become integral to the digital cinema of interactions. Introducing the app as a literary 
analogy to filmic Easter Eggs naturally indicates an attempt at a fusion. However, the label marks a tertium comparationis that eventually unveils divergence rather than convergence. In terms of the book's multimedia aesthetics, Easter eggs are introduced as explicitly retrospective and detached from the reading experience. In comparison, Scott's experience of the Cordova phenomenon, his contemporary cinematic experience, fundamentally revolves around Easter eggs. Throughout the narrative, Scott repeatedly meets up with film scholar Wolfgang Beckman to discuss the hidden messages and ambiguous details of the Black Tapes. Obviously, he hopes to stumble upon a decisive clue, which will help him to solve the mystery of the Cordova phenomenon. Beckman, who counts as a Black Tape expert, usually speaks of the director's socalled trademarks:

In every story Cordova constructs, rain or shine, at least one or two, sometimes up to five of these trademarks - signatures, if you will - show up unannounced, like long lost family members on Christmas Eve. Naturally they cause a great deal of drama. (527)

Looking for such connections in a director's oeuvre constitutes a typical Easter egg case. Ironically, Beckman has even named his nine cats after these Easter eggs or trademarks, so that every time Scott ends up in his house, he finds himself surrounded by "Murad Cigarettes. Boris the Burglar's Son. One-Eyed Pontiac. The Peeping Tom Shot. The Know Not What. Steak Tartare. ... Evil King. Phil Lumen. The Shadow" (527). What sounds like a funny gimmick is in fact an appropriate description for Scott's unending cinematic experience. He searches not only the Black Tapes for Easter eggs but his entire environment - the online archives, the Blackboards, the Peak, its neighborhood, and so forth. It is not only that investigative journalism has led Scott to cinema. Cinema, for him, prompts some sort of investigative journalism. He moves from one clue to another, looks for Easter eggs until he finally arrives at the Peak, the theme park, the main hiding place, as it were. There he finds living fish, watered plants, and a locked briefcase. In Scott's cinematic experience, Easter eggs have turned into the primary narrative. Throughout this narrative his attention is repeatedly scattered and redirected, as he virtually drowns in the variety of different clues, some of which do not lead anywhere. The novel's aesthetics and the resulting reading experience mirror Scott's journey, but only to an explicitly limited degree. However intended, the implied level of reader frustration is not merely the question of an authentic detective game, but in a more essential sense, the explicit question of the intermedial gap. 


\section{6 (Post-)Photography in Night Film}

The transmedial world of Cordova is characterized by two seemingly contradictory dynamics. It responds to a desire for authenticity, even a sort of greater truth, until in conclusion its utter artificiality is revealed. Due to its denouement the novel seems to make a second reading worthwhile in many respects. One of the most intriguing second glances will be about rethinking the novel's use of photography. Interestingly, the Cordova world's ambiguity reflects itself in Pessl's strategic take on and incorporation of photography. Especially at a second glance what comes to the surface is the cunning placement of rumpled versus slick photographs, their varying contextualization and the curious interplay between photographs and captions or, in more abstract terms, image and text. Overall, the novel's digitally literate incorporation of alleged visual evidence carries illuminating implications about photography in the digital age.

From the very outset, Night Film complicates the use of photography in its traditional role as testament. The book provides material marshalled by journalists to investigate Cordova's past, covering what Patricia Holland would identify as the full range of celebrity photography:

The popular press and celebrity magazines such as Hello! and $O K$ reveal the indiscretions and private moments of the well known and not so well known with an appealing gloss, using photographic styles which range from the captured paparazzi shot to the formal portrait, as well as the constructed hyperrealism of contemporary fashion photography. (178)

The fictional magazine clippings occurring in Night Film all strive to draw a picture of Cordova, the inscrutable figure. Ironically, the alleged photographs of Cordova even highlight his inscrutability, showing him from behind, blurred, in the background or veiled in some way or other. And even though it is not explicitly named, the novel introduces a certain dichotomy between more and less authentic pictures, referencing different photographic aesthetics and sources. This is the case, for example, "when uncovering personal snapshots of the reclusive director became a cult pastime of his fans" (Night Film 6). There is, for example, a photograph of boys playing soccer at a schoolyard, in the background stands another boy isolated from the group, his head has been encircled (6). The claim of a retired first-grade teacher that the picture features Cordova is supported by the fictional TIME editorial team who checked the school's attendance records. This curious finding of a trace of Cordova stands in contrast to another photograph of the TIME slideshow. It is a frontal shot of a white man crossing his hands in front 
of his face in order to reveal only his eye area to the camera lens (8). It is not only that the image looks more polished and slick. In the caption, we learn that the strange portrait is a publicity still released by Warner Bros.. What is more, "doubts were raised that he was, in fact, the man in this photo" (8). Obviously, credibility is assigned to private amateur snaps rather than to the professional image made for the public. This authenticity-wise juxtaposition corresponds to a general tendency within participatory culture. Jonas Larsen and Mette Sandbye, for example, point out the value of amateur tourist snapshots in the travel sector. Websites and mobile applications such as "VisitBritain" or "TripAdvisor" invite users to share their own visual documentation of their destinations, "implying that this kind of imagery is more 'honest' than the hotels' own photographs" (xvii). In his investigation of the Cordova phenomenon, Scott relies on the sincerity of user-generated material, the greatest amount of which can be found on the Blackboards. As already elaborated, the forum is staged as the most arcane and thus most valuable source of information about Cordova. It is abundant with gritty old family pictures and gruesome shots of thumbscrews and other torture devices which the director allegedly made use of in his filmmaking. This Blackboard section of "Real Cordova Photos" posted exclusively by Cordovites is in fact the only place where plain and coherent shots of Cordova are available, a Hispanic-looking, curly-haired man who, tellingly, does not at all resemble the man in the Warner Bros. publicity still. Additionally, each photograph is framed by the fans' personal account of where they happened to take or find the respective photograph and how it can be interpreted.

While there are no photos of Ashley on the Blackboards, her depiction throughout the novel applies to a similar 'slick versus rumpled' rhetoric. Even though there are some portraits and undisguised frontal shots of Ashley in the pages of Night Film, I would argue, that the reader does not necessarily finish the novel with a sense of having actually seen Ashley. The first time we get a glimpse of Ashley is in a publicity still depicted in a New York Times article about her sudden death (3). Its credit line reads "Photograph courtesy of K\&M Recording" and one can assume that it relates to a fictional record company to which Ashley was signed as a virtuous piano player. The front shot looks so conspicuously digital that it immediately connotes fake or artifice. Her impeccable and perfectly complexioned appearance leads to the assumption that Ashley has been subject to what Tanya Sheehan refers to as "digital cosmetic surgery" (181). In fact, the medical metaphor for digital manipulation makes sense in the case of Ashley's special circumstances. For one thing, the respective digital picture of health does not necessarily fit in with what Scott eventually finds out about her fate, namely that "she had cancer. Acute lymphoblastic leukemia. She had it off and on all her life" (540). Another hint 
that Cordova's daughter is not presented truthfully can be found in a facsimile of a missing person report that was made after she escaped from a mental hospital. What stands out on this more credible photograph are the dark circles under her eyes, the flat hair. Tellingly, she does not look into the camera, reluctant to reveal her soul in this less hypermediated snapshot.

At a later point in the novel, the Vanity Fair Daily special feature on "The Enchanter's Daughter" begins with yet another obviously retouched publicity shot of Ashley (223-227). However, the article continues with depictions of a different kind of photography: three Polaroids displaying a church, seagulls, and a family of swans, which Ashley's former roommate Emma Banks claims to have found behind Ashley's dresser after she moved out. Unlike her digital portraiture, these three Polaroids represent "artifacts of Ashley's lost existence, portholes into her world" (578). Night Film clearly draws an analogy between the productive slick/rumpled tension and the distinction between artifice and truthfulness, (or even a greater truth provided by the undoctored immediacy of Polaroids).

Of course, Ashley's mainstream beauty shots do also stand in stark contrast to the photographic material provided by the Blackboards, and in particular the film still of her brother Theo pressing his bloody cut fingers against a car window. As already mentioned, the respective fan post develops the rumor that Cordova profited from his son's actual accident and panic to spontaneously incorporate it into a film scene. The rumpled and gritty aesthetic of the image is supposed to support this impression of gruesome authenticity. This is the very antithesis to the artificiality assigned to his sister by mainstream media. In fact, one can hardly imagine a greater opposition than that between the digitally doctored Ashley and a blatantly and literally, if not tragically undoctored Theodore in the Dark Net film still.

Once the artificiality of Cordova's underworld is revealed, the novel's implied distinction between more and less indexical pictures, between slick and rumpled, professional and user-generated content crumbles. In the end, the slick/rumpled dichotomy is subverted and unveiled as utterly misleading. In conclusion, the reader realizes that the frozen moment of Theo's alleged reality is equally, if not even more profoundly manipulated than Ashley's instances of digital cosmetic surgery. In retrospect, it can be said that one of the novel's critical purposes is to expose contemporary media culture's conscious exploitation of both visible and invisible digital effects to mislead the supposedly gullible and confused consumer - and thus to reveal a common strategy to authenticate photographs in the digital age, be they fake or not.

The necessity of such practices is nothing particularly new as the mistrust in documentary is almost as old as photography itself. Take, for example, photographer Arthur 
Rothstein's politically charged and strategic placement of a steer's skull on cracked and waterless earth for a 1936 photograph about the agricultural crisis. What surfaced in consequence of such notorious cases as Rothstein's were habits such as printing black borders around photographs to stress the purity of the photographic frame and authenticate its content (see Price 92). What nowadays validates rumpled, grainy, and amateurish photography is according to Night Film its embeddedness in an environment of digital "hyperphotography" or digital hypermediacy, respectively (Price 92). In a New York Times interview about "Photography as a Weapon," documentary filmmaker Errol Morris compares the either/or reception of photography with one of history's most outstanding deceptions, the forged Hitler Diaries in 1983. In order to authenticate the diaries, specialists compared them to genuine examples of Hitler's handwriting, or what was believed to be genuine but turned out to originate from the pen of the very same prolific forger. Morris makes a conclusion that may perfectly be applied to the resolution of Night Film: "Often we make a comparison between something that we believe is real and something that we believe is fake. I guess the moral of the story is we should always consider the possibility that we may be comparing something fake with something else that is fake." For Derrick Price, however, this post-photographic sentiment derives from the need to authenticate in the first place:

To have to engage with particular conventions, technical processes and rhetorical forms in order to authenticate documentary undermines the notion of the objective camera and with it, one might imagine, any claim of documentary to be any more truthful to appearances than other forms of representation. (92)

In a similar vein does Danielewski's narrator Zampanò ponder the dystopic, post-photographic scenario that "truth will once again revert to the shady territories of the word" (145). Since Night Film celebrates this re-empowerment of language to tell truths or, respectively, lies, it qualifies itself as a literary offspring from House of Leaves. After all, it is important to note, that the greatest source of deception in Night Film is not digital synthesis or the slick/rumpled dichotomy but the text surrounding the pictures. Especially the photographs "uploaded" on the Blackboards serve as nothing but bedrock for wild conspiracy theories. In Night Film, however, text is more effective not only in terms of playful deception but also yearned-for revelation. The informative discrepancy between word and image even serves as a strategy of suspense within the novel. A good example is the aerial shot of the Peak on the seventh page of the TIME slideshow (11). Rather than unveiling the director's retreat to the reader, the limited scope of photography merely raises curiosity about "Cordova's life there," inside the estate. Only later 
in the novel's climax, tellingly framed by two black pages or "borders," Scott exploits the proficiency of language, and nothing else, to convey a graphic account of the Peak's interior. This observation fits in with the point about the supremacy of reading Night Film over consuming it as a multimedia event - in spite of the prominent integration of photographic elements it is both the deceiving and revelatory power of words that lies at the heart of Night Film. In his discussion of the digital age, Errol Morris underlines that fact that pictures never stood alone but were always framed by specific, meaningful contexts. He argues that

doctored photographs are the least of our worries. If you want to trick someone with a photograph, there are lots of easy ways to do it. You don't need Photoshop. You don't need sophisticated digital photo-manipulation. You don't need a computer. All you need to do is change the caption. ("Photography as a Weapon")

What the digital age adds to our reception of photography is the increasing complexity of the cultural codes of authenticity (see my conclusion in chapter 3.4, section "Rumpled vs. Slick Images," concerning the gulf between slick and rumpled).

What has this examination of photography in Night Film showed so far? In its intermedial reference to the transmedial world of Cordova the novel engages with photography in two respects. For one thing, a considerable continuum of photographic practices ranging from the nostalgic Polaroid to exposed cases of virtual plastic surgery installs varying degrees of credibility (dualism of truth/analogue versus construction/digital). Despite its implications of partial authenticity, the novel's final twist results in a retrospective and overarching sense of artificiality, concerning both the rumpled and the slick. For another thing, the novel includes photography to renegotiate the relation between image and text and to emphasize the significance of captions. Therefore, it is important to note that the artificiality of the mediated Cordova world does not necessarily have to be a question of computer-generated imagery, fake grain, and staged motifs - or any kind of photographic manipulation in the first place. It is as well, if not even more likely a question of ambivalent, verbal contextualization.

Another important aspect about the novel's use of photography is its critique of surveillance culture. At a first glance, it is not one of the main concerns of the novel how the (photographic) exposure of Cordova violates his privacy. But as the narrative proceeds, it begins to ask how the verbal and visual creation of the Cordova phenomenon clashes with the life reality of the Cordova family. Cordova's retreat from the public nurtures his cult, provoking a number of theories and rumors allegedly explaining the motivation of his secrecy. In the end 
of the novel, Scott meets Cordova's former assistant Inez Gallo and learns the truth about Cordova's many years of hiding at the Peak. As mentioned above, it turns out that his daughter Ashley suffered from cancer and it was her illness that motivated each and every of Cordova's steps. What Gallo further reveals is that the Peak has been a destination for the Cordovites long before its takeover. Cordova, in turn, felt like being under surveillance, fearing the digital dissemination of his daughter's private life:

Crowthorpe Falls is always swarming with Cordovites. It's their Mecca. They migrate there from around world, hoping for a sighting. The last thing he wanted was a fan trawling through his trash, discovering a prescription revealing that Ashley was sick and jabbering about it on the Internet. We had to protect her. Though in the end, protection is just another cage. (547)

Contrary to what is being implied by the replicated media reports, the last enigma that unfolds around Cordova has not triggered his cult following. Rather, his enigmatic existence can be considered the consequence of this invasive group of followers. It is no wonder that Cordova has gone underground given that among the Cordovites there are journalists like Scott McGrath, who turns out to be sensation-seeking rather than investigative:

I didn't want to believe it, didn't want to accept that Ashley - such a fierce presence in every story I heard about her - could be singlehandedly struck down by real life. I wanted a wilder explanation for her death, something darker, bloodier, more insane - a devil's curse. (544)

The novel's comment on today's surveillance culture is rounded off by its very last facsimile. Throughout the novel the notorious Rolling Stone interview with Cordova, the only interview he has ever given, is recurrently mentioned. After the closing line of the narrative the novel eventually discloses the excerpt from the December 1977 issue of the Rolling Stone with Cordova himself on its cover. In the frontal shot, Cordova wears dark sunglasses and holds what I assume is supposed to be a pistol-grip Super 8 camera. ${ }^{81}$ The pistol-grip label derives from the handle which drops down from the bottom of the camera and plays on the ambiguity of "shooting." Cordova looks through the movie camera and thus directs it not only at his photographer, but at everyone who happens to look at the cover. It is an interesting choice of

\footnotetext{
81 "If you look at the design of most old-school Super 8 cine cameras they have one thing in common: a handle dropping down from the bottom of the camera so you can hold it like a pistol (hence the 'pistol grip' label). Pistol grips were also used in the world of still photography - especially in the 1960s and 1970s - but fell out of favor as camera designs became more ergonomic. However, as cameras have become smaller and recording movies is now commonplace, a pistol grip is once again a useful tool when it comes to improving your camera handling" (Gatcum 71).
} 
Marisha Pessl to place this fictional Rolling Stone issue at the very end of the book, as if in conclusion of the narrative. In this context, the cover inspires interpretations that might not have been considered at the moment of its alleged publication.

Back in 1977, detached from the context of the narrative, the cover might have simply underlined what Cordova reveals about his art in the interview. Asked about his source of inspiration, the director remembers how he used to observe people from an early age:

I was raised by a single mother in the Bronx. We were poor. I often cut school, taking the subway into the city where I sat in cafés and bus stations and strip clubs. It was at this time I learned that the human mind is a blackened, overgrown place. Society tries to mow the lawn and trim back the plants, but every one of us is just days away from a wild jungle. And it's the jungle that interests me.

Directing his camera at the random Rolling Stone reader, Cordova communicates that his art aspires to the portrait of society per se. What is more, while watching the Black Tapes the viewer is supposed to face mortal fear which "cuts to the core of our being and shows us what we are" (591). ${ }^{82}$ While it is certainly plausible that Cordova holds up a mirror to his viewers, the contemporary digital age context offers a more intriguing interpretation.

After having read about the invasion of Cordova's privacy in the digital age, the cover can be interpreted in terms of self-defense if not revenge. Holding it in a pistol grip, he points with his camera at his smartphone-equipped followers and "shoots" back. One might wonder whether the revelation of the Rolling Stone cover is meant to be understood as another plot twist which enlightens the novel's surveillance theme in retrospect. One can assume that by leaving the Peak for the fans, Cordova has turned the tables, not only in terms of maintaining his mansion and cult but also in terms of exposure. What if the Cordovites have unknowingly become involved in both a complex fan labor and surveillance system? In fact, this thesis is already rooted in the way Scott's paranoia dramatically increases during his investigation and makes him believe that he is "inside a Cordova film ... and it's not over," not even outside the Peak (527). What is more, it allows me to approach the aforementioned killer's eye posters from a new angle. As I explained in section 4.3, the posters are dispersed throughout the entire

\footnotetext{
${ }^{82}$ Here, Pessl draws on the understanding of the horror genre as a reflection of social anxieties. Ian Conrich, for example, writes in Horror Zone that "horror films in particular can act as effective cultural and social barometers," which is why they peak "at times of war, and during periods of economic, political, and moral exigency" (3). Even though the 1970s horror cinema deserves a more complex approach, it is certainly true that many filmmakers were inspired by the social pressures of the times - and in the imaginary world of Marisha Pessl, Stanislas Cordova was one of them.
} 
city, containing encoded directions to the notorious red-band screenings. I interpreted the recurrent eye symbol with reference to the horror genre's preoccupation with vision. Now, in turn, I would like to entertain the idea that the Rolling Stone cover hints at the literal omnipresence of Cordova's "camera eye." What if, in other words, the killer's eye posters are equipped with tiny cameras that literally look back? In this context, Pessl's artwork is reminiscent of the monitoring billboard, which has become an actual practice among entrepreneurs: "The cameras, they say, use software to determine that a person is standing in front of a billboard, then analyze facial features (like cheekbone height and the distance between the nose and the chin) to judge the person's gender and age" (Clifford). These digitally updated billboards follow the example of the kind of Internet advertising that gathers information on the consumer's browsing activities. Based on the collected data, marketers create algorithms that cater to the user's preferences. ${ }^{83}$ In analogy to this targeted advertising, the "smart" billboard can measure the effectiveness of outdoor advertising. In this scenario, fans, who keep a sharp lookout for the killer's eye and a sighting at the Peak, end up exposing themselves to privacy threats. They look right into the eye, completely ignorant of the possibility that their gaze might be returned - not only in a metaphorical sense. The cunning irony of Marisha Pessl's killer's eye posters is that they make monitoring conspicuous, yet too conspicuous, or too ocular, to be noticed.

Of course, this line of argument could be developed even further, for example with regard to the uncanny Night Film Decoder App, which has better not hacked into the camera of my or any reader's smartphone. Rather than turning it into the flagship of her digital-age-novel, Pessl has managed to convey the subtleties and complexities of our constantly threatened privacy, first, by complicating the victim and perpetrator roles and second, by possibly confronting the readers with their own suspicion.

In the next chapter on Siri Hustvedt's The Sorrows of an American, I shall further enlarge upon the question of post-photography. Some of the aspects introduced in the preceding lines will thus be discussed in greater depth: the tension between the visual and the verbal, postphotographic practices that foster practices of surveillance, and the way the changing media landscape collides with the life reality of "an American."

\footnotetext{
${ }^{83}$ See Kirkpatrick for a more detailed account of this data-tracking practice.
} 


\section{5 "The world's going virtual anyway": Verbalizing Post-Photography in Siri Hustvedt's The Sorrows of an American (2008)}

\subsection{Siri Hustvedt's Intermediality}

Having arrived at the last of my case studies, it might be the right time to briefly reflect on the logic of their chronology. Selecting House of Leaves as the first case study was motivated by the fact that it provides a pseudo-scientific introduction to the media-philosophical questions of the digital revolution. From Zampanò's perspective, the digital shift is in the process of unfolding its full potential and permeating our daily lives as well as unsettling our ontological certainties. Written in the 1990s and published in 2000, the novel is set in and pronounces the dawn of the post-cinematic and post-photographic age. The Night Film protagonist, in turn, has to realize that he lives in the midst of the post-cinematic age. The transformation of the media landscape has been so rapid that it bypassed the attention of Pessl's main character. Here, questions of post-cinema exceed the indexicality of the image - in comparison to House of Leaves the focus has shifted from the analog/digital rupture to the cunning exploitation of the analog/digital continuities. This leads to the encounter with an industry that has long assimilated what a journalist still considers new and negotiable. The characters of Siri Hustvedt's The Sorrows of an American are surprised to find (pictures of) themselves in the midst of the postphotographic age. They are confronted with photographic practices that do not conform to their understanding of photography, which is deeply rooted, but may have become obsolete. Just as in Night Film, a clash of perspectives in Sorrows also serves to address the new digital practices in photography and the potential of its ideological implications.

Siri Hustvedt is the author of six novels, a book of poetry and several essay collections. In the author's note to her essay collection Living, Thinking, Looking (2012), Hustvedt explains that she synthesises the insights of many disciplines "for the simple reason that I have come to believe that no single theoretical model can contain the complexity of human reality" (ix). She reinvigorates the dialogue between the humanities and the sciences and brings together cognitive neuroscience, psychology, philosophy, and literature in order to illuminate such topics as memory, identity and, above all, the complexities of human perception. Hustvedt's characters are dreamers (The Enchantment of Lily Dahl, 1996), art historians (What I Loved, 2004), psychoanalysts and cultural critics (Sorrows), photographers and their subjects (The Blindfold, 1992, Sorrows), award-winning poets and Columbia professors (The Summer without Men, 2011) as well as painters and sculptors (The Blazing World, 2014). They meet at art galleries or universities and at times "seem over-intellectualised and over-intellectualising," as 
literary critic Geraldine Bedell writes. However, Hustvedt's purpose behind addressing this rarefied world of SoHo art galleries is to explicitly look beyond it and tackle questions of less sublime life realities and the ambiguity of the 'art' label. At second glance, there are also burglars, (identity) thieves and, most interestingly, stalkers among the (artistic) characters mentioned above. Birgit Däwes, whose research interests are the patterns of surveillance culture, writes:

From the celebrated debut of The Blindfold (1992) to her most recent The Blazing World (2014), Hustvedt's novels have been culturally concerned with questions of seeing and visual representation, and particularly with the connections between observation and power. (295)

Looking at pictures means to verbalize what has been seen and to "surround the pictures with our stories" (Hustvedt, Living 256). Rather than a mundane activity, the transformation of visual experiences into words is for Hustvedt a topic that requires critical reflection. If there is a golden thread permeating her oeuvre, it is the relationship between image and word. Crucial research on this correlation has already been done in Corinna Reipen's Visuality in the Works of Siri Hustvedt and in yet more detail in Johanna Hartmann's Literary Visuality in Siri Hustvedt's Works: Phenomenological Perspectives. Hartmann locates Sorrows in the relatively new field of "literary visuality" rather than intermedial studies. Instead of taking one particular medium (in my case photography) into focus, the novel is discussed with respect to the larger context of the relationship between word and image. ${ }^{84} \mathrm{I}$ do not necessarily agree with this comparison between intermediality and literary visuality. On the contrary, I would argue that in the case of Sorrows, it is the specific discussion of photography that stimulates a reconsideration of the more abstract relationship between the visual and the verbal. Then again, it is my shifting attention to the larger context that rounds off my project.

The sorrows of an American are narrated by Erik Davidsen, a Brooklyn psychoanalyst of Norwegian heritage who is grieving over his divorce and the recent death of his father, Lars. What initially comes as quite a welcome relief to Erik's sorrowful life is the appearance of his

\footnotetext{
84 "In addition, the relatively new field, literary visuality, investigates the role of literature(s) in visual culture(s): the approach is the result of a 'fast-developing dialogue of textual studies with visual culture studies' (Harrow $2013,1)$ and 'constitutes an alternative or complementary paradigm to intermediality studies in that it posits the larger framework of visual rather than media culture as the context in which to analyse the visualities of literature' (cf. Isekenmeier 17). Intermediality studies and ekphrasis research in particular, have been criticized by scholars working in the fields of visual culture and literary visuality for being mainly concerned with pictures and their media. Because of their understanding of cultures as semiotic systems, which combine social practices, material artifacts and conventional codes, literary visuality's range - according to Guido Iskenmeier - extends beyond (the) media and questions their centrality in or for visual culture(s) by putting visuality, i.e. vision, sight and seeing, center stage" (Rippl 19).
} 
new downstairs tenant Miranda, an artist of Jamaican heritage, whose beauty immediately captivates the lonely divorcee and whose paintings intrigue the curious psychoanalyst and intellectual. Even though Erik's amorous advances quickly turn out to be futile, he enjoys Miranda's company and that of her lively and affectionate five-year-old daughter, Eglantine (Eggy). But soon after the arrival of his new friends, someone begins to leave sinister photos on Erik's doorstep. Eggy's father, Jeffrey Lane, haunts his ex-lover Miranda with his photo camera and violates Erik's privacy as well. The life of Erik's sister, Inga, developed in a parallel plotline, is no less complicated. She must cope with an intrusive tabloid journalist who threatens to destroy both her reputation and the memory of her deceased husband, the famous director Max Blaustein. Further, there is Inga's teenage daughter Sonia who has been eye-witness of the terrorist attacks of September 11 and still struggles to come to terms with what she saw. Will she be able to translate the happening into her poetry or will language fail her since the masses of pictures turn out to be overwhelming? In fact, the novel draws on the discussion of how the collapse of the World Trade Center silenced the leading and most virtuous representatives of the US-American writing community. The scholar I shall reference in this context is Catherine Morley, who has discussed the challenge of translating the omnipresent pictures of the $9 / 11$ events into narrative coherence. The paradox of this debate is that it is pursued against the backdrop of the striking amount of 9/11 literature, which has been growing since the terror attacks. As my analysis will show, The Sorrows of an American can be discussed as a literary manifestation of precisely this paradox, as it mourns the loss of words in a suspiciously eloquent fashion. However, the novel's partly ambiguous tension between word and image manifests itself not only with regard to the post-9/11 theme, which is introduced rather casually through a minor character.

Hustvedt draws or, more precisely, articulates a picture of a media-saturated world that is based on the ubiquity of a camera and shifts the boundaries of what can be uttered or shown, of our privacy and reality. The latter shall be discussed with regard to Jean Baudrillard's theory of a culture of simulacra where words and images stand on their own and have no reference in the objective reality. "Simulacra, Baby!" may be one of the novel's pivotal exclamations (217), which perfectly captures the implied cultural climate, namely a certain enthusiasm for the increasing indistinguishability between the real and the imaginary, fact and fiction, Disneyland and "all of Los Angeles," to quote one of Baudrillard's most prominent examples (Simulacra 12). Miranda's ex-boyfriend Jeffrey Lane turns out to be a fervid proponent of this "hyperreality," which he seems to be convinced to live in. His belief in the simulacrum, which verges on worship, reinforces his specific understanding of photography. It nurtures his 
photographic obsession, or art as it were, with the freedom to disregard privacy as well as ethical boundaries and, for this purpose, employ digital manipulation techniques.

Given this variety of angles, approaches, and contexts accumulated in the novel, I shall at least briefly elaborate on the scope of the image. W.J.T. Mitchell divides "the family of images" into the following categories: graphic (pictures, statues, designs), optical (mirrors, projections), perceptual (sense data, "species", appearances), mental (dreams, memories, ideas, fantasmata), and verbal (metaphors, descriptions, writing) (see "What" 505). Mitchell's typology provides a basic level of classification. A more elaborate line should be drawn, for example, between mental and perceptual imagery. And also Mitchell's graphic images feature a lack of differentiation in terms of two- and three-dimensional works of art, stills and motion pictures. Nevertheless, I agree with Hartmann that Mitchell's heuristic approach to "the incredible variety of things that go by this name" provides an adequate terminological framework for a discussion of the images occurring in Hustvedt's work (Mitchell, "What" 504). Sorrows promotes a rather abstract and performative understanding of the image, which encourages precisely the blurring of its inherent boundaries and acknowledges that

... images are neither on the wall (or on the screen) nor in the head alone. They do not exist by themselves, but they happen; they take place whether they are moving images ... or not. They happen via transmission and perception. The German language ignores the difference between picture and image, which, though it seems to be a lack of distinction, nicely connects mental images and physical artifacts to one another... (Belting 302-303; emphasis in the original)

The Sorrows of an American is the story of an encounter between a highly verbal narrator and the varied and dynamic world of images represented by Miranda, Eggy, Jeff and supposedly the entire New York visual art community. Frustrated with the limitations and incongruities of language, Erik is strongly intrigued by Miranda's "dream drawings," which occur to him as a powerful alternative of self-expression (113). His fascination with the expressiveness of images gives way to indignation and anxiety when faced with the kind of images Jeffrey Lane produces. Oscillating somewhere between documentation and a subgenre of painting, Lane's photography makes its new subject, Erik, gradually turn into a victim of stalking and defamation. The "intellectualized" talk of postmodern theories collides with the life realities of a psychoanalyst, whose patients frequent New York art galleries without questioning the verisimilitude of the photographs hanging there. Hustvedt juxtaposes different understandings of photography and thereby articulates her version of post-photography which points out the unprecedented role of 
digitization without nurturing the questionable analog/digital dichotomy. It addresses a new degree of a hardly noticeable and thus specifically defaming manipulation. In a similar vein, it thematizes how theories such as those of the simulacrum can be put into "practice" with unprecedented ease.

What makes Hustvedt's account of the post-photographic sentiment particularly notable is its comparably modest conveyance. In fact, Sorrows might appear like an odd choice for a third analysis after House of Leaves and Night Film. It definitely does not aspire to a sort of experimentation comparable to that of the other novels, let alone the inclusion of actual images. Instead, my last case study is a linear narrative and classical novel. In terms of the ekphrastic confrontation with post-photography, Sorrows constitutes a curious counterpart to House of Leaves. The latter's ekphrasis of the post-cinematic NAVIDSON RECORD is not only a question of text, but also a question of typography, colors, individual letters, frames, and fonts culminating in an ekphrastic struggle for ontological clarity rather than a "mere" ekphrastic description. In comparison, Sorrows does not seem to be that "dependent" on its bookishness. Its leading question is whether Erik's efforts to articulate Lane's post-photographic transgressions and distortions deepen his linguistic crisis, or on the contrary, turn out to challenge and thus relieve it. Rather than ending on a note of intermedial rivalry, the novel has the ambition to find out how word and image enrich rather than exclude each other under postphotographic conditions.

In order to develop the argument, I shall proceed step by step and begin with explaining how Hustvedt's set of characters is divided in those who prefer to communicate via words and those who prefer to express themselves via images. Professionally preoccupied with the subtleties and limits of verbal language, Erik and Inga have conversations that appear symptomatic for the post-9/11 climate of linguistic insufficiency. Two worlds collide when Erik, whose constant companion is a notebook, gets to know Miranda and her own way to keep a journal - by making daily dream drawings. The third section is devoted exclusively to the question of Jeffrey Lane's (post)photography. It describes how Jeff involuntarily steps into Erik's life and confronts him with the results of his privacy assaults.

In the last section, I shall take a closer look at the novel's denouement, a four-page-long stream of consciousness that conjures up a series of mental images. It further illuminates Hustvedt's complex reading of today's post-photographic sentiment and its implications for the larger context of the word/image tension. 


\subsection{Two Worlds Collide: Writers Looking at Pictures}

More than in the sorrows of the American per se, novelist Siri Hustvedt seems to be interested in the way they are being expressed. When it comes to communicating their innermost thoughts and memories, the novel's characters show a variety of preferences, that is pictures, poems, photographs, diaries, letters, and dioramas. In more abstract terms, this variety of communication contexts can be discussed with regard to the relation between word and image. This theme is approached from the viewpoint of eloquent narrator Erik Davidsen who both personally and professionally is preoccupied with the impact and purpose of verbal language. As a psychoanalyst, Dr. Davidsen spends hours listening to his patients' life stories and helps them arrive at "an articulated understanding" of what has remained painfully unspoken for too long (Sorrows 86). The curative power of words is obvious for Erik as "telling always binds one thing to another. We want a coherent world, not one in bits and pieces" (276). He shares his innate sense of language with his sister, Inga, a brilliant cultural philosopher and passionate writer, with whom he recurrently discusses specific word choices and other linguistic subtleties. As a Kierkegaard scholar, Inga publishes cultural-critical papers and works on a book about perception. She shares Erik's view that “we make our narratives, and those created stories can't be separated from the culture in which we live" (86). All in all, a certain affinity for writing seems to run in the Davidsen family. Erik and Inga's recently deceased father, Lars, for example, had felt the urge to verbalize his immigrant childhood days and his horrific military experiences in World War II. Erik, in turn, comes to terms with the loss of his father by reading and cataloguing his memoirs and letters and thereupon starting his own notebook and private writing career. Reading about Lars's past, however, does not help Erik achieve the wished-for sense of completion and make peace with his rather aloof and distant father, but quite the contrary. In spite of the amount of insights Lars leaves for his children, Erik quickly realizes that "it was what my father hadn't said that took over my life for a while - what he hadn't told us" (1).

As Erik and Inga learn from a cryptic letter found among Lars's papers, he has shared a long-kept secret with a certain Lisa. It sets the siblings on a quest to track down the mysterious woman and find out more about their father's past and personality. Rather than blaming his father for dishonesty or mystery mongering, Erik turns out to be well aware of the limitations Lars had to face: 'Every memoir is full of holes. It's obvious that there are stories that can't be told without pain to others or to oneself..." (8). In this context, Erik is convinced, the body serves as a necessary threshold: "That is the strangeness of language: it crosses the boundaries 
of the body, is at once inside and outside, and it sometimes happens that we don't notice the threshold has been crossed" (16-17). Given the circumstance that certain words may cause pain, Erik sees himself confronted with the question whether to let them slip out or not, and, apart from that, which ones to choose. After all, "language is often flimsy" (196). In general, Erik and Inga, both intellectuals, seem to have a relationship to their preferred way of expressing that is not merely enthusiastic, but also burdened and especially in Inga's case rather characterized by frustration. Her striking language sensitivity even happens to verge on fastidiousness: "The word itself is offensive. I have a date. I'm going on a date" (31; emphasis in the original). And also Sonia sets much store by the accuracy of the words she chooses or is addressed with: "It's such a strange word, personal. I've often wondered exactly what's impersonal" (269; emphasis in the original). For the Davidsen family, using language represents a struggle to find the right words or words at all and to keep others from slipping out.

Being fully aware of the limitations of verbalizing different thoughts, experiences or sights, Erik has managed to develop a strategy to deal with these gaps in yet again verbal terms: what cannot be put into words can at least be summoned by visual metaphors. In this respect, Erik turns out to be a talented and passionate translator. In fact, he uses his "visual grasp on language" to articulate mental images and complement words, passages, or accounts that in one way or another are problematic, incomplete, or simply curious (Hartmann, Literary Visuality 206). It is a habit that proves fruitful in his therapy sessions, for instance. When one of his patients describes her emotional state as "frozen out," Erik immediately thinks of "Ms. L. standing outside the locked door of a house in a snowstorm, shivering on the step" (88). It is through this mental picture that Erik connects with Ms. L. and makes her feel understood:

We talked about her words frozen out then, and my picture of her locked outside in the snow, about feeling numb, empty, and unreal, about her revenge fantasies, and she grew calmer. I felt like a man who had managed to steer a ship out of a gale. (88)

Erik applies what Hartman calls "reimaginative appropriation" to various scenes and episodes from Lars Davidsen's memoirs as well (Literary 210). What intrigues him most, however, is the letter from Lisa, and he cannot help visualizing the mysterious woman, the secret she has imposed on his father, and the fact that he does not know about it. Ironically, Erik's mental picture is longer than the short thank-you note Lisa has written:

I see Lisa walking into Obert's Lunch on a Sunday afternoon. It's a fall day in 1941. Pearl Harbor is yet to come. I imagine a heavy-breasted blonde with blunt 
features, wearing a trench coat and those short boots on the ankle I've seen in period movies. Then I see her and my young father (with a full head of hair) outside on a nearly empty, muddy street. She has her hand on his arm and is speaking to him urgently, but I am too far away to hear what they're saying. $(38-9)$

It is not the Second World War but Lisa's secret that is presented as the most unspeakable and traumatic experience associated with Lars's legacy. Erik and Inga do a lot of research to find the person who can lift the secret. Eventually, the siblings track down Lisa herself and learn about her connection to Lars, yet not by reading about it or being told the whole story. Instead, a sequence of three dioramas visualizes how Lars helped Lisa giving birth, cut the stillborn baby's umbilical cord, and buried it shortly after. Not even on her deathbed can Lisa find words to describe, explain, and define the event. Erik, in turn, gets another chance to act as a mediator. He transforms Lisa's diorama into a coherent narrative to make sense of it.

During the first year after his father's death, Erik opens up towards forms of communication and coping other than verbal language. He encounters people who deal with their memories and sorrows in primarily visual formats, that is not via mental, verbal, or other “improper" images but via concrete graphic objects (W.J.T. Mitchell, "What" 507). What interrupts his language-centred life most powerfully is the arrival of his new tenants, Miranda - a woman whose slight accent features the "musicality of Caribbean English" - and her witty pre-school daughter, Eggy (14). Much to the chagrin of Erik, Miranda quickly turns out to be a taciturn woman, radiating "a proud distance that [he] rather admired, but which made conversation difficult" (14). Either way, Erik's immediate attraction to Miranda is of a striking visual character:

Her eyes were unusual. They were large, almond shaped, the color of a hazelnut, and tilted upward slightly, as if someone in the family had come from Asia, but her intense gaze was what held me during those initial seconds. She then lowered those remarkable eyes toward her daughter and said, 'No, Eggy, he's not a giant. He's a tall man.' (13)

Lonely since his divorce, Erik becomes increasingly fond of Miranda and her delicate beauty. But it is not only that Miranda does not reciprocate his romantic intentions; even though they are separated, Miranda's ex-boyfriend Jeffrey Lane still plays a prominent role in her life and "it was difficult to know what she felt or didn't feel for Lane" (113). What still unites Miranda and Jeffrey besides their daughter is their common passion for the world of images. It does not 
take young Eggy long to detect the main difference between her father and her new neighbor, namely that "'Dr. Erik doesn't take pictures. He likes to talk.' That's what she [Eggy] said" (217). In the eyes of Eggy, Erik unambiguously embodies the verbal, while she herself and her family personify the visual art community. Besides making a living as a book designer for a major publisher, Miranda is a passionate painter who hands down her remarkable skills to her imaginative daughter. Going downstairs and entering Miranda's flat is comparable to entering a gallery of personal memories and dream experiences. Miranda has the habit of making drawings in reflection of her various nightmares. Fantastic settings and grotesque figures dominate her "dream drawings," which help her deal with the Jamaican colonial history and the hardships it imposed on her ancestors. In one of the images Miranda shares with Erik, "a robust female torso with long, athletic limbs, colored a deep brown" is attached to a miniature head in "a whitish yellow" (113-4). Miranda herself provides the interpretation of her painted dream sequence:

This is like the little white colonial head that wanted to rule the huge black body of Jamaica. Look, one foot is chained, enslaved, the other is free, like the Maroons. It's as if my brain collapsed it all into a single horrible figure. (114115)

The distorted figures Erik recurrently encounters in Miranda's painted nightmare reflections make him think of

Goya and of monsters in general. What's frightening is not their strangeness, but their familiarity. We recognize the forms, both human and animal, that have been twisted, contorted, elongated, or mingled together until we can't say they're one thing or the other. Monsters burst the categories. (23-24)

This analysis will become an ironic harbinger when Erik realizes that in Jeff Lane's photography he himself turns out to be the monster - an aspect which I will discuss in more detail further on.

Erik becomes fascinated and intrigued by Miranda's means of expression and eager to see more of it, more than Miranda shares with him. When Erik is asked to take care of her plants while she is away, he cannot resist the temptation to linger over her drawings every evening (225). Paradoxically, Erik detects even the slightest irregularities in Miranda's fantastic dream worlds: "After a moment, I noticed that the perspective was slightly wrong, that is to say, it didn't follow the rules we have come to expect, and this slight alteration created the dream effect Miranda had mentioned at dinner" (227). As Corinna Reipen aptly remarks in her 
analysis, "looking at her drawings liberates him from the constraints of his mind and the structures in which he used to think" (231). What drives Miranda in her art is, after all, neither accuracy nor the aim for realism, but on the contrary, her intuition alone: "I begin with the rough drawings I do after I wake up and then I fill them in bit by bit, finding my way forward to make sure it doesn't feel wrong" (103). Do such intuitive processes occur in Erik's journals and notebooks? Erik, who often feels frustrated with the limited scope of verbal language, is fascinated by the freedom and limitlessness Miranda's visual art warrants. He acknowledges that images may represent an engaging alternative to words, once the latter's "limits" seem to be stretched. After all, Miranda's drawings confirm what Erik

had always felt was true in my patients: their memories of war, rape, near-fatal accidents, and collapsing buildings aren't like other memories. They are kept separate in mind ... Trauma doesn't appear in words, but in a roar of terror, sometimes with images. (84-85)

The novel's treatment of 'trauma' seems to lack complexity at this point. Erik's conclusion that images lend themselves better to the representation of trauma than words appears quite arbitrary; it is neither comprehensive nor nuanced. In general, Erik's perception of Miranda's art is not unproblematic, as it seems to be informed by a certain naivety. In this respect, the novel's distinction between word and image resorts to a number of rather clichéd dichotomies. The encounter between Erik, who prefers to write, and Miranda, who prefers to paint, manifests itself in a 'reason versus intuition' issue. The emphasis of her intuitive take on art, however, appears to be motivated by gender clichés rather than a genuine interest in the alleged supremacy of visual self-expression. What is more, her image of a little white colonial head "ruling" over the huge black body of Jamaica conveys a rather conventional if not racially stereotyped dichotomy. Reading these lines, one may wonder what warrants Erik's admiration of Miranda's visual art and the lack of the critical stance that he otherwise takes on verbal language. The expressiveness of Miranda's images is further questioned by the fact that she considers it necessary to explain her own image with words, as I have pointed out above. In a critical reading of Sorrows, it is thus significant to shift the focus from Erik's rather glorifying perception of Miranda's dream drawings, and possibly the visual art world in general, to the performative level of the text. Erik's encounter with Miranda and Eggy's world of images does not aggravate his linguistic frustration. It makes his verbal potential unfold in the first place:

Miranda had left the place spotless, but on a table in the front room seven drawings had been laid out ... The first three were of the woman in Miranda's 
dream, rendered several times in black ink on each page. The lines of the looming figure were swift and forceful, and I could see that she was trying to get it right. Each line had to do a lot of work. The woman appeared to be immensely tall, thin, but with powerful arm and leg muscles. A giantess. She wore a loose dress and held a raised knife in her right hand. We'll have to clean the knife. There were two drawings of a fetus: the first a shrunken little body in a sac and the second a hearty, much fatter creature with an open mouth. The enchanted manchild. The last two were unfinished - ink sketches of the same image. A man wearing a hat lay on top of a woman in a long white dress. He had pinned her to the ground by her wrists. There was an air of violence in the picture ... (225-226)

It is through his lengthy ekphrastic descriptions that Erik makes sense of Miranda's drawings and provides a better understanding of Miranda and her cultural identity issues. One can say that her paintings vitalize Erik's use of language by relieving it from the demands of realism. They inspire him to a more creative and less conformist selection of words. They make him speak of different colors, shapes, and creatures, and adopt dissonant perspectives - all warranted by the scope of Miranda's imagination. This is how a vivid communication between Erik and the taciturn Miranda takes place after all. What is accentuated is thus not the power of images in comparison to writing but, on the contrary, the ekphrastic power of language in response to images. Hence, the novel constructs a tension between word and image and in the very next moment resolves it in favor of language.

A similar construction occurs with reference to the "collapsing buildings" permeating the post-9/11 cultural landscape, which the novel explicitly situates itself in. The terrorist attacks cast a shadow over the setting and the characters; the smoke is still palpable and burdens the memory of Sonia, Erik's niece, who has been an immediate eye witness of the event. As the reader learns in the course of the novel, Sonia has not yet found a way to come to terms with what she saw. Not even her poetry skills afford her any relief:

There's supposed to be one [a poem] about September eleventh next, but I haven't been able to write it. I've tried over and over again, but it's too hard. Maybe I'll just have a blank there - a nothing, a big empty spot with only the date. (127)

This is how the novel draws on a discourse that reoccurred in the wake of the terrorist attacks from September 2001 and, most basically, concerns the lack of words in the face of tragedy. As 
Catherine Morley argues, language turned out inadequate not only in the face of the tragic character yet also in light of the overwhelmingly visual character of the events:

The world was suddenly presented with a series of awful images: the plane taking its course through the skyscraper, the burning tower, the falling man, the female executive covered in ashes, the red-faced fire-fighters, and, of course, the memorial-placard images of the dead. And with this sudden proliferation of compelling visual images, the ability of writing to approximate the real was, of course, called into question by practitioners and cultural commentators alike. (Morley 298)

Writers were preoccupied looking at pictures of this unprecedented tragedy. And in fact, numerous authors and thinkers, including Don DeLillo, Toni Morrison and Zadie Smith declared publicly that words failed them and voiced the need to be silent, at least in the immediate aftermath of the events. "The writer wants to understand what this day has done to us," declared Don DeLillo, but wondered, "Is it too soon?" ("In the Ruins"). "After a couple of hours at their desks, on September 12, 2001, all the writers on earth were reluctantly considering a change of occupation," wrote Martin Amis without foreseeing, of course, the rise of the post9/11 literature that would not take long to wait for.

This kind of (initial) silence is not a new phenomenon. In war aftermaths writers are faced with a "complex situation in which war simultaneously cannot be, should not be, and must be represented," as ethical risks clash with the necessity of protest, understanding, and education (McLoughlin 47). These contradictory imperatives have a long history and have not only since $9 / 11$ been greeted with silence:

It is fair to say that the debate regarding the potency of words in the face of the visual has a long history. In the American context, such questions have largely concerned photography and the rise of photojournalism throughout 'the American Century,' largely in the aftermath of World War I and II and the highly photographed Vietnam War. (Morley 299) ${ }^{85}$

Obviously, however, novelists have stuck to their profession. The silence has not been maintained and post-9/11 literature has arisen. And then again, reading post-9/11 literature does not simply mean reading accounts of 9/11. It is a complex and burdened genre that is concerned precisely with the renegotiation between word and image, with attempts rather than 'bold'

\footnotetext{
${ }^{85}$ For a closer examination of the subject's historical scope, see George Steiner, "The Retreat from the Word" (1961) and "Silence and the Poet" (1966).
} 
decisions to put painful memories into words. Kate McLoughlin describes this art of "not telling" as follows:

Paradoxical as it may seem, there do exist a number of strategies for not writing about war, and, more paradoxical still, they are deployed in the very process of writing about it. Such strategies, worked out in literature over centuries, range from topoi to subject matter, pushing linguistic resources to their limits in the project of not telling. (47)

One of these strategies is to write a 'counternarrative' rather than struggle with ekphrastic descriptions of an attack that has developed into a multifaceted media event. It is through the focus on her individual viewpoint that Sonia eventually manages to articulate what she witnessed. Before elaborating on the question of the "counternarrative" in section 5.4, however, I shall focus on the novel's complication of the word/image tension with reference to a severe case of privacy violation and digital manipulation. After all, the necessity of a counternarrative arises primarily in the wake of Erik's confrontation with Jeff's post-photography (rather than Miranda's drawings). Jeffrey produces images that can be located at the precarious threshold between the imaginary and yet (too) real. They complicate the relation between word and image by questioning the scope of ekphrasis, especially in cases in which words are supposed to defend rather than merely describe. When it begins to painfully interfere with Erik's concrete life realities, Jeff's photographic self-expression becomes even more precarious and questionable. Jeff's case is symptomatic for the complexities and ambiguities inherent in both the production and reception of photography in the digital age. It indicates multiple and diverging understandings of the photographic medium, which I shall take a closer look at in the next section.

\subsection{Jeff Lane's Post-Photography}

When Miranda and Eglantine move into Erik's house, they breathe new life into his daily routine. Even though his subtle advances ultimately remain futile, Miranda's beauty makes Erik rediscover his sexual longing and his desire to start a family one day. And also his friendship with the charming Eggy gets Erik's mind off the sorrows related to his recent divorce and father's death. What is more, Miranda's art opens him up to forms of self-expression other than verbal language. His new pastime is lingering on Miranda's impressive paintings, which can be examined and enjoyed beyond such categories as right or wrong, accurate or non-accurate. 
There is, however, also a negative side effect to the enrichment of Erik's life through Miranda and Eggy. The clear downside to his new acquaintance is that it involves coping with Miranda's bold ex-boyfriend, Jeffrey Lane. As already mentioned, for Eggy, Dr. Erik is the one who prefers to talk, while her father is the one who prefers taking pictures. Miranda seems to have a slightly more concrete idea of Jeffrey's career: 'He'd inherited money, and so he didn't have to work at a job. He just pursued his art, which is photography - digital stuff, mostly" (76). As far as one can conclude from Miranda's description of her ex-boyfriend, Lane's camera does not serve the recording of supremely accurate traces of reality; its purpose is not that of "an ideal Cartesian instrument" (W.J. Mitchell, The Reconfigured 27). Rather than relating to him as simply a photographer, Miranda speaks of a visual and performance artist, "the all-in-one," as it were (221). Primarily, Jeffrey comes across as a mysterious stranger, who steps into Erik's life via images. He makes Erik aware of his threatening presence by occasionally leaving photographs on the doorsteps of his house. The way Erik describes these findings, however, is not necessarily reminiscent of the way he would look at art:

There were four lying on the house steps when we returned. At first I mistook them for the flyers or menus that appear regularly outside Brooklyn houses. Prepared to discard them, I bent over and saw four Polaroids of Miranda and Eglantine in the park. Miranda was tying Eggy's show near the swings at the playground. Across Miranda's bent torso someone had drawn a black circle with a line through it. I muttered some low exclamation and picked up another picture, which must have been taken only minutes later. Miranda was pushing Eggy on a swing, and this time the crossed out circle was drawn across the mother's face. The two others were of similar recordings of the innocent outing, each one marked by the peculiar sign of another part of Miranda's body. My first impulse was to hide the pictures from both of them. (28)

By using a Polaroid camera Jeff confronts Erik with his perspective on very recent events and thus makes him aware of his close and uncanny proximity. In this case, the immediacy of Polaroid photography serves Jeff as evidence that he observed a recent scene in the park and keeps Miranda and Eggy under surveillance. ${ }^{86}$ Jeff's use of photography seems to be quite straightforward and unambiguous in this context. In line with the early phenomenological

\footnotetext{
${ }^{86}$ In his book The Camera Does the Rest: How Polaroid Changed Photography, Peter Buse points out the "Polaroid Difference" (59): Polaroid cameras produce instant photography, singular prints with fixed size restrictions and no usable negative. These aspects differentiate Polaroids from other forms of photography, which lend themselves to being copied and edited.
} 
photography theories by André Bazin and Roland Barthes, it simply confirms "what has been" (Barthes, Camera 93). His intention to provide imprints of real scenes rather than producing creative art is additionally stressed by the circumstance that he did not only record but also respond to what has been. Let me explain this aspect in a little more detail. On each photograph, a different part of Miranda's body has been covered by a crossed out black circle. This disfigurement reminds Corinna Reipen of Roland Barthes' concept of the "punctum," a small detail in the photograph which attracts the observer's attention in an unexpected fashion. Barthes' notion of the punctum oscillates between a concrete and a rather abstract conceptualization. In abstract terms, Barthes writes in Camera Lucida about an "element which rises from the scene, shoots out of it like an arrow, and pierces me" (26). "A photograph's punctum is that accident which pricks me (but also bruises me, is poignant to me)", he adds (27). It may, however, also be a "sting, speck, cut, little hole" (27) or simply a "mark made by a pointed instrument" (26). Reipen is convinced that only the latter, most elementary understanding of the punctum is relevant for the novel. She notes that

while the meaning of the punctum has been widely discussed in the greater photographic discourse, in the novel the sign of the photographer - 'black circle with a line through it' (TSoaA) - literally translates Barthes' conviction that there is always an element in a photograph that doesn't allow the spectator full access to the past reality it represents. (219)

Shooting Miranda and his daughter at the park, Jeff does not only document the scene but also his act of voyeurism. Erik, in turn, is explicitly denied full access to what Jeff saw when his view is disturbed by the various black circles or punctums. Despite their separation, Lane still lays claim to Miranda's beauty as well as the privilege of observing it.

When, in the course of the narrative, Erik finds yet another pile of images at his doorstep, the 'having-been-there' understanding of the photograph comes to play an even more significant role:

The seven photographs I found the following evening had been left for me, not Miranda ... The photos had been taken the day I walked home with Eggy and Miranda, the day we found the first Polaroids on the steps. They didn't include the discovery of the pictures, only our walk on Seventh and up Garfield. In each one Eggy had been wiped out - all that remained of her was a small white silhouette on the sidewalk. (73-74) 
His retrospective, manual editing of the pictures powerfully highlights his wish to alter 'what has been' and his displeasure that 'this has been' in the first place. He creates indexical traces of Erik, Miranda and Eggy's togetherness in order to respond to and "revise" it in front of Erik's eyes. That Eggy should not have been there seems to be the unambiguous message behind Lane's manipulation. His jealousy of Erik's increasing closeness with his daughter seems to turn the visual artist into a bold stalker.

Jeff's transgressive behaviour reaches its preliminary climax during his first personal encounter with Erik, which takes place in the latter's apartment, at night, without his consent. Armed with a hammer, Erik goes downstairs after hearing noises, ready to confront and ward off whom he erroneously expects to be an ordinary burglar:

I noticed that the thing the man had taken from his pocket was a small digital camera, and in that same instant I understood that I was face to face with Jeffrey Lane. The revelation caused me to lower the hammer. Then I froze. He saw his chance, turned and ran, but had the gall to stop and photograph me. (111-12)

For Jeff, "photography is a form of thievery," Erik concludes (113). "He was a man in the business of stealing appearances," whose intentions had little to do with art. And Erik is "involved now," be it in the role of the victim or in the role of the involuntary consumer of Jeff's spoils (76). After all, Jeff lures Erik into a form of voyeurism he formerly had denied to him, and carries it to extremes:

I saw a heap of papers on the top steps. Even before I bent over, I knew. There must have been a hundred pictures, most of them cheaply printed on ordinary paper - a glut of photographs of Eggy and Miranda and self-portraits of Lane with his camera... I shuffled through them, quickly casting them aside until the near bottom, I found an image of Miranda, naked and asleep in a bed, probably Lane's. She was lying on her side, her face partly hidden by the pillow. (209210)

This is when Erik realizes that appearance thievery is probably not the end of the story: "As I looked at the curves of Miranda's narrow hip, her breast covered by one arm, I felt a sudden rush of anxiety, walked to my window, and closed the shutters" (209-210). Jeffrey's stalking turns into a real threat to Erik's life and restriction of his freedom.

One day, Jeff appears at Erik's house to reveal to him his photographic agenda, which does not pose any ethical questions. On the contrary, “it can't be simple, and it has to be 
dangerous. I have to go as far as I can" (218). Rather than a stalker, he sees himself as an explorer who remakes his documentary trips "when it's over." "It's all staged," Jeff emphasizes and regards his supposedly artistic assault on Erik's privacy as fully valid and harmless. His rampancy and disregard of the private/public boundary result from his specific understanding of photography, which sticks to traditional practices (e.g. polaroid photography) on the one hand, and is strongly informed by digitization and its alleged consequences, on the other hand:

But I need the photos, you see, it's not like I can help it. It's documentation, man, it's my whole splendid mess on film. Digital magic. Jeff's life. Warts, sad, but there it is. Moi. Giving that up would be impossible. The world's going virtual anyway; there's no reality left. Simulacra, baby. (217)

Obviously, Jeff's worldview is informed by Jean Baudrillard's theory of the simulacrum, which for him as an artist warrants the transgression of certain boundaries. Jeff blends documentation with digital magic, third-person ("Jeff"s life") with first-person perspectives ("moi”) and speaks of his "whole splendid mass on film" only to conclude a few lines later that there are no vestiges of reality left anyway.

Simulacra are according to Jean Baudrillard copies for which there is no original, signs of a world in which "it is the map that precedes the territory," to quote but one of many popular lines from his seminal work Simulacra and Simulations (1). Baudrillard's case studies range from Disneyland to the Gulf War, which according to his controversial polemic "did not take place. ${ }^{~} 87$ He thereby points out the discrepancy between the so-called television war and the one that really took place or did not, respectively. With his suggestion Baudrillard aroused controversy and yet raised awareness of mass media's possible deviations from social reality. In this respect the novel's mention of the simulacrum resonates with the post-9/11 climate it conjures up. As it turns out, Erik's sister Inga, as a cultural-critical scholar, participates in the very same discourse that Baudrillard and other postmodern theorists have started. We learn that in one of her publications, namely American Reality: Examining a Cultural Obsession, "Inga has devoted one chapter to the media's version of September eleventh and its almost instantaneous construction of a heroic narrative to gloss the horror" (48-49).

What is palpable in Hustvedt's characterization of Inga's scholarship is the threat of hyperreality. As one of Baudrillard's core concepts, self-referential hyperreality is defined by its indistinguishability from the material world. As a consequence, the 'origin in reality'

\footnotetext{
${ }^{87}$ Baudrillard, Jean. The Gulf War Did Not Take Place. Bloomington: Indiana University Press, 1991.
} 
becomes non-existent - or at least increasingly irrelevant. However, hyperreality does not simply replace reality with fiction; it supersedes the distinction in the first place, and more often than not creates a somehow exaggerated or excessive version of the material world. Among the contemporary mainstream media formats that perpetuate Baudrillard's vision, the Reality TV show might serve as the perfect example. Under the pretext of exploiting the newest surveillance technology, the Reality TV show gives prominence to the evidential force of the photographic image. "The evidential aspirations of photographic discourse is (sic) powerfully carried on - if not stretched to its limits - in reality TV," writes Arild Fetveit (123). It is a reality that is endlessly recycled and literally hyped by marketing managers, advertisers and TV producers. Referring to one of the first examples of TV-Vérité, the PBS show "An American Family" (1973), Baudrillard wonders, "does it refer to the truth of this family, or to the truth of TV?" (Simulacra 28). The mass of contemporary reality TV shows operates under the same “infinitely reversible binary," as Jeffrey Sconce would phrase it (180). This indeterminacy whether TV dissolves into life or life into TV determines the zeitgeist that The Sorrows of an American is set in. Tellingly, Inga's critical meditations on postmodernity concern the reality TV boom as well:

At the same time, 'reality' in America has become synonymous with the rank and sordid. We've fetishized the true story, the tell-all confession, reality TV, real people in their real lives, celebrity marriages, divorces, addictions, humiliation as entertainment - our version of the public hanging. The crowd gathers to gape. (47)

Inga's use of the word real(ity) both in quotation marks and a markedly tiresome enumeration points to her awareness of its increasing relativity or meaninglessness. Much of the promotion of such reality formats actively encourages the confusion between fiction and reality and profits from the blurring boundaries in a media-saturated world as well as the viewers' need to gape rather than to see. One can conclude from Inga's precise observation that TV has collapsed not only reality and fiction, but also private and public. While she adopts an intellectual attitude to the "hackneyed pictures and dead words" of the hyperreal affecting the basis of human perception, Lane seems to enthusiastically embrace the "simulacra, baby!" (49). For him, the notion of hyperreality mainly implies to be freed from restrictions that came along with the differentiation between reality and fiction, documentation and manipulation.

Digital photography becomes the perfect instrument for Lane's Baudrillardian understanding of reality. Since his argumentation is based on the circumstance that "the world's 
going virtual anyway," one can assume that it was the analog/digital shift in photography that made him so assertive about "remaking the world" (118). He concludes this mission with an exhibition at an art gallery titled "Jeff's Lives: Multiple Fictions, or an Excursion into DID" (260). It is precisely at this art gallery in Chelsea where the clash between theoretical concepts and the lived realities of Hustvedt's characters reaches its climax. The question of the simulacrum and abstract understanding of today's mass mediation quickly turns into an issue of surveillance, disgrace, and assault when Erik learns from one of his patients, Ms. W., that she saw his photograph "at the opening of a show" (257). He "looked so different," it made her doubt the sense of the therapy and whether its "talk, talk, talk does any good." Here, the narrative hinges on an unlikely coincidence: Of all of New York's art exhibitions, Ms. W. happens to find herself in front of her therapist's "stolen appearance." At this point, the narrative betrays the construed character of the causality between radical photography and linguistic crisis. This causality is exposed as a performative act of the text. In other words, the narrative compels Erik to react to an unpleasant picture and an unpleasant situation, most probably to highlight the actual scope of his verbal abilities.

When Erik himself arrives at the gallery, he learns about the real purpose behind Jeffrey's recent burglary and tries to articulate what he sees:

It was an eight-by-ten photograph, mixed in among other pictures with the caption Head Doctor Goes Insane. But in that first moment, I wasn't sure who I was looking at. Anger had contorted my face to such a degree that I was almost unrecognizable. Like a rabid dog, my eyes bulged and my teeth shone. I was dressed only in a threadbare pajama top unbuttoned to the waist and a pair of boxer shorts. The cowlick jutting from my hairline stood at attention, my Adam's apple protruded, and my long naked legs and bony knees glowed pale in a dim light that had an unreal glint. In my lowered right hand, I gripped the hammer I had hastily retrieved from my closet. As I looked more closely, I noticed that the picture appeared to have been taken outside rather than from the stairs above the second-floor hallway. I saw the fuzzy outlines of parked cars, a sidewalk, and the street. Lane had altered the setting. Ms. W. had been mortified, not only by my vengeful expression and the sight of her analyst stripped of his dignity, but the photograph made it appear as if I had been raving half-naked in the street, wielding a hammer. Beside it was a large image of Lane with a large bruise on his forehead. Could I have caused it? No, I thought, he looked fine when he left. 
(Near my own image, I saw one of Lane's father, a photo of George Bush, the Twin Towers, a hospital corridor, and war images of Iraq. But I didn't stay to study them.) I backed away from the pictures, suddenly nauseated, and staggered out into the bright light of Twenty-fifth Street, where I squatted on the sidewalk for a moment with my head lowered to prevent the oncoming faint. Fathers. (262-63; emphasis in the original)

What might appear to the unknowing bystander as a documentation of Jeff's life, unfolds before Erik's eyes as a series of lies. By decontextualizing the image of Erik's rage, Jeffrey cunningly denies the fact that it has been caused by domestic disturbance on behalf of the photographer. And he makes a special effort to ensure that the roles of victim and perpetrator are reversed. By adding a photo that shows himself, Jeff implies a causal connection to an injury on his forehead, showcasing the alleged target of Erik's hammer and thus indicating a dimension of violence that has never occurred. The paradox of Erik's ekphrastic description is that he repeatedly applies the first person to a picture that repels him. When he writes that "I was unrecognizable" or that "I was dressed only in a threadbare pajama," the question arises whether he identifies with the distorted picture. Has the word "I" slipped out of Erik's mouth and betrayed a certain truth behind Jeff's portrait of an aggressive man? Has Jeff thus managed to reveal the flimsiness of language, and consequently reinforced Erik's frustration with the latter? Either way, Erik's ekphrastic use of language indicates an ontological uncertainty that might have been brought about by Jeff's cunning use of digital technologies, in combination with other forms of decontextualization.

Jeff has created the perfect simulacrum through digital technology. The fluidity and malleability of the image in digital photographic culture has provided him with an unprecedented precondition of living and creating art according to the Baudrillardian understanding of reality. It does not mean that he necessarily proceeds from a radical rupture between analog and digital photography. As already mentioned, this dichotomy is questionable anyway. Images have been manipulated long before the digital era, and digital photographs are still used as documents. Liz Wells and Derrick Price point out that in theory,

digital 'photographs' can be constructed with no reference to external phenomena. In practice, photography has become hybrid in that we continue to compose pictures in documentary idiom, but can amend and adjust - not to mention, delete - with great ease. (26) 
It is not easy to determine what it is that has changed in photography and to what degree. The attempt to take part in the discourse is accompanied by the permanent risk of either exaggerating or understating the (paradigm) shift that has occurred in the wake of digitization.

Siri Hustvedt, as I shall argue, has found a way to address this complex dilemma in her fiction and at the same time respond to it. With Jeffrey, she has developed a character that comes close to embodying a structure of feeling which could be considered post-photographic, including all its ambiguities. Baudrillard's pre-digital concept of hyperreality underpins if not stretches Jeffrey's artistic licence to arbitrarily amend and adjust his photography. Digital technology gives Jeffrey the possibility to amend, adjust, delete, add, or distort with unprecedented ease. Post-photography can thus be considered a more radical interpretation of Baudrillard. It concerns and encourages not digital manipulation but manipulation in the digital age, which to the same extent applies to Jeff's cut-out Polaroids. One can say that he has internalized a new understanding of photography that is explicitly detached from any documentary commitment whatsoever. Therefore, Jeff is a post-photographer rather than a digital photographer or artist, who confines himself to new technologies or new media. He takes photographs not in order to document the world but in order to gather material for the creation of his own world. For Jeffrey, indexicality is no longer the defining characteristic of the medium, be it analog or digital photography, but at most describes the first "raw" stadium of the image. And still, in the case of Jeffrey there does not seem to be a "raw" stage at all, as the violation of his subject begins with the impudent way he takes photographs.

Rather than an isolated case, Jeff's understanding of photography is indicated to be representative of the visual art community in New York. Ironically, it is Miranda, a member of this community and the main subject of Lane's 'art,' who arguments in favor of his images and defends it in front of Erik:

Jeff wanted me to tell you that he used it as an image of the dangerous father, not you as you ... That photo was a violation of your privacy, but it was powerful, and I understand why Jeff wanted it in the show. I can get really angry. Sometimes it's like a fire inside me, and it helps when I'm drawing, helps to push me ahead and not be frightened of what I'm doing. Jeff's father was an angry man. (274)

Miranda's paintings are inspired by her dreams; Jeff, in turn, steals appearances from people whom he thus makes vulnerable through his photography. Miranda seems to downplay this discrepancy between her and Jeffrey's art. In fact, she speaks of Jeff's photography as if it was 
a subcategory of painting. This is how Miranda's voice echoes Lev Manovich who made a very similar suggestion with regard to digital cinema due to its increasing indistinguishability from animation. $^{88}$

The question as to how far photography could be considered to be art dates back to the early days of the medium. Celebrated for the mechanical accuracy of its reality recordings and the minimum of human intervention, photography passed as the opposite to art in parts of the nineteenth-century criticism in Western culture. Baudelaire was one of the thinkers dictating photography's "true duty," that is being "the secretary and record-keeper of whomsoever needs absolute material accuracy for professional reasons" (Wells 15/ Baudelaire, "The Salon" 297). There were photographers who accepted this definition and thus could be assigned to the camp of "straight photography" proponents. Then there was the Pictorialist movement from the 1850s onwards, which sought to uncover the aesthetic value of photography and its potential resemblance to painting (see Wells 15). The repertoire of Pictorialists was resourceful: allegorical subjects were arranged in careful compositions; traces of technological perfection were reduced and made room for blurred, fuzzy, and out-of-focus sights; special printing methods such as the gum bichromate process served to imitate a canvas. Key figures like New York based artist Alfred Stieglitz devoted their entire careers to making photography an accepted art form.

The introduction of digital camera equipment and computer programs such as Photoshop have led to yet another dimension of photography as a true art form, by creating unprecedented opportunities for experimentation. This is when critics were ultimately convinced to speak of a multitude of photographic practices rather than struggling to work out a unified definition. Nowadays, the use of the photo camera as a surrogate paintbrush partly occurs in a very literal sense. A popular technique among digital photographers is, for instance, "painting with a slow shutter speed" (Peterson 60). Shutter speed or, in other words, exposure time denotes the interval of the opening and closing of the shutter. When you decide to move or even twirl and jiggle the camera at a slow shutter speed, the result is a fully blurred picture reminiscent of an abstract painting. And there is another virtue of this hybrid of art and digital photography which might appear trivial at first sight but may turn out significant after all: "Experimentation can, and often does, prove successful, and again, digital photographers never have to fret over the film cost of their experiments - since there are none" (Peterson 61).

\footnotetext{
${ }^{88}$ See section 3.4, "An 'Explicit' Approach to the Digital Age."
} 
But of course, there are a lot subtler examples of digital art photography, and numerous can be found at Jeff's exhibition, as Miranda would argue. Fetveit notes that "digitalization has substantially expanded the spectrum of photographic techniques available - especially within the increasingly blurred boundaries between painting and photography" (127). From this viewpoint, digital technology allows Jeff to re-emancipate himself from what the medium allegedly does best, its "true duty" as it were, namely accurate and dispassionate recordings, naturalistic documentation. It finally concludes the historical tension between a wholesale technological view and a rather conventionalist view of photography, in favor of the latter which is promoting a coreless photographic plurality. What has recently occurred is thus not a shift from photography to post-photography but from photography to post-photographies. Through Miranda's support this perspective is given considerably more authority within the novel.

This is, however, an understanding of photography which Jeffrey and Miranda do not necessarily share with the visitors of the exhibition. On the contrary, it is quite clear that Ms. W., for example, has not doubted for an instant the authenticity of the hammer scene. While it does not seem to make a difference for Jeffrey whether his manipulation is digital or manual, the case of his digitally manipulated exhibition piece is particularly dubious. While the traces of manipulation are visible and even striking in the Polaroids and the other images Jeff left at Erik's doorstep, the alteration of this disgraceful portrait of Erik goes unnoticed if one does not know the context. The photorealism of Jeff's doctored amateur photography has successfully misled Erik's patient. Not even the title of the exhibition, which hints at its "Multiple Fictions," has led to the slightest questioning of Erik's untypical display of violence and the evidential authority of his portrait.

Perhaps one of the most curious facets of contemporary imaging is that, despite knowing the extent to which pictures can be and are manipulated and the ease with which this can be archived through various software, we suspend disbelief and continue to ascribe authenticity to photographic images... (35)

writes Liz Wells and thus unknowingly articulates a sentiment conveyed by the novel. Ms. W.'s failure to detect the fraud can be explained with the still prevalent, if not paradoxically increasing trust in the documentary function of photographs, which occurs in the scope of a vicious circle: The fascination with indexical photography resulted from its conveyance of a closeness to something infinitely remote. According to Arild Fetveit, digital technology permeated photography at the expense of this "sense of connectedness, of contact with the 
world" (132). ${ }^{89}$ With its focus on footage from surveillance videos or authentic amateur recordings, the Reality TV format compensates this (at least partial) loss. But it satisfies its viewers' longing for a lost touch with reality at yet another expense. It is not only that the Reality TV show further relativizes our sense of reality (for example, by introducing the experience of "too much reality" together with an immediate "relief" that can be achieved by a touch on the remote control). As Inga has aptly observed, the Reality TV format stimulates an almost frantic obsession with the recorded evidence and puts it in the context of sensationalism. Of course, one could argue that it is simply Ms. W.'s lack of media competence that stops her from differentiating between the imprint of a real scene and a fake, or at least from taking the latter into consideration. And yet, I would argue that Hustvedt indicates a more radical juxtaposition that is Jeff's knowing exploitation of his viewers' naivety, on the one hand, and a certain readiness of a frustrated patient to believe in the weakness of his or her all-knowing psychotherapist, on the other. This thorny combination makes the outcome for the protagonist all the more ethically questionable. What counts for Erik is that his reputation as a psychotherapist is at stake and that Jeff's photography unpleasantly, to say the least, collides with his private and professional life. Jeff has freed himself from the restrictions of a realist notion of photography. For Erik however, the non-reality or hyperreality of Jeff's oeuvre becomes a sober and bitter reality: “The photograph lived on, however, in Ms. W.'s head, as well as in mine" (264).

The reading of The Sorrows of an American necessarily goes around in circles. Is Jeffrey Lane a contemporary artist, a convinced (post-)photographer, or simply an ill-tempered and revengeful stalker, who possibly even misuses a current cultural climate as the perfect pretext for (stealing appearances for the sake of) his dubious images? Or is he all at once, "half artist, half paparazzo" (78), as Miranda would say, "the all-in-one," as it were (221)? On the one hand, Jeff is clearly introduced as someone who in the postmodern world of the simulacrum escapes the ethical responsibility for his photography and its public display. On the other hand, The Sorrows of an American provides a compelling read precisely because it illustrates the discrepancy of perspectives. This discrepancy complicates any "ekphrastic attempt" at Jeff's images. Heuristically, one could say that Miranda's pictures were "imaginary enough" to be made verbally sense of; the pictures of the terrorist attacks seem "too real" or, to put it differently, too painful in their actuality to be met by appropriate words (by Sonia, for example).

\footnotetext{
${ }^{89}$ Roland Barthes' anecdote about Napoleon in Camera Lucida appears noteworthy in this context. When he saw a photograph of Napoleon's youngest brother Jerome, it made him realize with amazement that he was "looking at eyes that looked at the Emperor" (3).
} 
Jeff's images, in turn, are neither imaginary nor real; they occupy a strange liminal space, which, on the one hand, can hardly be grasped by words in spite of Erik's efforts to do so: "I couldn't understand what Lane had meant by the pictures" (263). On the other hand, it is precisely this ambivalence of Jeff's photography that seems to make a verbal reaction, if not correction, all the more necessary. But are the territories of the word not too "shady" or too “flimsy" (to quote both Mark Z. Danielewski's narrator Zampanò and Siri Hustvedt's narrator Erik) to mediate between the ontologically confused viewer and the digitally manipulated picture?

Hyperreality stretches the boundaries of photography. Does it not affect language in a similar way and thus render it even "shadier"? ${ }^{90}$ And what if it is this parallelism that turns out to be a productive source of counteraction after all? In regard to these questions, the next section discusses how the novel's characters renegotiate (or test) the boundaries of language, partly in response to the bold transgression of Jeff's photography, partly in response to the post-9/11 image flood, and partly out of (un)professional and "tabloidy" reasons.

\subsection{Erik's Verbal "Counter-Exhibition"}

Erik and Inga's struggle with the limits of verbal language conjures up a long history of linguistic scepticism. It is reminiscent of a crisis of language that took place in the second half of the nineteenth century and produced Hugo von Hofmannsthal's "Lord Chandos Letter" (1902), in which he recapitulates and describes his resistance to verbal communication. This wide intellectual crisis in Europe left its imprint on the writings of Joyce, Kafka, Musil, Rilke, T.S. Eliot, and, obviously, Siri Hustvedt. In her novel, she ponders 9/11 and its impact on her characters' use of language. Psychoanalyst Erik's verbal inhibition is not necessarily a result of 9/11. But one can assume that the event has at least increased his sensitivity to the difference between words that are supposed to be uttered and those that are better not. Erik carries with him an internal censorship. Language is for him a tool of expression that is both involuntarily and necessarily limited.

\footnotetext{
${ }^{90}$ Most contemporary examples for the "stretched boundaries of language," or the shift of the utterable, comprise the current discourse of the so-called post-truth politics which has dominated the 2016 US-American presidential race between Hillary Clinton and Donald Trump. It is about the subversion of the private-public dichotomy for the sake of an emotive language and how the delivery of facts has been replaced by the production of facts (see Brooks, Davies and Petrovic). Another example would be the increasing tabloidization of mass media, which shall be addressed in further detail in the next section.
} 
Siri Hustvedt takes up this point in her short story "The World Trade Center" (2002): “It may be easy to say, 'Burning bodies fell from the windows of the World Trade Center,' but it isn't easy to embrace the reality of that sentence" (158). Next, Hustvedt describes how second-graders had to face the collapsing towers through their classroom window and the range of their different reactions. It is this subjectivity that makes her argue for more linguistic sensitivity. "We have to talk, but we should be careful with our words," reads the short story's conclusion (159).

With Erik Davidsen, Hustvedt has created a character that takes this post-9/11 responsibility for his word choice, and what is more, has internalized it to a degree that controls his life and stifles his self-expression. In the course of the narrative, Erik, or to speak metonymically, the crisis of language has fateful encounters with all sorts of images. Miranda moves into his house and turns his first floor into a tempting gallery of dream drawings. Photographies pile up at his doorstep and make him experience what has been in a radical, even threatening way. For a better understanding of Erik's encounter with the painted and especially the recorded, it makes sense to rethink the relationship between photograph and language from scratch. Hartmut Winkler, for instance, makes the following observation:

The entire evolution of media, I would like to suggest, can be understood as a series of attempts to come to terms with the problem [the limits of language] outlined above. This becomes especially obvious with regard to so-called 'technical images.' Around 1900, photography and film were enthusiastically embraced as a redemption from language. Photography and film are able to transform into a cultural practice what in Hofmannsthal's 'Chandos Letter' remained a numinous aesthetic experience: photography and film are indeed a radical language, articulating themselves in concreteness. They set the particular against the universal, whose value is increasingly doubted; they contrast the unity of general concepts with a multiplicity of concrete examples. The concept 'table', for instance, can be dissolved into the plurality of all the tables that can be photographed, which means that abstraction as well as the generation of signifieds can be avoided. Technical images are able to operate without any reference to the organized system required by natural language. They are able to counter the conventionalized norms of natural language with a more open structure. This structure might not be entirely devoid of rules and norms, but these do not support the system of representation as a whole and are not 
dependent on the establishment of a social consensus. 'Openness' fundamentally belongs to the promise of technical images. Wherever language seems dependent on conventionalized meaning, images can offer a multiplicity of meanings. (234)

Siri Hustvedt draws the picture of a society in which the conviction that "photography never lies" is deeply rooted (Barthes, Camera 87). At the same time, the lie that photography can tell has become unprecedentedly convincing in the digital age. Jeff's half-photographed, halfcomputer-generated lie brings us back to the role of language and the significance of the caption. After all, the undetectability of digital fake "makes us more heavily reliant upon the truthfulness of the claims made about photographic images" (Fetveit 127). Already in 1930, Walter Benjamin predicted the increasing importance of captions in the wake of technological progress:

The camera will become smaller and smaller, more and more prepared to grasp fleeting, secret images whose shock will bring the mechanism of association in the viewer to a halt. At this point captions must begin to function, captions which understand the photography which turns all the relations of life into literature, and without which all photographic construction must remain bound in coincidences ... Will not captions become the essential component of pictures? (“A Short History” 215)

As mentioned above, for House of Leaves narrator Zampanò this vision rather gives reason for concern: "Truth will once again revert to the shady territories of the word and humanity's abilities to judge its peculiar modalities" (145). And US-American filmmaker Errol Morris provides yet another perspective on the power relation between word and image, caption and photograph, stating that "doctored photographs are the least of our worries ... All you need to do is change the caption." Especially tabloid journalism tends to decontextualize and dramatize shots of celebrities' private moments by their captions. Ironically, Erik's sister Inga has become subject of precisely this sort of journalism. In fact, Erik and Inga seem to be trapped in a strikingly similar situation, even though one springs from an unexpectedly transgressive use of photography and the other from an unexpectedly transgressive use of language. While Erik has a stalker who is equipped with a photo camera, Inga has a stalker who is equipped with words, the red-haired tabloid journalist Linda Fehlburger.

Fehlburger's investigation centers on a certain Edie Bly, actress and former lover of Inga's deceased husband, Max Blaustein. She claims that she has received love letters from the director whose content, if published, might compromise Inga and her daughter. The most 
sensational part of the story is, however, that Blaustein could turn out to be the father of Edie's son. What is more, it turns out that Inga had already lived at the precarious threshold between private and public when her friend and secret long-time admirer, Bernard Burton, informs Erik about his sister's considerable digital footprint, which has been manipulated by the "Burger woman":

It's unlikely that you're aware of the various materials to be found online about your sister. I confess to having kept abreast of the articles, interviews, and notices over the years. I had imagined that in this specific case, the target was Max Blaustein, muddying his reputation, but it has come to my attention that this Fehlburger personage, curious name, Fehl is fault or blemish in German, as you are no doubt aware. I seem to remember you studied German. In all events, this Fehlburger is intent on injuring, not the reputation of your deceased brother-inlaw, but that of your sister, for whom she has particular venom, the cause of which I have not been able to uncover. There exist, however, online, several startlingly cruel and gratuitous attacks on your sister and her work written under several names, three of which I have been able to connect to this single woman... It's been some time since you and I spoke, hence the plethora of news in this front, much of it available at the touch of keys. (212)

Erik's stalker, Jeff, indicates that the lack of boundaries warranting his art is a result of the digital age ("The world's going virtual anyway" (217; emphasis added)). And also Inga's privacy violation is ultimately put into a digital context. While Inga is undoubtedly subject to digital transparency, one might argue that being subject to tabloid journalism is not a new, and definitely not a primarily digital phenomenon. When, however, the novel discusses the digital relativization of the real, the popularity of Reality TV and the crowd's desire to "gape," it names key symptoms of today's digitally propelled, so-called tabloidization. According to sociologist Gianpietro Mazzoleni,

it is undeniable that a 'tabloidization' of the information industry as a whole is under way on a global scale, induced by new ICT and online news media. Sensationalism, the salacious coverage of scandals, a focus on personal details and an abundance of 'soft news' and lifestyle stories, are just a few features of the news-making style that several quality newspapers, as well as public service broadcasting companies, adopt in their news and current affairs sections (including domestic and international politics) ... The online editions offer 
further scope for this trend towards 'tabloidization' by soliciting the active participation of their readers and viewers via the social media. (51)

This phenomenon of tabloidization has also been an obvious motif in Marisha Pessl's Night Film, as it is worth mentioning here, to make an illustrative comparison. In Night Film, the comment sections, online forums and (dark net) communities represent a haven for the users' (the so-called Cordovites') darkest fantasies, which would remain unuttered in any other context. In this respect, Cordova's online presence constitutes a perfect hotbed for the generation and perpetuation of a cult following. The drawback of this kind of anonymous communication, however, is that it promotes the circulation of defaming rumors and may have fatal consequences for a lived reality. In this respect, Night Film and The Sorrows of an American show how an online ethical code, if there ever was one, does not at all prevent users and journalists from exploiting an unprecedented "freedom of speech." Jacek Sobczak further elaborates on the latter's prioritization over such forgotten values as human dignity as well as the right to privacy and intimacy and the verbal disinhibition it brings about:

An enormous impact on the tabloidization of the print press and then television and subsequently the radio had the Internet, and particularly, the interactive digital versions of the printed press published on it which enables the users placing various, often insulting, obscene, defaming or slandering comments. The social media also contributed greatly to the tabloidization of the media which allegedly enable free exchange of thoughts but ultimately give the green light to various kinds of verbal excesses. (176)

Even though the influence of social media is not explicitly mentioned in The Sorrows of an American, the novel obviously introduces Linda Fehlburger as a leading representative of the ongoing tabloidization or, in other words, verbal excess, and thus as the writing counterpart to Jeffrey Lane. The latter does not consider photography as "the secretary and record-keeper of whomsoever needs absolute material accuracy" (Baudelaire 297). Despite the variety of today's photographic practices, Erik's discovery of himself among Jeff's exhibition pieces marks a moment of profound disillusion. One might even say that Hustvedt narrates the encounter between Erik and Jeff to allegorize a turning point in the media history of photography. In a similar vein, the tabloidy representation of Max Blaustein marks a moment of disillusion for Inga and Sonia. Fehlburger's verbal excess and blatant disregard for any realistic portrayal stands in diametrical opposition to their increase in language sensitivity in the wake of 9/11. 
The novel addresses yet another example of not necessarily tabloid but excessive journalism with regard to the "media's version of September eleventh and its almost instantaneous construction of a heroic narrative to gloss the horror" (48). In her book American Reality: Examining a Cultural Obsession, Inga has noted

...the use of cinematic devices in television reporting, the footage of firemen set to music with American flags waving on a split screen, the spectacular images, the pious announcements that irony had come to an end as the bitter ironies multiplied one on top of another. She wrote about the cheering crowds in other places in the world, who had manufactured their own fiction of heroic martyrdom, one so powerful it snuffed out empathy. (48-49)

The necessity of a counternarrative to these "hackneyed pictures and dead words" surrounding 9/11 makes the boundaries of the (un)utterable eventually shift in a productive rather than sensational way (49). Once her struggle to deal with $9 / 11$ is relieved from the "duty" to find the right caption for her perceptual image of the colliding skyscrapers, Sonia regains her poetic voice. As I mentioned in one of the preceding sections (5.1), Sonia is desperate to find words for her memories of 9/11. Her eventual emancipation from the governing narrative and the struggle for an all-encompassing realism manifests itself in a poem she confides to her beloved uncle Erik:

Policemen came one day to search our roof,/ two long-faced men with gloves and plastic bags./They climbed the stairs in hope of finding proof/ that body parts still lay beneath the flags/ we flew before their meaning turned to spoof./ I see him clearly still. He kneels and drags / the tar, an officer whose empty eyes / betray no hope, no sorrow, no surprise. (127)

What Sorrows refers to here are the significant quantities of human remains that have been recovered on the roofs surrounding the World Trade Center. Most of them have turned up on top of the Deutsche Bank building, which stands about 400 feet to the former South Tower. What Sonia imagines is that the drama of $9 / 11$ has outranged the Ground Zero by far and makes her shoulder her own share of the unimaginable emotional burden. It is a relatively small yet harrowing detail of the 9/11 narrative and thus can be considered a powerful counternarrative. It is with regard to Don DeLillo's novel Falling Man (2007) that Catherine Morley enlarges upon the significance of counternarratives in the post $9 / 11$ era: ${ }^{91}$

\footnotetext{
${ }^{91}$ Falling Man tells the story of 9/11 survivor Keith Neudecker and his struggle to return to a domestic routine and cope with identity issues after the attacks. The novel is frequently mentioned in the same breath with Jonathan
} 
Then, as now, his notion of counternarrative was that which slipped past the governing, official narrative of history, the stories that go untold, obliterated by the dominant narrative of the attack. Counternarrative is the writer's attempt, through words, to wrestle power from the actions of the terrorist. All that breaks from the overwhelming narrative of the attack and the hole in the landscape is counternarrative: the hundreds of stories criss-crossing New York City on the day, the memories real and imagined, the photographs of missing people, the fragments and shards of strewn personal belongings. For DeLillo, the writer must seize on these smaller, multiple stories, these individual moments and possessions, and pitch them against the massive spectacle of the attacks that seems to defy normal frames of response. (250)

Sonia has emancipated herself from the desire or pressure to tell the story of this life-changing event and instead has decided to (re)make her own post-9/11 world. In this respect, Sonia resembles her father, who has not let any internal censorship obstruct his art. On the contrary, it seems that it has been a crucial part of Blaustein's art to cross the boundary between fact and fiction. After all, he is partly described as having lived beyond that boundary: Linda Fehlburger's research on Inga's marriage faces a dead end when it turns out that Max Blaustein's love letters were not addressed to the person Edie Bly but instead a character that she impersonated in one of his movies. With his creative exploitation of hyperreality, Blaustein has unknowingly subverted Linda's defaming, badly intentioned investigation.

And also in the case of Jeff's post-photography, the question of the right caption has turned out to be obsolete. In fact, Jeff's captions even have drawn attention to the fictionality of his work. Nevertheless, it was the images that lived on in Ms. W.'s head as well as in Erik's (264). Also, the latter's attempts at ekphrasis are characterized by vagueness and the ontological uncertainty of detecting "some kind of digital distortion" (261). With regard to the pending question of how to cope with the haunting pictures of Jeff's exhibition, Erik finally arrives at two different strategies. The first is rather pragmatic and includes a lawyer who manages to ban Erik's face from the exhibition. The second seems to be inspired by Sonia and her 9/11"counter-poem", that relieves her from the lack of words.

Safran Foer's Extremely Loud and Incredibly Close (2005), as well as works by Siri Hustvedt and Paul Auster tackling the topic. Tellingly, the novel has been criticized for falling short of "the significance of the events themselves," which, however, is the very sense of a counternarrative, if not a characterizing feature of the post9/11 literary genre (English). 
When I left the hospital, it was snowing - large wet flakes that would whiten sidewalks and streets only briefly - but the snow was beautiful, and as I paused to watch it fall, illuminated by the building's lights against the darkness of the evening, it struck me as a moment when the boundary between inside and outside loosens, and there is no loneliness because there is no one to be lonely. (301)

These lines introduce the novel's denouement, a four-page long stream of consciousness, in which Erik conjures up a series of mental images. When he claims that the "boundary between inside and outside loosens," Erik obviously refers to a citation from the outset of the novel in which he describes his body as a gatekeeper, filtering (un)utterable words. ${ }^{92}$ Towards the end of the narrative, Erik has grown tired of his inner censorship, just as Sonia has grown tired of her verbal inhibition. But once the boundary loosens, Erik provides a highly associative account of the mental images that he has possibly suppressed due to their liminality between real and imaginary, past and (desirable) future:

I see Laura laughing across the table and I feel her warm ass under my hands in bed. ${ }^{93}$ Miranda's head is on my shoulder. I see her dreamed streets and her house with its disquieting rooms and curious furniture. I see a woman lying beneath a man struggle for an instant under his grip. I stand in front of her chest of drawers, and I want so much to look inside, to touch her things ... I see my father's orderly desk: paper clips, ammo, unknown keys. Sonia's closet is messy now. She throws her clothes all over the room, and Arkadi pulls open the chest of drawers in the vast room and finds nothing but a voice ... And then I see Ms. W. at the end of our last session. She is smiling at me ... She puts out her hand and I take it. She says, 'I will miss you.' - 'I will miss you, too.' (302-4)

It seems that Erik strolls along an inner gallery and tells the reader what he sees at every other corner. In a sense, Jeff's work seems to have inspired Erik to articulate what can be considered a "counter-exhibition" rather than a counternarrative. He actually follows the example of his stalker who has freed himself from any restrictions and created his own world in visual terms. In the world Erik has created on the last pages of the novel, he reconciles with Ms. W. and he also admits the voyeuristic appeal of his friendship with Miranda. Unlike Jeff, Erik does not blend the indexical with the synthetic. But in response and also a certain analogy to Jeff's hybrid

\footnotetext{
92 "That is the strangeness of language: it crosses the boundaries of the body, is at once inside and outside, and it sometimes happens that we don't notice the threshold has been crossed" (16-17).

${ }^{93}$ Laura is a woman with whom Erik enters a casual sexual relationship, in order to distract himself from loneliness and his unreturned love for Miranda.
} 
approach, the compilation of Erik's mental images combines moments, or sights, of pure imagination with those of confession. In his post-photographic manifestation of language or, in other words, verbal manifestation of post-photography, Erik even admits a certain truth behind Jeff's way of looking at him. Ironically, it is Jeff's unbridled obsession with images that in the end helps Erik to look back on and reappraise the burdened relationship with his aloof father. The picture captures a layer of his identity that resembles his father's and thus Erik has been reluctant to realize or articulate: "Lane saw it in me. The violence, the violence my father wanted to walk off but couldn't" (303). When Erik thus to a certain degree even reconciles with Jeff's exhibition, the latter's post-photography does not end on an exclusively negative, but ambiguous note. After all, Jeff's post-photographic emphasis of Erik's “hidden fury” may also be crucial for the reader's mental image of the first-person narrator (265). It rounds off the picture of the protagonist, whose account of the burglary situation might have not been fully reliable. And there is another aspect that ultimately relativizes the clear-cut offender-victim relationship between Jeff and Erik: their common voyeurism in relation to Miranda.

In the age of post-photography, massive boundary shifts occur with ambiguous outcomes that turn out revealing or misleading, fruitful or harmful, inspiring or silencing. In the wake of these shifts, Siri Hustvedt has reconsidered the relationship between word and image. To be more precise, the text has created a conflict between the verbal and the visual and confronted its characters with images that do not only need to be described but, at best, corrected or put right by words. It is at the same time presented as a naive expectation that the ontological uncertainty brought about by the digital age might be resolved by simply the right caption. Due to the shady territories of the word, neither captions nor ekphrases can serve as powerful or defensive responses to images that represent a perfect hybrid of indexical and synthetical parts. The latter eventually drive Erik to overcome his verbal inhibitions and articulate a counterexhibition that is as ambiguous as Jeff's post-photography. The novel's concluding stream of consciousness does not only point to a certain reconciliation between Erik and his stalker; in more abstract terms, it indicates a reconciliation between words and images. After all, Jeff's post-photographic provocation - and the need to answer it - eventually relieves Erik from his crisis of language and brings about a visual evocation of words that does not hinge on an allegedly extratextual picture, drawing or photograph.

In the next section, which is the conclusion of this thesis, I will take another look at the meaning of this denouement of Sorrows, put it in relation to the other case studies and the broader context of the difficulties implied by writing contemporary fiction in the digital age. 


\section{Conclusion}

The present study set out to determine how the digital revolution affects literature-based intermedial references to (audio-)visual media. The leading question was, on the one hand, how literature contributes to a better understanding of the contacted media, that is film and photography, and their current embedment in a post-cinematic media landscape. On the other hand, my research interest pertained to the contacting medium, the print novel, and the way it renegotiates its own media-specific potential in response to the media culture in question. My dissertation has produced three individual responses to these research questions. In the following, I shall treat the analytical body of my study as a whole and conclude it against the backdrop of my twofold research agenda. This last chapter is thus divided into two main parts. The first part reviews the previous chapters by combining them into a single narrative of postcinema. It further shows how contemporary US-American literature accentuates our understanding of the post-cinematic sentiment. The second part provides an assessment of the intermedial hierarchy between the contacting and contacted medium. These concluding thoughts shall demonstrate the range of angles that can be mobilized to reach a more nuanced understanding of the contemporary novel, its effort to keep up with the digital revolution and yet remain credible and recognizable as a traditional medium.

\section{The Assets of an Intermedial Approach}

Before responding to my first research question, I shall provide a final reflection of the benefits of a literary lens. In this study, I have discussed the impact of digital technology on the reception and ontological understanding of film and photography. To find case studies of post-cinema is, however, a rather difficult undertaking. After all, post-cinema is comparable to a Velvet Revolution: The changes in cinema are radical and at the same time subtle; they only gradually come to the surface. In this respect, it makes sense to rethink the fine line between post-cinema and digital cinema. Most basically, digital cinema describes the technological conversion of cinema. In the preceding pages, I have discussed the post-cinematic character of this conversion, that is its thin line between continuity and rupture. In a more abstract sense, digital cinema bears the promise of an aesthetic emancipation from the liminal post-cinematic condition. Post-cinematic is, in other words, "the difficult search of digital cinema for its own unique aesthetics" (Manovich, DV Realism 1). A concrete manifestation of this search could be the horror film UNFRIENDED (2014), which is set entirely on the user interface of high school student Blair. The mouse cursor stars when an uncanny entity joins in the Skype conversation 
between the teenager and her friends. Even though the movie got a wide theatrical release, it appears most promising to watch it on one's own, private (laptop) computer. The concurrence of diegetic and non-diegetic cursors, windows, icons, and notification sounds promises to confuse and thus additionally terrify the viewer. This attempt at a sort of digital-interfacerealism could count as a trace of post-cinema, a hypermediate case of digital cinema's gradual pursuit of creative autonomy.

But there is also the less visible and less detectable side of post-cinema. What I have thus identified as more intriguing is the question of the special effect, which seems to warrant its special prefix now more than ever. At the same time, it has been terminologically relativized to mere visual effects by the Academy of Motion Picture Arts and Sciences. Resorting to Steven Shaviro's wording, I argue that to look at today's special effects means

to look at developments that are so new and unfamiliar that we scarcely have the vocabulary to describe them, and yet that have become so common, and so ubiquitous, that we tend not even to notice them any longer. (2)

Therefore, I have adopted an intermedial perspective rather than sought cinematic or filmic case studies. In the introduction, I have pointed out the "revealing" agenda of intermedial literature, that would not be given in a filmic adaptation of the respective literary work. What may pass unnoticed in the cinema hall and appear common or ubiquitous becomes "special" between the lines of my case studies.

What has turned out to be another benefit of an intermedial approach to post-cinema is that literature bears a response to the question of a post-cinematic structure of feeling, which permeates the discourse in a largely unanswered fashion. "If post-cinema concerns the emergence of a new 'structure of feeling' or 'episteme,' new forms of affect or sensibility," Julia Leyda and Shane Denson explain, "then traditional scholarly forms and methods for investigating these issues are unlikely to provide adequate answers" (6). When I focus on the way contemporary novels convey this episteme, I primarily focus on the general reception and assessment of film and photography as media of the digital age. Hence, my approach concerns the sentiment towards post-cinematic phenomena rather than the sentiments allegedly postcinematic case studies produce. Here, my rather narrow understanding of this concept differs from Shaviro's very broad understanding of the post-cinematic affect, which is detectable in filmic interpretations of transnationality, neoliberalism, and global financial flows. My study, in other words, remains in the microcosm of (new) media-related experiences, anxieties, and anticipations. It tries to provide a less conventional, less traditionally scholarly response to the 
post-cinematic questions of our times and thus meet the challenges Leyda and Denson have identified.

My intermedial readings have revealed three perspectives on post-cinema that apply varying emphases: Danielwski's dystopian media philosophy and its nuanced treatment of the question of indexicality in the digital age, Pessl's simulation of a contemporary media phenomenon and revelation of its misleading mechanisms, and Hustvedt's media-ecological translation of post-photography into her characters' realities of life. Many of the films and photographs, scholars and artists mentioned in the novels have actual counterparts in the empirical, extra-textual world. The main (audio)visual works that the novels revolve around, however, are imaginary. Their extra-textual context is, at most, meticulously feigned: Night Film and House of Leaves pretend to be but one of many references to the Cordova or Navidson phenomenon (see, for instance, the comic strips in the appendix of House of Leaves and the university syllabus provided by the Night Film Decoder App). The novels, one can say, present themselves as parts of (potential) transmedial worlds. In the process of working on Night Film, Marisha Pessl gave a lecture at Lenoir-Rhyne University and cited Cordova, pretending to refer to an actual filmmaker: "When asked in a 1986 Life interview to explain his films' wide popularity, the American film director Stanislas Cordova replied, 'I don't know. I just let the audience quietly spy on themselves"” (Abebe). Pessl's deadpan comment, though it might be dismissed as a promotional, even narcissistic gimmick, mirrors the way she and Danielewski integrate the films into their novels and thus "write" film history. "Writers who describe invented works of art usually echo and allude to real ones, thereby intentionally producing an ambiguous blend" (Fusillo xiii). It is precisely such an ambiguous blend that informs this study's account of contemporary cinema and its post-cinematic sentiment or anxiety.

\section{$\underline{\text { The Pitfalls of Post-Cinema }}$}

If there was a cohesive narrative of post-cinema to be derived from the analytical body of my project, it would feature two main protagonists: Johnny Truant, a Los Angeles drug-addict, who has been drawn into the cult of THE NAVIDSON RECORD after finding a manuscript describing the movie, and New York journalist Scott McGrath, who cultivates an obsession with the Black Tapes, the horror movies of director Stanislas Cordova. McGrath does not think of the Black Tapes as fictional live-action films, for him they truthfully represent Cordova's reclusive, ecstatic, and deadly life at his myth-enshrouded residence, the Peak. Scott and Johnny are not primarily preoccupied with watching the movies they speculate about. In fact, Johnny has never 
seen THE NAVIDSON RECORD himself. But he studies the entire discourse that has arisen on the question of how the Navidson house could have shifted in this unexplainable fashion. It draws on multiple disciplines to find an answer to this phenomenon that seems impossible, and yet has been caught on camera. Different schools of thoughts have developed analyzing individual scenes from the record. And Scott also looks at various remediations of Cordova's oeuvre rather than the Black Tapes themselves. Naturally, he is specifically attracted to those that make a rumpled, user-generated, and thus faithful impression. It is on the dark net, among the Blackboards fan forum entries, where he finds gritty film stills and old Cordova snapshots. In a similar vein, THE NAVIDSON RECORD is so low-end, so badly overexposed, and so chaotic that it virtually must be true - despite its depiction of an impossible house. It builds a contrast to what the digital film industry produces these days: Such slick films as LA BELLE NICOISE ET LE BEAU CHIEN, whose pseudo-horror obviously results from digital manipulation, may serve as an example here. It is the omnipresence of such over-accurate, cumbersome, and conspicuously expensive movies as LA BELLE NICOISE that has increased Scott, Johnny, and many other cinephiles' appetite for (more) real horror.

This is, however, not the end of Scott and Johnny's story of post-cinema, which turns out to be informed by major plot twists: The media industry has begun to exploit the changing viewing habits, which are characterized by an increasing faith in rumpled images and an increasing mistrust in ostensible products of sophisticated technology and cumbersome postproduction, in short, slick images. The post-cinematic landscape turns out to be a dystopian landscape that is replete with potential pitfalls. It means, in general, that the mechanisms of the post-cinematic industry are always one step ahead of the ones who want to see through the system or try to defy it. Once Scott has broken into the Peak to encounter "lively" soundstages, he finds out that he has undertaken this adventurous odyssey to break into an around-the-clock theme park, whose original creator has moved away many years ago. And when Johnny travels the country to find out about the Navidsons' fate, he makes an even more extraordinary discovery: neither has there ever been a Navidson house, nor a movie about it. While Scott has been trapped into believing in the authenticity of the Black Tapes, Johnny has been trapped into believing that "The Navidson Record" exists in any other form than written text. ${ }^{94}$ While the faith in (even the mere description of) rumpled images and rumpled worlds may turn out to be naive, the precautionary mistrust in slick images proves to be even dangerous, as the case of LA

\footnotetext{
${ }^{94}$ Johnny even learns that the notorious book that has appeared on the Internet does not only include the notes of Zampanò but those of a certain Johnny Truant as well. His discovery can thus be considered a verly literal case of the digital, post-cinematic system being one step ahead of its participants, publishing Johnny's notes and turning him into the protagonist of an eerie media project before he even got the chance to notice.
} 
BELLE NICOISE ultimately shows. What has been celebrated in theaters worldwide was the actual murder of a young girl, merely glossed over by a slick look. ${ }^{95}$

It is of course fallacious to strictly distinguish between the naive spectators, on the one hand, and calculated media moguls, on the other. In fact, it is the blurring boundaries between producer, user, actor, and viewer that propel ontological uncertainty and account for the postcinematic pitfalls in the first place. The transmedial dynamic behind the Cordova phenomenon is considerably nurtured by the Cordovites. Scott McGrath's position in this Cordovian network, however, is most difficult to determine. After having been introduced as the chief opponent of the Black Tapes, the journalist quickly gains access to the Blackboards and assumes the online identity of a Cordovite. Scott's investigation, while targeted at the ruination of Cordova, thus ends up supporting his cult. Following this line of interpretation, the dogged journalist involuntarily plays the major role in Cordova's new project when he roams around the dark corridors of the Peak under video surveillance. His thorough absorption and integration into this transmedia dynamic comes along with an ambiguous privacy situation that turns the observer fairly quickly into the observed and indicates a scenario in which Scott is deceived by "just another" large-scale business strategy. If there is a major studio behind Cordova's underworld, its influence, authority and invasion of privacy is hardly palpable, smartly veiled under the guise of interactivity and fan labor. ${ }^{96}$

In the post-cinematic age, the cine(il)literate and curious fan is faced with the pitfalls of a corporate-driven, exploiting media landscape whose strategies have become all the more refined with the rise of digital technology. However, the potential of post-cinematic manipulation does not necessarily manifest itself in cinematic events, cult followings, or other large entertainment contexts. It can be exerted by jealous ex-boyfriends such as New Yorker Jeffrey Lane, who breaks into other people's apartments to take photos. He steals appearances to smoothly integrate them into a decontextualized collage and does not scruple to exhibit these post-photographic works. Post-cinema - from this viewpoint - is not only a matter of profound

\footnotetext{
${ }^{95}$ One could, of course, wonder why this case of an actual event is conveyed with such an unshakable sense of truth and resolution while the narrative's agenda is to create a sense of ontological confusion. These two aspects, as I would argue, are not mutually exclusive in an experimental novel like House of Leaves, whose complex network of footnotes consists of different voices, diametrically opposed viewpoints, arbitrary claims as well as in-depth analyses.

${ }^{96}$ The correlation between participatory culture and surveillance culture has already proven to provide intriguing ground for both in-depth studies (e.g. Social Media as Surveillance by Daniel Trottier) and contemporary literature, whose most prominent example would be Dave Eggers' 2013 novel The Circle. While The Circle entertains the dystopian idea of a corporate identity that denies employees any right to privacy and exerts this power via social media, Night Film portrays the violation of a fan's privacy as a subtly orchestrated pitfall of an elaborate, corporate-driven transmedial world.
} 
ontological confusion when it comes to distinguishing between indexical and synthetic pictures. It features protagonists who have given up on the effort to make this distinction in the first place, and thus stick to an ethics of privacy protection.

This story of post-cinema - narrated by House of Leaves, Night Film and The Sorrows of an American - draws a picture of chaos and ethical transgressions. It creates a scenario in which the importance of interactivity and demystification rises to an extent that not only supersedes the cinema-going experience but renders it obsolete. Film reception takes place on the Internet, in theme parks, and in the process of organizing the disheveled remains of a complex manuscript, written by an old, blind man. It takes place, regardless of whether the respective film has ever been watched or produced. On the one hand, cinema has never been as ubiquitous as in this fragmented and multiply remediated audiovisual culture. On the other hand, the (hypothetical) spectatorship described above seems to have witnessed the end of cinema: Given that the project of Cordova's underworld has set off as a genuine, nostalgic countermovement to digital overexposure, it has quickly reached a dead-end in the postcinematic landscape. After all, it is precisely the enigmatic character of the cult, its many unanswered questions, that produce encyclopedic ambitions among fans and thus the right condition for transmedial world-building and demystification. In this scenario, the attempt to relocate Cordovian cinema to a more reclusive, dark space has ultimately resulted in a thorough remediation of the Cordova phenomenon. It has superseded rather than recovered the traditional cinematic experience.

All three novels draw the picture of a highly complex media landscape, which, depending on the viewpoint, oscillates between the death and continuity of cinema and photography. The novels' critical reflection on the contacted media, however, needs to be questioned against the backdrop of their own aesthetic, formal and material manifestation. Did they sacrifice the classical form of the print novel in order to take part in the digital world? Or, on the contrary, did they cleverly exploit the potential of the book to encourage a particularly self-reflective and contemplative reading experience and underline the resilience of the novel? What conclusions can be drawn with regard to the more general debate on contemporary literature and its competence to grasp the digital present? What role does reading literature play in a society permeated by digital technology? Is it subverted by other alternatives in terms of screen media? In the next and last section, I will look into recent voices and trends regarding the question of the continuing relevance of the (print) novel. 


\section{Thoughts on the Continuing Relevance of the (Print) Novel}

But it is possible that the novel and literature in general are becoming before our very eyes something actually quite marginal in comparison with other forms of narration. That the weight of the image and of new forms of directly transmitting experience - film, photography, virtual reality - will constitute a viable alternative to traditional reading. Reading is quite a complicated psychological and perceptual process. To put it simply: first the most elusive content is conceptualized and verbalized, transforming into signs and symbols, and then it is 'decoded' back from language into experience. That requires a certain intellectual competence. And above all it demands attention and focus, abilities ever rarer in today's extremely distracting world.

Olga Tokarczuk, “The Tender Narrator” 12

In her 2019 Nobel lecture, Polish author and laureate, Olga Tokarczuk, has expressed strong concern about the current state of literature. Even though the novel has faced a long history of debates about its various "rivalries" with other media and allegedly looming irrelevance in comparison to comics, cinema, television, radio, to name just a few, Tokarczuk's critical and skeptical voice refers to the digital present: She observes how a new kind of digital flexibility, immediacy and efficiency permeates the everyday lives of her (potential) readers - whose predominant mode of reading becomes a matter of skimming and scanning rather than deep contemplation..$^{97}$ The continuing relevance and also technological up-to-dateness of literature is still being reconsidered and quite possibly has become a more pressing question than ever before in Gutenbergian history. At the same time, it is the rise of digital technology that yields new answers to this question and fosters new perspectives in literary studies.

The first and possibly most obvious answer would be that literature is alive because it does not take place in the margins of the digital progress - it is part of it. After all, digital technology has also created new opportunities for literature. It has diversified and enriched the production of literary fiction, which includes such phenomena as enhanced e-books, hyperfiction, cell-phone novels, or the autobiographical blog - they all encourage a flexible understanding of literature as an art form. ${ }^{98}$ Computer scientists become authors, authors

\footnotetext{
${ }^{97} \mathrm{Cf}$. my excursus on the discourse of screen versus print reading in the introduction of this study (pp. 20-27).

${ }^{98} \mathrm{Cf}$. Simone Winko, describing the changing medium of literature today as "an extremely diverse, dynamic ensemble of different media formats and forms of communication, a lively practice that transcends printed individual works and authors mentioned by the feuilleton and is part of the current culture of participation." [original: “...ein extrem vielfältiges, dynamisches Ensemble unterschiedlicher medialer Formate und
} 
becomes computer scientists, and literary scholars are faced with a whole range of new research subjects. "Electronic literature" or, in other words, "digital literature" does not simply mean a text that is digitally available. It is "born-digital" and thus denotes a literary text that is "produced for the digital medium," as one can learn from the informative website of the Electronic Literature Organization ("Welcome to the ELO"). ${ }^{99}$

In this conclusion, I would like to point out a characteristic of digital-born literature that most fundamentally illustrates the up-to-dateness of the medium, and yet can be considered a downside with regard to its continuing relevance: it is supposed to be consumed on a screen. Drawing on Tokarczuk's above-cited, worried claim and thereby reversing it, I suggest looking at the current situation of media consumption from a different, maybe even "bold" point of view. After all, the predominance of mass entertainment including cinema, video-on-demand, series and gaming can be considered a status quo rather than still unfolding "before our eyes." To refer to them as merely "viable alternatives" would thus be an understatement. What if it is the omnipresence of screen media and their indispensability in business and daily-life contexts that creates an oversaturation - and thus itself the need for alternatives? This is what brings me back to the novel and specifically the print novel as this study's main interest. In fact, I would argue that - rather than being threatened by alternatives - the print novel itself is in the process of (re)gaining significance as an important alternative to screen media. This implication corresponds to a trend in fast-paced careers and lifestyles that is referred to as "digital detox" and promises a well-deserved relief from screen fatigue, poor work-life balance, 24/7 availability and a permanent stress of staying connected. ${ }^{100}$ The lack of time and opportunities to $\log$ off and reunite with nature, people and the physical world has also produced a business model in tourism industry. Special getaways are offered to remote areas without connectivity. ${ }^{101}$

\footnotetext{
Kommunikationsformen, eine lebendige Praktik, die weit über gedruckte Einzelwerke und vom Feuilleton wahrgenommene Autoren hinausgeht und Teil der aktuellen Partizipationskultur ist."] ("Literatur und Literaturwissenschaft im digitalen Zeitalter", 2)

${ }^{99}$ See also Hayles: "Electronic literature, generally considered to exclude print literature that has been digitized, is by contrast 'digital born', a first-generation digital object created on a computer and (usually) meant to be read on a computer" ("Electronic Literature", 3).

${ }^{100}$ See Trine Syvertsen's definition of digital detox: "Digital detox is often understood as taking a distinct break from smartphones of social media, but the term may cover different activities and mindsets. Offline periods vary from several months to less than a day. Digital detox is used to describe rules for screen-free periods and spaces, extensive and moderate lifestyle changes, gradual reductions or media diets" (Digital Detox: The Politics of Disconnecting, 2). See also Trine Syvertsen and Gunn Enli, whose approach to the phenomenon of digital detox includes a comprehensive analysis of the variety of (self-help) literature and corporate websites promoting digital diets. The paper takes into consideration the long tradition of media resistance, and shows how digital detox unfolds as a comparably mainstream trend, that prioritizes balance on a daily basis over radical and uncompromising rejection.

101 "Two of the first media mentions of digital detox were in 2008 and described a Canadian resort where visitors were encouraged to log off, and in 2012, The World Travel Market Global Trends Report pointed to digital detox as one of the hottest trends in the travel industry" (Syvertsen 5).
} 
The non-WiFi vacation homes are equipped with a variety of leisure-time alternatives to the mobile phone and other digital tools: There are radios, newspapers, board games, coloring antistress mandalas, and of course: richly filled, physical bookshelves.

"If you're reading this on a screen, fuck off. I'll only talk if I'm gripped with both hands," reads the first sentence of Joshua Cohen's epic novel Book of Numbers, which The New York Times describes as a "digital-age 'Ulysses"” (Sarvas). Cohen's work, which experiments with the impact of fake news in the internet age, demands to be read offline for the sake of a haptic experience. The first line sounds determined and defensive and yet is not entirely true. After all, Book of Numbers' simultaneous availability as an e-book will not silence the novel. However, Cohen's opening is not rendered meaningless by the potential screen existence either; it raises the readers' awareness of their pending reading experience to be a conscious and meaningful choice - and perhaps makes them reach for the print copy after all.

Print novels that highlight their materiality and produce a context of an intermedial tension to screen media for that purpose, do not only actively encourage this trend - they provoke self-reflection on the part of their readers. House of Leaves is solely available as a print copy. By means of its intermedial self-awareness, the narration presents itself as the primary narrative of THE NAVIDSON RECORD. Watching the (non-existent) movie is no option, the novel explicitly remains the only alternative. And it could hardly be more present and "weighty" while gripped with the readers' both hands. What is more, the novel's structure - its comprehensive appendix, numerous footnotes, cross-references and lengthy digressions - or, in short, the novel's different options of being approached confront the readers with their respective reader identity and reading habits. To grasp the House of Leaves fully is an undertaking that demands time, focus, patience and passionate curiosity. It seems tempting to miss out on some of the additional information mentioned above. What follows, however, might be the decision to reread the novel - for example, in order to gain a deeper understanding of Johnny Truant's character by catching up on the 59-page appendix including letters from his schizophrenic mother. One could argue that Danielewski encourages his audience to reenter if not reread the entire novel and thus become what Vladimir Nabokov defines as a "good reader, a major reader, an active and creative reader" - one that in Tokarczuk's words would probably not be distracted by an constant stream of incoming e-mails (“Good Readers and Good Writers”, 3).

Even though Night Film is available as an e-book, I have discussed it as a novel that has been written and assembled for print. By its experimental investigation of the intermedial gap, Night Film self-reflexively offers its audience a "retreat" into its offline manifestation and raises 
awareness of offline-reading as a conscious choice with regard to the variety of other options. Tellingly, the novel explicitly thematizes the desire for digital breaks in today's society, that is imbued with "the ceaseless chatter of Internet culture" (353). Professor Beckman's provocative question to McGrath whether he has "seen the world lately" is equally supposed to address the reader and achieve the eye-opening effect that too much time is "wasted" in front of screens. He is convinced that "we're living no longer, we social network alone with our screens, and our depth of feeling gets shallower." Pessl's Night Film invites its audience to take a digital timeout and benefit from what Vera Nünning identifies as the affective and cognitive merits of reading fiction, that is fostering such competencies as empathy, open-mindedness and perspectivetaking. ${ }^{102}$

A first conclusion that can be drawn from these observations would be that the print novel does not need to be digitized, let alone transformed and simplified into a cell phone novel - it has to live on in its traditional form not despite but precisely because of the rise of the digital age. Another internet-age phenomenon that confirms this claim - yet from a slightly different angle - is a new trend on the social media platform Instagram, which is known as "Bookstagram." "Bookstagram"-hashtagged photographies and associated user accounts cultivate a special kind of bibliophilia, "combining a love of books with stylized, eye-catching photos, to the delight of large fanbases" (Pope). Individual book covers take center stage in these photographs - together with a selection of various props. The multi-clicked portrayals of novels as aesthetic objects imply commercialization. It is, in fact, unquestionable that numerous publishers cooperate with bookstagrammers or book influencers, profit from their follower range and use the platform as a vital part of their marketing strategy. ${ }^{103}$

The critique that the value of novels is being downgraded to the Instagram-friendliness of their cover might be valid in some cases. ${ }^{104}$ At the same time, it is important to note that apart from the artful book shot, many posts include a review text, which in turn sets off an exchange of thoughts and views regarding different reading experiences in the comments section. There are many ways in which Bookstagram transcends the commercial sphere: In 2018, the New York Public Library initiated "Insta Novels" - "a project bringing classic novels to Instagram Stories in an attempt to reach a new generation of readers" (Rahim). But apart from the

\footnotetext{
102 See Vera Nünning: Reading Fictions, Changing Minds (2014).

103 "Influencer marketing" is an established business model, that booms particularly in the fashion, beauty, food and beverage, or sports industries.

${ }^{104}$ Cf. Rahim, Zamira: "Social media has connected literary communities, challenged gatekeepers and helped sell books which may otherwise have been ignored. But Instagram is an inherently visual platform and comes with obvious drawbacks. More ornate book covers attract the most attention on the site, leading to accusations that the Bookstagram community judges by cover alone."
} 
socializing factor and the re-appreciation of the novel as an art object, Bookstagram implies another intriguing aspect that concerns a certain notion of reading. The photographs usually stage the act of reading as an experience of calmness, relaxation, and homely retreat. The book covers are frequently embedded in minimalistic and cozy environments - surrounded by coffee mugs, cuddly blankets, a few (dried) flowers. In short, reading environments represented and staged on Bookstagram are, in fact, evocative of "safe havens" - as if the remote digital-detox destinations were equally to be found in one's own four walls. There seem to be no sources of distraction - apart, of course, from the user's mobile phone that is used to take the respective picture. The good thing about this alleged paradox: It encourages reconciliation between reading literature and a daily routine that would not be realistic when entirely dispensed with digital tools.

As already indicated, trends like digital detox and Bookstagram certainly have an economic motivation. But rather than dismissing them as shallow marketing strategies, I would like to approach them as cultural phenomena that charge the print novel with new meaning, or to put it differently, restore its role as significant and, yes, necessary part of our lives, also and all the more in the digital age. During digital diets, the print novel is considered a viable alternative to screen media while at the same time the documentation of "reading retreats" becomes a popular screen content, as in the case of Instagram. It is as if - in the specific context of the rise of digital screen media - the allure of the print book was recovered, yet not just in a nostalgic sense. Rather than (polemically) speaking of its pending end, one could thus take into consideration the novel's new beginning, ironically induced by social and screen media. It is, in other words, intriguing to observe how the print novel becomes a new lifestyle product while staying the same - at least in terms of its outward appearance. Still, the answer to the question of the continuing relevance of the print novel cannot be confined to the fact that it is not a screen medium - while it still remains an important aspect that is closely linked to the following consideration of the medium's important role as a cultural compass. To retreat with a book is a perfect occasion to immerse oneself in fantasy worlds or historical, epic events. It is, however, also the ideal if not urgent occasion to reflect on and make sense of the fast technological progress that the digital age has entailed during the last decades.

I proceed from an understanding of literature as a medium of cultural self-reflection, which "offers alternative worlds that put the actual one in a new light" (Bruner 10). ${ }^{105}$ In Making Stories: Law, Literature, Life, psychologist Jerome Bruner examines how literature

${ }^{105}$ Cf. also Butter, Stella. Literatur als Medium kultureller Selbstreflexion (2007). 
translates global events into individual stories of human experience and gives readers a deeper understanding of the world we live in. He argues that "literature's chief instrument in creating this magic is, of course, language: its tropes and devices that carry our meaning-making beyond banality into the realm of the possible" (10). But do these tropes and devices also keep up with the confusing, infinitely interconnected, digital world? The continuing relevance of the novel is also, if not most importantly, a matter of its ability to grasp the complexities and abstractions of our times. And this is exactly what informs Tokarczuk's anxiety of obsolescence articulated in her Nobel lecture:

Today our problem lies - it seems - in the fact that we do not yet have ready narratives not only for the future, but even for a concrete now, for the ultra-rapid transformations of today's world. We lack the language, we lack the points of view, the metaphors, the myths and new fables ... In a word, we lack new ways of telling the story of the world.

To be more precise, the question we have to ask is whether the novels written or published in the twenty-first century can be contemporary. Do they provide creative and meaningful responses to our chaotic present - and in a further step - what role can their materiality play in this context?

To bring the present - its changes, challenges and concerns - into focus is an undertaking that is met by many authors with hesitation and insecurity. The circumstance that contemporary literature seems to lack contemporaneity is according to Peter Boxall a general and untimely problem. In his study Twenty-First-Century Fiction: A Critical Introduction, Boxall states that "this illegibility of the present ... is always involved in thinking about the contemporary, whenever that contemporaneity happens to take place, and is not a problem that is confined to the twenty-first century" (2). Drawing on Jean-Paul Sartre and his 1939 essay on William Faulkner's The Sound and the Fury, he further explains that "the time we are living through is very difficult to bring into focus, and often only becomes legible in retrospect" (1). It is still worth asking what cultural characteristics of the digital age could make contemporary writers shrink from writing about it. What is the difficulty of approaching a specifically twentyfirst-century sensibility? What about it is possibly too "new and unformed and elusive" (Boxall $6)$ ?

In my study, I have discussed the challenges of understanding today's world and translating the abstraction of the digital revolution into human experience by using the example of post-cinema; I have referred to Velvet Revolutions and the parasite-host logic as major 
metaphors of the analog/digital shift - metaphors that arise from the invisibility of technological progress; I have shown how ontological uncertainties shape and affect the structure of feeling in the digital age. A related topic has been the unprecedented omnipresence and availability of fake news and alternate facts, that have been propelled by the rise of social media. Do not all these aspects raise new questions about the epistemological nature of literary fiction and what kind of truth it "owes" its readers - or whether it can provide truth as an antidote to an increasingly unreliable information age? Tokarczuk admits to feel irritated by this sort of questions (while at the same time confirming their increasing occurrence). How could she explain "the ontological status of Hans Castorp, Anna Karenina or Winnie the Pooh" (10)? Citing Aristotle, one could argue that fiction is "always a kind of truth" (11). However, it does not resort to Wikipedia or Google for this truth - but to the complexities of human experience.

In the age of digitization, mass entertainment and fake news, the struggle of the novel to be contemporary and thus remain relevant is considerable. All the more should it be the literary scholar's aim to detect and appreciate powerful, novelistic answers to our challenging present. According to Boxall, there is hope: “... it is nevertheless possible to begin to see a series of responses, in the novel today, to this transformed being in the world ..." (7). Using the examples of House of Leaves and Night Film, I have shown how print novels push the generic conventions of the novel beyond the traditional limits of narrative and fiction in order to be able to respond to the uncertainties of the digital age - in full awareness of "talking as a print novel." Still, I have also shown that the claim to contemporariness does not hinge on (visual) experimentation - an insight, that I would like to elaborate in the following lines.

Siri Hustvedt's The Sorrows of an American proves that a creative response to the challenges of the present can also lie in the identification of these challenges. Throughout the narration, Erik Davidsen provides elaborate ekphrastic descriptions of different kinds of images and thus demonstrates his outstanding eloquence and analytical viewpoint. Post-photographer Jeffrey's violent intrusion into Erik's apartment and life unsettles the latter's self-image and (verbal) confidence. The ekphrastic description of a picture that shows himself in a digitally manipulated situation makes him verbalize and articulate what seems to be a simple lie. And yet, Jeffrey's decontextualization and subjective interpretation of Erik's anger also leads to hesitation and self-doubt. The hybrid image represents neither the truth nor complete falsity according to Erik - it remains impossible for him to grasp, classify or let alone define what he has seen and experienced. Erik Davidsen's encounters with the phenomena of the postphotographic age and its actors makes him question and reflect on his verbal ability to make 
sense of the contemporary world and its delusive mechanisms. His ultimate articulation of a counter-narrative or verbal counter-exhibition implicates a sense of "ekphrastic hope."106 The stream of consciousness illustrates a poetic attempt to come to terms with his distorted selfimage and shattered faith in what looks like photographic realism.

It is telling in this context that Erik as a first-person narrator happens to be a psychologist. It can be considered a circumstance that alludes to the fundamentally psychological character of literary narration - its capacity for in-depth reflection, focus on internal reasoning, encouragement of empathy and perspective-taking. In fact, Erik's viewpoint and verbal struggle against post-photographic indignities stands in contrast to Jeffrey and his quite simplistic ontological worldview, which relies on the polemic claim that "the world's going virtual anyway" and his shallow motto: "Simulacra, baby!" - turning a complex cultural theory and philosophical mindset into a kind of advertising slogan (217).

My analysis has shown that (at least at first sight) the novel's story level is informed by the tension between those who write and those who create images. However, reading the novel can be informed by another layer of encounters: On the one side: the "intellectualizing" part of New York society represented by psychoanalyst Erik, his sister Inga who works as a cultural theorist, and his niece Sonja who is a young poet struggling for months to put into words what she saw on September 11, 2001. On the other side: tabloid journalist Linda Fehlburger, who does not mind if her pieces are based on fake news, and Jeffrey, who does not question the ethics of his digital manipulations and violation of privacy. What Hustvedt compares here in figurative terms is, on the one hand, the complexity of human conflict and, on the other hand, the trend of quick answers and solutions in an era of pseudo-information and comments sections under YouTube videos. Interestingly, Miranda's role in this scenario is comparable to that of a mediator. As an artist, she is used not to think in the categories of true or false, right or wrong and thus even develops an understanding for her ex-boyfriend Jeff - though she herself has become subject of his stalking and manipulation. She is the one who inspires Erik to use his primary means of self-expression, which is language, in a more personal, creative and artistic way.

A novel that more explicitly spells out the difficulty of writing contemporary fiction and I therefore would like to use as an example in this context is Sigrid Nunez' The Friend, which has been awarded with the 2018 National Book Award for Fiction. It is basically the story of a

\footnotetext{
${ }^{106}$ According to W.J.T. Mitchell, "ekphrastic hope" is driven by such "utopian aspirations" as "achieving vision, iconicity, or a 'still moment' of plastic presence through language” (Picture Theory 156).
} 
woman taking care of a deceased friend's 180-pound Great Dane. The novel's more prominent theme, however, is the contemporary literary scene and the changing status of literature. The unwitting dog owner and unnamed first-person narrator happens to be both a writer and creative-writing professor, who contemplates at length the psychological dimension and therapeutic effects of creating literature. She also opens up a more pragmatic, ecological and economic vision of what it means to devote one's life to this profession. The Friend, in other words, reads like a writer's notebook or journal, that provides anecdotes and critical insights of a hypocritical literary scene and de-romanticizes the life of the literary genius. Most intriguingly, the grieving narrator compares an older generation of authors - of which her dead friend was a typical representative - with a younger generation. In an era of Reality TV and the sensational media exploitations of personal fates, the narrator encounters English students and aspiring writers, who are interested in (if not oversensitive to) the motivation and ethos of writing fiction; a generation that debates the writers' (moral) responsibility for their inspirational sources - if based in the physical world - and raises ontological questions with regard to literary texts. In The Friend, Nunez does not shrink from this kind of question or dismiss it as "apocalyptic" with regard to the status of literature (unlike Tokarczuk, for whom this kind of question sounds like "the end of literature" (10)). On the contrary, Nunez even provides both a literal and pointed response. In fact, the novel concludes with a meta-fictional turning point that indicates her friend's "actual" fate and thus suggests an allegory of the relation between literature and truth: The "truthfulness" of literary fiction is a continuum that ranges from a Great Dane to a small wiener dog (as the latter turns out to be the "real-life" counterpart of the former - a juxtaposition that still takes place within the diegesis). What counts is the friend she has found in the dog, not its size. To satisfy the readers' supposed ontological curiosity with such playful honesty, could be an effective way to hold up a mirror to the audience's expectations and show that the value of literature exceeds any ontological dichotomies. A more detailed analysis, however, would rather be the subject of future research as it transcends the scope of this excursus that is supposed to put my three case studies in a broader context of US-American literature - and its multiple, subtle and self-reflexive ways to be contemporary.

At the same time, The Friend and The Sorrows of an American show that there could hardly be a better or more reliable way to understand and process the challenges of (writing about) the present than reading literature. Another observation that Nunez' unnamed narrator makes during her career as a creative-writing professor and is particularly interesting with regard to this study's focus on digitization, reads as follows: 
It is one of the great bafflements of student fiction. I have read that college students can spend up to ten hours a day on social media. But for the people they write about - also mostly college students - the internet barely exists. Cell phones do not belong in fiction, an editor once scolded in the margin of one of my manuscripts, and ever since - more than two decades now - I have wondered at the disconnect between tech-filled life and techless story. (102; emphasis in the original)

For the narrator, this circumstance simply remains "another mystery" (103). What this citation suggests, however, is that there is a strong and deeply rooted desire for literature to represent an antidote to modern, multitasking lives. Following this line of thought, one can assume that the "techless story" is supposed to represent a compensation for an all too "tech-filled life." In the era of multiple browser windows, the ability of deep reading that both presupposes and fosters deep contemplation becomes an increasingly important since fading virtue. ${ }^{107}$ In this era of simultaneously burgeoning trends like digital detox and Bookstagram, the print novel is fetishized as "the ultimate repository of ... irreplaceable knowledge" outside of internet browsers and as a retreat from the omnipresence of screens. ${ }^{108}$ According to the creative-writing students in The Friend, this kind of screen-relief should also be concluded on the story level.

After all, a "tech-filled" novel like Mariha Pessl's Night Film is quickly accused of struggling for attention and thus betraying its medium of the traditional print novel. My detailed analysis of the novel and its reception has shown that there is a thin line between contemporariness and - to draw on the partly negative connotation of Rajewsky's terminology - a desperate "contamination" with digital technologies. In other words: To evoke the digital present with an experimental approach to the intermedial gap (by means of apps or visual experiments) can either signify up-to-dateness or an anxiety of obsolescence. Are these extras nothing but redundant literary special effects, that render a more spectacular reading experience and cater to the readers who are used to a minimum dose of daily distraction?

Throughout the analysis, I have also assumed that such attempts to dismiss these literary experiments as desperate detours or attention-seeking pretexts are too simplistic. Instead, I have shown how two examples of "tech-filled" novels can be considered innovative cases of literary contemporariness. Night Film and House of Leaves inspire a notion of the contemporary novel that provides self-reflexive, bold and experimental responses to the digital revolution; it does

\footnotetext{
${ }^{107}$ Cf. page 24 .

108 Nick Offerman, host of the 2018 National Book Award ceremony, qtd. in Harmon.
} 
not deny the fact the both narrators and readers spend a considerable amount of their day using new technologies; on the contrary, it explicitly draws on changing habits of media consumption in order to rethink the role of literature in this context; it creates an intermedial tension that takes into consideration the question of the book's materiality and the question of reading; it features a comprehensive cineliteracy and digital literacy that allows to be one step ahead in manifold ways: It turns out to be one step ahead of the readers, as crucial turning points reveal the (calculated) dynamics of the post-cinematic landscape in retrospect. Once the complexity of this contemporary setting has been realized and the perspective readjusted, re-reading the respective novel becomes a logical or at least worthwhile consequence.

As Night Film and House of Leaves show, contemporary intermedial literature can also be one step ahead of the media it refers to. They are literature-centered gesamtkunstwerks that anticipate and thus inhibit their visual adaptation and digital remediation. They themselves create the post-cinematic contexts that they respond to as print books and narrative literary texts. Night Film creates the illusion of an entire transmedial world by means of print paper in order to eventually subvert it. Also, it makes the readers cross the intermedial gap (thus actually use a digital device) only to redirect them to the book and its reading experience. The novel's striking multimedia character is thus not to be confused with a literary craving for meaningfulness in the new media environment or its naive praise. Rather, my intermedial analysis has pointed out the critical potential of these references to numerous sources of digital distraction. What Night Film offers is a self-conscious reconsideration of the act of (contemplative) reading despite or precisely because of its intermedial emphasis on the interactive temptations surrounding readers in the digital age.

As already mentioned, the pseudo-academic footnotes in House of Leaves explicitly discuss the question of digital manipulation. The main ekphrasis of THE NAVIDSON RECORD, however, does not struggle with words to grasp the invisible special effects of the record. Instead, it creates its own and thus "The Navidson Record's" literary special effects. This is how House of Leaves eventually responds to the problem of ontological uncertainty - by turning the undetectable special effect into a matter of careful reading and physical interaction with the print book. As one of the first publications of the new millennium, the novel has impressively set the bar for the literary grasp of the present - if not the future and its complex maze of universally available yet mutually antagonizing information. Rather than struggling to remain up-to-date as a medium, House of Leaves keeps its readers up-to-date by increasing their (critical) awareness of the fast-developing post-cinematic era and its many ambiguities. 
Reading contemporary literature is not only an alternative to one's participation in the postcinematic digital landscape - it is a necessary complement. 


\section{Works Cited}

\section{$\underline{\text { Primary Sources }}$}

\section{Literary}

Auster, Paul. The Book of Illusions. New York: Picador, 2002. Print.

Bova, Ben. Cyberbooks. London: Mandarin, 1989. Print.

Cohen, Joshua. Book of Numbers. New York: Random House, 2015. Print.

Danielewski, Mark Z. Mark Z. Danielewski's House of Leaves. 2nd ed. New York: Pantheon, 2000. Print.

DeLillo, Don. Falling Man. New York: Scribner, 2007. Print.

---. Point Omega. New York: Scribner, 2010. Print.

Eggers, Dave. The Circle. New York: Alfred A. Knopf, 2013. Print.

Eliot, T.S. "The Love Song of J. Alfred Prufrock." 1915. The Waste Land, Prufrock and Other Poems. Ed. Paul Negri. Mineola, New York: Dover Publications, 1998. 1-5. Print.

Foer, Jonathan Safran. Extremely Loud and Incredibly Close. Boston: Houghton Mifflin Company, 2005. Print.

Hall, Steven. The Raw Shark Texts. Edinburgh: Canongate Books, 2007. Print.

Hustvedt, Siri. The Blazing World. New York: Simon \& Schuster, 2014. Print.

---. The Blindfold. New York: Norton, 1992. Print.

---. The Enchantment of Lily Dahl. New York: Holt, 1996. Print.

---. Living, Thinking, Looking. Sceptre, 2012. Print.

---. The Sorrows of an American. New York: Picador, 2009. Print.

---. The Summer Without Men. New York: Picador, 2011. Print.

---. What I Loved. New York: Picador, 2004. Print

---. “The World Trade Center.” 110 Stories: New York Writes After September 11. Ed. Ulrich Baer. New York and London: New York University Press, 2002. 158-159. Print. 
King, Stephen. Riding the Bullet. Simon \& Schuster, 2000. E-Book.

Martin, George R.R. A Song of Ice and Fire. Novel series. London: Harper Voyager, 19962011. Print.

Nabokov, Vladimir. Pale Fire. New York: G.P. Putnam’s Sons, 1962. Print.

Nunez, Sigrid. The Friend. New York: Riverhead Books, 2018. Print.

Pessl, Marisha. Night Film. London: Hutchinson, 2013. Print.

---. Special Topics in Calamity Physics. New York: Viking Press, 2006. Print.

Pynchon, Thomas. V. 1963. New York: Penguin Press, 2012. Print.

Wallace, David Foster. Infinite Jest. New York: Back Bay Books, 1996. Print.

\section{Audiovisual}

Alice in Wonderland. Dir. Tim Burton. Perf. Johnny Depp, Anne Hathaway, and Mia Wasikowska. Walt Disney, 2010.

AliEN. Dir. Ridley Scott. Perf. Sigourney Weaver. Twentieth Century Fox Film Corp., 1979.

AliEnS. Dir. James Cameron. Perf. Sigourney Weaver. Twentieth Century Fox Film Corp., 1986.

AliEN 3. Dir. David Fincher. Perf. Sigourney Weaver. Twentieth Century Fox Film Corp., 1992.

Alien: ResurRection. Dir. Jean-Pierre Jeunet. Perf. Sigourney Weaver and Winona Ryder. Twentieth Century Fox Film Corp., 1997.

Arrival of a Train at La CiOTAT. Dir. Louis Lumière and Auguste Lumière. Société Lumière, 1895.

Bates Motel. Carlton Cuse, Kerry Ehrin, and Anthony Cipriano, creators. Perf. Vera Farminga. A\&E Networks, 2013-2017.

Beasts of No Nation. Dir. Cary Joji Fukunaga. Perf. Idris Elba, Abraham Attah, and Kurt Egyjawan. Netflix, 2015.

Boardwalk Empire. Terence Winter, creator. Prod. Martin Scorsese, Mark Wahlberg, and Howard Korder. HBO Enterprises, 2010-2014.

The Blair Witch Project. Dir. Daniel Myrick and Eduardo Sanchez. Artisan Entertainment, 1999. 
“Corporate Cannibal.” Online Video Clip. Wall of Sound Recording. Dir. Nick Hooker. Perf. Grace Jones. YouTube. YouTube, 3 Feb. 2010. Web. 25 Feb. 2018.

EXISTENZ. Dir. David Cronenberg. Perf. Jude Law, Jennifer Jason Leigh, and Willem Dafoe. Studiocanal, 1999.

FARGO. Dir. Joel Coen. Prod. Ethan Coen. Perf. Frances McDormand, Steve Buscemi, William H. Macy, and Harve Presnell. Gramercy Pictures, 1996.

Fargo. Noah Hawley, creator. Perf. Billy Bob Thornton, Martin Freeman, and Kirsten Dunst. 20th Television, 2014.

Festival de Cannes (Officiel). "Cannes 2014 - Quentin Tarantino: The Press Conference.” Online Video Clip. YouTube. YouTube, 2014. Web. 2 Feb. 2018.

Final Destination. Dir. James Wong. New Line Cinema, 2000. DVD.

Final Destination 3. Dir. James Wong. New Line Cinema, 2006. DVD.

FORREST GuMP. Dir. Robert Zemeckis. Dir. Tom Hanks, Robin Wright, and Gary Sinise. Paramount Pictures, 1994.

Game of Thrones. Benioff, David, and D.B. Weiss, creators. Warner Bros. Television Distribution (original network: HBO), 2011.

GoDZILla. Dir. Ishirō Honda. Toho, 1954.

GoDZILLA. Dir. Gareth Edwards. Warner Bros., 2014.

Grindhouse: Death Proof \& Planet Terror. Dir. Quentin Tarantino und Roberto Rodriguez. Dimension Films, 2007.

HARRY POTTER (film series). Dir. Chris Columbus, Alfonso Cuarón, Mike Newell, and David Yates. Perf. Daniel Radcliffe, Rupert Grint, and Emma Watson. Warner Bros., 2001-2011.

The Hateful Eight. Dir. Quentin Tarantino. Perf. Samuel L. Jackson, Kurt Russell, and Jennifer Jason Leigh. The Weinstein Company, 2015.

“Honest Trailers - ...." Online Video Series. Screen Junkies. YouTube. YouTube, 2012. Web. 2 Feb. 2018.

House of Cards. Beau Willimon, creator. Prod. David Fincher, Kevin Spacey, and Eric Roth. Perf. Kevin Spacey and Robin Wright. Netflix, 2013. 
The Jungle Book. Dir. Jon Favreau. Perf. Bill Murray, Ben Kingsley, Idris Elba, and Neel Sethi. Walt Disney, 2016.

The Knick. Jack Amiel and Michael Begler, creators. Dir. Steven Soderbergh. Cinemax, 2014-2015.

The Lego Movie. Dir. Phil Lord and Christopher Miller. Perf. Chris Pratt and Elizabeth Banks. Prod. Dan Lin and Roy Lee. Warner Bros. Pictures, 2014.

THE LORD OF THE Rings (film series). Dir. Peter Jackson. Perf. Elijah Wood, Ian Mckellen, and Liv Tyler. New Line Cinema, 2001-2003.

The MatriX. Dir. The Wachowskis. Perf. Keanu Reeves, Laurence Fishburne, and CarrieAnne Moss. Warner Bros., 1999.

Mad Men. Matthew Weiner, creator. Perf. Jon Hamm, Elisabeth Moss, and January Jones. Lionsgate Television, 2007-2015.

Memento. Dir. Christopher Nolan. Perf. Guy Pearce. Prod. Suzanne Todd, Jennifer Todd. EuroVideo Medien, 2002. DVD.

O Brother, Where Art Though? Dir. Joel Coen. Perf. George Clooney, John Goodman, and John Turturro. Prod. Ethan Coen. Buena Vista Pictures Distribution, 2000.

PleasantVille. Dir. Gary Ross. Perf. Reese Witherspoon, Tobey Maguire, and Jeff Daniels. New Line Cinema, 1998.

Prometheus. Dir. Ridley Scott. Perf. Michael Fassbender and Charlize Theron. Twentieth Century Fox Film Corp., 2012.

PsYCHO. Dir. Alfred Hitchcock. Perf. Anthony Perkins, Vera Miles, and John Gavin. Paramount Pictures, 1960.

The Revenant. Dir. Alejandro González Iñárritu. Perf. Leonardo DiCaprio, Tom Hardy, and Domhnall Gleeson. 20th Century Fox, 2015.

Rise of the Planet of the APES. Dir. Rupert Wyatt. Perf. James Franco, Freida Pinto, and Andy Serkis. 20th Century Fox, 2011.

Savage Man Savage Beast. Dir. Antonio Climati and Mario Morra. Titanus Distribuzione, 1975.

SCREAM 2. Screenplay by Kevin Williamson. Dir. Wes Craven. Perf. Courteney Cox, Neve Campbell, and David Arquette. Dimension Films, 1997. 
SCREAM 3. Screenplay by Ehren Kruger. Dir. Wes Craven. Perf. Courteney Cox, Neve Campbell, and David Arquette. Dimension Films, 2000.

SCREAM 4. Screenplay by Kevin Williamson. Dir. Wes Craven. Perf. Courteney Cox, Neve Campbell, and David Arquette. Dimension Films, 2011.

Scream. Jill Blotevogel, Dan Dworkin, and Jay Beattie, creators. The Weinstein Company, 2015.

The Sopranos. David Chase, creator. Perf. James Gandolfini, Lorraine Bracco, and Edie Falco. HBO, 1999-2007.

Spielberg, Steven, dir. JURASSIC PARK. Perf. Sam Neill, Laura Dern, and Jeff Goldblum. Universal Pictures, 1993.

StaR WARS (film series). Created by George Lucas. Dir. George Lucas, Gareth Edwards, J.J. Abrams. Prod. Lucasfilm Ltd. 20th Century Fox/Walt Disney, 1977-2017.

The Strain. Guillermo del Torro and Chuck Hogan, creators. Perf. Corey Stoll, David Bradley, and Kevin Durand. 20th Television (original network: FX), 2014-2017.

The Thief of BAgdad. Dir. Ludwig Berger, Michael Powell. Perf. Conrad Veidt, Sabu, and June Duprez. United Artists, 1940.

The Thirteenth Floor. Dir. Josef Rusnak. Columbia Pictures, 1999.

Through the Eyes of ForRest GumP: The MAKIng of AN EXTRAORDINARY FILM. Dir.

Peyton Reed. Paramount Pictures, 1995. DVD.

Traces of DeAth. Prod. Brain Damage and Foxx Entertainment Enterprises. Written and narrated by Damon Fox. Brain Damage Films, 1993.

True Detective. Nic Pizzolatto, creator. Dir. Cary Joji Fukunaga. Perf. Matthew McConaughey, Woody Harrelson, and Colin Farrell. HBO, 2014.

\section{$\underline{\text { Secondary Sources }}$}

Abebe, Nitsuh. "Lit Wunderkind Marisha Pessl Plays Detective with Night Film." Vulture. New York Media LLC, 14 Aug 2013. Web. 22 March 2018.

Adorno, Theodor W. Prisms. Cambridge: MIT Press, 1983. Print. 
Ahmed, Tufayel. “'Batman v Superman' Gets Mixed Reviews from Critics.” Newsweek. Newsweek Media Group, 23 March 2016. Web. 27 July 2017.

Albanese, Andrew. "London Book Fair 2017: More Evidence of a Print Renaissance in the U.K.” PublishersWeekly.com. PWxyz, 13 Mar. 2017. Web. 30 July 2017.

Alberge, Dalya. "Pack of 800 Computer Artists Brings The Jungle BooK to Life." The Times \& The Sunday Times. News Corp UK \& Ireland Limited, 21 Feb. 2016. Web. 26 July 2017.

Alter, Alexandra. "The Plot Twist: E-Book Sales Slip, and Print Is Far from Dead." The New York Times. The New York Times Company, 22 Sept. 2015. Web. 30 July 2017.

Amis, Martin. "The Voice of the Lonely Crowd." The Guardian. Guardian News and Media, 1 June 2002. Web. 6 Nov. 2017.

Arcagni, Simone. "Pattern Recognition: The 'Postcinema' Seen by William Gibson.” Imaginary Films in Literature. Ed. Stefano Ercolino et al. Brill, 2015. 203-212. Print.

Austin, Michael. "Why I Read War and Peace on a Kindle (and Bought the Book When I Was Done)." The Edge of the Precipice: Why Read Literature in the Digital Age? Ed. Paul Socken. London: McGill-Queen's University Press, 2013. 13-27. Print.

Baetens, Jan. “'Writing the Making of': A New Literary Genre?” Imaginary Films in Literature. Ed. Stefano Ercolino et al. Brill, 2015. 37-48. Print.

Baron, Naomi S. Words Onscreen: The Fate of Reading in a Digital World. New York: Oxford University Press, 2015. Print.

Barthes, Roland. Camera Lucida: Reflections of Photography. New York: Hill and Wang, 1981. Print.

---. "The Photographic Message.” Image, Music, Text. Ed. Stephen Heath. New York: Hill and Wang, 1977. Print.

Bartlett, Jamie. The Dark Net: Inside the Digital Underworld. London: Random House, 2014. Print.

Barzillai, Mirit, and Maryanne Wolf. "The Importance of Deep Reading.” Educational Leadership 66 (2009): 32-37. Web. 18 Jul. 2017. 
Bassett, Caroline. "Is This Not a Screen? Notes on the Mobile Phone and Cinema."

Transmedia Frictions: The Digital, the Arts, and the Humanities. Ed. Marsha Kinder and Tara McPherson. Oakland: University of California Press, 2014. 147-158. Print.

Baudelaire, Charles. "The Salon of 1859." Baudelaire: Selected Writings on Art and Artists. Cambridge: Cambridge University Press, 1972. 285-324. Print.

Baudrillard, Jean. The Gulf War Did Not Take Place. Bloomington: Indiana University Press, 1991. Print.

---. Simulacra and Simulation. The University of Michigan Press, 1994. Print.

Baudry, Jean-Louis. "The Apparatus: Metapsychological Approaches to the Impression of Reality in Cinema." Film Theory and Criticism. Ed. Leo Braudy and Marshall Cohen. New York: Oxford, 2009. 171-188. Print.

Bedell, Geraldine. “At Long Last - An Intellectual Page-Turner.” The Guardian. Guardian News and Media, 19 Jan. 2003. Web. 3 Feb. 2018.

Bell, David A. "The Bookless Future: What the Internet is doing to Scholarship." The New Republic, May 2 \& 9 (2005): 27-33. Web. 30 July 2017.

Belting, Hans. "Image, Medium, Body: A New Approach to Iconology.” Critical Inquiry 31.2 (Winter 2005): 302-318. JSTOR. Web. 5. Nov. 2017.

Benjamin, Walter. “On Some Motifs in Baudelaire.” Illuminations: Walter Benjamin. Ed. Hannah Arendt. London: Pimlico, 1999. 152-196. Print.

---. “A Short History of Photography." Classic Essays on Photography. Ed. Alan Trachtenberg. New Haven: Leete's Island Books, 1980. 199-216. Print.

---. "The Work of Art in the Age of Its Technological Reproducibility." The Work of Art in the Age of Its Technological Reproducibility, and Other Writings on Media. Ed. Michael W. Jennings, Brigid Doherty and Thomas Y. Levin. London: The Belknap Press of Harvard University Press, 2008. 19-55. Print.

Bilsky, Brianne. “(Im)possible Spaces: Technology and Narrative in House of Leaves.” Revolutionary Leaves: The Fiction of Mark Z. Danielewski. Ed. Sascha Pöhlmann. Newcastle: Cambridge Scholars Publishing, 2012. 137-166. Print.

Birkerts, Sven. The Gutenberg Elegies: The Fate of Reading in an Electronic Age. Faber \& Faber, 2006. Print. 
---. "Reading in a Digital Age: Notes on Why the Novel and the Internet Are Opposites, and Why the Latter Both Undermines the Former and Makes It More Necessary." The Edge of the Precipice: Why Read Literature in the Digital Age? Ed. Paul Socken. London: McGill-Queen's University Press, 2013. 27-41. Print.

Bolter, Jay David, Blair MacIntyre, Maribeth Gandy and Petra Schweitzer. "New Media and the Permanent Crisis of Aura." Convergence 12.1 (2006): 21-39. Sage Publications. Web. 2 Feb. 2018.

Bolter, Jay David, and Richard Grusin: Remediation: Understanding New Media. Cambridge: MIT Press, 2000. Print.

Bottomore, Stephen. "The Panicking Audience?: Early Cinema and the Train Effect."” Introduction. Historical Journal of Film, Radio and Television 19.2 (1999): 177-216.

Boxall, Peter. Twenty-First-Century Fiction: A Critical Introduction. New York: Cambridge University Press, 2013. Print.

Bray, Joey, Alison Gibbons, and Brian McHale. Introduction. The Routledge Companion to Experimental Literature. Ed. Joe Bray et al. Abingdon, VA: Routledge. 1-18. Print.

Breitbach, Julia. Analog Fictions for the Digital Age: Literary Realism and Photographic Discourses in Novels after 2000. Rochester, New York: Camden House, 2012. Print.

Brooks, David. "The Lost Language of Privacy." The New York Times. The New York Times Company. 14 Apr. 2015. Web. 2 Nov. 2017.

Brown, William. Supercinema: Film-Philosophy for the Digital Age. New York: Berghahn, 2015. Print.

Bruner, Jerome. Making Stories: Law, Literature, Life. Cambridge: Harvard University Press, 2002. Print.

Bukatman, Scott. Foreword. Special Effects: New Histories, Theories, Contexts. Ed. Michael S. Duffy, Dan North, and Bob Rehak. London: Palgrave, 2015. ix-xii. Print.

Buse, Peter. The Camera Does the Rest: How Polaroid Changed Photograph. Chicago: The University of Chicago Press, 2016. Print.

Butter, Stella. Literatur als Medium kultureller Selbstreflexion: Literarische Transversalität und Vernunftskritik in englischen und amerikanischen Gegenwartsromanen aus funktionsgeschichtlicher Sicht. Trier: WVT, 2007. Print. 
Cain, Sian. "Ebook Sales Continue to Fall as Younger Generations Drive Appetite for Print." The Guardian. Guardian News and Media, 2017. Web. 19 July 2017.

Carroll, Noël. Theorizing the Moving Image. Cambridge University Press, 1996. Print.

Casetti, Francesco. "The Relocation of Cinema." Post-Cinema: Theorizing $21^{\text {st }}$-Century Film. Ed. Shane Denson and Julia Leyda. Falmer: REFRAME Books, 2016. 569-615. Web. 30 Jan. 2017.

Chambers, Deborah. Changing Media, Homes and Households: Cultures, Technologies and Meanings. New York: Routledge, 2016. Print.

Clifford, Stephanie. "Billboards That Look Back.” The New York Times. The New York Times Company, 31 May 2008. Web. 2 Nov. 2017.

Clover, Carol J. "The Eye of Horror." Viewing Positions: Ways of Seeing Film. Ed. Linda Williams. New Jersey: Rutgers University Press, 1994. 184-231. Print.

Conrich, Ian. Introduction. Horror Zone: The Cultural Experience of Contemporary Horror Cinema. Ed. Conrich. London: I.B. Tauris, 2010. 1-8. Print.

Cope, Bill, and Angus Phillips eds. The Future of the Book in the Digital Age. Oxford: Chandos Publishing, 2006. Print.

Cope, Bill, and Mary Kalantzis. "New Text Technologies, Globalization and the Future of the Book." The Future of the Book in the Digital Age. Ed. Bill Cope and Angus Phillips. Oxford: Chandos Publishing, 2006. 191-209. Print.

Däwes, Birgit. “'Openings That Can’t Be Closed’: Patterns of Surveillance Culture in Siri Hustvedt's Novels." Zones of Focused Ambiguity in Siri Hustvedt's Works: Interdisciplinary Essays. Ed. Johanna Hartmann, Christine Marks, and Hubert Zapf. Berlin/Boston: De Gruyter, 2016. 295-310. Print.

Danielewski, Mark Z. MZD Forums. vBulletin Solutions, 2000. Web. 12 Aug. 2016.

Davies, William. “The Age of Post-Truth Politics.” The New York Times. The New York Times Company, 24 Aug. 2016. Web. 2 Nov. 2017.

Davis, Douglas. "The Work of Art in the Age of Digital Reproduction (An Evolving Thesis: 1991-1995)." Leonardo 28.5 (1995): 381-86. JSTOR. Web. 30 Jan. 2017. 
Davis, Robert E. “The Instantaneous Worldwide Release: Coming Soon to Everyone, Everywhere". Transnational Cinema: The Film Reader. Ed. Elizabeth Ezra and Terry Rowden. New York: Routledge, 2006. 73-80. Print.

DeLillo, Don. "In the Ruins of the Future." The Guardian. Guardian News and Media, 22 Dec. 2001. Web. 15 Dec. 2017.

Denson, Shane, and Julia Leyda. "Perspectives on Post-Cinema: An Introduction." Introduction. Post-Cinema: Theorizing $21^{\text {st }}$-Century Film. Ed. Shane Denson and Julia Leyda. Falmer: REFRAME Books, 2016. 1-18. Web. 30 Jan. 2017.

Derrida, Jacques. Paper Machine. Standford: Standford University Press, 2005. Print.

Döring, Tobias. "Und hinter tausend Masken keine Welt.” FAZ.NET. Frankfurter Allgemeine Zeitung GmbH, 2013. Web. 30 Jan. 2017.

Doherty, Maggie. “The Novelist Goes to the Movies: Marisha Pessl's Night Film." Los Angeles Review of Books. LARB, 2013. Web. 30. Jan. 2017.

Drewes, Miriam. "Nach dem Film ist vor dem Film: Zur Wechselwirkung ästhetischer, technischer und ökonomischer Produktionsprozesse." Transformationen in den Künsten: Grenzen und Entgrenzung in bildender Kunst, Film, Theater und Musik. Ed. Ruth Reiche et al. Bielefeld: transcript, 2011. 63-76. Print.

Duffy, Michael S., Dan North, and Bob Rehak. Introduction. Special Effects: New Histories, Theories, Contexts. Ed. Duffy, North, and Rehak. London: Palgrave, 2015. Print. 1-13. Eliassen, Knut Ove. "Media Ecology in the Literal Sense: Mark Z. Danielewski's House of Leaves." Literature in Contemporary Media Culture: Technology - SubjectivityAesthetics. Ed. Sarah J. Paulson and Anders Skare Malvik. Amsterdam/Philadelphia: John Benjamins Publishing Company, 2016. 79-103. Print.

Elsaesser, Thomas. "Digital Cinema: Convergence or Contradiction.” The Oxford Handbook of Sound and Image in Digital Media. Ed. A. Herzog, J. Richardson, C. Vernallis. Oxford: Oxford University Press, 2013. 13-44. Print.

---. "Digital Cinema: Delivery, Event, Time". Cinema Futures: Cain, Abel or Cable? The Screen Arts in the Digital Age. Ed. Thomas Elsaesser and Kay Hoffmann. Amsterdam: Amsterdam University Press, 1998. 201-222. Print. 
---. “Truth or Dare: Reality Checks on Indexicality, or the Future of Illusionism." Cinema Studies into Visual Theory? Ed. Anu Koivunnen and Astrid Söderbergh-Widding. Turku: D-Vision, 1998. 31-50. Print.

Emden, Christian J., and Gabriele Rippl. Introduction. ImageScapes: Studies in Intermediality. Ed. Christian J. Emden and Gabriele Rippl. Oxford: Peter Lang, 2010. 1-18. Print.

Engelberg, Stephen. “The Velvet Revolution Gets Rough.” The New York Times. The New York Times Company, 1992. Web. 12 Aug. 2016.

English, Sandy. “Casting About for the Truth of 9/11: Don DeLillo's Falling Man”. World Socialist Web Site. ICFI, 27 Aug. 2008. Web. 18 Oct. 2017.

Enli, Gunn, and Trine Syvertsen. "Digital Detox: Media Resistance and the Promise of Authenticity." Convergence: The International Journal of Research into New Media Technologies (OnlineFirst: 16 May 2019): 1-15. Web. 14 May 2020.

Ercolino, Stefano, et al., eds. Imaginary Films in Literature. Brill, 2015. Print.

Ezra, Elizabeth, and Terry Rowden eds. Transnational Cinema: The Film Reader. London: Routledge, 2006. Print.

Farid, Hany. "Digital Doctoring: Can We Trust Photographs?" Deception: From Ancient Empires to Internet Dating. Ed. Brooke Harrington. Stanford: Stanford University Press, 2009. 95-108. Print.

Fetveit, Arild. "Reality TV in the Digital Era: A Paradox in Visual Culture?" Reality Squared: Televisual Discourse on the Real. Ed. James Friedman. New Brunswick: Rutgers University Press, 2002. 119-137. Print.

Fitzpatrick, Kathleen M. The Anxiety of Obsolescence: The American Novel in the Age of Television. Nashville: Vanderbilt University Press, 2006.

Frank, David A., and Caroline J.S. Picart. "Horror and the Holocaust: Genre Elements in Schindler's List and Psycho.” The Horror Film. Ed. Stephen Prince. New Jersey: Rutgers University Press, 2004. 26-224. Print.

Frayssé, Olivier, and Mathieu O’Neil. Introduction. "Hacked in the USA: Prosumption and Digital Labour.” Digital Labour and Prosumer Capitalism: The US Matrix. Ed. Frayssé and O’Neil. New York: Palgrave Macmillan, 2015. 1-19. Print. 
Fusillo, Massimo. Introduction. Imaginary Films in Literature. Ed. Stefano Ercolino et al. Brill, 2015. xiii-xv. Print.

Gabriel, Nicole, Bogna Kazur, and Kai Matuszkiewicz. "Reconsidering Transmedia(1) Worlds." Convergence Culture Reconsidered: Media - Participation-Environments. Ed. Claudia Georgi and Brigitte Johanna Glaser. Göttingen: Universitätsverlag Göttingen, 2015. 163-194. Print.

Gahan, Gordon. Pyramids of Giza. Cover. National Geographic Feb. 1982. Print.

Gass, William H. "In Defense of the Book: On the Enduring Pleasures of Paper, Type, Page, and Ink.” Harper's Magazine (November 1999): 45-51. Web. 31 July 2017.

Gatcum, Chris. Creative Photography: 52 More Weekend Projects. London: Ilex Press, 2012. Print.

Gibbons, Alison. "Crossing Thresholds and the Exploring Reader of House of Leaves by Mark Z. Danielewski.” Multimodality, Cognition, and Experimental Literature. Ed. Alison Gibbons. New York: Routledge, 2012. 46-85. Print.

Gilloch, Graeme: "Fabricating Aura: The Face in Film." Actualities of Aura: Twelve Studies of Walter Benjamin. Ed. Dag Petersson and Erik Steinskog. Svanesund: NSU Press, 2005. 1-25. Print.

“Godzilla (2014) Behind the Scenes.” YouTube. YouTube, 25 Apr. 2014. Web. 27 July 2017. Gonçalves, Diana. "Collapsing the Boundaries of Literature: 9/11 Fiction." 9/11: Culture, Catastrophe and the Critique of Singularity. Berlin/Boston: Walter de Gruyter, 2016. 152-200. Print.

Grusin, Richard. "DVDs, Video Games, and the Cinema of Interactions." Post-Cinema: Theorizing $21^{\text {st }}$-Century Film. Ed. Shane Denson and Julia Leyda. Falmer: REFRAME Books, 2016. 65-87. Web. 30 Jan. 2017.

Guerrasio, Jason. "How That Infamous Bear-Attack Scene in The Revenant Was Made, and Other Secrets of the Movie Revealed.” Business Insider. Business Insider Deutschland, 26 Dec. 2015. Web. 27 July 2017.

Gunkel, David. J. “What's the Matter with Books?” Configurations 11.3 (2003): 277-303. Print. 
Gunning, Tom. "An Aesthetic of Astonishment: Early Film and the (In)Credulous Spectator.” Viewing Positions: Ways of Seeing Film. Ed. Linda Williams. New Brunswick: Rutgers University Press, 1995. 114-133. Print.

---. "Theory and History: Narrative Discourse and the Narrator System." D.W. Griffith and the Origins of American Narrative Film: The Early Years at Biograph. Ed. Gunning. Urbana and Chicago: University of Illinois Press, 1991. 10-30. Print.

---. "The Cinema of Attraction[s]: Early Film, Its Spectator and the Avant-Garde." The Cinema of Attractions Reloaded. Ed. Wanda Strauven. Amsterdam: Amsterdam University Press, 2006. 381-388. Print.

Hagen, Chuck. "The Power of a Video Image Depends on the Caption." The New York Times. The New York Times Company, 10 May 1992. Web. 12 Aug. 2017.

Hagener, Malte, Vinzenz Hediger, and Alena Strohmaier. "Like Water: On the ReConfigurations of the Cinema in the Age of Digital Networks." Introduction. The State of Post-Cinema: Tracing the Moving Image in the Age of Digital Dissemination. Ed. Hagener, Hediger, and Strohmaier. London: Palgrave Macmillan, 2016. 1-13. Print.

Hallet, Wolfgang. "The Multimodal Novel: The Integration of Modes and Media in Novelistic Narration." Narratology in the Age of Cross-Disciplinary Narrative Research. Ed. Sandra Heinen and Roy Sommer Berlin: de Gruyter, 2009. 129-153. Print.

Hamilton, Natalie. "The A-Mazing House: The Labyrinth as Theme and Form in Mark Z. Danielewski's House of Leaves." Critique: Studies in Contemporary Fiction 50.1 (2008): 3-16. Print.

Hansen, Mark B.N. “The Digital Topography of Mark Z. Danielewski's House of Leaves". Contemporary Literature 45.4 (2004): 597-636. Project MUSE. Web. 12 May 2015. Hardwick, Hannasofia. The Narrative Role of Films in Four Contemporary Novels. Dissertation, University of Helsinki, 2017. Print.

Harmon, Steph. "National Book Awards: Sigrid Nunez Wins Fiction Prize as Isabel Allende is Honoured." The Guardian. Guardian News and Media, 2018. Web. 24 May 2020.

Hartmann, Johanna. "Ekphrasis in the Age of Digital Reproduction." Handbook of Intermediality. Ed. Gabriele Rippl. Berlin/Boston: De Gruyter, 2015. 113-127. Print.

---. Literary Visuality in Siri Hustvedt's Works: Phenomenological Perspectives.

Königshausen \& Neumann, 2016. Print. 
Hartmann, Johanna, Christine Marks, and Hubert Zapf eds. Zones of Focused Ambiguity in Siri Hustvedt's Works: Interdisciplinary Essays. Berlin: De Gruyter, 2016. Print.

Hassler-Forest, Dan. Science Fiction, Fantasy and Politics: Transmedia World-Building Beyond Capitalism. London: Rowman \& Littlefield International, 2016. Print.

Hayles, N. Katherine. How We Think: Digital Media and Contemporary Technogenesis. Chicago, London: The University of Chicago Press, 2012. Print.

---. "Saving the Subject: Remediation in House of Leaves." American Literature 74.4 (2002): 779-806. Project MUSE. Web. 12 May 2016.

---. Writing Machines. Cambridge, MA: MIT, 2002. Print.

Hefferenan, James A.W. The Museum of Words: The Poetics of Ekphrasis from Homer to Ashbery. Chicago: Chicago University Press, 1993. Print.

---. "Notes toward a Theory of Cinematic Ekphrasis." Imaginary Films in Literature. Ed. Stefano Ercolino et al. Brill, 2015. 3-17. Print.

Heidegger, Martin. Being and Time. Albany: State University of New York Press, 2010. Print. Heller-Nicholas, Alexandra. Found Footage Horror Films: Fear and the Appearance of Reality. Jefferson: McFarland, 2014. Print.

Helmore, Edward. "Silver Screen to Small Screen: Why Film Directors Are Taking Over TV." The Guardian. Guardian News and Media, 2014. Web. 30 Jan. 2017.

Heyman, Stephen. "Google Books: A Complex and Controversial Experiment.” The New York Times. The New York Times Company, 28 Oct. 2015. Web. 2 Jan. 2018.

Hill, Joe. "Underground Idol.” The New York Times. The New York Times Company, 2013. Web. 30 Jan. 2017.

Hofmannsthal, Hugo von. “A Letter.” The Lord Chandos Letter and Other Writings. Ed. Joel Rotenberg. New York: New York Review Books, 2005. 117-128. Print.

Holland, Patricia. “'Sweet is to scan...': Personal Photographs and Popular Photograph.” Photography: A Critical Introduction. Ed. Liz Wells. London: Routledge, 2015. 133188. Print.

Huber, Sebastian. “'A House of One's Own': House of Leaves as a Modernist Text”. Revolutionary Leaves: The Fiction of Mark Z. Danielewski. Ed. Sascha Pöhlmann. Newcastle: Cambridge Scholars Publishing, 2012. 123-136. Print. 
Huy Mai. "The Making of Honest Trailers.” Online video clip. YouTube. YouTube, 2015. Web. 2 Feb. 2018.

The Internet Movie Database. IMDb.com, Inc, 1990. Web. 29 Oct 2009.

Jenkins, Henry. Convergence Culture: Where Old and New Media Collide. New York: New York University Press, 2006. Print.

---. "The Revenge of the Origami Unicorn: Seven Principles of Transmedia Storytelling

(Well, Two Actually. Five More on Friday).” Henry Jenkins. N.p., 12 Dec. 2009. Web. 22 Nov. 2017.

Kinder, Marsha. „Medium Specificity and Productive Precursors: An Introduction.” Transmedia Frictions: The Digital, the Arts, and the Humanities. Ed. Marsha Kinder and Tara McPherson. Oakland: University of California Press, 2014. 3-19. Print.

Kirkpatrick, Keith. "Advertising via Algorithm." Communications of the ACM. The Association for Computing Machinery. 18 Feb. 2016. Web. 30 Nov. 2017.

Klastrup, Lisbeth, and Susana Tosca. "Transmedial Worlds: Rethinking Cyberworld Design." Proceedings International Conference on Cyberworlds 2004. Los Alamitos, CA: IEEEE Computer Society. 18 Nov. 2004. Web. 5 March 2014.

Kracauer, Siegfried. "Basic Concepts.” Film Theory and Criticism. Ed. Leo Braudy and Marshall Cohen. New York: Oxford, 2009. 147-158. Print.

Kuhn, Annette, and Guy Westwell. Oxford Dictionary of Film Studies. UK: Oxford University Press, 2012. Print.

Larsen, Jonas, and Mette Sandbye eds. Digital Snaps: The New Face of Photography. London: I.B. Tauris \& Co Ltd, 2014. Print.

Larsen, Jonas, and Mette Sandbye. "Introduction: The New Face of Snapshot Photography." Digital Snaps: The New Face of Photography. Ed. Jonas Larsen and Mette Sandbye. London: I.B. Tauris \& Co Ltd, 2014. xv-xxxii. Print.

Levy, Steven. “Amazon: Reinventing the Book.” Newsweek. Newsweek Media Group, 17 Nov. 2016. Web. 27 July 2017.

Lister, Martin. Introduction. The Photographic Image in Digital Culture. Ed. Lister. New York: Routledge, 1995. 1-28. Print. 
Magny, Claude-Edmonde. The Age of the American Novel: The Film Aesthetic of Fiction Between the Two Wars. New York: Ungar, 1972. Print.

Manovich, Lev. “After Effects, or Velvet Revolution (Part 1).” manovich. Lev Manovich, 2006. Web. 18 Oct. 2015.

---. "From DV Realism to a Universal Recording Machine." manovich. Lev Manovich, 2001.

Web. 25 Dec. 2015.

---. “Image Future.” manovich. Lev Manovich, 2006. Web. 13 Aug. 2015.

---. The Language of New Media. Cambridge, Mass.: MIT Press, 2001.

---. "Postmedia Aesthetics." Transmedia Frictions: The Digital, the Arts, and the Humanities.

Ed. Marsha Kinder and Tara McPherson. Oakland: University of California Press, 2014. 34-44. Print.

---. “What Is Digital Cinema?” manovich. Lev Manovich, 1995. Web. 18 Nov. 2015.

Marcsek-Fuchs, Maria. Dance and British Literature: An Intermedial Encounter. Boston: Brill Rodopi, 2015. Print.

Mazzoleni, Gianpietro. "Mediatization and Political Populism." Mediatization of Politics: Understanding the Transformation of Western Democracies. Ed. Frank Esser and Jesper Strömbäck. New York: Palgrave Macmillan, 2014. 42-56. Print.

McCaffery, Larry and Sinda Gregory. "Haunted House - An Interview with Mark Z. Danielewski." Critique: Studies in Contemporary Fiction 44. 2 (2003): 99-135. Print. McCausland, Phil. "Night Film by Marisha Pessl Review.” Paste. Paste Magazine, 2014. Web. 30 Jan. 2017.

McCormick, Paul. "House of Leaves, Cinema and the New Affordances of Old Media." Contemporary American and Canadian Writers: Mark Z. Danielewski. Ed. Joe Bray and Alison Gibbons. Manchester University Press, 2011. 52-67. Print.

McLoughlin, Kate. "Not Writing About War.” Fighting Words and Images: Representing War Across the Disciplines. Ed. Stephan Jaeger, Elena Viktorovna Baraban, and Adam Muller. Toronto: University of Toronto Press, 2012. 46-64. Print.

McRoy, Jay. "Simulating Auras and Marketing Nostalgia in Robert Rodriguez and Quentin Tarantino's GRINDHOUSE." American Horror Film: The Genre at the Turn of the 
Millennium. Ed. Steffen Hantke. Jackson: University Press of Mississippi, 2010. 221234. Print.

Menand, Louis. "The Promise of Freedom, the Friend of Authority: American Culture in Postwar France." Americanism: New Perspectives on the History of an Ideal. Ed. Michael Kazin and Joseph A. McCartin. Chapel Hill: The University of North Carolina Press, 2006. 205-220. Print.

Meltzer, Francoise, and Christian Metz. “"Trucage' and the Film.” Critical Inquiry 3.4 (1977): 657-675. JSTOR. Web. 9 June 2017.

Metz, Christian. "The Fiction Film and Its Spectator: A Metapsychological Study."

Apparatus. Ed. Theresa Hak Kyung Cha. New York: Tanam Press, 1980. N.pag. Print.

Meyrowitz, Joshua. "Images of Media: Hidden Ferment - and Harmony - in the Field." Informationskontexte für Massenmedien: Theorien und Trends. Ed. Peter Ludes. Opladen: Westdeutscher Verlag, 1996. 37-47. Print.

Miller, Claire Cain. "E-Books Top Hardcovers at Amazon." The New York Times. The New York Times Company, 10 July 2010. Web. 14 June 2017.

Miller, Laura J. Reluctant Capitalists: Bookselling and the Culture of Consumption. Chicago: The University of Chicago Press, 2006. Print.

Minzesheimer, Bob. "Digital devices give a big boost to book reading." USA Today. USA Today Network, 7 October 2013. Web. 12 May 2019.

Mitchell, W.J. The Reconfigured Eye: Visual Truth in the Post-Photographic Era. Cambridge, MA: MIT, 1994. Print.

---. "When is Seeing Believing?" Scientific American 270.2. (Feb 1994): 68-75. Web. 8 May 2017.

Mitchell, W.J.T. Picture Theory: Essays on Visual and Verbal Representation. Chicago: The University of Chicago Press, 1994. Print.

---. "Realism and the Digital Image." Travels in Intermedia[lity]: Reblurring the Boundaries. Ed. Bernd Herzogenrath. Dartmouth College Press, 2012. 46-62. Print. ---. "What is an Image?” New Literary History 15.3 (Spring, 1984): 503-537. JSTOR. Web. 5 Nov. 2017. 
Morley, Catherine. "Writing in the Wake of 9/11." American Thought and Culture in the 21st Century. Ed. Martin Halliwell and Catherine Morley. Edinburgh: Edinburgh University Press, 2008. 245-258. Print.

Morris, Errol. "Photography as a Weapon." The New York Times. The New York Times Company, 11 Aug. 2015. Web. 30 Jan. 2017.

Moses, Gavriel. The Nickel was for the Movies. Film in the Novel from Pirandello to Puig. Berkeley: University of California Press, 1995. Print.

Nabokov, Vladimir. "Good Readers and Good Writers." Lectures on Literature. Ed. Fredson Bowers. New York: Harcourt, 1980. 1-6. Print.

Nelles, Drew. "Solitary Reading in an Age of Compulsory Sharing." The Edge of the Precipice: Why Read Literature in the Digital Age? Ed. Paul Socken. London: McGill-Queen's University Press, 2013. 42-54. Print.

Niessen, Niels. "Lives of Cinema: Against Its 'Death." Film in the Post-Media Age. Ed. Ágnes Pethő. Newcastle: Cambridge Scholars Publishing, 2012. 161-184. Print.

Nünning, Vera. Reading Fictions, Changing Minds: The Cognitive Value of Fiction. Heidelberg: Winter, 2014. Print.

Perlman, Mark. 'If It Isn't on the Internet, It Doesn't Exist: How the New Generation View Books as Archaic Relics." The Future of the Book in the Digital Age. Ed. Bill Cope and Angus Phillips. Oxford: Chandos Publishing, 2006. 19-26. Print.

Peterson, Bryan. Understanding Digital Photography: Techniques for Getting Great Pictures. New York: Watson-Guptill Publications, 2005. Print.

Petrovic, Stefan. "The American Dichotomy: Private and Public Language in the 2016 Presidential Race." Harvard Political Review. Harvard Political Review, 9 Oct. 2016. Web. 2 Nov. 2017.

Poole, Steven. "Night Film by Marisha Pessl - Review." The Guardian. The Guardian, 2013. Web. 30 Jan. 2017.

Pope, Shelby. “Why Instagram's Biggest Book Accounts Aren’t Your Usual Influencers.” The Guardian. Guardian News and Media, 27 Sep. 2019. Web. 18 May 2020.

Pressman, Jessica. "The Aesthetic of Bookishness in Twenty-First Century Literature." In: "Bookishness: The New Fate of Reading in the Digital Age," special issue. Michigan Quarterly Review 48.4 (2009): 465-483. Print. 
---. "House of Leaves: Reading the Networked Novel." Studies in American Fiction 34.1 (2006): 107-28. Project MUSE. Web. 10 Oct. 2016.

Price, Derrick. "Surveyors and Surveyed: Photography Out and About." Photography: A Critical Introduction. Ed. Liz Wells. London: Routledge, 2015. 75-132. Print.

Prince, Stephen. Digital Visual Effects in Cinema: The Seduction of Reality. New Brunswick: Rutgers University Press, 2012. Print.

---. "The Emergence of Filmic Artifacts: Cinema and Cinematography in the Digital Era." Film Quarterly 57.3 (2004): 24-33. JSTOR. Web. 14 Nov. 2017.

---. "True Lies: Perceptual Realism, Digital Images, and Film Theory.” Film Quarterly 49.3 (1996): 27-37. JSTOR. Web. 1 Dec. 2016.

Radke, J. Richard. Computer Vision for Visual Effects. New York: Cambridge University Press, 2013. Print.

Rahim, Zamira. "How the \#bookstagram Movement Has Changed the Way Fiction Is Marketed, Reviewed and Read." Independent. The Independent, 22 Sep. 2019. Web. 18 May 2020.

Rajewsky, Irina O. Intermedialität. Tübingen: A. Francke, 2002. Print.

---. "Intermediality, Intertextuality, and Remediation: A Literary Perspective on Intermediality." Intermédialités: Histoire Et Théorie Des Arts, Des Lettres Et Des Techniques Intermédialités 6 (2005): 43-64. Print.

Rehak, Bob. "We Have Never Been Digital: CGI as the New 'Clumsy Sublime."” Graphic Engine: Bob Rehak's Blog about Special Effects, Videogames, Film, and Television. N.p., 24 March 2012. Web. 6 June 2017.

Reipen, Corinna Sophie. Visuality in the Works of Siri Hustvedt. Peter Lang, 2014. Print.

Richter, Sebastian. Digitaler Realismus: Zwischen Computeranimation und Live-Action. Die Neue Bildästhetik in Spielfilmen. Bielefeld: Transcript, 2008. Print.

Rippl, Gabriele. Introduction. Handbook of Intermediality: Literature - Image -SoundMusic. Ed. Gabriele Rippl. Berlin/Boston: De Gruyter, 2015. 1-31. Print.

Rodowick, David Norman. The Virtual Life of Film. Cambridge, MA: Harvard UP, 2007. Print. 
Rogers, Ariel. Cinematic Appeals: The Experience of New Movie Technologies. New York: Columbia University Press, 2013. Print.

Rombes, Nicholas. Cinema in the Digital Age. London: Wallflower, 2009. Print.

---. 10/40/70: Constraint as Liberation in the Era of Digital Film Theory. Alresford. UK: 0, 2014.

Rosen, Philip. Change Mummified: Cinema, Historicity, Theory. Minneapolis: U of Minnesota, 2001. Print.

Ryan, Marie-Laure. "Story/Worlds/Media: Tuning the Instruments of a Media-Conscious Narratology." Storyworlds Across Media: Toward a Media-Conscious Narratology. Ed. Ryan and Thon. Lincoln: University of Nebraska Press, 2014. 25-49. Print.

Ryan, Marie-Laure, and Jan-Noël Thon. Introduction. Storyworlds Across Media: Toward a Media-Conscious Narratology. Ed. Ryan and Thon. Lincoln: University of Nebraska Press, 2014. 1-24. Print.

Sarvas, Mark. “'Book of Numbers,' by Joshua Cohen.” The New York Times. The New York Times Company, 2 July 2015. Web. 14 May 2020.

Schmitz-Emans, Monika. "Im Reich der Königin Loana. Einführende Bemerkungen zum Stichwort Visual Culture." Visual Culture: Beiträge zur XIII. Tagung der Deutschen Gesellschaft für Allgemeine und Vergleichende Literaturwissenschaft, Potsdam, 18. 21. Mai 2005. Ed. Schmitz-Emans, Monika and Gertrud Lehnert. Heidelberg: Synchron, 2008. 9-27. Print.

Schrey, Dominik. "Mediennostalgie und Cinephilie im Grindhouse-Doublefeature".

Techniknostalgie und Retrotechnologie. Ed. Andreas Böhn and Kurt Möser. Karlsruhe: KIT Scienti-fic Publ., 2010. 183-196. Print.

Schwanecke, Christine. "Filmic Modes in Literature." Handbook of Intermediality: Literature - Image - Sound - Music. Ed. Gabriele Rippl. Berlin/Boston: De Gruyter, 2015. 268286. Print.

Sconce, Jeffrey. Haunted Media: Electronic Presence from Telegraphy to Television. Duke University Press, 2000. Print.

Scott, A.O. "“Beasts of No Nation,' a Brutal Tale of Child Soldiers in Africa." The New York Times. The New York Times Company, 2015. Web. 30 Jan 2017. 
Self, Will. "The Novel Is Dead (this Time It's for Real).” The Guardian. Guardian News and Media, 2 May 2014. Web. 31 July 2017.

Shaviro, Steven. Post Cinematic Affect. Winchester, UK: 0, 2010. Print.

Sheehan, Tanya. "Retouch Yourself: The Pleasures and Politics of Digital Cosmetic Surgery." Digital Snaps: The New Face of Photography. Ed. Jonas Larsen and Mette Sandbye. London: I.B. Tauris \& Co Ltd, 2014. 179-204. Print.

Sickels, Robert. American Film in the Digital Age. Santa Barbara: Praeger, 2011. Print.

Sobczak, Jacek. "The Language Correctness of Journalistic Communication and the Phenomenon of Stereotyping and Tabloidization of the Mass Communication Media." Professionalism in Journalism in the Era of New Media. Ed. Jacek Sobczak and Jedrzej Skrzypczak. Berlin: Logos Verlag Berlin, 2015. 175-190. Print.

Socken, Paul ed. The Edge of the Precipice: Why Read Literature in the Digital Age? London: McGill-Queen's University Press, 2013. Print.

Sontag, Susan. On Photography. London: Penguin Books, 1978. Print.

Speidel, Susan. "Film Form and Narrative." Introduction to Film Studies (Fifth Edition). Ed. Jill Nelmes. London and New York: Routledge, 2012. 79-112. Print.

Sprengler, Christine. "Complicating Camelot: Surface Realism and Deliberate Archaism." Analyzing Mad Men: Critical Essays on the Television Series. Ed. Scott F. Stoddart. Jefferson: McFarland, 2011. 234-252. Print.

Starre, Alexander. Metamedia: American Book Fictions and Literary Print Culture after Digitization. Iowa: Iowa University Press, 2015. Print.

Steiner, George. "The Retreat from the Word.” The Kenyon Review 23. 2 (Spring, 1961): 187216. JSTOR. Web. 6 Nov. 2017.

Steiner, George. "Silence and the Poet." 1966. Language and Silence: Essays on Language, Literature, and the Inhuman. London: Yale University Press, 1998. 36-54. Print.

Striphas, Ted. The Late Age of Print: Everyday Book Culture from Consumerism to Control. New York: Columbia University Press, 2009. Print.

Sweney, Mark. “'Screen Fatigue' Sees UK Ebook Sales Plunge 17\% as Readers Return to Print." The Guardian. Guardian News and Media, 27 Apr. 2017. Web. 30 July 2017. 
Syvertsen, Trine. Digital Detox: The Politics of Disconnecting. Emerald Publishing Limited, 2020. Print.

Tappen-Scheuermann, Diana. Literarischer Narzissmus: Spiegelverhältnisse zwischen Autor, Text und Leser. Marburg: Tectum Verlag, 2012. Print.

Thomas, Lindsay. "Information." American Literature in Transition, 2000-2010. Ed. Rachel Greenwald Smith. Cambridge University Press, 2017. 181-192. Print.

Tokarczuk, Olga. “The Tender Narrator.” Nobel Lecture. Translated by Jennifer Croft and Antonia Lloyd-Jones. The Nobel Prize. Nobel Media AB 2020, 2019. Web. 13 May 2020.

Tomasula, Steve. "Code Poetry and New-Media Literature." The Routledge Companion to Experimental Literature. Ed. Joe Bray, Alison Gibbons and Brian McHale. Abingdon, VA: Routledge. 483-96. Print.

Trottier, Daniel. Social Media as Surveillance: Rethinking Visibility in a Converging World. Farnham: Ashgate, 2012.

Verhoeff, Nanna. Mobile Screens: The Visual Regime of Navigation. Amsterdam: Amsterdam University Press, 2012. Print.

Walker, Johnny. "Traces of Snuff: Black Markets, Fan Subcultures, and Underground Horror in the 1990s." Snuff: Real Death and Screen Media. Ed. Neil Jackson et al. New York: Bloomsbury, 2016. 137-152. Print.

Wallace, David Foster. "E Unibus Pluram: Television and U.S. Fiction.” A Supposedly Fun Thing I'll Never Do Again: Essays and Arguments. Ed. David Foster Wallace. Abacus, 1997. 21-82. Print.

Wampler, Scott. "Could Marisha Pessl's Night Film Really Be the New House of Leaves?" Birth. Movies. Death. Birth. Movies. Death., 2013. Web. 30 Jan. 2017.

"Welcome to the ELO." Electronic Literature Organization: To facilitate and promote the writing, publishing, and reading of literature in electronic media. Electronic Literature Organization. Web. 13 May 2020.

Wells, Liz, and Derrick Price. "Thinking about Photography: Debates, Historically and Now." Photography: A Critical Introduction. Ed. Liz Wells. London: Routledge, 2015. 9-74. Print. 
Williamson, Eugenia. "Night Film by Marisha Pessl." The Boston Globe. Boston Globe Media Partners, 2013. Web. 30 Jan. 2017.

Winkler, Hartmut. "The Computer and the Audiovisual: Ruptures and Continuities in Media History." ImageScapes: Studies in Intermediality. Ed. Christian Emden and Gabriele Rippl. Bern: Peter Lang, 2010. 215-244. Print.

Winko, Simone. "Literatur und Literaturwissenschaft im digitalen Zeitalter. Ein Überblick." Der Deutschunterricht LXVIII/5 (2016): 2-13. Print.

Winthrop-Young, Geoffrey: "Hardware/Software/Wetware." Critical Terms for Media Studies. Ed. W.J.T. Mitchell / Mark B.N. Hansen. Chicago, London: University of Chicago Press, 2010. 186-198. Print.

Wolf, Mark J.P. Building Imaginary Worlds: The Theory and History of Subcreation. New York and London: Routledge, 2012. Print.

Wolf, Werner. "Intermedialität als neues Paradigma der Literaturwissenschaft? Plädoyer für eine literaturzentrierte Erforschung von Grenzüberschreitungen zwischen Wortkunst und anderen Medien am Beispiel von Virginia Woolfs The String Quartet." AAA Arbeiten aus Anglistik und Amerikanistik 21.1 (1996): 85-116. JSTOR. Web. 4 Jan. 2018.

---. "Intermedialität: Ein weites Feld und eine Herausforderung für die Literaturwissenschaft.” Literaturwissenschaft: intermedial - interdisziplinär. Ed. Herbert Foltinek and Christoph Leitgeb. Vienna: Verlag der Österreichischen Akademie der Wissenschaften, 2002: 163-192. Print.

---. The Musicalization of Fiction: A Study in the Theory and History of Intermediality. Amsterdam: Rodopi, 1999. Print.

Wu, Tim. "What Ever Happened to Google Books?" The New Yorker. Condé Nast, 11 Sep. 2015. Web. 9 Jan. 2018. 


\section{Eigenständigkeitserklärung}

Ich versichere hiermit, dass ich die vorliegende wissenschaftliche Abhandlung (Dissertation) ohne fremde Hilfe selbstständig verfasst und nur die von mir angegebenen Quellen und Hilfsmittel verwendet habe. Wörtlich oder sinngemäß aus anderen Werken entnommene Stellen habe ich unter Angabe der Quellen kenntlich gemacht. Die Richtlinien zur Sicherung der guten wissenschaftlichen Praxis an der Universität Göttingen wurden von mir beachtet. Zudem versichere ich, dass anderweitig keine entsprechende Promotion beantragt wurde und hierbei die eingereichte Dissertation oder Teile daraus vorgelegt worden sind.

Bogna Kazur

\section{Die digitale Version}

Hiermit bestätige ich außerdem, dass die digitale Version meiner Dissertation mit der schriftlichen wissenschaftlichen Abhandlung übereinstimmt.

\section{Bogna Kazur}

